UNIVERSIDADE DE BRASÍLIA

INSTITUTO DE QUÍMICA

PROGRAMA DE PÓS-GRADUAÇÃO EM QUÍMICA

LABORATÓRIO DE QUÍMICA COMPUTACIONAL

\title{
Estudo Teórico da Adsorção de COVs Aromáticos em Dióxido de
} TITÂNIO E ZIRCÔNIO

\author{
Marcos dos Reis Vargas
}

Tese de Doutorado apresentada ao Instituto de Química da Universidade de Brasília como requisito parcial para obtenção do título de Doutor em Química

Orientador: Prof. Dr. João Batista Lopes Martins 


\section{UNIVERSIDADE DE BRASÍLIA \\ INSTITUTO DE QUÍMICA \\ PROGRAMA DE PÓS-GRADUAÇÃO EM QUÍMICA \\ LABORATÓRIO DE QUÍMICA COMPUTACIONAL}

Marcos dos Reis Vargas

Estudo Teórico da AdsorçÃo de COVs AromÁticos em Dióxido de TITÂNIO E ZIRCÔNIO

Tese de Doutorado apresentada ao Instituto de Química da Universidade de Brasília como requisito parcial para obtenção do título de Doutor em Química

Orientador: Prof. Dr. João Batista Lopes Martins

BRASÍLIA - DF 


\section{Folha de Aprovação}

Comunicamos a aprovação da Defesa de Tese de Doutorado do (a) aluno (a) Marcos dos Reis Vargas, matrícula no 11/0092007, intitulada "Estudo Teórico da Adsorção de COVs Aromáticos em Dióxido de Titânio e Zircônio", apresentada no (a) Auditório Verde do Instituto de Química (IQ) da Universidade de Brasília (UnB) em 10 de dezembro de 2015.

Prof. Dr. João Batista Lopes Martins

Presidente de Banca (IO/UnB)

Prof. Dr. Ricardo Gargano

Membro Titular (IF/UnB)

Prof. Dr. José Roberto dos Santos Politi Membro Titular (IQ/UnB)

Prof. Dr. Elton Anderson Santos de Castro

Membro Titular (UEG/Formosa)

Prof. Dr. Geraldo Magela e Silva

Membro Titular (IF / UnB)

Prof. Dr. Edgardo Garcia

Membro Suplente (IQ/UnB)

Em 10 de dezembro de 2015. 
À Deus, minha família e minha esposa 


\section{Agradecimentos}

À Deus por estar sempre presente em minha vida, auxiliando, dando forças e conduzindo meus caminhos;

À minha família que sempre me apoiou e acolheu nos momentos de dificuldades;

À minha esposa Nágella pelo carinho, apoio, amor e principalmente pela paciência;

Ao meu orientador Prof. Dr. João Batista Lopes Martins, pela paciência, compreensão, ensinamentos e confiança;

Aos amigos Politi, Elton, Daniel, Sérgio, Jussara, Ítalo, Diego, Rogério, Fernanda, Alanna, Vitor, Gustavo, Paulo;

Ao amigo Breytner, companheiro de licença, estrada e de pós-graduação;

Aos professores do IFG, pelo apoio e motivação;

Ao IFG pela licença concedida;

À todos que de alguma forma contribuíram para o desenvolvimento desse trabalho. 
"A mente que se abre a uma nova ideia jamais voltará ao seu tamanho original."

Albert Einstein 


\section{Resumo}

O estudo teórico da adsorção de compostos orgânicos voláteis em superfícies de óxidos metálicos, tais como $0 \mathrm{TiO}_{2}$ e $\mathrm{ZrO}_{2}$, é importante para compreender as mudanças estruturais e eletrônicas ocasionadas pela interação. Nesse trabalho, foi estudada a adsorção das moléculas de benzeno, tolueno, etilbenzeno, o-xileno, mxileno e p-xileno (conhecidas como BTEX) sobre as superfícies (110) do $\mathrm{TiO}_{2}$ rutilo, (101) do $\mathrm{TiO}_{2}$ anatásio e (001) do $\mathrm{ZrO}_{2}$ tetragonal. A Teoria do Funcional de Densidade com condições de contorno periódicas, conjunto de funções de base de ondas planas e o funcional de troca e correlação PW91 e PBE foram usados. Os resultados mostraram que o uso de 300 eV e $3 \times 3 \times 3$ para a energia de corte das ondas planas e a malha de pontos $k$, respectivamente, foram considerados apropriados para os cálculos da adsorção do BTEX. As supercélulas com quatro camadas (3x2) para a superfície (110) do $\mathrm{TiO}_{2}$ rutilo, $(3 \times 1)$ para a superfície (101) do $\mathrm{TiO}_{2}$ anatásio e (3x3) para a superfície (001) do $\mathrm{ZrO}_{2}$ tetragonal foram usadas para a modelagem dos complexos BTEX-superfície. As interações das moléculas de BTEX indicaram que a adsorção ocorre, mais favoravelmente, na posição paralela à superfície. A influência das interações de van der Waals foi levada em consideração através da correção semiempírica DFT-D2, mostrando-se um importante componente na energia de interação, porém sem grandes efeitos sobre a geometria. A otimização das geometrias foi feita em etapas, de modo que, no final conduziram a uma otimização completa do sistema (adsorbato e superfície). A adsorção da molécula de benzeno sobre o rutilo apresentou um resultado de energia de interação mais próximo ao experimental, comparado com outros estudos teóricos. A utilização de uma otimização completa, além da inclusão de correção para as interações de van der Waals, contribuíram para a melhora na descrição do sistema. No caso do benzeno, elevando a distância de interação de $3,40 \AA$, reportada na literatura e obtida com uma otimização parcial usando aproximação LDA, para 4,00 , calculada neste trabalho. A metodologia utilizada foi então estendida para interação dos demais hidrocarbonetos monoaromáticos e ao estudo das interações com o anatásio e $\mathrm{O} \mathrm{ZrO}_{2}$ tetragonal. As energias de adsorção obtidas para todos os complexos apresentaram tendências semelhantes entre os funcionais PW91 e PBE. A partir dos resultados das energias de adsorção para todos os sistemas estudados, a interação das moléculas de BTEX foi maior com a superfície (110) do $\mathrm{TiO}_{2}$ rutilo, seguida pela (101) do $\mathrm{TiO}_{2}$ anatásio e, por último, a (001) do $\mathrm{ZrO}_{2}$ tetragonal. As análises de CDD apresentaram um aumento na densidade eletrônica entre as moléculas de BTEX e a superfície para o rutilo e o anatásio. Para o $\mathrm{TiO}_{2}$ e $\mathrm{ZrO}_{2}$, observou-se a interação entre os átomos de hidrogênio e oxigênio, através das análises de CDD e ELF, evidenciada pelo decréscimo de cargas nas vizinhanças dos átomos de hidrogênio e pelo aumento da densidade eletrônica próximo aos oxigênios bicoordenados da superfície. A densidade de estados para todos os sistemas estudados apresentou uma translação dos estados para regiões de menor energia após a adsorção, sugerindo uma estabilização do sistema ao formar os complexos. As análises das energias de adsorção, em concordância com tendências experimentais, indicam que estes materiais são candidatos promissores que poderiam ser utilizados como sensores químicos e catalisadores para a adsorção de moléculas de BTEX. 


\begin{abstract}
The theoretical study of the adsorption of volatile organic compounds on metal oxides surfaces, such as $\mathrm{TiO}_{2}$ and $\mathrm{ZrO}_{2}$, is important to understand the structural and electronic changes caused by this interaction. In this work, we studied the adsorption of benzene, toluene, ethylbenzene, o-xylene, m-xylene and p-xylene (known as BTEX) molecules on the (110) surface of rutile $\mathrm{TiO}_{2}$, (101) of anatase $\mathrm{TiO}_{2}$ and (001) of tetragonal $\mathrm{ZrO}_{2}$. The Density Functional Theory with periodic boundary conditions and plane wave basis set with the PW91 and PBE exchange-correlation functional were used. The results showed that $300 \mathrm{eV}$ for the cutoff energy of the plane waves and $3 \times 3 \times 3 \mathrm{k}$ points mesh were appropriate for the BTEX adsorption calculation. A supercell with four layers $(3 \times 2)$ for the $(110)$ rutile $\mathrm{TiO}_{2},(3 \times 1)$ for the (101) anatase $\mathrm{TiO}_{2}$ and $(3 \times 3)$ for the (001) tetragonal $\mathrm{ZrO}_{2}$ were considered for the BTEX-surface complex modeling. The interactions of BTEX molecules indicated that adsorption occurs, most favorable, at a position parallel to the surface. The influence of van der Waals interactions was taken into account by semiempirical DFT-D2 correction, being an important component in the energy of interaction, but without major effects on the geometry. The optimization of the geometry was taken into several steps, so that it leds to a complete optimization system (adsorbate and surface). The adsorption of the benzene molecule on the rutile performed in this study, presented a result of energy closer to the experimental interaction than theoretical studies in the literature. The use of a complete optimization and the inclusion of correction for van der Waals interactions must have contributed to the improvement in the system description, increasing the interaction distance from $3.40 \AA$, reported in the literature and obtained with a partial optimization using LDA approximation to $4.00 \AA$, calculated in this work. The methodology was then extended to interaction of other monoaromatic hydrocarbons and the study of interactions with the anatase and the tetragonal $\mathrm{ZrO}_{2}$. The adsorption energies obtained for all complexes showed similar trends between the PW91 and PBE functionals. From the results of the adsorption energies for all systems studied, the interaction of BTEX molecules was higher with the (110) $\mathrm{TiO}_{2}$ rutile surface, followed by (101) of $\mathrm{TiO}_{2}$ anatase, and finally the (001) tetragonal $\mathrm{ZrO}_{2}$. CDD analyses showed an increase on electron density between the BTEX molecules and the rutile and anatase surfaces. For $\mathrm{TiO}_{2}$ and $\mathrm{ZrO}_{2}$, we observed the interaction between hydrogen and oxygen through the CDD and ELF, as evidenced by the decrease of charges of the hydrogen atoms and increased electron density close to bicoordinated surface oxygen atoms. The density of states for all systems studied showed a translation of the states to lower energy regions after adsorption, showing a stabilization of the system to form the complex. The adsorption energies analysis suggest that these materials are promising candidates that could be used as chemical sensors and catalysts for the adsorption of BTEX molecules.
\end{abstract}


Índice

Lista de Abreviaturas e Acrônimos $\quad$ xi

Lista de Tabelas $\quad$ Xv

Lista de Figuras $\quad$ xviii

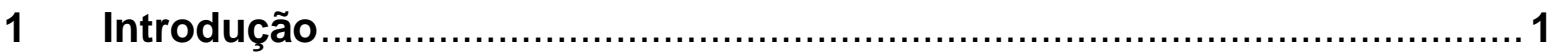

1.1 Objetivos

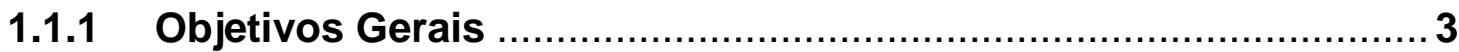

1.1.2 Etapas a Serem Desenvolvidas ….................................................

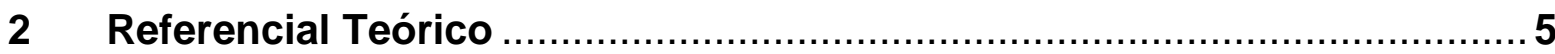

2.1 A Poluição Atmosférica e os Compostos Orgânicos Voláteis ................

2.2 Estruturas e Propriedades do Dióxido de Titânio $\left(\mathrm{TiO}_{2}\right)$ e do Dióxido de

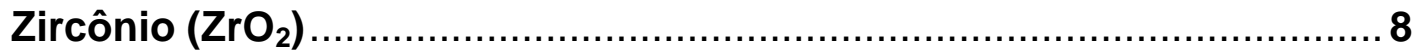

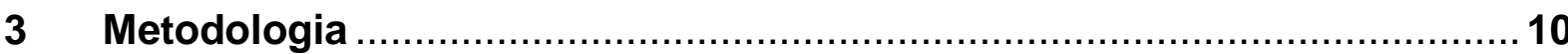

3.1 A Equação de Schrödinger Para Sistemas Com Muitos Corpos ...........10

3.1.1 A Teoria do Funcional de Densidade (DFT) …........................12

3.1.2 Ondas Planas, Pseudopotenciais e o Método Projector Augmented

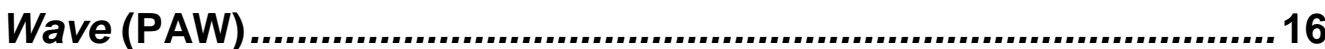

3.2 Metodologia Aplicada ao Estudo do Dióxido de Titânio $\left(\mathrm{TiO}_{2}\right)$ e Dióxido

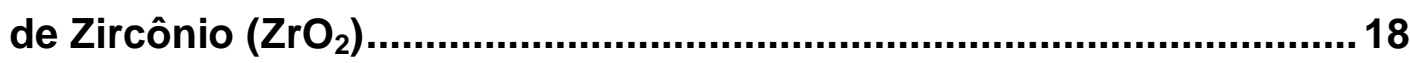

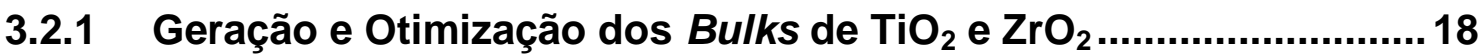

3.2.2 Geração dos Slabs e Formação dos Complexos BTEX-TiO $\mathrm{T}_{2} \mathrm{e}$

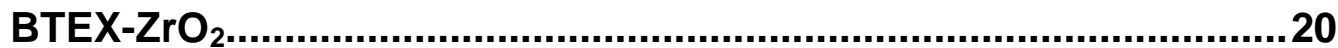

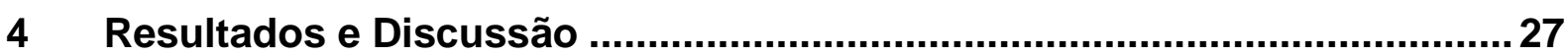

4.1 Otimização dos Parâmetros de Corte das Superfícies (110) do $\mathrm{TiO}_{2}$ 
Rutilo, (101) do $\mathrm{TiO}_{2}$ Anatásio e (001) do $\mathrm{ZrO}_{2}$ Tetragonal para o Estudo da Adsorção das Moléculas de BTEX

4.1.1 Análise da Energia de Corte das Ondas Planas e dos Pontos k ...27

4.1.2 Análise do Número de Camadas Necessárias para Representar a Superfície (110) do $\mathrm{TiO}_{2}$ Rutilo, (101) do $\mathrm{TiO}_{2}$ Anatásio e (001) do $\mathrm{ZrO}_{2}$ Tetragonal 33

4.1.3 Análise da Área Superficial das Superfícies (110) do $\mathrm{TiO}_{2}$ Rutilo, (101) do $\mathrm{TiO}_{2}$ Anatásio e (001) do $\mathrm{ZrO}_{2}$ Tetragonal .35

4.2 Adsorção de BTEX: Formação do Complexo $\mathrm{BTEX}^{-\mathrm{TiO}_{2}}$ Rutilo .38

4.2.1 Adsorção das Moléculas de BTEX..................................................38

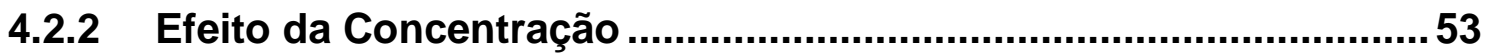

4.3 Adsorção de BTEX: Formação do Complexo BTEX-TiO ${ }_{2}$ Anatásio ........66

4.4 Adsorção de BTEX: Formação do Complexo BTEX-ZrO ${ }_{2}$ Tetragonal ...77

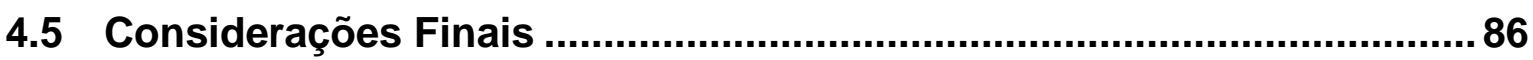

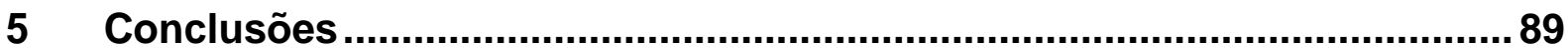

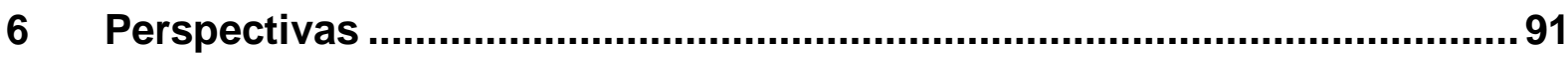

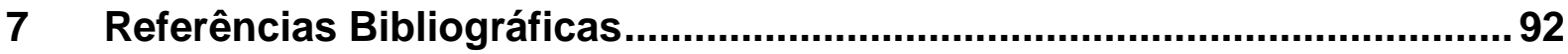

Anexo I 


\section{Lista de Abreviaturas e Acrônimos}

$\mathrm{ABO}$

APW

B3LYP

BGC

BTEX

BTEX-O $\mathrm{Cl}_{1}-\mathrm{ZrO}_{2}$-tetragonal

BTEX-O $\mathrm{CCS}_{2}-\mathrm{ZrO}_{2}$-tetragonal

BTEX-O ${ }_{3 c}$-anatásio

BTEX-O ${ }_{3 C}-\mathrm{O}_{3 \mathrm{C}}$-rutilo

BTEX-O ${ }_{3 C}$-rutilo

BTEX-O ${ }_{3 C}-\mathrm{Ti}_{5 \mathrm{C}}$-rutilo

BTEX-Ti ${ }_{5 C}$-anatásio

BTEX-Ti ${ }_{5 C}$-rutilo
Aproximação de Born-Oppenheimer

Augmented Plane Waves

Becke 3, Lee, Yang e Parr

Gradiente Corrigido de Becke (Becke Gradient Corrected)

Benzeno, Tolueno, Etilbenzeno, orto-Xileno, metaXileno e para-Xileno

BTEX na configuração em ponte sobre os $\mathrm{O}_{2 \mathrm{Cl}}$

BTEX na configuração em ponte sobre os $\mathrm{O}_{2 c s}$

BTEX na configuração centrada sobre o átomo de oxigênio tricoordenado

Duas moléculas de BTEX na configuração em ponte sobre os átomos de oxigênio tricoordenados

BTEX na configuração em ponte sobre os átomos de oxigênio tricoordenados

Uma molécula de BTEX na configuração em ponte sobre os átomos de oxigênio tricoordenados e a outra sobre os átomos de titânio pentacoordenados

BTEX na configuração centrada sobre o átomo de titânio pentacoordenado.

BTEX na configuração em ponte sobre os átomos de titânio pentacoordenados

Diferença de Densidade de Carga (Charge Density Difference) 


\begin{tabular}{|c|c|}
\hline $\mathrm{CIF}$ & $\begin{array}{l}\text { Arquivos de Informação Cristalográfica } \\
\text { (Crystallographic Information File) }\end{array}$ \\
\hline COVs & Compostos Orgânicos Voláteis \\
\hline $\mathrm{c}-\mathrm{ZrO}_{2}$ & Óxido de Zircônio Cúbico \\
\hline DFT & $\begin{array}{l}\text { Teoria do Funcional de Densidade (Density } \\
\text { Functional Theory) }\end{array}$ \\
\hline DOS & Densidade de Estados (Density of States) \\
\hline ELF & $\begin{array}{l}\text { Função de Localização Eletrônica (Electron } \\
\text { Localization Function) }\end{array}$ \\
\hline GGA & $\begin{array}{l}\text { Aproximação de Gradiente Generalizado } \\
\text { (Generalized Gradient Approximation) }\end{array}$ \\
\hline $\mathrm{HF}$ & Hartree-Fock \\
\hline HSC & Hamann, Schlüter e Chiang \\
\hline IARC & $\begin{array}{l}\text { Agência Internacional de Pesquisa sobre o Câncer } \\
\text { (International Agency for Research on Cancer) }\end{array}$ \\
\hline LAPW & Linear Augmented-Plane-Wave \\
\hline LDA & $\begin{array}{l}\text { Aproximação da Densidade Local (Local Density } \\
\text { Approximation) }\end{array}$ \\
\hline MOLDEN & Molecular Eletronic Density \\
\hline MTE & Ministério do Trabalho e Emprego \\
\hline M-TF & Modelo de Thomas-Fermi \\
\hline M-TFD & Modelo de Thomas-Fermi-Dirac \\
\hline $\mathrm{m}-\mathrm{ZrO}_{2}$ & Óxido de Zircônio Monoclínico \\
\hline NR & Norma Regulamentadora \\
\hline
\end{tabular}




\begin{tabular}{|c|c|}
\hline $\mathrm{O}_{2 \mathrm{C}}$ & Oxigênios Bicoordenados \\
\hline $\mathrm{O}_{2 \mathrm{Cl}}$ & $\begin{array}{l}\text { Oxigênio bicoordenados mais internos à superfície } \\
\text { do } \mathrm{ZrO}_{2} \text { tetragonal }\end{array}$ \\
\hline $\mathrm{O}_{2 C S}$ & $\begin{array}{l}\text { Oxigênio bicoordenados mais próximos à } \\
\text { superfície do } \mathrm{ZrO}_{2} \text { tetragonal }\end{array}$ \\
\hline $\mathrm{O}_{3 \mathrm{C}}$ & Oxigênios Tricoordenados \\
\hline $\mathrm{O}_{4 \mathrm{C}}$ & Oxigênios Tetracoordenados \\
\hline PAW & Projected Augmented Waves \\
\hline PBE & Perdew-Burke-Ernzerhof \\
\hline PDOS & $\begin{array}{l}\text { Densidade de Estados Projetada (Projecteo } \\
\text { Density of States) }\end{array}$ \\
\hline PW91 & Perdew-Wang 91 \\
\hline SCF & Ciclo Auto-Consistente (Self Consistent Field) \\
\hline STM & $\begin{array}{l}\text { Microscopia de Tunelamento com Varredura } \\
\text { (Scanning Tunneling Microscopy) }\end{array}$ \\
\hline $\mathrm{Ti}_{5 \mathrm{C}}$ & Titânios Pentacoordenados \\
\hline $\mathrm{Ti}_{6 \mathrm{C}}$ & Titânios Hexacoordenados \\
\hline TPD & $\begin{array}{l}\text { Dessorção Térmica Programada (Temperature } \\
\text { Programmed Desorption) }\end{array}$ \\
\hline $\mathrm{t}-\mathrm{ZrO}_{2}$ & Óxido de Zircônio Tetragonal \\
\hline US-PP & $\begin{array}{l}\text { Pseudopotenciais } \quad \text { Ultrasoft } \\
\text { Pseudopotentials) }\end{array}$ \\
\hline VASP & Vienna ab initio Simulation Program \\
\hline VESTA & Visualization for Eletronic and Structural Analysis \\
\hline
\end{tabular}


XCrysDen

XPS

$\mathrm{Zr}_{6 \mathrm{C}}$

$\mathrm{Zr}_{8 \mathrm{C}}$
X-window Crystalline Structures and Densities

Espectroscopia de Fotoelétrons Excitados por Raios-x (X-ray Photoelectron Spectroscopy)

Zircônios Hexacoordenados

Zircônios Octocoordenados 


\section{Lista de Tabelas}

Tabela 1. Comparação entre as equações utilizadas nas teorias de Hartree-Fock (HF) e do funcional de densidade (DFT). Reimpresso do trabalho de Morgon e Custódio 15

Tabela 2. Representação do ciclo auto-consistente (SCF) nos métodos de HartreeFock (HF) e na Teoria do Funcional de Densidade (DFT). Reimpresso do trabalho de Morgon e Custódio. 15

Tabela 3. Parâmetros de rede e grupo espacial do $\mathrm{TiO}_{2}$ e do $\mathrm{ZrO}_{2}$. 18

Tabela 4. Parâmetros de rede $(\AA ̊)$ do $\mathrm{TiO}_{2}$ rutilo e anatásio e $\mathrm{ZrO}_{2}$ tetragonal obtidos com os cálculos variando-se o número de pontos $\mathrm{k}$ e a energia de corte das ondas planas. Foram usados os funcionais de troca e correlação PW91 e PBE. .28

Tabela 5. Energia da superfície em $\mathrm{J} / \mathrm{m}^{2}$ em função do número de camadas para a superfície (110) do $\mathrm{TiO}_{2}$ rutilo, (101) do $\mathrm{TiO}_{2}$ anatásio e (001) do $\mathrm{ZrO}_{2}$ tetragonal usando os funcionais de troca e correlação PW91 e PBE.

Tabela 6. Parâmetros de rede $(\AA)$ e área superficial $\left(\AA^{2}\right)$ para as superfícies $(1 \times 1)$ dos planos (110) do $\mathrm{TiO}_{2}$ rutilo, (101) do $\mathrm{TiO}_{2}$ anatásio e (001) do $\mathrm{ZrO}_{2}$ tetragonal usando os funcionais PW91 e PBE.

Tabela 7. Parâmetros de rede $a$ e $b$ das supercélulas estudadas para a superfície (110) do $\mathrm{TiO}_{2}$ rutilo, (101) do $\mathrm{TiO}_{2}$ anatásio e (001) do $\mathrm{ZrO}_{2}$ tetragonal. .36

Tabela 8. Energias de adsorção $(\mathrm{kJ} / \mathrm{mol})$ das moléculas de BTEX perpendiculares à superfície usando o funcionais PW91, PBE e PBE-D2.

Tabela 9. Distância adsorbato-superfície $(\AA)$ entre as moléculas de BTEX e os átomos de titânio pentacoordenados $\left(\mathrm{Ti}_{5 \mathrm{C}}\right)$ : $\mathrm{BTEX}-\mathrm{O}_{3 \mathrm{C}}$-rutilo e BTEX-Ti $\mathrm{i}_{5 \mathrm{C}}$-rutilo, usando os funcionais PW91, PBE e PBE-D2.

Tabela 10. Ângulos entre as moléculas adsorvidas e o plano da superfície (110) do $\mathrm{TiO}_{2}$ rutilo

Tabela 11. Energias de adsorção $(\mathrm{kJ} / \mathrm{mol})$ usando o funcionais PW91, PBE, PBED2//PBE e PBE-D2 para os complexos BTEX-O ${ }_{3 C}$-rutilo e BTEX-Ti $i_{5 c}$-rutilo. 
Tabela 12. Cargas (e) das moléculas de BTEX após a adsorção usando o modelo de Bader.

Tabela 13. Energias de ligação dos níveis do caroço $C 1$ s Ti2p. .53

Tabela 14. Distância adsorbato-superfície $(\AA ̊)$ entre as moléculas de BTEX e os

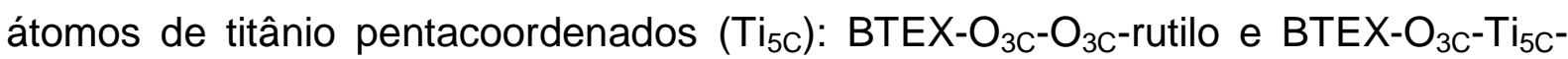
rutilo, usando os funcionais PW91, PBE e PBE-D2.

Tabela 15. Ângulos entre as moléculas adsorvidas e o plano da superfície (110) do $\mathrm{TiO}_{2}$ rutilo.

Tabela 16. Energias de adsorção $(\mathrm{kJ} / \mathrm{mol})$ usando o funcionais PW91, PBE, PBED2//PBE e PBE-D2 para os complexos BTEX-O ${ }_{3 C}-\mathrm{O}_{3 \mathrm{C}}$-rutilo e BTEX-O ${ }_{3 \mathrm{C}}-\mathrm{Ti}_{5 \mathrm{C}}$-rutilo.

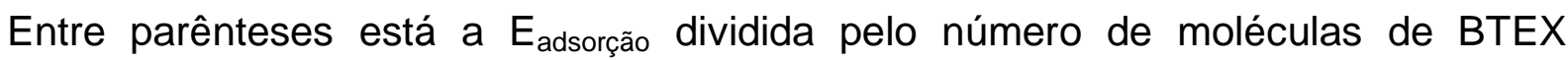

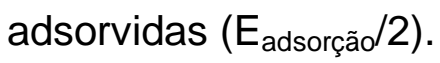

Tabela 17. Cargas (e) das moléculas de BTEX após a adsorção usando o modelo de Bader.

Tabela 18. Distância adsorbato-superfície $(\AA ̊)$ entre as moléculas de BTEX e os átomos de titânio pentacoordenados $\left(\mathrm{Ti}_{5 \mathrm{C}}\right)$ : BTEX-Ti ${ }_{5 \mathrm{C}}$-anatásio e BTEX-O ${ }_{3 \mathrm{C}}$ anatásio, usando os funcionais PW91, PBE e PBE-D2.

Tabela 19. Energias de adsorção $(\mathrm{kJ} / \mathrm{mol})$ usando o funcionais PW91, PBE, PBED2//PBE e PBE-D2 para os complexos BTEX-Ti ${ }_{5 C}$-anátasio e BTEX-O ${ }_{3 C}$-anatásio. 71

Tabela 20. Cargas (e) das moléculas de BTEX após a adsorção usando o modelo de Bader.

Tabela 21. Distância adsorbato-superfície (Å) entre as moléculas de BTEX e os átomos de zircônio hexacoordenados $\left(\mathrm{Zr}_{6 \mathrm{C}}\right)$ : $\mathrm{BTEX}-\mathrm{O}_{2 \mathrm{Cs}}-\mathrm{ZrO}_{2}$-tetragonal e BTEX$\mathrm{O}_{2 \mathrm{Cl}}-\mathrm{ZrO}_{2}$-tetragonal, usando os funcionais PW91 e PBE.

Tabela 22. Ângulos entre as moléculas adsorvidas e o plano da superfície (001) do $\mathrm{ZrO}_{2}$ tetragonal. .80 
Tabela 23. Energias de adsorção $(\mathrm{kJ} / \mathrm{mol})$ usando o funcionais PW91, PBE e PBE-

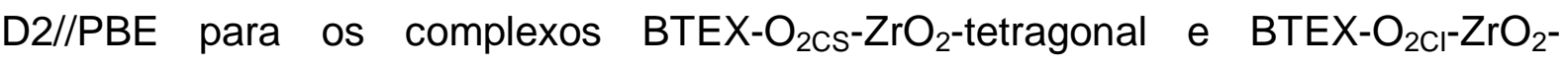

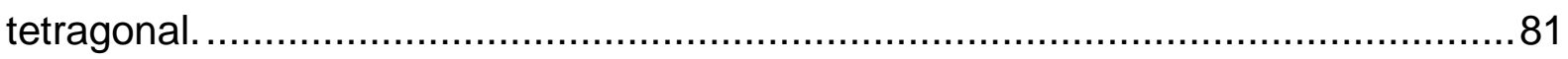




\section{Lista de Figuras}

Figura 1. Fórmula estrutural do benzeno. 6

Figura 2. Fórmulas estruturais do: (a) tolueno; (b) etilbenzeno; (c) o-xileno; (d) mxileno e (e) p-xileno. 7

Figura 3. Estruturas para: (a) $\mathrm{TiO}_{2}$ rutilo; (b) $\mathrm{TiO}_{2}$ anatásio; (c) $\mathrm{TiO}_{2}$ brookita; (d) $\mathrm{ZrO}_{2}$ monoclínico; (e) $\mathrm{ZrO}_{2}$ cúbico e (f) $\mathrm{ZrO}_{2}$ tetragonal. Aqui e nas demais figuras o cinza, azul e vermelho representam os átomos de titânio, zircônio e oxigênio, respectivamente.

Figura 4. Estruturas do $\mathrm{TiO}_{2}$ rutilo (110), $\mathrm{TiO}_{2}$ anatásio (101) e $\mathrm{ZrO}_{2}$ (001): (a) e (b) vista lateral e superior da superfície (110) do $\mathrm{TiO}_{2}$ rutilo, respectivamente; (c) e (d) vista lateral e superior da superfície (101) do $\mathrm{TiO}_{2}$ anatásio, respectivamente; (e) e (f) vista lateral e superior da superfície (001) do $\mathrm{ZrO}_{2}$ tetragonal, respectivamente..21

Figura 5. Superfícies com duas, quatro, seis, oito, dez e doze camadas para o (a) $\mathrm{TiO}_{2}$ rutilo (110); para o (b) $\mathrm{TiO}_{2}$ anatásio (101) e para o (c) $\mathrm{ZrO}_{2}$ tetragonal (001).. 23

Figura 6. Variação Relativa Percentual (VRP) dos parâmetros de rede "a" e "c" obtidos com o funcional de troca e correlação PW91 para o (a) e (b) $\mathrm{TiO}_{2}$ rutilo; para o (c) e (d) $\mathrm{TiO}_{2}$ anatásio e para o (e) e (f) $\mathrm{ZrO}_{2}$ tetragonal em relação ao valor experimental ${ }^{120-122}$

Figura 7. Variação Relativa Percentual (VRP) dos parâmetros de rede "a" e "c" obtidos com o funcional de troca e correlação PBE para o (a); (b) $\mathrm{TiO}_{2}$ rutilo; para o (c); (d) $\mathrm{TiO}_{2}$ anatásio e para o (e); (f) $\mathrm{ZrO}_{2}$ tetragonal em relação ao valor experimental ${ }^{120-122}$ .30

Figura 8. Energia total (eV) em função da energia de corte $(\mathrm{eV})$ para cada uma das malhas de pontos $\mathrm{k}$ calculadas para o (a) e (b) $\mathrm{TiO}_{2}$ rutilo; para o (c) e (d) $\mathrm{TiO}_{2}$ anatásio e para o (e) e (f) $\mathrm{ZrO}_{2}$ tetragonal usando os funcionais PW91 e PBE........32

Figura 9. Energia total para as moléculas de benzeno, tolueno, etilbenzeno, oxileno, m-xileno e p xileno em relação ao tamanho da supercélula para o (a), (b) $\mathrm{TiO}_{2}$ rutilo, (c), (d) $\mathrm{TiO}_{2}$ anatásio e (e), (f) $\mathrm{ZrO}_{2}$ tetragonal usando os funcionais PW91 e PBE. 
Figura 10. Vista superior da superfície (110) do $\mathrm{TiO}_{2}$ rutilo, indicando por um "x" os sítios para a adsorção da molécula de benzeno. Adaptado da referência 22.

Figura 11. Estrutura otimizada da interação da molécula de benzeno perpendicular à superfície (110) do $\mathrm{TiO}_{2}$ rutilo usando o funcional PW91.

Figura 12. Estruturas otimizadas usando o funcional PW91 da interação das moléculas de BTEX com a superfície (110) do $\mathrm{TiO}_{2}$ rutilo, mostrando as ligações CC em uma configuração em ponte sobre os $\mathrm{O}_{3 \mathrm{c}}$ : (a) benzeno- $\mathrm{O}_{3 \mathrm{c}}$-rutilo; (b) tolueno$\mathrm{O}_{3 c}$-rutilo; (c) etilbenzeno- $\mathrm{O}_{3 c}$-rutilo; (d) o-xileno- $\mathrm{O}_{3 \mathrm{c}}$-rutilo; (e) m-xileno- $\mathrm{O}_{3 \mathrm{c}}$-rutilo e (f) $\mathrm{p}$-xileno- $\mathrm{O}_{3 \mathrm{c}}$-rutilo.

Figura 13. Estruturas otimizadas usando o funcional PW91 da interação das moléculas de BTEX com a superfície (110) do $\mathrm{TiO}_{2}$ rutilo, mostrando as ligações CC em uma configuração em ponte sobre os $\mathrm{Ti}_{5 \mathrm{c}}$ : (a) benzeno-Ti ${ }_{5 \mathrm{c}}$-rutilo; (b) toluenoTi $i_{5 c}$-rutilo; (c) etilbenzeno-Ti $i_{5 c}$-rutilo; (d) o-xileno-Ti ${ }_{5 c}$-rutilo; (e) m-xileno-Ti $i_{5 c}$-rutilo e (f) $p$-xileno-Ti $i_{5 c}$-rutilo.

Figura 14. Diferença de densidade de carga (CDD) do (a) Benzeno- $\mathrm{O}_{3 \mathrm{C}}$-rutilo; (b) Benzeno-Ti ${ }_{5 c}$-rutilo; (c) Tolueno-O ${ }_{3 c}$-rutilo; (d) Tolueno-Ti ${ }_{5 c}$-rutilo; (e) Etilbenzeno$\mathrm{O}_{3 c}$-rutilo; (f) Etilbenzeno-Ti ${ }_{5 c}$-rutilo; (g) o-Xileno- ${ }_{3 c}$-rutilo; (h) o-Xileno-Ti ${ }_{5 c}$-rutilo; (i) m-Xileno- ${ }_{3 c}$-rutilo; (j) m-Xileno-Ti ${ }_{5 c}$-rutilo; (I) $p$-Xileno- $\mathrm{O}_{3 \mathrm{c}}$-rutilo; (m) $\mathrm{p}$-Xileno-Ti ${ }_{5 \mathrm{c}^{-}}$ rutilo. A cor vermelha é para valores negativos (decréscimo de densidade eletrônica), e azul para valores positivos (aumento da densidade eletrônica). O valor da isosuperfície é $0,0005 \mathrm{e} / \mathrm{bohr}^{3}$.

Figura 15. ELF das moléculas de BTEX na geometria otimizada BTEX- $\mathrm{O}_{3 c}$-rutilo: (a) benzeno; (b) tolueno; (c) etilbenzeno; (d) o-xileno; (e) m-xileno e (f) p-xileno. O valor da isosuperfície é 0,8 .

Figura 16. Função de localização eletrônica (ELF) para os complexos (a) Benzeno$\mathrm{O}_{3 c}$-rutilo; (b) Benzeno-Ti ${ }_{5 c}$-rutilo; (c) Tolueno- $\mathrm{O}_{3 \mathrm{c}}$-rutilo; (d) Tolueno-Ti $\mathrm{i}_{5 \mathrm{c}}$-rutilo; (e) Etilbenzeno- $\mathrm{O}_{3 \mathrm{C}}$-rutilo; (f) Etilbenzeno-Ti ${ }_{5 \mathrm{C}}$-rutilo; (f) o-Xileno- $\mathrm{O}_{3 \mathrm{c}}$-rutilo; (g) o-Xileno$\mathrm{Ti}_{5 \mathrm{c}}$-rutilo; (h) m-Xileno- $\mathrm{O}_{3 \mathrm{c}}$-rutilo; (i) $\mathrm{m}$-Xileno-Ti ${ }_{5 \mathrm{c}}$-rutilo; (I) $\mathrm{p}$-Xileno- $\mathrm{O}_{3 \mathrm{c}}$-rutilo; (m) p-Xileno-Ti ${ }_{5 c}$-rutilo. $O$ valor da isosuperfície é 0,8 . 
Figura 17. Densidade de estados total e projetada para a adsorção da molécula de benzeno na superfície (110) do $\mathrm{TiO}_{2}$ rutilo: (a) Benzeno- $\mathrm{O}_{3 c}$-rutilo e (b) Benzeno$\mathrm{Ti}_{5 \mathrm{C}}$-rutilo. $\mathrm{Na}$ parte inferior: DOS total da superfície livre e projetado sobre a superfície após a adsorção. No meio: DOS total da superfície livre e do benzeno isolado. Na parte superior: DOS total dos complexos benzeno- $\mathrm{O}_{3 \mathrm{C}}$-rutilo e benzeno$\mathrm{Ti}_{5 \mathrm{c}}$-rutilo e projetado sobre a molécula de benzeno do complexo. A energia de Fermi está definida para zero. .51

Figura 18. PDOS calculado para os estados $d$ dos titânios da primeira camada da superfície (110) do $\mathrm{TiO}_{2}$ rutilo livre e após a adsorção do benzeno. PDOS para os estados $p$ do benzeno isolado e adsorvido sobre a superfície (110) do $\mathrm{TiO}_{2}$ rutilo. (a) Benzeno- $\mathrm{O}_{3 \mathrm{C}}$-rutilo; (b) Benzeno- $\mathrm{Ti}_{5 \mathrm{C}}$-rutilo. A energia de Fermi está definida para zero.

Figura 19. Estruturas otimizadas usando o funcional PW91 da interação das moléculas de BTEX nos dois sítios da superfície (110) do $\mathrm{TiO}_{2}$ rutilo: (a) benzeno$\mathrm{O}_{3 \mathrm{C}}-\mathrm{O}_{3 \mathrm{c}}$-rutilo; (b) tolueno- $\mathrm{O}_{3 \mathrm{C}}-\mathrm{O}_{3 \mathrm{c}}$-rutilo; (c) etilbenzeno- $\mathrm{O}_{3 \mathrm{C}}-\mathrm{O}_{3 \mathrm{c}}$-rutilo; (d) o-xileno$\mathrm{O}_{3 c}-\mathrm{O}_{3 c}$-rutilo; (e) m-xileno- $\mathrm{O}_{3 c}-\mathrm{O}_{3 c}$-rutilo e (f) p-xileno- $\mathrm{O}_{3 \mathrm{c}}-\mathrm{O}_{3 c}$-rutilo.

Figura 20. Estruturas otimizadas usando o funcional PW91 da interação das moléculas de BTEX nos dois sítios da superfície (110) do $\mathrm{TiO}_{2}$ rutilo: (a) benzeno$\mathrm{O}_{3 \mathrm{C}}-\mathrm{Ti}_{5 \mathrm{c}}$-rutilo; (b) tolueno- $\mathrm{O}_{3 \mathrm{c}}-\mathrm{Ti}_{5 \mathrm{c}}$-rutilo; (c) etilbenzeno- $\mathrm{O}_{3 \mathrm{c}}-\mathrm{Ti}_{5 \mathrm{c}}$-rutilo; (d) o-xileno$\mathrm{O}_{3 c}-\mathrm{Ti}_{5 \mathrm{c}}$-rutilo; (e) m-xileno- $\mathrm{O}_{3 \mathrm{c}}-\mathrm{Ti}_{5 \mathrm{c}}$-rutilo e (f) p-xileno- $\mathrm{O}_{3 \mathrm{c}}-\mathrm{Ti}_{5 \mathrm{c}}$-rutilo.

Figura 21. Diferença de densidade de carga (CDD) do (a) Benzeno- $\mathrm{O}_{3 \mathrm{C}}-\mathrm{O}_{3 \mathrm{C}}$-rutilo; (b) Benzeno- $\mathrm{O}_{3 \mathrm{C}}-\mathrm{Ti}_{5 \mathrm{c}}$-rutilo; (c) Tolueno- $\mathrm{O}_{3 \mathrm{C}}-\mathrm{O}_{3 \mathrm{C}}$-rutilo; (d) Tolueno- $\mathrm{O}_{3 \mathrm{C}}-\mathrm{Ti}_{5 \mathrm{C}}$-rutilo; (e) Etilbenzeno- $\mathrm{O}_{3 \mathrm{C}}-\mathrm{O}_{3 \mathrm{C}}$-rutilo; (f) Etilbenzeno- $\mathrm{O}_{3 \mathrm{C}}-\mathrm{Ti}_{5 \mathrm{c}}$-rutilo; (f) o-Xileno- $\mathrm{O}_{3 \mathrm{C}}-\mathrm{O}_{3 \mathrm{C}}$

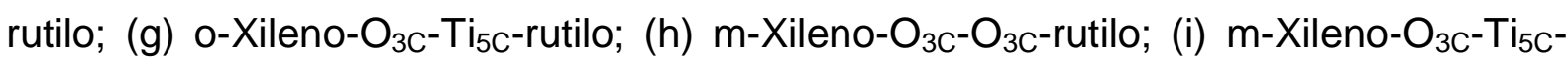
rutilo; (I) p-Xileno- $\mathrm{O}_{3 \mathrm{c}}-\mathrm{O}_{3 \mathrm{c}}$-rutilo; (m) p-Xileno- $\mathrm{O}_{3 \mathrm{c}}-\mathrm{Ti}_{5 \mathrm{c}}$-rutilo. A cor vermelha é para valores negativos (decréscimo de densidade eletrônica), e azul para valores positivos (aumento da densidade eletrônica). O valor da isosuperfície é 0,0005 e/bohr ${ }^{3}$.

Figura 22. ELF das moléculas de $B T E X$ na geometria otimizada $B T E X-\mathrm{O}_{3 c}-\mathrm{O}_{3 c}$-rutilo e BTEX-O ${ }_{3 c}-$ Ti $_{5 c}$-rutilo: (a) e (b) benzeno; (c) e (d) tolueno; (d) e (f) etilbenzeno; (g) e (h) o-xileno; (i) e (j) m-xileno; (l) e (m) p-xileno. 62 
Figura 23. Função de localização eletrônica (ELF) para os complexos (a) Benzeno$\mathrm{O}_{3 \mathrm{c}}-\mathrm{O}_{3 \mathrm{C}}$-rutilo; (b) Benzeno- $\mathrm{O}_{3 \mathrm{C}}-\mathrm{Ti}_{5 \mathrm{C}}$-rutilo; (c) Tolueno- $\mathrm{O}_{3 \mathrm{c}}-\mathrm{O}_{3 \mathrm{c}}$-rutilo; (d) Tolueno$\mathrm{O}_{3 \mathrm{C}}-\mathrm{Ti}_{5 \mathrm{C}}$-rutilo; (e) Etilbenzeno- $\mathrm{O}_{3 \mathrm{C}}-\mathrm{O}_{3 \mathrm{C}}$-rutilo; (f) Etilbenzeno- $\mathrm{O}_{3 \mathrm{C}}-\mathrm{Ti}_{5 \mathrm{C}}$-rutilo; (f) oXileno- $\mathrm{O}_{3 \mathrm{c}}-\mathrm{O}_{3 \mathrm{c}}$-rutilo; (g) o-Xileno- $\mathrm{O}_{3 \mathrm{c}}-\mathrm{Ti}_{5 \mathrm{c}}$-rutilo; (h) m-Xileno- $\mathrm{O}_{3 \mathrm{c}}-\mathrm{O}_{3 \mathrm{c}}$-rutilo; (i) $\mathrm{m}$ Xileno- $\mathrm{O}_{3 \mathrm{c}}-\mathrm{Ti}_{5 \mathrm{c}}$-rutilo; (I) $\mathrm{p}$-Xileno- $\mathrm{O}_{3 \mathrm{c}}-\mathrm{O}_{3 \mathrm{c}}$-rutilo; (m) $\mathrm{p}$-Xileno- $\mathrm{O}_{3 \mathrm{C}}-\mathrm{Ti}_{5 \mathrm{c}}$-rutilo. O valor da isosuperfície é 0,8 .

Figura 24. Densidade de estados total e projetada para a adsorção da molécula de benzeno na superfície (110) do $\mathrm{TiO}_{2}$ rutilo: (a) Benzeno- $\mathrm{O}_{3 \mathrm{c}}-\mathrm{O}_{3 \mathrm{c}}$-rutilo e (b) Benzeno- $\mathrm{O}_{3 \mathrm{C}}-\mathrm{Ti}_{5 \mathrm{C}}$-rutilo. $\mathrm{Na}$ parte inferior: DOS total da superfície livre e projetado sobre a superfície após a adsorção. No meio: DOS total da superfície livre e do

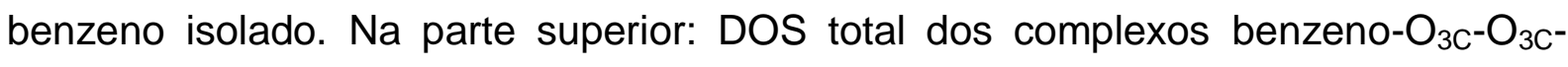
rutilo e benzeno- $\mathrm{O}_{3 \mathrm{C}}-\mathrm{Ti}_{5 \mathrm{C}}$-rutilo e projetado sobre a molécula de benzeno do complexo. A energia de Fermi está definida para zero.

Figura 25. PDOS calculado para os estados $d$ dos titânios da primeira camada da superfície (110) do $\mathrm{TiO}_{2}$ rutilo livre e após a adsorção dos benzenos. PDOS para os estados $p$ dos benzenos isolados e adsorvidos sobre a superfície (110) do $\mathrm{TiO}_{2}$ rutilo. (a) Benzeno- $\mathrm{O}_{3 \mathrm{C}}-\mathrm{O}_{3 \mathrm{C}}$-rutilo; (b) Benzeno- $\mathrm{O}_{3 \mathrm{C}}-\mathrm{Ti}_{5 \mathrm{c}}$-rutilo. A energia de Fermi está definida para zero. .66

Figura 26. Estruturas otimizadas usando o funcional PW91 da interação das moléculas de BTEX com a superfície (101) do $\mathrm{TiO}_{2}$ anatásio: (a) benzeno- $\mathrm{Ti}_{5 \mathrm{C}^{-}}$ anatásio; (b) tolueno-Ti ${ }_{5 c}$-anatásio; (c) etilbenzeno-Ti ${ }_{5 c}$-anatásio; (d) o-xileno-Ti ${ }_{5 C^{-}}$ anatásio; (e) m-xileno-Ti $i_{5 c}$-anatásio e (f) p-xileno-Ti ${ }_{5 c}$-anatásio.

Figura 27. Estruturas otimizadas usando o funcional PW91 da interação das moléculas de BTEX com a superfície (101) do $\mathrm{TiO}_{2}$ anatásio: (a) benzeno- $\mathrm{O}_{3 \mathrm{C}^{-}}$

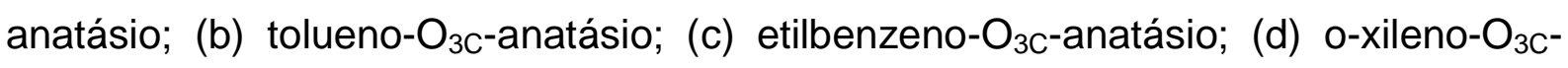
anatásio; (e) m-xileno- $\mathrm{O}_{3 \mathrm{c}}$-anatásio e (f) p-xileno- $\mathrm{O}_{3 \mathrm{c}}$-anatásio. 68

Figura 28. Ângulos formados entre as moléculas de BTEX e o plano da superfície (110) do $\mathrm{TiO}_{2}$ anatásio para a interação: (a) BTEX-Ti ${ }_{5 c}$-anatásio e (b) BTEX-O ${ }_{3 C^{-}}$ anatásio. .70 
Figura 29. Diferença de densidade de carga (CDD) do (a) Benzeno-Ti ${ }_{5 c}$-anatásio; (b) Benzeno- $\mathrm{O}_{3 \mathrm{C}}$-anatásio; (c) Tolueno-Ti ${ }_{5 \mathrm{c}}$-anatásio; (d) Tolueno- $\mathrm{O}_{3 \mathrm{C}}$-anatásio; (e) Etilbenzeno-Ti ${ }_{5 \mathrm{C}}$-anatásio; (f) Etilbenzeno- $\mathrm{O}_{3 \mathrm{C}}$-anatásio; (g) o-Xileno-Ti $\mathrm{i}_{5 \mathrm{c}}$-anatásio; (h) o-Xileno- $\mathrm{O}_{3 \mathrm{C}}$-anatásio; (i) $\mathrm{m}$-Xileno-Ti ${ }_{5 \mathrm{c}}$-anatásio; (j) $\mathrm{m}$-Xileno- $\mathrm{O}_{3 \mathrm{c}}$-anatásio; (I) pXileno-Ti $\mathrm{ic}_{5 \mathrm{c}}$-anatásio; $(\mathrm{m}) \mathrm{p}$-Xileno- $\mathrm{O}_{3 \mathrm{c}}$-anatásio. $\mathrm{A}$ cor vermelha é para valores negativos (decréscimo de densidade eletrônica), e azul para valores positivos (aumento da densidade eletrônica). O valor da isosuperfície é 0,0005 e/bohr ${ }^{3}$. 72

Figura 30. ELF das moléculas de BTEX na geometria otimizada BTEX-Ti ${ }_{5 \mathrm{C}}$-anatásio: (a) benzeno; (b) tolueno; (c) etilbenzeno;(d) o-xileno; (e) m-xileno e (f) p-xileno. O valor da isosuperfície é 0,8 .

Figura 31. Função de localização eletrônica (ELF) para os complexos (a) Benzeno$\mathrm{Ti}_{5 \mathrm{c}}$-anatásio; (b) Benzeno- $\mathrm{O}_{3 \mathrm{C}}$-anatásio; (c) Tolueno-Ti ${ }_{5 \mathrm{c}}$-anatásio; (d) Tolueno- $\mathrm{O}_{3 \mathrm{C}^{-}}$ anatásio; (e) Etilbenzeno-Ti ${ }_{5 \mathrm{c}}$-anatásio; (f) Etilbenzeno- $\mathrm{O}_{3 \mathrm{c}}$-anatásio; (g) o-XilenoTi $i_{5 c}$-anatásio; (h) o-Xileno- $\mathrm{O}_{3 \mathrm{c}}$-anatásio; (i) m-Xileno-Ti ${ }_{5 \mathrm{c}}$-anatásio; (j) m-Xileno- $\mathrm{O}_{3 \mathrm{C}}$ anatásio; (I) p-Xileno-Ti ${ }_{5 c}$-anatásio; (m) p-Xileno- $\mathrm{O}_{3 \mathrm{c}}$-anatásio. $\mathrm{O}$ valor da isosuperfície é 0,8 .

Figura 32. Densidade de estados total e projetada para a adsorção da molécula de benzeno na superfície (101) do $\mathrm{TiO}_{2}$ anatásio: (a) Benzeno- $\mathrm{Ti}_{5 \mathrm{C}}$-anatásio e (b) Benzeno- $\mathrm{O}_{3 \mathrm{C}}$-anatásio. Na parte inferior: DOS total da superfície livre e projetado sobre superfície após a adsorção. No meio: DOS total da superfície livre e do benzeno isolado. Na parte superior: DOS total dos complexos Benzeno-Ti ${ }_{5 c}$-anatásio e Benzeno- $\mathrm{O}_{3 \mathrm{C}}$-anatásio e projetado sobre a molécula de benzeno do complexo. A energia de Fermi está definida para zero.

Figura 33. PDOS calculado para os orbitais d dos titânios da primeira camada da superfície (101) do $\mathrm{TiO}_{2}$ anatásio livre e após a adsorção do benzeno. PDOS para os orbitais $p$ do benzeno isolado e adsorvido sobre a superfície (101) do $\mathrm{TiO}_{2}$ anatásio. (a) Benzeno-Ti ${ }_{5 c}$-anatásio; (b) Benzeno- $\mathrm{O}_{3 \mathrm{C}}$-anatásio. A energia de Fermi está definida para zero.

Figura 34. Estruturas otimizadas usando o funcional PW91, da interação das moléculas de BTEX com a superfície (001) do $\mathrm{ZrO}_{2}$ tetragonal, mostrando as ligações $\mathrm{CC}$ em uma configuração em ponte sobre os $\mathrm{O}_{2 \mathrm{Cs}}$ : (a) benzeno- $\mathrm{O}_{2 \mathrm{Cs}}-\mathrm{ZrO}_{2^{-}}$ 
tetragonal; (b) tolueno- $\mathrm{O}_{2 \mathrm{cs}}-\mathrm{ZrO}_{2}$-tetragonal; (c) etilbenzeno- $\mathrm{O}_{2 \mathrm{Cs}}-\mathrm{ZrO}_{2}$-tetragonal; (d) o-xileno- $\mathrm{O}_{2 \mathrm{Cs}}-\mathrm{ZrO}_{2}$-tetragonal; (e) m-xileno- $\mathrm{O}_{2 \mathrm{Cs}}-\mathrm{ZrO}_{2}$-tetragonal e (f) p-xileno$\mathrm{O}_{2 \mathrm{Cs}}-\mathrm{ZrO}$-tetragonal.

Figura 35. Estruturas otimizadas usando o funcional PW91, da interação das moléculas de BTEX com a superfície (001) do $\mathrm{ZrO}_{2}$ tetragonal, mostrando as ligações $\mathrm{CC}$ em uma configuração em ponte sobre os $\mathrm{O}_{2 \mathrm{Cl}}$ : (a) benzeno- $\mathrm{O}_{2 \mathrm{Cl}}-\mathrm{ZrO}_{2}$ tetragonal; (b) tolueno- $\mathrm{O}_{2 \mathrm{C}-}-\mathrm{ZrO}_{2}$-tetragonal; (c) etilbenzeno- $\mathrm{O}_{2 \mathrm{Cl}}-\mathrm{ZrO}_{2}$-tetragonal; (d) o-xileno- $\mathrm{O}_{2 \mathrm{Cl}}-\mathrm{ZrO}_{2}$-tetragonal; (e) m-xileno- $\mathrm{O}_{2 \mathrm{Cl}}-\mathrm{ZrO}_{2}$-tetragonal e (f) p-xileno- $\mathrm{O}_{2 \mathrm{Cl}}$ $\mathrm{ZrO}_{2}$-tetragonal.

Figura 36. Diferença de densidade de carga (CDD) do (a) Benzeno- $\mathrm{O}_{2 \mathrm{Cs}}-\mathrm{ZrO}_{2}$ tetragonal; (b) Benzeno- $\mathrm{O}_{2 \mathrm{Cl}}-\mathrm{ZrO}_{2}$-tetragonal; (c) Tolueno- $\mathrm{O}_{2 \mathrm{Cs}}-\mathrm{ZrO}_{2}$-tetragonal; (d) Tolueno- $\mathrm{O}_{2 \mathrm{Cl}}-\mathrm{ZrO}_{2}$-tetragonal; (e) Etilbenzeno- $\mathrm{O}_{2 \mathrm{Cs}}-\mathrm{ZrO}_{2}$-tetragonal; (f) Etilbenzeno$\mathrm{O}_{2 \mathrm{Cl}}-\mathrm{ZrO}_{2}$-tetragonal; (g) o-Xileno- $\mathrm{O}_{2 \mathrm{cs}}-\mathrm{ZrO}_{2}$-tetragonal; (h) o-Xileno- $\mathrm{O}_{2 \mathrm{Cl}}-\mathrm{ZrO}_{2}$ tetragonal; (i) $\mathrm{m}$-Xileno- $\mathrm{O}_{2 \mathrm{cs}}-\mathrm{ZrO}_{2}$-tetragonal; (j) $\mathrm{m}$-Xileno- $\mathrm{O}_{2 \mathrm{Cl}}-\mathrm{ZrO}_{2}$-tetragonal; (I) $\mathrm{p}$ Xileno- $\mathrm{O}_{2 \mathrm{Cs}}-\mathrm{ZrO}_{2}$-tetragonal; (m) $\mathrm{p}$-Xileno- $\mathrm{O}_{2 \mathrm{Cl}}-\mathrm{ZrO}_{2}$-tetragonal. A cor vermelha é para valores negativos (decréscimo de densidade eletrônica), e azul para valores positivos (aumento da densidade eletrônica). O valor da isosuperfície é 0,0005 e/bohr ${ }^{3}$. .82

Figura 37. ELF das moléculas de BTEX na geometria otimizada BTEX-O $\mathrm{O}_{2 \mathrm{Cs}}-\mathrm{ZrO}_{2}$ tetragonal: (a) benzeno; (b) tolueno; (c) etilbenzeno;(d) o-xileno; (e) m-xileno e (f) pxileno. O valor da isosuperfície é 0,8 .

Figura 38. Função de localização eletrônica (ELF) para os complexos (a) Benzeno-

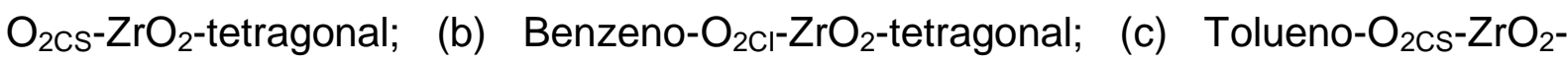
tetragonal; (d) Tolueno- $\mathrm{O}_{2 \mathrm{Cl}}-\mathrm{ZrO}_{2}$-tetragonal; (e) Etilbenzeno- $\mathrm{O}_{2 \mathrm{Cs}}-\mathrm{ZrO}_{2}$-tetragonal;

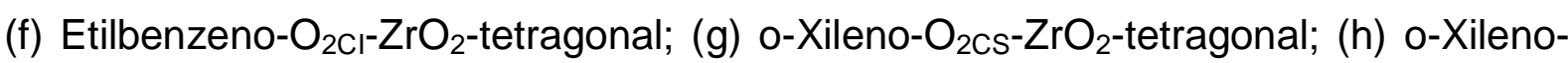
$\mathrm{O}_{2 \mathrm{Cl}}-\mathrm{ZrO}_{2}$-tetragonal; (i) m-Xileno- $\mathrm{O}_{2 \mathrm{cs}}-\mathrm{ZrO}_{2}$-tetragonal; (j) $\mathrm{m}$-Xileno- $\mathrm{O}_{2 \mathrm{Cl}}-\mathrm{ZrO}_{2^{-}}$ tetragonal; (I) $\mathrm{p}$-Xileno- $\mathrm{O}_{2 \mathrm{Cs}}-\mathrm{ZrO}_{2}$-tetragonal; (m) $\mathrm{p}$-Xileno- $\mathrm{O}_{2 \mathrm{C}-}-\mathrm{ZrO}_{2}$-tetragonal. O valor da isosuperfície é 0,8 .

Figura 39. Densidade de estados total e projetada para a adsorção da molécula de benzeno na superfície (001) do $\mathrm{ZrO}_{2}$ tetragonal: (a) Benzeno- $\mathrm{O}_{2 \mathrm{Cs}}-\mathrm{ZrO}_{2}$-tetragonal e (b) Benzeno- $\mathrm{O}_{2 \mathrm{C}-}-\mathrm{ZrO}_{2}$-tetragonal. Na parte inferior: DOS total da superfície livre e 
projetado sobre superfície após a adsorção. No meio: DOS total da superfície livre e do benzeno isolado. Na parte superior: DOS total dos complexos Benzeno- $\mathrm{O}_{2 \mathrm{Cs}}$ $\mathrm{ZrO}_{2}$-tetragonal e Benzeno- $\mathrm{O}_{2 \mathrm{C}-}-\mathrm{ZrO}_{2}$-tetragonal e projetado sobre a molécula de benzeno do complexo. A energia de Fermi está definida para zero. .85 


\section{Capítulo 1}

\section{1 - Introdução}

A publicação constante de trabalhos relatando a síntese e as propriedades inovadoras de materiais na escala nanométrica tem mostrado a importância de uma nova área do conhecimento, chamada nanotecnologia. Essa nova área rapidamente desenvolveu técnicas de síntese e caracterização de novos materiais, expandindo os limites dos diversos campos da ciência, tal como a área ambiental. ${ }^{1}$

A cada dia a população tem se preocupado com as condições ambientais a que estão expostas, sendo a poluição atmosférica uma das que afeta diretamente a qualidade de vida nas cidades, podendo causar ou agravar problemas de saúde. As principais fontes da poluição atmosférica são antropogênicas, destacando-se as emissões pelas indústrias e a queima e evaporação de combustíveis. Esse tipo de poluição não atinge somente os ambientes externos. Os ambientes fechados também são afetados pela presença de inúmeros compostos químicos usados em tintas, adesivos, vernizes, ceras, revestimentos, solventes, produtos de limpeza, dentre outros. Entre os principais compostos químicos que ocorrem nos ambientes externos e fechados estão os Compostos Orgânicos Voláteis (COVs) ${ }^{2-5}$ Destacamse pela sua elevada toxicidade, os hidrocarbonetos monoaromáticos: benzeno, tolueno, etilbenzeno, o-xileno, m-xileno e p-xileno, conhecidos pela sigla BTEX..$^{6-14}$ Atualmente, o benzeno, que é um constituinte da gasolina, é a principal preocupação, uma vez que é considerado o mais carcinogênico desse grupo. ${ }^{15}$ Além disso, uma considerável atenção tem sido dada para a adsorção de benzeno em superfícies de metais de transição e outros sistemas. Assim, o benzeno é um modelo para os hidrocarbonetos aromáticos e sua adsorção pode influenciar propriedades fundamentais para aplicação na eletrônica e óptica. ${ }^{16-22}$

A utilização da nanotecnologia para a melhora da qualidade do ar surge como uma área de grande importância. Dentre os materiais utilizados para esse fim, os dióxidos de titânio $\left(\mathrm{TiO}_{2}\right)$ e zircônio $\left(\mathrm{ZrO}_{2}\right)$ são nanomateriais promissores que podem ser usados na remediação da qualidade do ar. ${ }^{23-29} \mathrm{O} \mathrm{TiO}_{2}$ apresenta estruturas cristalinas de rutilo, anatásio e brookita, com os seus nanomateriais sendo utilizados em tintas, proteção ultravioleta, como sensores, na catálise, dentre outras 
aplicações. ${ }^{30-33} \mathrm{O} \mathrm{ZrO}_{2}$ possui estrutura cristalina cúbica, tetragonal e monoclínica, apresentando uma variedade de aplicações, tais como em tecnologias de células combustíveis, catalisadores e em preparações piezoelétricas, optoeletrônicas e dielétricas. ${ }^{30,31,34,35}$

$\mathrm{O} \mathrm{TiO}_{2}$ rutilo é a forma polimórfica mais abundante e, dentre todas as faces naturais de baixos índices, a (110) é a mais estável. ${ }^{36}$ Embora a fase rutilo do $\mathrm{TiO}_{2}$ seja a termodinamicamente mais estável, nanopartículas de $\mathrm{TiO}_{2}$ comumente apresentam a forma do anatásio, no qual a superfície (101) é a mais estável. ${ }^{37-39} \mathrm{~A}$ superfície (110) do $\mathrm{TiO}_{2}$ rutilo e (101) do anatásio tem sido estudada teórica ${ }^{38-42}$ e experimentalmente ${ }^{36,43-48}$. Portanto, estudos teóricos e experimentais da adsorção e reatividade são importantes para as superfícies de $\mathrm{TiO}_{2} \cdot{ }^{32,49-58} \mathrm{~A}$ utilização do $\mathrm{TiO}_{2}$ na detecção e degradação de COVs tem surgido como uma promissora tecnologia de controle desses compostos no ambiente. Destaca-se, nessa área, a degradação do BTEX e de outros compostos orgânicos voláteis presentes em produtos responsáveis pela poluição do ar em ambientes internos e externos. ${ }^{59-62}$ Sensores de gases usando óxidos metálicos fotoativos baseados em $\mathrm{TiO}_{2}$ apresentam alta sensibilidade, resposta rápida, boa estabilidade e baixo custo. ${ }^{63,64}$

Os estudos experimentais sobre qual plano cristalográfico do $\mathrm{ZrO}_{2}$ está envolvido nos processos catalíticos ainda não está totalmente definido. ${ }^{65,66}$ Os resultados de cálculos teóricos usando a Teoria do Funcional de Densidade (DFT) mostraram que para o $\mathrm{ZrO}_{2}$ tetragonal a superfície (111) é a mais estável, seguida pela (001) e (101). ${ }^{65,67} \mathrm{~A}$ adsorção de gases em diversos planos da fase tetragonal do $\mathrm{ZrO}_{2}$ encontram-se descritos em trabalhos teóricos ${ }^{66,68,69}$ e experimentais, ${ }^{70-72}$ inclusive a degradação de compostos orgânicos voláteis. ${ }^{73}$ 


\section{1 - Objetivos}

\subsection{1 - Objetivos Gerais}

Para que ocorra a degradação das moléculas na superfície dos óxidos metálicos, é necessário inicialmente que elas sejam adsorvidas. Neste trabalho, o objetivo foi estudar a adsorção das moléculas de benzeno, tolueno, etilbenzeno, oxileno, m-xileno e p-xileno sobre as superfícies (110) do $\mathrm{TiO}_{2}$ rutilo, (101) do $\mathrm{TiO}_{2}$ anatásio e (001) do $\mathrm{ZrO}_{2}$ tetragonal. O estudo foi realizado utilizando-se a Teoria do Funcional de Densidade (DFT) com condições de contorno periódicas e função de base de ondas planas. $\mathrm{O}$ uso da química teórica, nesse caso, é importante para analisar dados estruturais e eletrônicos da adsorção. Os resultados foram comparados com dados teóricos e experimentais, quando existentes na literatura.

\subsection{2 - Etapas a Serem Desenvolvidas}

Para a adsorção das moléculas de BTEX sobre as diferentes superfícies estudadas, tem-se os seguintes objetivos específicos:

a) Análise da malha de pontos $\mathrm{k}$ e da energia de corte das ondas planas que foram usadas nos cálculos de adsorção;

b) Análise da área superficial e da espessura da supercélula adequada para a adsorção das moléculas de BTEX;

c) Obter informações das geometrias e das energias de adsorção;

f) Análise da diferença de densidade de carga (CDD) e da função de localização eletrônica (ELF) entre os complexos BTEX-superfícies e as moléculas de BTEX e superfícies isoladas;

g) Análise das cargas de Bader das moléculas de BTEX depois da adsorção;

h) Análise da densidade de estados (DOS) para os complexos BTEX-superfície, BTEX e superfícies isoladas.

Foi realizada a análise da influência das interações de van der Waals no processo de adsorção de todas as espécies. Um conhecimento detalhado da interação gás-superfície ajuda no entendimento da sensibilidade, seletividade e 
reatividade da adsorção das moléculas de BTEX em sensores e catalisadores baseados em dióxido de titânio e zircônio. 


\section{Capítulo 2}

\section{2 - Referencial Teórico}

Neste capítulo, faremos uma breve descrição sobre os compostos orgânicos voláteis monoaromáticos, conhecidos como BTEX. Além disso, as propriedades e as estruturas dos dióxidos de titânio $\left(\mathrm{TiO}_{2}\right)$ e zircônio $\left(\mathrm{ZrO}_{2}\right)$ também são discutidas.

\section{1 - A Poluição Atmosférica e os Compostos Orgânicos Voláteis}

A preocupação com as condições ambientais a que estamos expostos tem aumentado a cada dia. A poluição atmosférica pode ocasionar danos ao ecossistema e causar, ou agravar, problemas de saúde humana, provocando asmas, bronquites, alergias, doenças cardiovasculares. Além disso, muitos dos poluentes são considerados carcinogênicos. ${ }^{10-13}$

Entre os compostos químicos que ocorrem nos ambientes abertos e fechados, têm-se os COVs. Estas substâncias incluem todo o conjunto de compostos orgânicos presentes na atmosfera, na fase de vapor, possuindo pontos de ebulição entre $50{ }^{\circ} \mathrm{C}$ e $260{ }^{\circ} \mathrm{C}$. Os hidrocarbonetos monoaromáticos benzeno, tolueno, etilbenzeno e xilenos (o-xileno, m-xileno e p-xileno), conhecidos pela sigla BTEX, pertencem a classe dos COVs e destacam-se pela sua elevada toxicidade. ${ }^{13,14}$

O benzeno $\left(\mathrm{C}_{6} \mathrm{H}_{6}\right)$ é um líquido volátil, altamente inflamável e que possui odor característico, sendo usado, por exemplo, como constituinte nas indústrias de tintas, vernizes, solventes e colas. Também é usado como material de partida e intermediário na indústria química e farmacêutica, além de estar presente na gasolina. O benzeno é considerado um composto carcinogênico pela Agência Internacional de Pesquisa sobre o Câncer (International Agency for Research on Cancer - IARC). No Brasil, as ações, atribuições e procedimentos de prevenção da exposição ocupacional ao benzeno são estabelecidos pela Norma Regulamentadora № 15 (NR 15), anexo N. 13-A da Portaria 3.214, de 08/06/1978, do Ministério do Trabalho e Emprego (MTE). A fórmula estrutural do benzeno pode ser visualizada na Figura 1. ${ }^{15,74}$ 


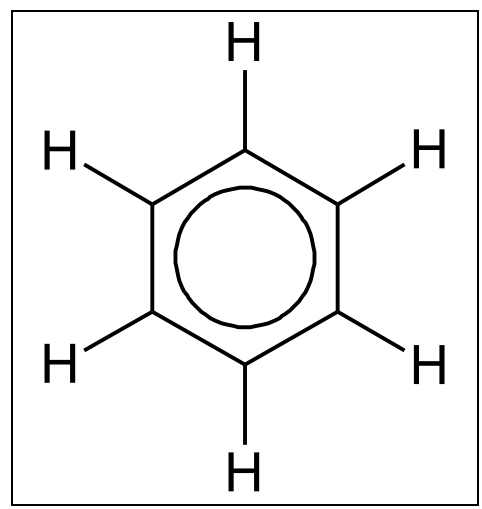

Figura 1. Fórmula estrutural do benzeno.

O tolueno $\left(\mathrm{C}_{7} \mathrm{H}_{8}\right)$ é um líquido inflamável com odor semelhante ao benzeno, sendo utilizado como solvente industrial de tintas, em adesivos, agentes sanitizantes, removedores de tintas, na indústria farmacêutica, na produção do benzeno, além de estar presente na mistura da gasolina. $\mathrm{O}$ etilbenzeno $\left(\mathrm{C}_{8} \mathrm{H}_{10}\right)$ é um líquido incolor com odor característico, utilizado principalmente na produção do estireno, onde apenas uma pequena parte (cerca de $1 \%$ ) é usada como solvente industrial de tintas, adicionado em combustíveis de aviação como antidetonante e como solvente na indústria de semicondutores. ${ }^{75,76}$

Por último, têm-se os xilenos $\left(\mathrm{C}_{8} \mathrm{H}_{10}\right)$, formados por uma mistura de isômeros: orto-xileno (o-xileno), meta-xileno (m-xileno) e para-xileno ( $\mathrm{p}$-xileno). $\mathrm{O}$ xileno comercial geralmente possui misturas que variam de $10-25 \%$ de o-xileno, $45-70 \%$ de m-xileno e $6-15 \%$ de p-xileno, sendo usado na gasolina de aviação, como solvente industrial para resinas e esmaltes, como um intermediário em sínteses orgânicas, entre outras aplicações. Segundo a IARC, o tolueno e os xilenos não são classificados como carcinogênicos para humanos, já o etilbenzeno é possivelmente carcinogênico para humanos. Na Figura 2 podem ser visualizadas as fórmulas estruturais do tolueno, etilbenzeno e xilenos. ${ }^{75,76}$ 


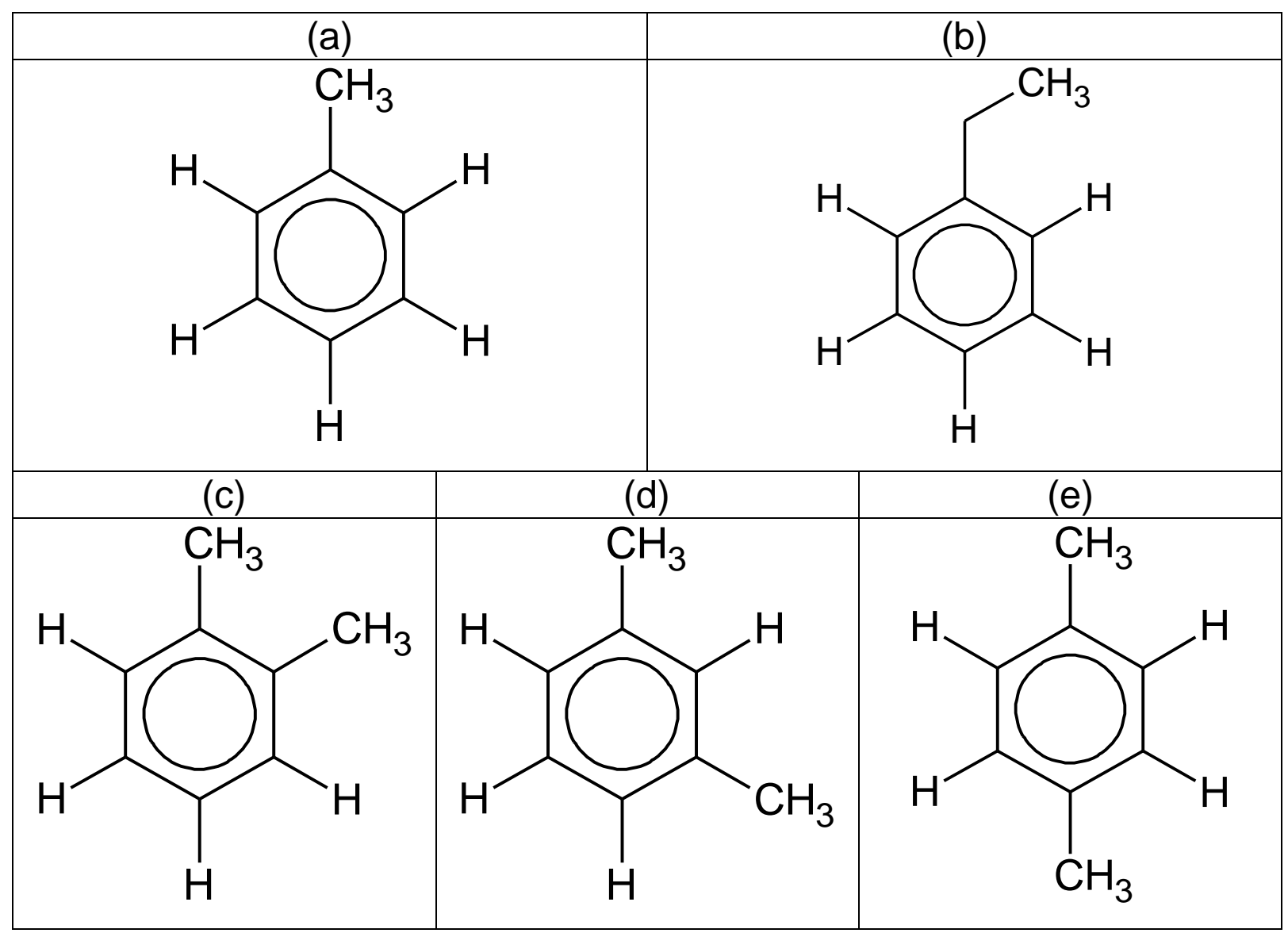

Figura 2. Fórmulas estruturais do: (a) tolueno; (b) etilbenzeno; (c) o-xileno; (d) m-xileno e (e) p-xileno.

Apesar de somente o benzeno ser considerado como carcinogênico pela IARC, o tolueno, o etilbenzeno e os xilenos são compostos que também apresentam elevada toxicidade e contribuem para o aumento da poluição atmosférica em ambientes externos e internos. As informações sobre avaliações de risco desses compostos são muitas vezes insuficientes, não sabendo ao certo quais são os níveis seguros que o ser humano pode ser exposto a cada um deles. Desta forma, é necessário encontrar soluções que minimizem as emissões do BTEX, por meio da sua substituição e/ou redução de uso e da sua degradação. ${ }^{13,77}$

Os principais métodos de deteç̧ão e quantificação dos BTEX são as análises por cromatografia e espectroscopia de absorção no ultravioleta, que são técnicas caras e demoradas, apesar de confiáveis e precisas. Assim, existe a necessidade do desenvolvimento de dispositivos de baixo custo e portáteis para o monitoramento das concentrações e/ou degradação do BTEX na atmosfera. Desta forma o uso de óxidos metálicos, tais como o dióxido de titânio $\left(\mathrm{TiO}_{2}\right)$ e o dióxido de zircônio $\left(\mathrm{ZrO}_{2}\right)$ podem ser alternativas bastante promissoras para serem usadas em 
dispositivos que atuem como adsorventes, sensores ou na decomposição catalítica desses compostos. ${ }^{77-80}$

\section{2 - Estruturas e Propriedades do Dióxido de Titânio $\left(\mathrm{TiO}_{2}\right)$ e do Dióxido de Zircônio $\left(\mathrm{ZrO}_{2}\right)$}

O dióxido de titânio $\left(\mathrm{TiO}_{2}\right)$, também chamado de titânia, é um óxido metálico que apresenta propriedades catalíticas. É utilizado como sensor de gases e em dispositivos eletrônicos, podendo ser aplicado nas indústrias farmacêuticas, de pigmentos, cosméticos, alimentos e em indústrias que utilizem as suas propriedades catalíticas, principalmente na degradação de poluentes orgânicos. ${ }^{49} \mathrm{Na}$ catálise, o estudo das superfícies desse material é de extrema importância, descrevendo-se a adsorção e, quando possível, a reatividade das espécies adsorvidas. A adsorção das moléculas nas superfícies é a etapa inicial de processos químicos, tais como as reações catalíticas e os sensores de gases. $\mathrm{O} \mathrm{TiO}_{2}$ possui três formas alotrópicas: rutilo, anatásio e brookita, sendo o rutilo a forma alotrópica mais estável. ${ }^{49,81}$

As estruturas das células unitárias do rutilo e anatásio possuem octaedros de $\mathrm{TiO}_{6}$, nas quais, cada íon $\mathrm{Ti}^{4+}$ possui em suas vizinhanças um octaedro de seis íons $\mathrm{O}^{2-}$. As distâncias Ti-Ti são maiores na fase anatásio, enquanto as distâncias Ti-O são maiores na fase rutilo. Devido às características catalíticas do $\mathrm{TiO}_{2}$, esse material é considerado como uma alternativa mais econômica nos processos de remoção de compostos orgânicos voláteis, tais como o BTEX. ${ }^{32,61,82-88}$ As estruturas do $\mathrm{TiO}_{2}$ rutilo, anatásio e brookita com os poliedros de coordenação estão representadas na Figura 3 (a), (b) e (c), respectivamente.

A zircônia (dióxido de zircônio - $\mathrm{ZrO}_{2}$ ) é um material cerâmico que apresenta importantes propriedades mecânicas, elétricas, térmicas e ópticas. Devido a essas propriedades, possui várias aplicações, tais como filmes de proteção, barreira térmica, sensores de gases, catalisador, dentre outras. ${ }^{35,89,90}$

O óxido de zircônio possui três formas cristalinas: monoclínico, cúbico e tetragonal. No óxido de zircônio monoclínico $\left(\mathrm{m}-\mathrm{ZrO}_{2}\right)$, os átomos de zircônio são heptacoordenados pelos átomos de oxigênio, possuindo oxigênios tricoordenados e tetracoordenados. $\mathrm{O}$ óxido de zircônio cúbico $\left(\mathrm{c}-\mathrm{ZrO}_{2}\right)$ possui os átomos de zircônio octocoordenados por átomos de oxigênio com todas as distâncias de ligação $\mathrm{Zr}-\mathrm{O}$ 
iguais. A forma cristalina tetragonal do $\mathrm{ZrO}_{2}\left(\mathrm{t}-\mathrm{ZrO}_{2}\right)$ apresenta os átomos de zircônio octocoordenados pelos átomos de oxigênio, assim como na forma cúbica; porém na tetragonal existem duas distâncias de ligação $\mathrm{Zr}-0 .{ }^{91,92}$ As estruturas do $\mathrm{ZrO}_{2}$ monoclínico, cúbico e tetragonal com os poliedros de coordenação estão representadas na Figura 3 (d), (e) e (f), respectivamente.

(a)

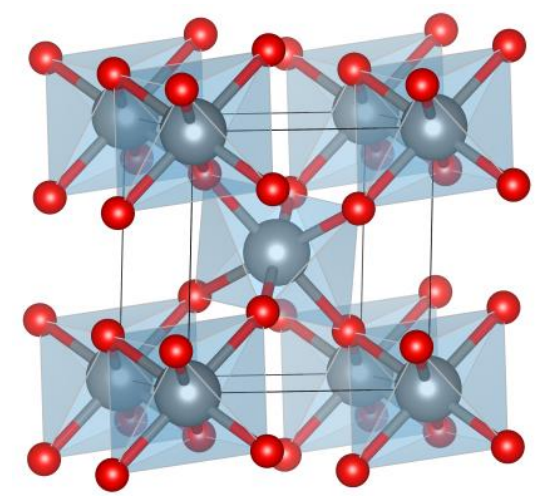

(d)

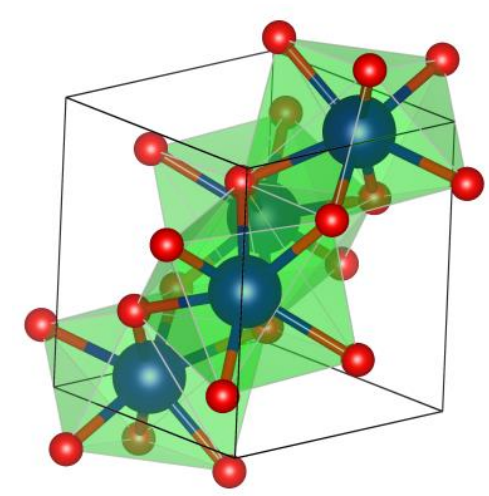

(b)

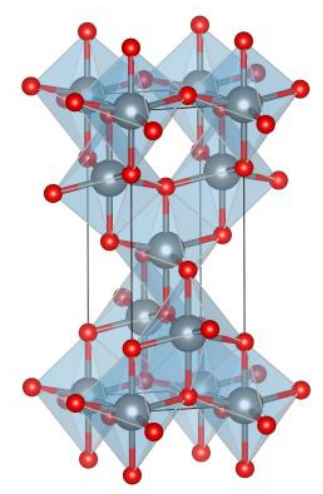

(e)

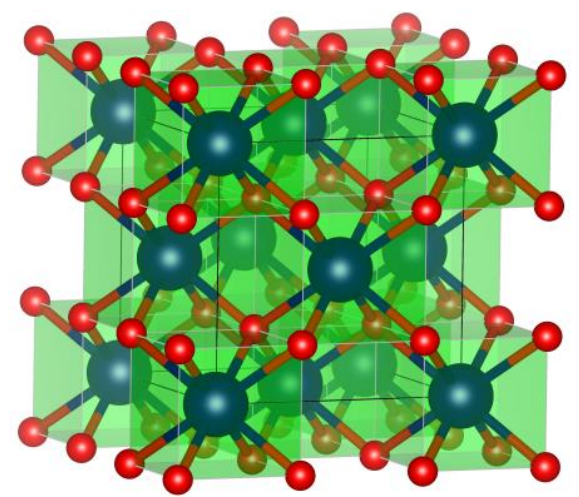

(c)

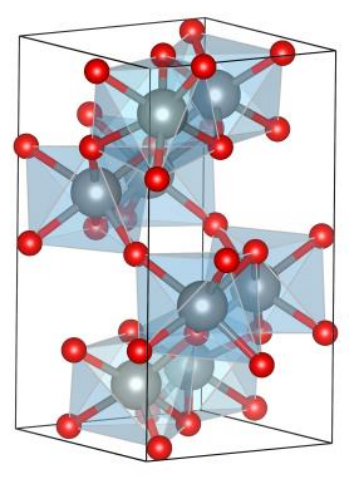

(f)

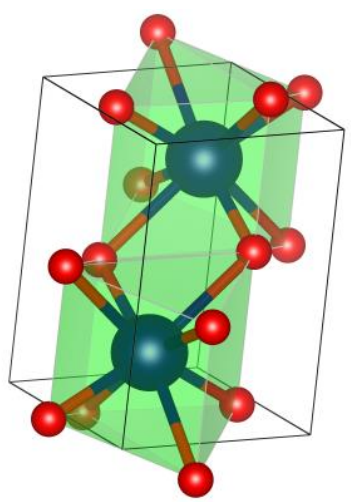

Figura 3. Estruturas para: (a) $\mathrm{TiO}_{2}$ rutilo; (b) $\mathrm{TiO}_{2}$ anatásio; (c) $\mathrm{TiO}_{2}$ brookita; (d) $\mathrm{ZrO}_{2}$ monoclínico; (e) $\mathrm{ZrO}_{2}$ cúbico e (f) $\mathrm{ZrO}_{2}$ tetragonal. Aqui e nas demais figuras o cinza, azul e vermelho representam os átomos de titânio, zircônio e oxigênio, respectivamente.

A adsorção de gases em superfícies de $\mathrm{ZrO}_{2}$ nas fases monoclínica, cúbica e tetragonal é encontrada na literatura, por exemplo, a adsorção de monóxido e dióxido de carbono em zircônia tetragonal e monoclínica. ${ }^{72}$ 


\section{Capítulo 3}

\section{3 -Metodologia}

Algumas das formas de se estudar as propriedades relacionadas com a adsorção de compostos na superfície de sólidos requer a resolução da equação de Schrödinger eletrônica. A sua resolução analítica para a grande maioria dos sistemas não é possível, sendo feita através de métodos aproximados. A Teoria do Funcional de Densidade (Density Functional Theory - DFT), que será usada nesse trabalho, é uma teoria em que nenhum parâmetro, a priori, precisa de ajuste ou ser determinado empiricamente, desta forma, é considerada uma teoria ab initio. Porém para aplicá-la de forma prática, é necessária a utilização de funcionais de troca e correlação aproximados.

Neste capítulo, são descritos, de forma sucinta, alguns dos métodos utilizados e a metodologia de geração dos bulks (sólido massivo) que representam o interior do sólido, da superfície (slab) e das adsorções do benzeno, tolueno, etilbenzeno, o-xileno, m-xileno e p-xileno (BTEX) em superfícies do dióxido de Titânio $\left(\mathrm{TiO}_{2}\right)$ na fase rutilo, do $\mathrm{TiO}_{2}$ na fase anatásio e do dióxido de zircônio $\left(\mathrm{ZrO}_{2}\right)$ na fase tetragonal. Além disso, mostra-se também como foram feitas as análises dos resultados obtidos utilizando-se os cálculos de química quântica.

\section{1 - A Equação de Schrödinger Para Sistemas Com Muitos Corpos}

A equação de Schrödinger independente do tempo e não relativística possui solução analítica somente para sistemas com até dois corpos. Considerando um sistema com i elétrons e $A$ núcleos descritos pelos vetores posição $\mathbf{r}_{\mathbf{i}}$ e $\mathbf{R}_{\mathbf{A}}$, respectivamente, a equação de Schrödinger pode ser escrita conforme mostrado na Equação 1:93-96

$\hat{H} \Psi_{j}\left(\mathbf{r}_{\mathbf{i}}, \mathbf{R}_{\mathbf{A}}\right)=E_{j} \Psi_{j}\left(\mathbf{r}_{\mathbf{i}}, \mathbf{R}_{\mathbf{A}}\right)$ 
Em que $\hat{\mathrm{H}}$ é o operador Hamiltoniano do sistema, $\Psi_{\mathrm{j}}\left(\mathbf{r}_{\mathrm{i}}, \mathbf{R}_{\mathbf{A}}\right)$ é a função de onda e $E_{\mathrm{j}}$ é a energia total do sistema. Em unidades atômicas, o Hamiltoniano para $\mathrm{n}$ elétrons e k núcleos é o operador dado pela Equação 2: ${ }^{93-96}$

$$
\hat{H}=-\sum_{i=1}^{n} \frac{1}{2} \nabla_{i}^{2}-\sum_{A=1}^{k} \frac{1}{2 M_{A}} \nabla_{A}^{2}-\sum_{i=1}^{n} \sum_{A=1}^{k} \frac{Z_{A}}{r_{i A}}+\sum_{i=1 j>1}^{n} \sum_{j}^{n} \frac{1}{r_{i j}}+\sum_{A=1}^{k} \sum_{A>1}^{k} \frac{Z_{A} Z_{B}}{R_{A B}}
$$

$\mathrm{Na}$ Equação 2, $M_{A}$ é a massa do núcleo $A$ em unidades atômicas, $Z_{A}$, o número atômico do núcleo $A$ e $Z_{B}$ do núcleo $B$. Os primeiros dois termos são a energia cinética dos elétrons $\left(T_{e}\right)$ e dos núcleos $\left(T_{n}\right)$, respectivamente. Nos termos de energia cinética, $\nabla_{i}^{2}$ e $\nabla_{\AA}^{2}$ são os operadores diferenciais laplacianos dos i elétrons e A núcleos com relação às suas coordenadas. ${ }^{93-96}$

Os últimos três termos da Equação 2 representam potenciais, sendo o terceiro $\left(-\sum_{\mathrm{i}=1}^{n} \sum_{\mathrm{A}=1}^{\mathrm{k}} \frac{\mathrm{Z}_{\mathrm{A}}}{\mathrm{r}_{\mathrm{iA}}}\right)$ referente a atração coulombiana entre elétrons e núcleos $\left(V_{\text {en }}\right)$. O quarto $\left(\sum_{i=1}^{n} \sum_{j>1}^{n} \frac{1}{\mathbf{r}_{i j}}\right)$ e o quinto $\left(\sum_{A=1}^{k} \sum_{A>1}^{k} \frac{Z_{A} Z_{B}}{R_{A B}}\right)$ referem-se a repulsão entre elétrons $\left(V_{\text {ee }}\right)$ e núcleos $\left(V_{n n}\right)$, respectivamente. Em um sistema de elétrons que interagem, busca-se a função de onda $(\Psi)$ que depende de $3 n$ coordenadas espaciais e $\mathrm{n}$ coordenadas de spin de elétrons, onde $\mathrm{n}$ é o número de elétrons do sistema e três são os graus de liberdade. ${ }^{93-96}$

Uma primeira aproximação é a chamada "Aproximação de BornOppenheimer (ABO)", no qual, a massa dos núcleos é muito maior que a massa dos elétrons, portanto, esses últimos se movem mais rápido que os núcleos. Considerase, então, que os elétrons do sistema estão se movendo no campo de núcleos fixos. Com essa aproximação, pode-se fazer a separação e a resolução da equação de Schrödinger em uma parte nuclear e uma parte eletrônica que apresenta uma dependência paramétrica em relação à posição dos núcleos. ${ }^{97}$

Dentre os métodos existentes para a solução da equação Schrödinger eletrônica, tem-se, por exemplo, o método de Hartree-Fock, bem como a teoria do Funcional de Densidade (DFT), sendo que a última utiliza a densidade eletrônica $(\rho(\mathbf{r}))$, ao invés da função de onda, para obter os observáveis do sistema. A 
utilização da densidade eletrônica reduz a dependência espacial a apenas três variáveis $(\mathrm{x}, \mathrm{y}, \mathrm{z}){ }^{98}$

\subsection{1 - A Teoria do Funcional de Densidade (DFT)}

A Teoria do Funcional de Densidade (Density Functional Theory - DFT) surgiu fundamentada nos teoremas de Hohenberg e Kohn. Esses teoremas são baseados na teoria proposta por Thomas e Fermi, segundo o qual é possível obter propriedades eletrônicas a partir da densidade eletrônica $(\rho(\mathbf{r}))$, sem a função de onda do sistema. ${ }^{99-101}$ Os cálculos feitos utilizando a $\rho(\mathbf{r})$ são facilitados, pois a equação para $\mathrm{N}$ partículas fica reduzida a um problema de três dimensões. A teoria proposta por Thomas e Fermi não produzia bons resultados para moléculas, pois considerava o comportamento dos elétrons no sistema como um gás não interagente, desconsiderando, desta forma, as interações elétron-elétron. A aplicação desta teoria conseguia descrever sistemas atômicos e impurezas em metais. ${ }^{100,102}$

Em 1964, Hohenberg e Kohn mostraram que as propriedades do estado de um sistema são funcionais da densidade eletrônica, podendo-se obter, desta forma, a energia do estado fundamental e todas as propriedades eletrônicas de sistemas moleculares. O potencial externo $(\mathrm{v}(\mathbf{r}))$ determina a $\rho(\mathbf{r})$, e a partir dela, calcula-se o número total de elétrons $(n)$. O v(r) é chamado assim porque depende das cargas e posições nucleares, ou seja, é originado de partículas diferentes dos elétrons que compõem o sistema. O número total de elétrons é definido pela normalização do funcional de densidade, conforme mostrado na Equação 3:100,102-104

$\int \rho(\mathbf{r}) d \mathbf{r}=n$

Determinando-se o número total de elétrons através da Equação 3 e 0 potencial externo pela densidade eletrônica, pode-se escrever o Halmitoniano $(\hat{H})$ que fornecerá a energia do sistema e as demais propriedades. Assim, tem-se a energia como um funcional da densidade eletrônica $E=E[\rho(r)]$. Portanto, em princípio, dada a densidade, as propriedades do estado fundamental podem ser determinadas. ${ }^{102-104}$ 
Todas as observações apresentadas até aqui fazem parte do primeiro teorema de Hohenberg e Kohn. O segundo teorema surge do questionamento de que a função densidade seria realmente aquela do estado fundamental que se procura. Hohenberg e Kohn provaram que uma determinada função densidade tentativa $\left(\rho_{\mathrm{t}}(\mathbf{r})\right)$, que determine o potencial externo e forneça o número total de elétrons através da sua normalização, conforme mostrado na Equação 3, conduz a uma energia maior ou igual a energia do estado fundamental (funcional da densidade exata), como indicado na Equação 4: ${ }^{102-104}$

$$
E\left[\rho_{t}(\mathbf{r})\right] \geq E_{o}\left[\rho_{o}(\mathbf{r})\right]
$$

No qual, $E$ é a energia como um funcional da densidade tentativa $\left(\rho_{t}(\mathbf{r})\right)$ e $E_{0}$ é a energia do estado fundamental como um funcional da densidade do estado fundamental $\left(\rho_{0}(\mathbf{r})\right)$.

Nos teoremas propostos por Hohenberg e Kohn não se descreve uma forma para se encontrar a densidade eletrônica do sistema e, consequentemente, a energia do estado fundamental e as demais propriedades eletrônicas. Assim, em 1965, Kohn e Sham sugeriram um meio de encontrar o funcional da densidade. ${ }^{102-105}$ Através dos teoremas de Hohenberg e Kohn pode-se obter a teoria para muitos corpos usando a densidade eletrônica, em que a energia de um sistema com muitos elétrons sujeito a um potencial externo é dado pela Equação 5 , na qual, $F[\rho(\mathbf{r})]$ é o funcional universal da densidade eletrônica independente do potencial externo e que contém as contribuições de energia cinética, a interação de Coulomb clássica e os efeitos de correlação e troca eletrônicos..$^{102-105}$

$$
E[\rho(\mathbf{r})]=F[\rho(\mathbf{r})]+\int \rho(\mathbf{r}) v(\mathbf{r}) d \mathbf{r}
$$

O funcional universal da densidade eletrônica, $F[\rho(r)]$, considerando um sistema atômico ou molecular de $\mathrm{n}$ elétrons pode ser escrito como uma soma dos funcionais de energia cinética $(T[\rho(r)])$ e de repulsão eletrônica $\left(v_{r e}[\rho(r)]\right)$ como indicado na Equação 6: ${ }^{102-105}$

$$
\mathrm{F}[\rho(\mathbf{r})]=\mathrm{T}[\rho(\mathbf{r})]+\mathrm{v}_{\mathrm{re}}[\rho(\mathbf{r})]
$$


Kohn e Sham fizeram a consideração que em um sistema de referência não interagente, fornecendo um potencial externo efetivo $\left(\mathrm{v}_{\mathrm{ef}}\right)$, pode-se definir uma energia cinética $\left(T_{\text {ef }}\right)$ e uma densidade eletrônica $\left(\rho_{\text {ef }}\right)$ também efetiva, sendo representada por meio da autofunção $\left(\varphi_{i}\right)$ associada aos autovalores do Hamiltoniano monoeletrônico não interagente $\left(\mathrm{H}_{\mathrm{ef}}\right)$. $^{103}$

Através da proposta de Kohn e Sham, esse Halmitoniano poderia ser resolvido em vários potenciais externos, sendo que em um determinado potencial, encontrar-se-ia uma densidade eletrônica efetiva igual a densidade eletrônica do sistema real. Essa, sendo aplicada nos teoremas de Hohenberg e Kohn, forneceria a energia do estado fundamental e as propriedades eletrônicas. ${ }^{102,103}$

Como através da resolução do Hamiltoniano não interagente obtém-se a densidade eletrônica, pode-se, assim, encontrar a energia do estado fundamental através da energia cinética do sistema não interagente e do potencial clássico repulsivo elétron-elétron. Esses termos subtraídos da energia cinética e do potencial repulsivo elétron-elétron real fornecem os desvios dessas energias, sendo denominado de termo de troca e correlação $\left(E_{x c}[\rho(r)]\right)$, que é adicionado ao funcional universal da densidade eletrônica. Em que, $E_{K s}[\rho(r)]$ é a energia de Kohn-Sham, e os termos de energia cinética e potencial são de um sistema não interagente como mostrado na Equação 7:102,103

$$
E_{\mathrm{KS}}[\rho(\mathbf{r})]=\int \rho(\mathbf{r}) \mathrm{v}(\mathbf{r}) \mathrm{d} \mathbf{r}+\mathrm{T}[\rho(\mathbf{r})]+\mathrm{v}_{\mathrm{re}}[\rho(\mathbf{r})]+\mathrm{E}_{\mathrm{xc}}[\rho(\mathbf{r})]
$$

Para encontrar a função densidade eletrônica do sistema não interagente, Kohn e Sham utilizaram a ideia de orbitais monoeletrônicos, chamados de orbitais de Kohn-Sham. A soma do módulo ao quadrado desses orbitais fornece a densidade do estado fundamental do sistema interagente de elétrons. ${ }^{102,103}$

Através das ideias de Hohenberg, Kohn e Sham, a expressão da função densidade eletrônica e, consequentemente, a energia e propriedades eletrônicas do estado fundamental podem ser encontradas de forma muito parecida com aquela usada no método de Hartree-Fock (HF). A Tabela 1 (adaptada do trabalho de Morgon e Custódio ${ }^{104}$ ) apresenta a comparação entre as equações usadas nos dois métodos. ${ }^{102-104}$ 
Tabela 1. Comparação entre as equações utilizadas nas teorias de Hartree-Fock (HF) e do funcional de densidade (DFT). Reimpresso do trabalho de Morgon e Custódio. ${ }^{104}$

Método de Hartree-Fock (HF) $\mathrm{E}=\mathrm{E}[\Psi(\mathbf{r})]$

$$
\begin{aligned}
& E=\int \Psi^{*} H_{H F} \Psi d \tau \\
& \Psi=\Psi\left(x_{1}, x_{2}, \ldots, x_{n}\right)=\left\|\psi_{1}\left(x_{1}\right) \psi_{2}\left(x_{2}\right) \ldots \psi_{n}\left(x_{n}\right)\right\| \\
& \frac{\partial \mathrm{E}}{\partial \psi(r)}=0 \\
& {\left[-\frac{1}{2} \nabla^{2}+v_{C}(r)+v_{x}(r)\right] \psi_{i}=\varepsilon_{i} \psi_{i}} \\
& E_{K S}[\rho(\mathbf{r})]=\int \rho(\mathbf{r}) v(\mathbf{r}) d \mathbf{r}+T[\rho(\mathbf{r})]+v_{r e}[\rho(\mathbf{r})]+E_{x c}[\rho(\mathbf{r})] \\
& \rho(\mathbf{r})=\sum_{\mathrm{i}}^{\mathrm{n}}\left|\psi_{\mathrm{i}}(\mathbf{r})\right|^{2} \\
& \frac{\partial \mathrm{E}}{\partial \rho(\mathbf{r})}=0 \\
& {\left[-\frac{1}{2} \nabla^{2}+v_{\text {ef }}(r)+v_{x c}(r)\right] \psi_{i}=\varepsilon_{i} \psi_{i}}
\end{aligned}
$$

Teoria do Funcional de Densidade (DFT) $\mathrm{E}=\mathrm{E}[\rho(\mathbf{r})]$

A Teoria do Funcional de Densidade (DFT) também utiliza o ciclo autoconsistente (Self Consistent Field - SCF). A comparação de como é feito esse ciclo no método Hartree-Fock e na DFT são apresentados na Tabela 2. ${ }^{102-104}$

Tabela 2. Representação do ciclo auto-consistente (SCF) nos métodos de Hartree-Fock (HF) e na Teoria do Funcional de Densidade (DFT). Reimpresso do trabalho de Morgon e Custódio. ${ }^{104}$ Método de Hartree-Fock (HF) Teoria do Funcional de Densidade (DFT)

1. Definição das bases atômicas e dos coeficientes iniciais;

2. Construção dos Orbitais moleculares: $\psi_{\mathrm{i}}=\sum_{\mathrm{i}}^{\mathrm{n}} \mathrm{c}_{\mathrm{i} \mu} \phi_{\mu}$

3. Cálculo dos elementos da matriz de Fock $\left(\mathrm{F}_{\mu \mathrm{v}}\right)$;

4. Resolução de $\mathrm{FC}=\varepsilon S C$ e obter $\psi_{\mathrm{i}}(\mathbf{r})$;

5. Cálculo dos novos orbitais moleculares e coeficientes;

6. Consistência? Se:

Não - Volta a etapa 3 e calcula-se novos elementos da matriz de Fock;

Sim - Calcula-se a energia total $(E=E[\Psi])$ e as propriedades do sistema.
I. Definição das bases atômicas e dos coeficientes iniciais;

II. Construção dos Orbitais moleculares:

$\psi_{\mathrm{i}}=\sum_{\mathrm{i}}^{\mathrm{n}} \mathrm{c}_{\mathrm{i} \mu} \phi_{\mu}$ e $\rho(\mathbf{r})=\sum_{\mathrm{i}}^{\mathrm{n}}\left|\psi_{\mathrm{i}}(\mathbf{r})\right|^{2}$

III. Cálculo dos elementos da matriz de Fock $\left(\mathrm{F}_{\mu \mathrm{v}}\right)$;

IV. Resolução de $\mathrm{FC}=\varepsilon S C$ e obter $\psi_{\mathrm{i}}(\mathbf{r})$;

V. Calcular novamente a densidade eletrônica a partir dos orbitais moleculares obtidos;

VI. Consistência? Se:

Não - Volta a etapa 3 e calcula-se novos elementos da matriz de Fock;

Sim - Calcula-se a energia total $(E=E[\rho])$ e as propriedades do sistema.

O termo de energia de troca e correlação $\left(E_{x c}[\rho(r)]\right)$ que contém as informações referentes a energia não clássica é desconhecido. Esta energia vai determinar a qualidade dos resultados, sendo encontrada de forma empírica através de aproximações, tal como o modelo de Thomas-Fermi (M-TF), em que utiliza-se a 
representação de um gás uniforme de elétrons, sem a inserção da energia de troca e correlação. No modelo de Thomas-Fermi-Dirac (M-TFD), inclui-se a energia de troca à energia potencial de Coulomb. Tem-se, também, a aproximação LDA (Local Density Approximation), em que considera-se a densidade eletrônica pouco dependente da posição, ou seja, as regiões das moléculas apresentam comportamento de gás homogêneo de elétrons, apresentando um potencial de troca e correlação com caráter local. Devido a estas características a aproximação LDA foi aplicada principalmente na física do estado sólido. Para tratar sistemas em que a densidade eletrônica não é homogênea, surgiram outras aproximações, entre elas, a GGA (Generalized Gradient Approximation) e a BGC (Becke Gradient Corrected), nas quais utiliza-se uma expressão mais precisa para o gradiente. Essas correções poderiam, portanto, fornecer melhores resultados para a energia de troca. Existem também os funcionais híbridos em que combinam-se as aproximações DFT/GGA e $\mathrm{HF}$, tendo como exemplo o funcional híbrido de troca e correlação B3LYP, amplamente utilizado. ${ }^{102-104}$

\subsection{2 - Ondas Planas, Pseudopotenciais e o Método Projector Augmented Wave (PAW)}

Os sistemas cristalinos apresentam periodicidade, formando a chamada rede de Bravais. Essa rede possui simetria de translação, de modo que, a energia potencial $(u)$ tem a propriedade de ser periódica conforme a periodicidade da rede analisada, ou seja: ${ }^{96,106-108}$

$$
\mathrm{u}(\mathbf{r}+\mathbf{R})=\mathrm{u}(\mathbf{r})
$$

A condição de contorno das soluções da equação de Schrödinger para um potencial periódico é conhecido como Teorema de Bloch. Essa formulação permite obter os autovalores com a inclusão de um novo número quântico $\mathbf{k}$, de modo que, as autofunções assumem a forma de uma onda plana ( $e^{\text {ik.r. }}$ ) multiplicada por uma função com a periodicidade da rede de Bravais: $:^{96,106,108}$ 
$\psi_{i}(\mathbf{k}, \mathbf{r})=e^{i \mathbf{k} . r} u_{i}(\mathbf{k}, \mathbf{r})$

Em que $u_{i}(\mathbf{k}, \mathbf{r}) \equiv u_{i}(\mathbf{k}, \mathbf{r}+\mathbf{R})$ e $\psi_{i}(\mathbf{k}, \mathbf{r})$ satisfaz a relação:

$\psi_{\mathrm{i}}(\mathbf{k}, \mathbf{r}+\mathbf{R})=\mathrm{e}^{\mathrm{i} \mathbf{k} \cdot \mathbf{r}} \mathrm{u}_{\mathrm{i}}(\mathbf{k}, \mathbf{r})$

A utilização das ondas planas satisfaz automaticamente as condições de contorno do cristal, porém, a descrição dos sistemas exige um número de ondas planas muito grande. Isso ocorre, porque o potencial nos sólidos possui duas regiões com comportamentos distintos: 1) perto dos núcleos, o potencial apresenta uma forte variação, com as funções de onda do sistema apresentado fortes oscilações; 2) na região dos elétrons de valência, o potencial é bem menor que perto dos núcleos e a função de onda varia de forma suave. ${ }^{96,108}$

A maioria das propriedades químicas e físicas dos materiais são dependentes dos elétrons dos níveis de valência. A utilização de muitos elétrons nas aproximações da química quântica aumenta o número de operações matemáticas a serem realizadas, elevando dessa forma, o custo computacional. Com a utilização de pseudopotenciais, somente os elétrons de valência são tratados explicitamente, substituindo-se os elétrons internos (core - caroço) por um pseudopotencial que varia de forma suave na região dos elétrons internos. Os elétrons de valência sentem um potencial efetivo originado da sua interação com o núcleo juntamente com os elétrons do caroço. ${ }^{109}$

Dentre os pseudopotenciais, destacam-se os de norma conservada e os ultrasoft (US-PP). Os pseudopotenciais de norma conservada foram desenvolvidos inicialmente por Hamann, Schlüter e Chiang $(\mathrm{HSC})^{110}$ e posteriormente gerados através de novas formas usando cálculos $a b$ initio por outros autores, tais como, Troullier e Martins (1991) $)^{111,112}$ e Li e colaboradores (1993) ${ }^{113}$. Os pseudopotenciais ultrasoft (US-PP) foram introduzidos por Vanderbilt (1990) $)^{114,115}$ e diferentemente dos de norma conservada, não representa a função de onda de valência completamente por ondas planas, permitindo reduzir o número de ondas planas utilizadas nos cálculos.

Outra forma de contornar os problemas gerados pelo uso direto das ondas planas em cálculos de sólidos, são os chamados métodos all electrons. Esses 
métodos dividem o potencial em duas regiões distintas: 1) a região centrada nas posições atômicas, com as funções de base desenvolvidas em harmônicos esféricos; 2) a região dos elétrons de valência, em que o potencial varia lentamente, com as funções de base desenvolvidas em ondas planas. Esse método deu origem às bases augmented plane waves (APW). ${ }^{116,117}$ Dentro dessa classe destaca-se o método projected augmented waves (PAW).

O método PAW foi desenvolvido por Blöchl (1994) e generaliza os métodos do pseudopotencial juntamente com o método all electron, chamado de linear augmented-plane-wave (LAPW). ${ }^{118} \mathrm{O}$ método PAW é amplamente utilizado e permite tratar sistemas com uma boa precisão. ${ }^{119}$

\section{2 - Metodologia Aplicada ao Estudo do Dióxido de Titânio $\left(\mathrm{TiO}_{2}\right)$ e Dióxido de Zircônio $\left(\mathrm{ZrO}_{2}\right)$}

\subsection{1 - Geração e Otimização dos Bulks de $\mathrm{TiO}_{2}$ e $\mathrm{ZrO}_{2}$}

As estruturas do $\mathrm{TiO}_{2}$ nas fases rutilo e anatásio e do $\mathrm{ZrO}_{2}$ na fase tetragonal foram geradas a partir dos arquivos de informação cristalográfica (Crystallographic Information File - CIF). Os parâmetros de cela, os parâmetros de distorção tetragonal e o grupo espacial de cada um dos modelos estudados podem ser visualizados na Tabela $3{ }^{120-122} \mathrm{O}$ parâmetro u para o $\mathrm{TiO}_{2}$ rutilo é definido como a distância entre os átomos de titânio e oxigênio no plano perpendicular à direção c, já para o $\mathrm{TiO}_{2}$ anatásio, esse parâmetro é obtido através da razão entre o comprimento da ligação TiO apical na direção [001] e o parâmetro de rede c. Para $\circ \mathrm{ZrO}_{2}$ tetragonal, o parâmetro $A$ é calculado através da relação $c / a \sqrt{2}$ e o dz, representa o tamanho do deslocamento do íon oxigênio em relação a célula cúbica, dada em termos do comprimento do eixo $\mathrm{c}$ tetragonal.

Tabela 3. Parâmetros de rede e grupo espacial do $\mathrm{TiO}_{2}$ e do $\mathrm{ZrO}_{2}$.

\begin{tabular}{|c|c|c|c|c|c|c|c|c|c|}
\hline Estrutura & a & $\mathrm{b}$ & c & $\alpha$ & $\beta$ & $\gamma$ & $\mathrm{c} / \mathrm{a}$ & $\mathrm{u}$ & Grupo espacial \\
\hline $\mathrm{TiO}_{2}$ rutilo $^{120}$ & 4,587 & 4,587 & 2,954 & 90,000 & 90,000 & 90,000 & 0,644 & 0,305 & $136-\mathrm{P} 4_{2} / \mathrm{mnm}$ \\
\hline $\mathrm{TiO}_{2}$ anatásio ${ }^{121}$ & 3,784 & 3,784 & 9,515 & 90,000 & 90,000 & 90,000 & 2,515 & 0,208 & $141-\mid 4_{1} /$ amd \\
\hline Estrutura & $a$ & $\mathrm{~b}$ & C & $\alpha$ & $\beta$ & $\gamma$ & $\mathrm{A}$ & $d_{z}$ & Grupo espacial \\
\hline $\mathrm{ZrO}_{2}$ tetragonal $^{122}$ & 3,574 & 3,574 & 5,154 & 90,000 & 90,000 & 90,000 & 1,020 & 0,047 & $137-\mathrm{P} 4_{2} / \mathrm{nmc}$ \\
\hline
\end{tabular}


Para os cálculos dos sólidos ("bulks"), das superfícies e das adsorções das moléculas de benzeno, tolueno, etilbenzeno, o-xileno, m-xileno e p-xileno (BTEX) foi usada a Teoria do Funcional de Densidade (Density Functional Theory - DFT) com condições de contorno periódicas. A DFT tem sido amplamente utilizada para estudar superfícies e adsorções de gases com resultados confiáveis para as propriedades estruturais e eletrônicas. ${ }^{42,52,123-125}$ Os cálculos DFT foram realizados com o código computacional de simulação ab initio VASP4.6 ${ }^{126-129}$ (Vienna ab initio simulation program), somente os resultados incluindo a correção de van der Waals foram obtidos com o VASP5.3.5 $5^{126-129}$. A aproximação do gradiente generalizado (Generalized Gradient Approximation - GGA) foi usada juntamente com os funcionais de troca e correlação de Perdew-Wang $91^{130,131}$ (PW91) e Perdew-BurkeErnzerhof $^{132,133}$ (PBE). As correções de van der Waals foram levadas em consideração com o funcional PBE. O VASP utiliza a densidade eletrônica de valência expandida em um conjunto de bases de ondas planas. A interação dos elétrons de caroço com os elétrons dos níveis de valência foi representada através do método Projected Augmented Wave ${ }^{119,134}$ (PAW) de Blöchl. Os elétrons de valência considerados para cada átomo foram: titânio $\left[3 d^{3} 4 s^{1}\right]$, zircônio $\left[4 s^{2} 4 p^{6} 5 s^{2}\right.$ $4 d^{2}$ ], oxigênio $\left[2 s^{2} 2 p^{4}\right]$, carbono $\left[2 s^{2} 2 p^{2}\right]$ e hidrogênio [ $\left.1 s^{1}\right]$. Os pseudopotenciais usados para tratar os elétrons do caroço foram o PAW-PW91e o PAW-PBE.

Para que os cálculos sejam realizados de forma prática é necessário fazer o truncamento da base, usando um conjunto de bases de ondas planas finito. A forma de realizar esse procedimento é através da escolha de uma energia máxima (energia de corte), de modo que sejam incluídas na base apenas as ondas planas que apresentam energias menores que o valor escolhido. O número de pontos $\mathrm{k}$ na zona de Brillouin também pode ser variado para obter a densidade eletrônica, sendo que a escolha da energia de corte e da malha de pontos $k$ são feitas para alcançar critérios de convergência. Neste estudo foram analisados os parâmetros de corte: número de pontos $\mathrm{k}$ e energia de corte das ondas planas para a convergência da energia com o menor custo computacional. Os modelos para os sólidos foram otimizados variando-se o número de pontos $\mathrm{k}(2 \times 2 \times 2,3 \times 3 \times 3,4 \times 4 \times 4$ e $5 \times 5 \times 5)$ e a energia de corte das ondas planas ( $250 \mathrm{eV}, 300 \mathrm{eV}, 350 \mathrm{eV}, 400 \mathrm{eV}$ e $500 \mathrm{eV})$.

A otimização do bulk foi inicialmente realizada permitindo a relaxação dos pontos da rede (denominada de iônica). Em seguida, fez-se a otimização total, ou 
seja, a relaxação iônica da estrutura cristalina e do volume do bulk (parâmetros de rede), simultaneamente. Os valores obtidos com as otimizações para os parâmetros de rede e de distorção tetragonal foram comparados com os resultados experimentais. ${ }^{120-122}$

As estruturas que apresentaram os parâmetros de rede mais próximos ao valor experimental foram utilizadas para analisar a convergência da energia em função dos pontos $k$ e da energia de corte das ondas planas. Para isto, calculou-se a energia total de cada uma das estruturas em função desses dois parâmetros, sem otimizar a geometria do sistema. Para os cálculos da superfície e da adsorção das moléculas de BTEX, foram utilizados o número de pontos $\mathrm{k}$ e a energia de corte, para os quais a energia total apresentava convergência, com valores para os parâmetros de rede não divergindo mais que $2,5 \%$ do valor experimental.

\subsection{2 - Geração dos Slabs e Formação dos Complexos $\mathrm{BTEX}^{-\mathrm{TiO}_{2}}$ e $\mathrm{BTEX}^{-\mathrm{ZrO}_{2}}$}

Com as estruturas otimizadas foi feito o corte dos planos cristalinos na direção (110) para o $\mathrm{TiO}_{2}$ rutilo e (101) para o $\mathrm{TiO}_{2}$ anatásio, que são os planos mais estáveis para essas duas estruturas. ${ }^{83}$ Para $\circ \mathrm{ZrO}_{2}$ tetragonal foi utilizado o plano (001). Os estudos experimentais sobre qual plano cristalográfico do $\mathrm{ZrO}_{2}$ está envolvido nos processos catalíticos ainda não está totalmente definido. ${ }^{65,66}$ Os resultados de cálculos teóricos usando a DFT mostraram que para o $\mathrm{ZrO}_{2}$ tetragonal a superfície (111) é a mais estável, seguida pela (001) e (101) ${ }^{65,67} \mathrm{~A}$ adsorção de gases em diversos planos da fase tetragonal do $\mathrm{ZrO}_{2}$ encontram-se descritos em trabalhos teóricos ${ }^{66,68,69}$ e experimentais ${ }^{70-72}$, inclusive a degradação de alguns compostos orgânicos voláteis, tais como o isopropanol e o tolueno ${ }^{73}$.

$\mathrm{Na}$ Figura 4, podem ser visualizados cada um dos planos estudados, nos quais as superfícies apresentam quatro camadas, considerando como camada a linha formada pelos átomos $\mathrm{O}-\mathrm{Ti}-\mathrm{O}$ e $\mathrm{O}-\mathrm{Zr}-\mathrm{O}$. Usando a notação de Wood na Figura 4 (a) e (b) tem-se uma superfície (4x2) do $\mathrm{TiO}_{2}$ rutilo; na Figura 4 (c) e (d), uma superfície (4x1) do $\mathrm{TiO}_{2}$ anatásio e na Figura 4 (e) e (f), uma superfície (3×3) do $\mathrm{ZrO}_{2}$ tetragonal. As superfícies foram modeladas periodicamente em uma supercélula, no qual foi feita somente a relaxação iônica mantendo-se a forma e o 
volume do sistema. A condição de contorno periódica permite simular superfícies sem os efeitos de borda, presentes nos modelos de cluster.

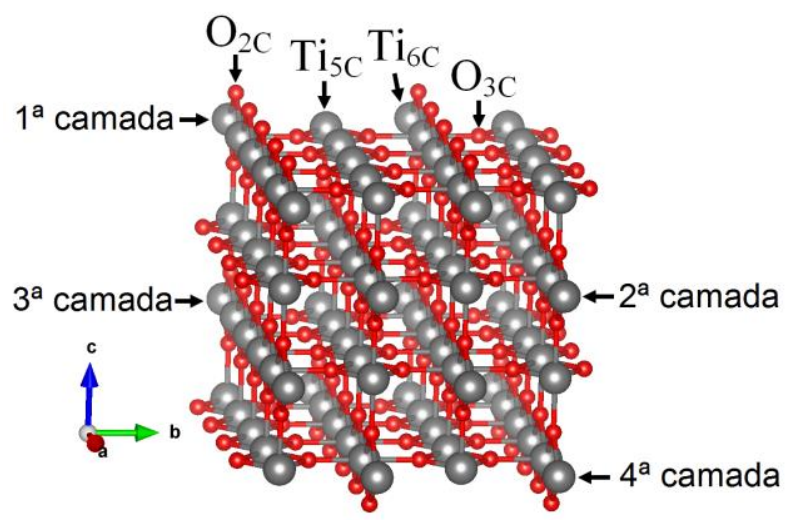

(a)

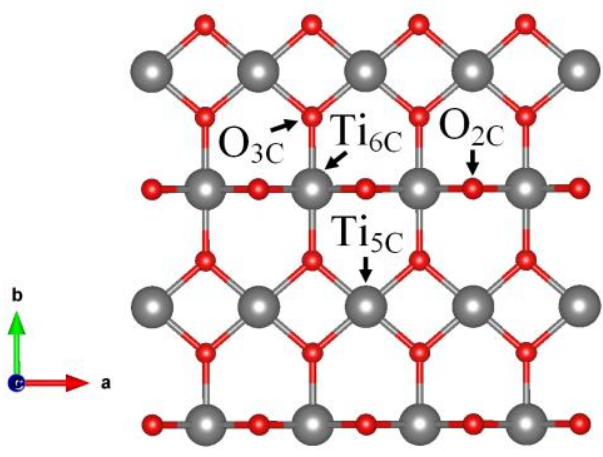

(b)

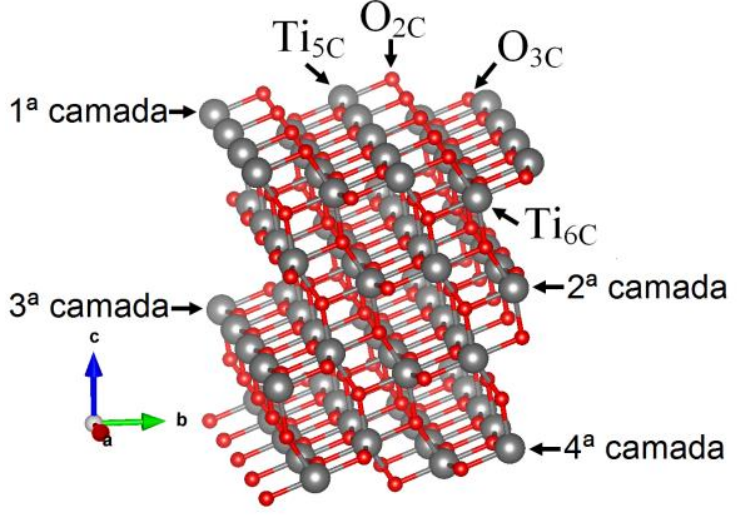

(c)

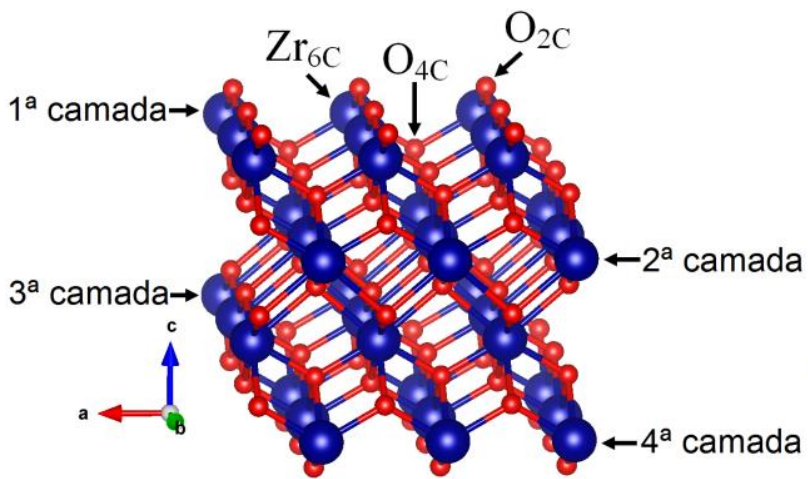

(e)

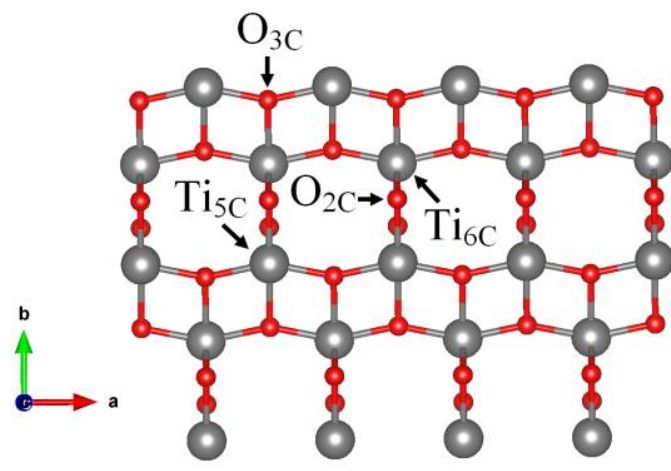

(d)

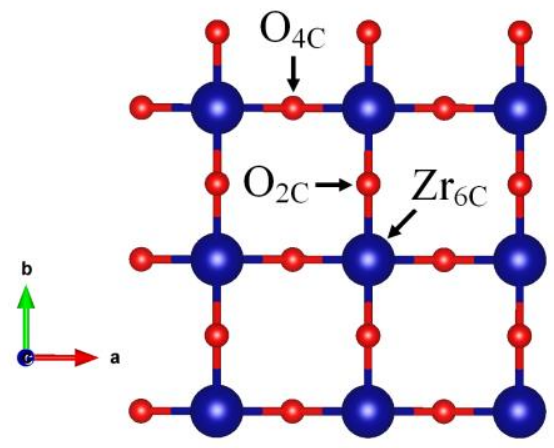

(f)

Figura 4. Estruturas do $\mathrm{TiO}_{2}$ rutilo (110), $\mathrm{TiO}_{2}$ anatásio (101) e $\mathrm{ZrO}_{2}$ (001): (a) e (b) vista lateral e superior da superfície (110) do $\mathrm{TiO}_{2}$ rutilo, respectivamente; (c) e (d) vista lateral e superior da superfície (101) do $\mathrm{TiO}_{2}$ anatásio, respectivamente; (e) e (f) vista lateral e superior da superfície (001) do $\mathrm{ZrO}_{2}$ tetragonal, respectivamente.

Na Figura 4 (a) e (b) pode-se observar que a superfície (110) do $\mathrm{TiO}_{2}$ rutilo é terminada por átomos de oxigênio bicoordenados $\left(\mathrm{O}_{2} \mathrm{C}\right)$ e tricoordenados $\left(\mathrm{O}_{3} \mathrm{C}\right)$, além de átomos de titânio pentacoordenados $\left(\mathrm{Ti}_{5 \mathrm{C}}\right)$ com uma ligação a menos 
perpendicular à superfície. Os $\mathrm{Ti}_{5 \mathrm{c}}$ são alternados com átomos de titânio hexacoordenados $\left(\mathrm{Ti}_{6 \mathrm{C}}\right)$. Contudo, no bulk, os átomos de oxigênio e titânio são tricoordenados $\left(\mathrm{O}_{3 \mathrm{C}}\right)$ e hexacoordenados $\left(\mathrm{Ti}_{6 \mathrm{C}}\right)$, respectivamente. Na superfície (101) do $\mathrm{TiO}_{2}$ anatásio representada na Figura 4 (c) e (d), assim como a superfície do rutilo, tem-se os átomos de oxigênio bicoordenados $\left(\mathrm{O}_{2} \mathrm{C}\right)$ e tricoordenados $\left(\mathrm{O}_{3 \mathrm{C}}\right)$ e os átomos de titânio pentacoordenados $\left(\mathrm{Ti}_{5 \mathrm{C}}\right)$ e hexacoordenados $\left(\mathrm{Ti}_{6 \mathrm{C}}\right)$. Enquanto o bulk do $\mathrm{TiO}_{2}$ anatásio apresenta átomos de oxigênio tricoordenados $\left(\mathrm{O}_{3 \mathrm{C}}\right)$ e de titânio hexacoordenados $\left(\mathrm{Ti}_{6 \mathrm{C}}\right)$.

A superfície (001) do $\mathrm{ZrO}_{2}$ tetragonal possui átomos de oxigênio bicoordenados $\left(\mathrm{O}_{2 \mathrm{C}}\right)$ e tetracoordenados $\left(\mathrm{O}_{4 \mathrm{C}}\right)$, já os átomos de zircônio são hexacoordenados $\left(\mathrm{Zr}_{6 \mathrm{C}}\right)$. Por outro lado, para os átomos de oxigênio tetracoordenados $\left(\mathrm{O}_{4 \mathrm{C}}\right)$, existem duas ligações com distâncias semelhantes às do oxigênio bicoordenado $\left(\mathrm{O}_{2} \mathrm{C}\right)$ e duas ligações que apresentam distâncias maiores em aproximadamente $0,4 \AA$. $\mathrm{Na}$ estrutura do bulk do $\mathrm{ZrO}_{2}$ tetragonal, os átomos de zircônio são octocoordenados $\left(\mathrm{Zr}_{8 \mathrm{C}}\right)$ e os átomos de oxigênio são tetracoordenados $\left(\mathrm{O}_{4 c}\right)$. Surge aí uma distorção: quatro átomos de oxigênio estão a uma distância menor e quatro com uma distância de ligação maior em cerca de $0,4 \AA$, formando assim, um tetraedro regular e um alongado.

Para simulação das superfícies, analisou-se quantas camadas seriam necessárias para descrevê-las. Essa etapa foi feita avaliando-se a convergência da energia da superfície em função do número de camadas. As energias da superfície com quatro, seis, oito, dez e doze camadas para os slabs (1x1) foram calculadas no estudo da influência da espessura usando-se a Equação 11. Os cálculos foram realizados através da relaxação da metade do número de camadas em um dos lados da superfície, utilizando-se um vácuo de separação de $20 \AA$ entre os slabs. Este foi previamente testado para garantir que não houvesse interação ao longo do eixo c. A energia da superfície é dada por: ${ }^{123}$

$$
E_{\text {Superfície }}=\frac{\left(E_{\text {slab }}-n E_{\text {bulk }}\right)}{2 A}
$$

no qual, $E_{\text {Superfície }}$ é a energia da superfície, $\mathrm{E}_{\text {slab }}$ é a energia do slab relaxado. $\mathrm{E}_{\text {bulk }}$ é a energia do bulk otimizado, $\mathrm{n}$ é a razão entre o número de átomos do slab e do bulk. A é a área da superfície. Na Figura 5 (a), (b) e (c) podem ser visualizadas as 
superfícies (1x1) com duas, quatro, seis, oito, dez e doze camadas para o $\mathrm{TiO}_{2}$ rutilo e anatásio e para o $\mathrm{ZrO}_{2}$ tetragonal, respectivamente.

(a)
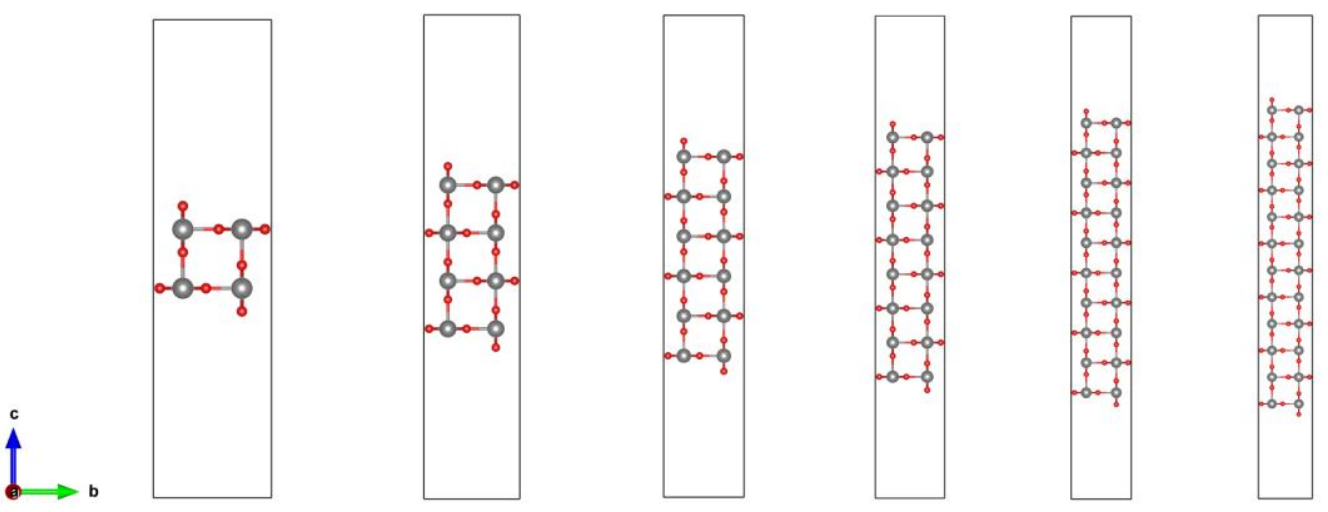

(b)
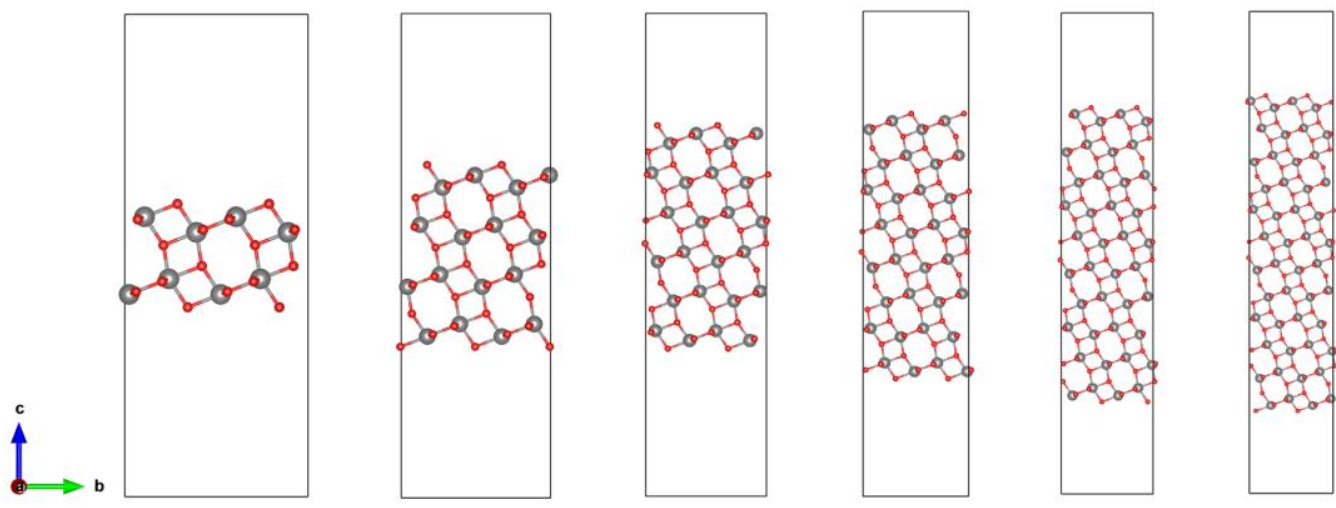

(c)
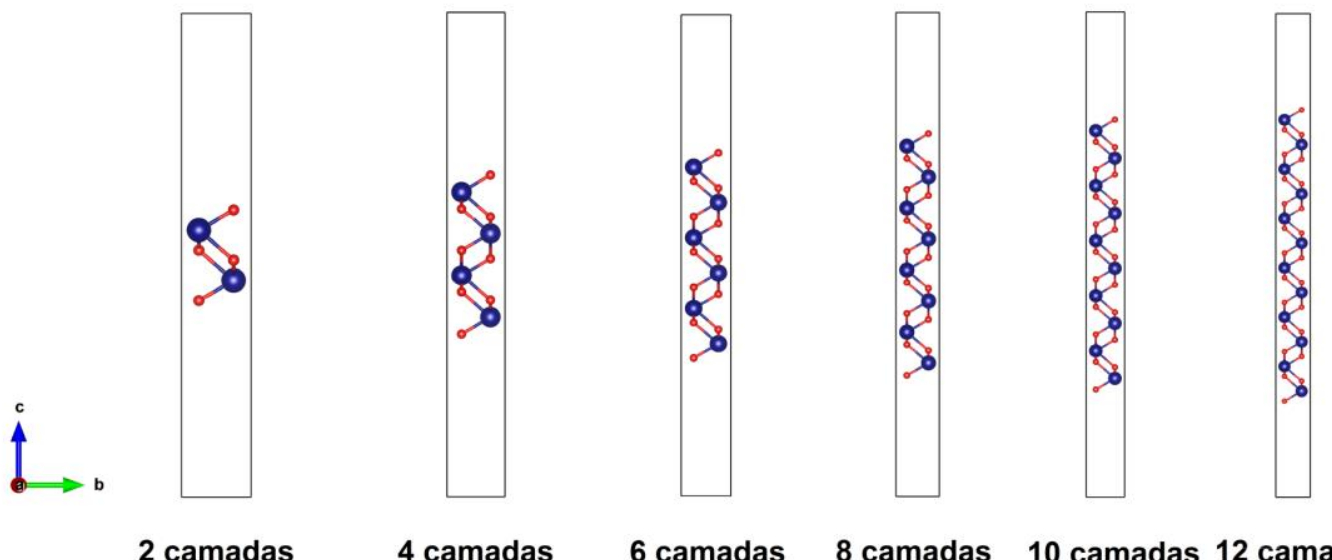

2 camadas

4 camadas

6 camadas

8 camadas

10 camadas 12 camadas

Figura 5. Superfícies com duas, quatro, seis, oito, dez e doze camadas para o (a) $\mathrm{TiO}_{2}$ rutilo (110); para o (b) $\mathrm{TiO}_{2}$ anatásio (101) e para o (c) $\mathrm{ZrO}_{2}$ tetragonal (001).

Depois de encontrado o número de camadas para simular a superfície, fez-se estudos para determinar qual seria a área da superfície necessária para que não 
ocorresse interação lateral entre as moléculas que seriam adsorvidas. Para tanto realizou-se o cálculo das moléculas de benzeno, tolueno, etilbenzeno, o-xileno, mxileno e p-xileno isolados em supercélulas que possuíam o mesmo tamanho das

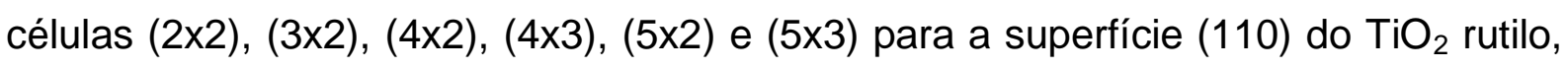

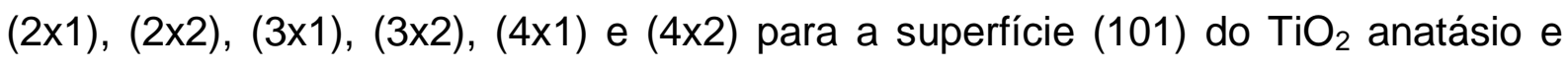
(2x2), (3x3), (4x4) e (5x5) para a superfície (001) do $\mathrm{ZrO}_{2}$ tetragonal. Foi utilizada a menor superfície em que a energia total manteve-se constante em comparação com outras que possuíam áreas maiores.

Depois de definido qual o número de camadas e a área da superfície que seria utilizada, iniciou-se a adsorção das moléculas de BTEX. A otimização dos complexos $\mathrm{BTEX}^{-\mathrm{TiO}}{ }_{2}$ e BTEX-ZrO $\mathrm{Zr}_{2}$ usando os funcionais PW91 e PBE sem e com a correção de van der Waals foi feito seguindo cinco etapas:

$1^{\text {a) }}$ Otimizou-se duas camadas da superfície isolada;

$2^{a}$ ) Otimizou-se as moléculas isoladas de BTEX na supercélula com os mesmos parâmetros de rede da superfície;

$3^{a}$ ) Colocou-se a molécula e a superfície otimizada nas etapas 1 e 2 para interagirem e, fez-se a relaxação somente da coordenada $z$ dos adsorbatos sobre as superfícies fixas;

$4^{a}$ ) Com o resultado da etapa 3 , fez a relaxação das coordenadas $x, y$ e $z$ dos absorbatos sobre as superfícies fixas e;

5a) Com o resultado da etapa 4, continuou-se a otimização das coordenadas $x, y$ e $z$ das moléculas de BTEX e das posições atômicas referentes à metade do número de camadas próximas ao adsorbato. Os átomos das outras camadas foram mantidos fixos para simular o cristal semi-infinito.

Foram utilizadas todas essas etapas de relaxação devido à dificuldades encontradas durante a otimização. A partir do resultado da quinta etapa, calculou-se a energia de adsorção do BTEX sobre as superfícies (110) do $\mathrm{TiO}_{2}$ rutilo, (101) do $\mathrm{TiO}_{2}$ anatásio e (001) do $\mathrm{ZrO}_{2}$ tetragonal usando-se a Equação $12 .{ }^{123}$

$$
E_{\text {Adsorção }}=-\left(E_{\text {slab+adsorbato }}-E_{\text {adsorbato }}-E_{\text {slab }}\right)
$$

Em que, $E_{\text {Adsorção }}$ é a energia da interação entre a superfície e o adsorbato, $E_{\text {slab }}$ +adsorbato é a energia do complexo BTEX-superfície obtida na quinta etapa de 
otimização, $E_{\text {adsorbato }}$ é a energia da molécula isolada na geometria obtida na etapa 5

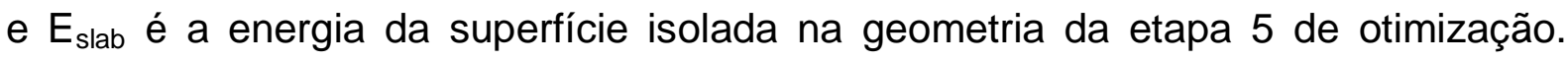
Quanto mais elevado for o valor da energia de adsorção calculada dessa forma, maior será a adsorção do substrato.

As moléculas de BTEX apresentam uma alta polarização, e a interação com as superfícies de $\mathrm{TiO}_{2}$ e $\mathrm{ZrO}_{2}$ requer a inclusão de termos de dispersão para descrever as interações de van der Waals de forma correta. Para este caso, foi utilizada a correção semiempírica proposta por Grimme ${ }^{135}$, no qual, é adicionado o termo de dispersão ( $\left.E_{\text {disp }}\right)$ às energias convencionais calculadas com a DFT ( $\left.E_{D F T}\right)$. $O$ termo de dispersão $\left(E_{\text {disp }}\right)$ foi levado em consideração para o funcional PBE, sendo escrito conforme a Equação 13.

$$
E_{\text {disp }}=-s_{6} \sum_{i=1}^{N_{\text {at }}-1} \sum_{j=i+1}^{N_{a t}} \frac{C_{6}^{i j}}{R_{i j}^{6}} f_{d m p}\left(R_{i j}\right)
$$

No qual, $s_{6}$ é um fator de escala que depende do funcional usado, no caso do PBE, é igual a $0,75, \mathrm{~N}_{\mathrm{at}}$ é o número de átomos do sistema, $\mathrm{C}_{6}^{\mathrm{ij}}$ representa o coeficiente de dispersão para o par de átomos ij, $R_{i j}$ é a distância interatômica e $f_{d m p}$ é uma função de amortecimento (damping function).

A contribuição do termo de dispersão de Grimme $\left(E_{\text {disp }}\right)$ foi calculada usando duas abordagens: a) para os complexos BTEX-superfícies na geometria fixa predita pelos cálculos com o potencial de troca e correlação PBE sem o termo de dispersão, com a finalidade de estimar a contribuição desse termo sobre a energia de adsorção, esses cálculos são denominados aqui como PBE-D2//PBE; b) as geometrias dos complexos BTEX-superfície foram reotimizadas, avaliando-se dessa forma, se o termo de dispersão terá efeito na geometria da molécula adsorvida, esses cálculos são representados como PBE-D2.

Todos os cálculos realizados no VASP4.6 e VASP5.3.5 utilizaram a mesma precisão, onde o relaxamento dos graus de liberdade eletrônicos foram interrompidos quando a mudança de energia total e energia da estrutura de bandas entre dois passos fossem menores que $10^{-5}\left(E D I F F=10^{-5}\right)$, determinando a precisão para a otimização eletrônica. A palavra-chave PREC que também afeta a precisão dos cálculos foi colocado como Accurate, no qual evita erros através do uso de uma 
malha maior para a representação das pseudofunções de onda, sendo indicada quando necessita-se de alta precisão. O número máximo de passos iônicos foi fixado em 100, a palavra-chave IBRION=2 também foi utilizada, determinando o uso do algoritmo do gradiente conjugado na relaxação (conjugate gradient algorithm). As demais configurações do programa foram mantidas como o padrão.

Com as estruturas otimizadas na etapa 5 foi feita a análise da distância e do ângulo das moléculas de BTEX em relação à superfície, da energia de adsorção, além do cálculo da diferença de densidade de carga (charge density difference CDD), das cargas de Bader, da função de localização eletrônica (Electron Localization Function - ELF) e da densidade de estados (Density of States - DOS). Para a visualização e manipulação das estruturas e análise das propriedades foram utilizados os programas VESTA ${ }^{136,137}$ (Visualization for Eletronic and Structural Analysis), MOLDEN ${ }^{138}$ (Molecular Eletronic Density), p4vasp ${ }^{139}$, XCrysDen ${ }^{140,141}$ (Xwindow Crystalline Structures and Densities) e Vaspview ${ }^{142}$. 


\section{Capítulo 4}

\section{4 - Resultados e discussão}

Neste capítulo são apresentados os resultados obtidos através dos cálculos DFT usando condições de contorno periódicas, com as suas respectivas discussões. Quando disponíveis na literatura, fez-se a comparação dos resultados encontrados com dados teóricos e experimentais existentes. O capítulo foi dividido em quatro seções: 1) Otimização dos parâmetros de corte das superfícies (110) do $\mathrm{TiO}_{2}$ rutilo, (101) do $\mathrm{TiO}_{2}$ anatásio e (001) do $\mathrm{ZrO}_{2}$ tetragonal para o estudo da adsorção das moléculas de BTEX; 2) Estudo da formação dos complexos $\mathrm{BTEX}^{-\mathrm{TiO}_{2}}$ rutilo; 3) Estudo da formação dos complexos $\mathrm{BTEX}-\mathrm{TiO}_{2}$ anatásio e, 4) Estudo da formação dos complexos BTEX-ZrO 2 tetragonal.

\section{1 - Otimização dos parâmetros de corte das superfícies (110) do $\mathrm{TiO}_{2}$ rutilo, (101) do $\mathrm{TiO}_{2}$ anatásio e (001) do $\mathrm{ZrO}_{2}$ tetragonal para o estudo da adsorção das moléculas de BTEX}

\subsection{1 - Análise da Energia de Corte das Ondas Planas e dos Pontos k}

Nesta seção serão apresentados dois estudos, analisando-se a influência da energia de corte e dos pontos $\mathrm{k}$ sobre os parâmetros de rede e a energia total dos sistemas estudados. Na primeira parte, os resultados para os parâmetros de rede obtidos com os cálculos de otimização variando-se a energia de corte e a malha de pontos $\mathrm{k}$ foram comparados com os valores experimentais. Na segunda, analisou-se a convergência da energia total em função da energia de corte e da malha de pontos k. As estruturas do bulk (maciço) de $\mathrm{TiO}_{2}$ nas fases rutilo e anatásio e $\mathrm{ZrO}_{2}$ tetragonal foram otimizadas usando os funcionais de troca e correlação PW91 e PBE. Variou-se o número de pontos $\mathrm{k}$ e a energia de corte das ondas planas conforme apresentado na Tabela 4. Em cada uma das combinações de energia de corte e pontos k estão os parâmetros de rede obtidos com a otimização. 
Tabela 4. Parâmetros de rede $(\AA)$ do $\mathrm{TiO}_{2}$ rutilo e anatásio e $\mathrm{ZrO}_{2}$ tetragonal obtidos com os cálculos variando-se $\mathrm{o}$ número de pontos $\mathrm{k}$ e a energia de corte das ondas planas. Foram usados os funcionais de troca e correlação PW91 e PBE.

\begin{tabular}{|c|c|c|c|c|c|c|c|c|}
\hline \multicolumn{9}{|c|}{$\mathrm{TiO}_{2}$ rutilo } \\
\hline \multicolumn{5}{|c|}{ PW91 } & \multicolumn{4}{|c|}{ PBE } \\
\hline $\begin{array}{c}\text { Pontos } k \\
\text { Energia de corte } \\
(\mathrm{eV})\end{array}$ & $2 \times 2 \times 2$ & $3 \times 3 \times 3$ & $4 \times 4 \times 4$ & $5 \times 5 \times 5$ & $2 \times 2 \times 2$ & $3 \times 3 \times 3$ & $4 \times 4 \times 4$ & $5 \times 5 \times 5$ \\
\hline 250 & $\begin{array}{l}a=4,566 \\
c=2,911\end{array}$ & $\begin{array}{l}a=4,544 \\
c=2,935\end{array}$ & $\begin{array}{l}a=4,553 \\
c=2,924\end{array}$ & $\begin{array}{l}a=4,551 \\
c=2,927\end{array}$ & $\begin{array}{l}a=4,584 \\
c=2,917\end{array}$ & $\begin{array}{l}a=4,560 \\
c=2,946\end{array}$ & $\begin{array}{l}a=4,567 \\
c=2,937\end{array}$ & $\begin{array}{l}a=4,564 \\
c=2,940\end{array}$ \\
\hline 300 & $\begin{array}{l}a=4,648 \\
c=2,926\end{array}$ & $\begin{array}{l}a=4,612 \\
c=2,935\end{array}$ & $\begin{array}{l}a=4,614 \\
c=2,948\end{array}$ & $\begin{array}{l}a=4,614 \\
c=2,949\end{array}$ & $\begin{array}{l}a=4,666 \\
c=2,943\end{array}$ & $\begin{array}{l}a=4,632 \\
c=2,973\end{array}$ & $\begin{array}{l}a=4,642 \\
c=2,961\end{array}$ & $\begin{array}{l}a=4,638 \\
c=2,966\end{array}$ \\
\hline 350 & $\begin{array}{l}a=4,666 \\
c=2,926\end{array}$ & $\begin{array}{l}a=4,626 \\
c=2,959\end{array}$ & $\begin{array}{l}a=4,636 \\
c=2,945\end{array}$ & $\begin{array}{l}a=4,628 \\
c=2,951\end{array}$ & $\begin{array}{l}a=4,689 \\
c=2,946\end{array}$ & $\begin{array}{l}a=4,650 \\
c=2,978\end{array}$ & $\begin{array}{l}a=4,662 \\
c=2,965\end{array}$ & $\begin{array}{l}a=4,657 \\
c=2,970\end{array}$ \\
\hline 400 & $\begin{array}{l}a=4,662 \\
c=2,925\end{array}$ & $\begin{array}{l}a=4,624 \\
c=2,962\end{array}$ & $\begin{array}{l}a=4,634 \\
c=2,945\end{array}$ & $\begin{array}{l}a=4,620 \\
c=2,954\end{array}$ & $\begin{array}{l}a=4,688 \\
c=2,945\end{array}$ & $\begin{array}{l}a=4,649 \\
c=2,977\end{array}$ & $\begin{array}{l}a=4,661 \\
c=2,964\end{array}$ & $\begin{array}{l}a=4,656 \\
c=2,969\end{array}$ \\
\hline 500 & $\begin{array}{l}a=4,661 \\
c=2,925\end{array}$ & $\begin{array}{l}a=4,625 \\
c=2,961\end{array}$ & $\begin{array}{l}a=4,634 \\
c=2,942\end{array}$ & $\begin{array}{l}a=4,622 \\
c=2,952\end{array}$ & $\begin{array}{l}a=4,687 \\
c=2,945\end{array}$ & $\begin{array}{l}a=4,648 \\
c=2,977\end{array}$ & $\begin{array}{l}a=4,660 \\
c=2,964\end{array}$ & $\begin{array}{l}a=4,655 \\
c=2,970\end{array}$ \\
\hline Experimental $^{120}$ & \multicolumn{8}{|c|}{$a=4,587$ e $c=2,954$} \\
\hline \multicolumn{9}{|c|}{$\mathrm{TiO}_{2}$ anatásio } \\
\hline \multicolumn{5}{|c|}{ PW91 } & \multicolumn{4}{|c|}{ PBE } \\
\hline $\begin{array}{c}\text { Pontos } k \\
\text { Energia de corte } \\
(\mathrm{eV})\end{array}$ & $2 \times 2 \times 2$ & $3 \times 3 \times 3$ & $4 \times 4 \times 4$ & $5 \times 5 \times 5$ & $2 \times 2 \times 2$ & $3 \times 3 \times 3$ & $4 \times 4 \times 4$ & $5 \times 5 \times 5$ \\
\hline 250 & $\begin{array}{l}a=3,814 \\
c=8,857\end{array}$ & $\begin{array}{l}a=3,745 \\
c=9,450\end{array}$ & $\begin{array}{l}a=3,751 \\
c=9,417\end{array}$ & $\begin{array}{l}a=3,754 \\
c=9,397\end{array}$ & $\begin{array}{l}a=3,828 \\
c=8,893\end{array}$ & $\begin{array}{l}a=3,763 \\
c=9,459\end{array}$ & $\begin{array}{l}a=3,768 \\
c=9,432\end{array}$ & $\begin{array}{l}a=3,770 \\
c=9,417\end{array}$ \\
\hline 300 & $\begin{array}{l}a=3,868 \\
c=8,939\end{array}$ & $\begin{array}{l}a=3,775 \\
c=9,676\end{array}$ & $\begin{array}{l}a=3,780 \\
c=9,665\end{array}$ & $\begin{array}{l}a=3,780 \\
c=9,664\end{array}$ & $\begin{array}{l}a=3,886 \\
c=9,005\end{array}$ & $\begin{array}{l}a=3,799 \\
c=9,699\end{array}$ & $\begin{array}{l}a=3,803 \\
c=9,697\end{array}$ & $\begin{array}{l}a=3,806 \\
c=9,678\end{array}$ \\
\hline 350 & $\begin{array}{l}a=3,883 \\
c=8,940\end{array}$ & $\begin{array}{l}a=3,782 \\
c=9,704\end{array}$ & $\begin{array}{l}a=3,788 \\
c=9,676\end{array}$ & $\begin{array}{l}a=3,789 \\
c=9,676\end{array}$ & $\begin{array}{l}a=3,903 \\
c=9,007\end{array}$ & $\begin{array}{l}a=3,808 \\
c=9,744\end{array}$ & $\begin{array}{l}a=3,816 \\
c=9,720\end{array}$ & $\begin{array}{l}a=3,816 \\
c=9,718\end{array}$ \\
\hline 400 & $\begin{array}{l}a=3,882 \\
c=8,915\end{array}$ & $\begin{array}{l}a=3,780 \\
c=9,693\end{array}$ & $\begin{array}{l}a=3,786 \\
c=9,675\end{array}$ & $\begin{array}{l}a=3,786 \\
c=9,673\end{array}$ & $\begin{array}{l}a=3,903 \\
c=9,009\end{array}$ & $\begin{array}{l}a=3,807 \\
c=9,741\end{array}$ & $\begin{array}{l}a=3,815 \\
c=9,718\end{array}$ & $\begin{array}{l}a=3,815 \\
c=9,716\end{array}$ \\
\hline 500 & $\begin{array}{l}a=3,879 \\
c=8,930\end{array}$ & $\begin{array}{l}a=3,779 \\
c=9,694\end{array}$ & $\begin{array}{l}a=3,785 \\
c=9,674\end{array}$ & $\begin{array}{l}a=3,785 \\
c=9,673\end{array}$ & $\begin{array}{l}a=3,902 \\
c=9,011\end{array}$ & $\begin{array}{l}a=3,806 \\
c=9,740\end{array}$ & $\begin{array}{l}a=3,813 \\
c=9,717\end{array}$ & $\begin{array}{l}a=3,814 \\
c=9,715\end{array}$ \\
\hline Experimental $^{121}$ & \multicolumn{8}{|c|}{$a=3,784$ e $c=9,515$} \\
\hline \multicolumn{8}{|c|}{$\mathrm{ZrO}_{2}$ tetragonal } & \\
\hline $\begin{array}{c}\text { Pontos } k \\
\text { Energia de corte } \\
(\mathrm{eV})\end{array}$ & $2 \times 2 \times 2$ & $3 \times 3 \times 3$ & $4 \times 4 \times 4$ & $5 \times 5 \times 5$ & $2 \times 2 \times 2$ & $3 \times 3 \times 3$ & $4 \times 4 \times 4$ & $5 \times 5 \times 5$ \\
\hline 250 & $\begin{array}{l}a=3,602 \\
c=5,178\end{array}$ & $\begin{array}{l}a=3,604 \\
c=5,188\end{array}$ & $\begin{array}{l}a=3,604 \\
c=5,187\end{array}$ & $\begin{array}{l}a=3,606 \\
c=5,186\end{array}$ & $\begin{array}{l}a=3,589 \\
c=5,151\end{array}$ & $\begin{array}{l}a=3,591 \\
c=5,167\end{array}$ & $\begin{array}{l}a=3,591 \\
c=5,166\end{array}$ & $\begin{array}{l}a=3,593 \\
c=5,162\end{array}$ \\
\hline 300 & $\begin{array}{l}a=3,630 \\
c=5,261\end{array}$ & $\begin{array}{l}a=3,638 \\
c=5,266\end{array}$ & $\begin{array}{l}a=3,637 \\
c=5,266\end{array}$ & $\begin{array}{l}a=3,638 \\
c=5,263\end{array}$ & $\begin{array}{l}a=3,627 \\
c=5,257\end{array}$ & $\begin{array}{l}a=3,636 \\
c=5,263\end{array}$ & $\begin{array}{l}a=3,635 \\
c=5,264\end{array}$ & $\begin{array}{l}a=3,636 \\
c=5,261\end{array}$ \\
\hline 350 & $\begin{array}{l}a=3,633 \\
c=5,279\end{array}$ & $\begin{array}{l}a=3,643 \\
c=5,273\end{array}$ & $\begin{array}{l}a=3,640 \\
c=5,286\end{array}$ & $\begin{array}{l}a=3,644 \\
c=5,286\end{array}$ & $\begin{array}{l}a=3,634 \\
c=5,286\end{array}$ & $\begin{array}{l}a=3,644 \\
c=5,297\end{array}$ & $\begin{array}{l}a=3,644 \\
c=5,301\end{array}$ & $\begin{array}{l}a=3,646 \\
c=5,296\end{array}$ \\
\hline 400 & $\begin{array}{l}a=3,633 \\
c=5,279\end{array}$ & $\begin{array}{l}a=3,641 \\
c=5,285\end{array}$ & $\begin{array}{l}a=3,642 \\
c=5,287\end{array}$ & $\begin{array}{l}a=3,643 \\
c=5,289\end{array}$ & $\begin{array}{l}a=3,634 \\
c=5,285\end{array}$ & $\begin{array}{l}a=3,644 \\
c=5,296\end{array}$ & $\begin{array}{l}a=3,643 \\
c=5,303\end{array}$ & $\begin{array}{l}a=3,646 \\
c=5,301\end{array}$ \\
\hline 500 & $\begin{array}{l}a=3,633 \\
c=5,280\end{array}$ & $\begin{array}{l}a=3,642 \\
c=5,286\end{array}$ & $\begin{array}{l}a=3,642 \\
c=5,289\end{array}$ & $\begin{array}{l}a=3,645 \\
c=5,293\end{array}$ & $\begin{array}{l}a=3,633 \\
c=5,291\end{array}$ & $\begin{array}{l}a=3,643 \\
c=5,297\end{array}$ & $\begin{array}{l}a=3,643 \\
c=5,303\end{array}$ & $\begin{array}{l}a=3,645 \\
c=5,300\end{array}$ \\
\hline Experimental $^{122}$ & & & & $a=3,5$ & 5,154 & & & \\
\hline
\end{tabular}


Os valores da Variação Relativa Percentual (VRP) de cada parâmetro de rede obtido com a otimização em relação ao valor experimental ${ }^{120-122}$ estão apresentados nas Figuras 6 e 7, usando os funcionais de troca e correlação PW91 e PBE, respectivamente. Em cada uma das Figuras 6 e 7 tem-se: (a) para o parâmetro de rede "a" do $\mathrm{TiO}_{2}$ rutilo; (b) para o parâmetro de rede "c" do $\mathrm{TiO}_{2}$ rutilo; (c) para o parâmetro de rede "a" do $\mathrm{TiO}_{2}$ anatásio; (d) para o parâmetro de rede "c" do $\mathrm{TiO}_{2}$ anatásio; (e) para o parâmetro de rede "a" do $\mathrm{ZrO}_{2}$ tetragonal e (f) para o parâmetro de rede "c" do $\mathrm{ZrO}_{2}$ tetragonal.

(a)

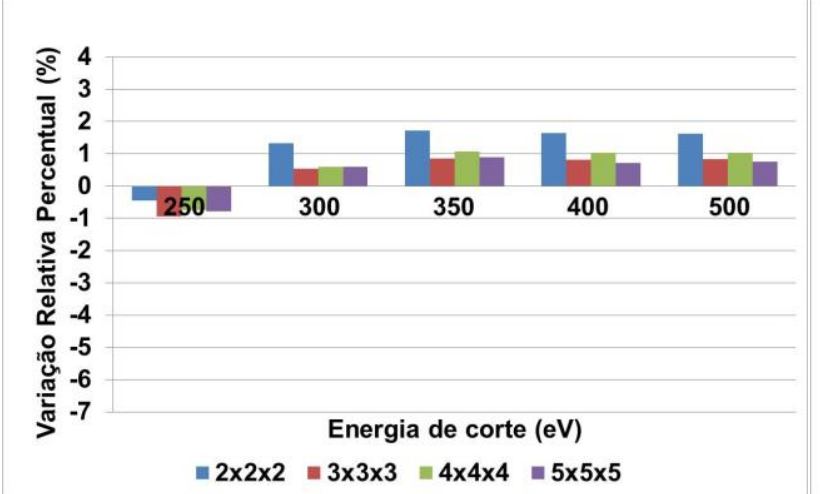

(c)

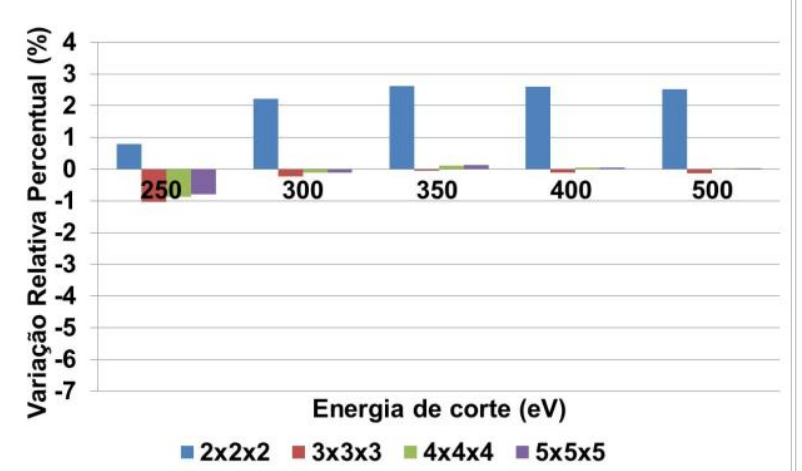

(e)

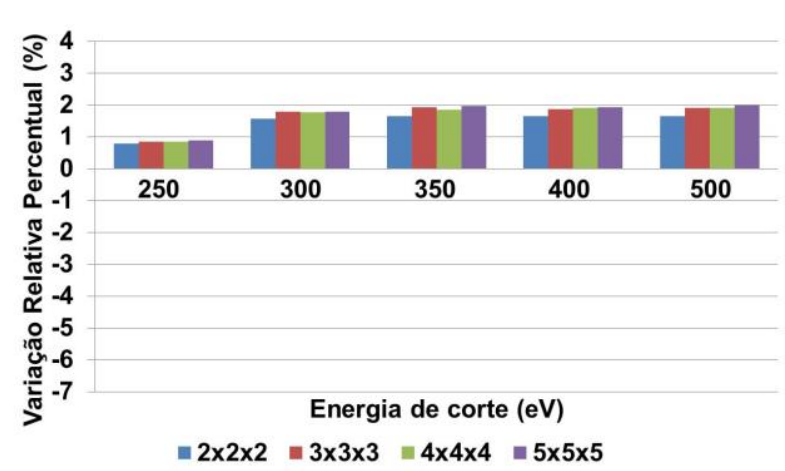

(b)

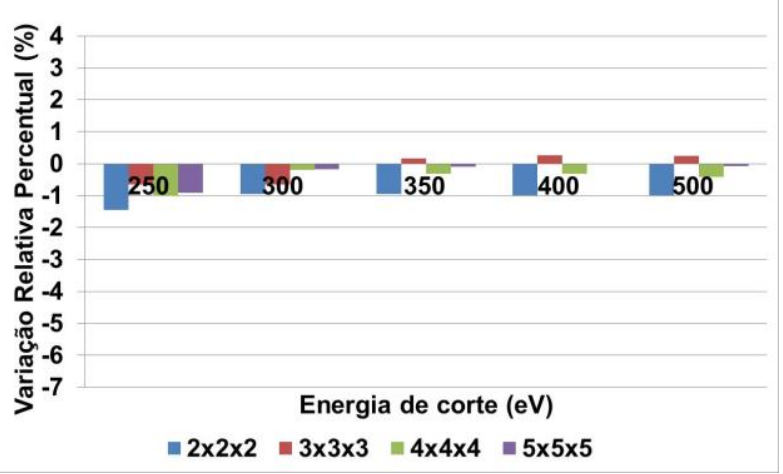

(d)

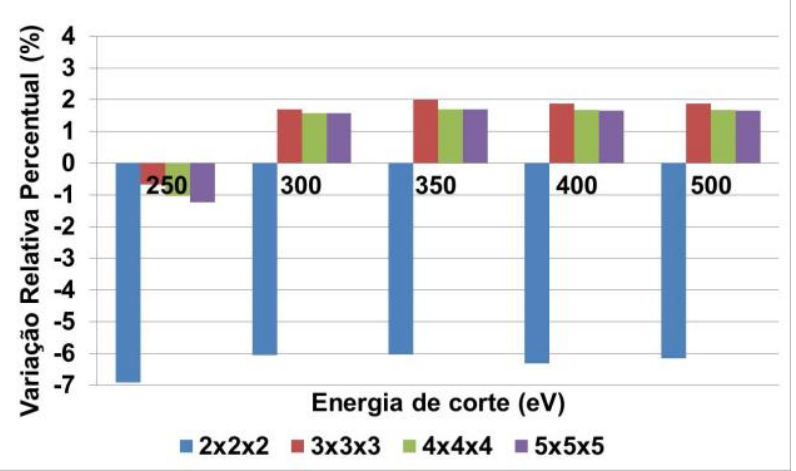

(f)

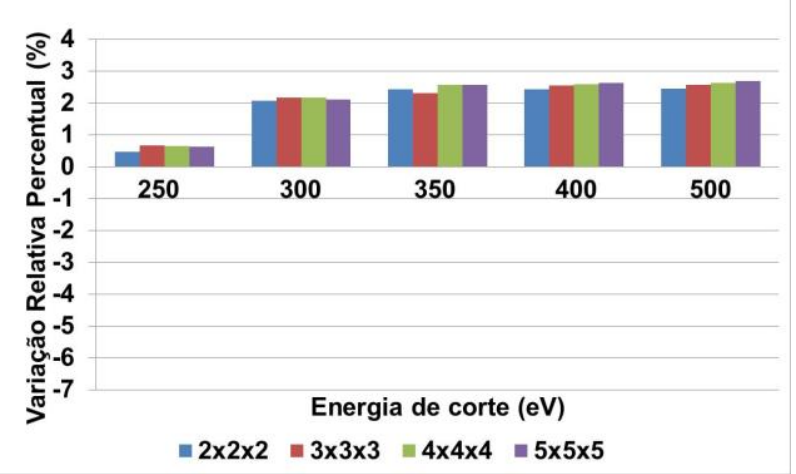

Figura 6. Variação Relativa Percentual (VRP) dos parâmetros de rede "a" e "c" obtidos com o funcional de troca e correlação PW91 para o (a) e (b) $\mathrm{TiO}_{2}$ rutilo; para o (c) e (d) $\mathrm{TiO}_{2}$ anatásio e para $\mathrm{o}(\mathrm{e})$ e (f) $\mathrm{ZrO}_{2}$ tetragonal em relação ao valor experimental ${ }^{120-122}$. 
Como em cada um desses cálculos fez-se a otimização dos parâmetros de rede do bulk, avaliou-se com isso, em qual combinação de pontos $\mathrm{k}$ e energia de corte das ondas planas foram obtidos resultados que mais se aproximam dos parâmetros de rede experimentais ${ }^{120-122}$ de cada um dos materiais estudados. Foi possível também buscar uma combinação mínima que possibilitasse a realização dos cálculos da superfície e adsorções de BTEX, já que esses adsorbatos são moléculas relativamente volumosas, que também irão exigir uma supercélula contendo muitos átomos.

(a)

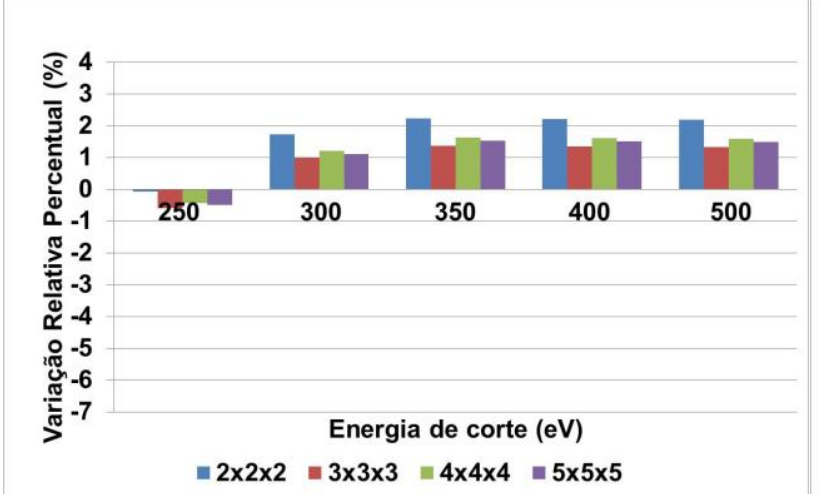

(c)

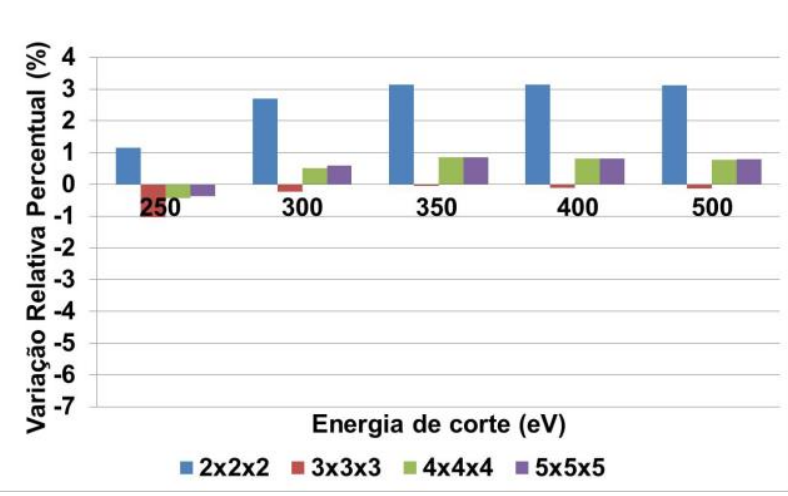

(e)

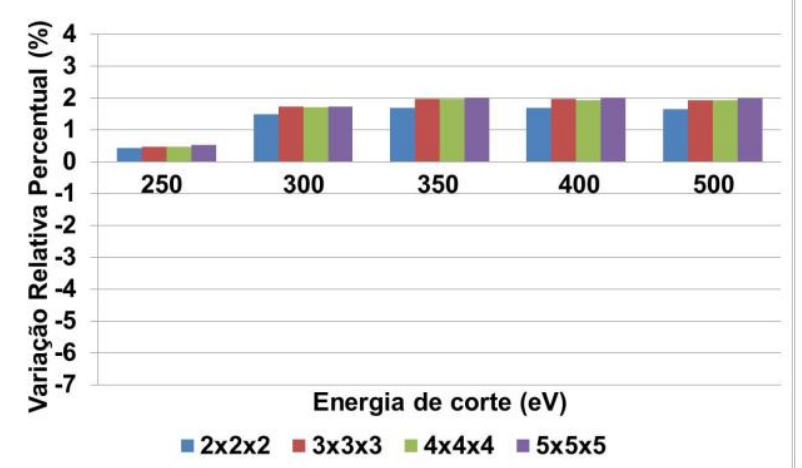

(b)

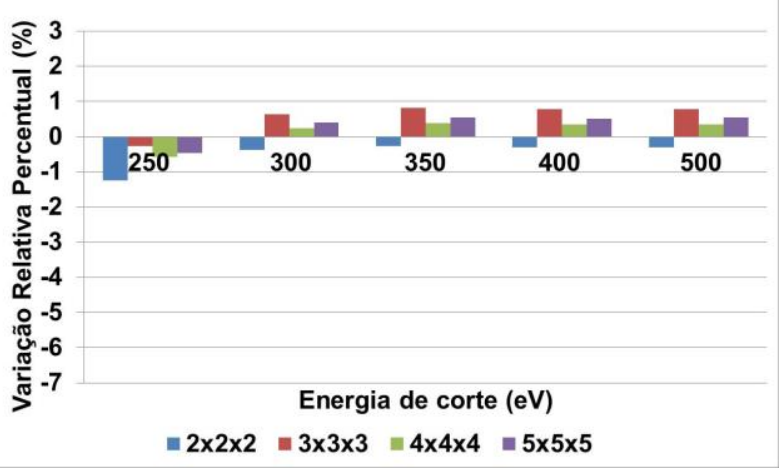

(d)

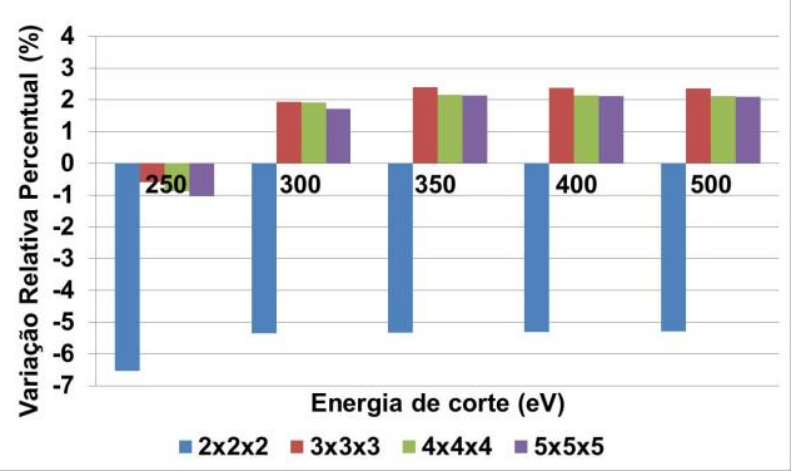

(f)

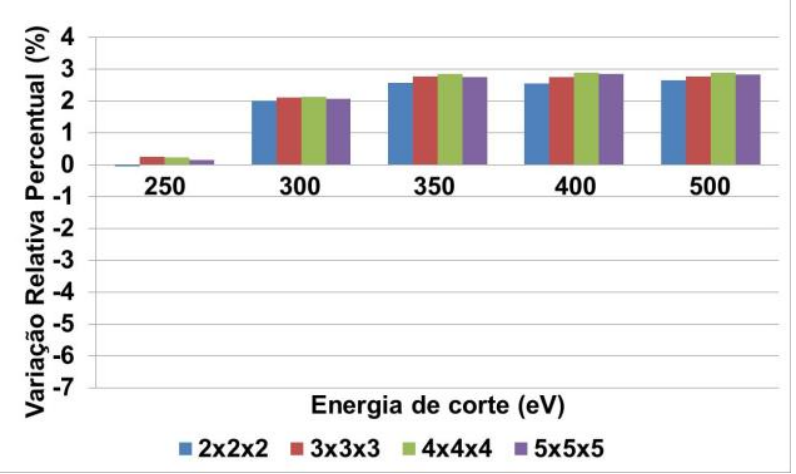

Figura 7. Variação Relativa Percentual (VRP) dos parâmetros de rede "a" e "c" obtidos com o funcional de troca e correlação PBE para o (a); (b) $\mathrm{TiO}_{2}$ rutilo; para o (c); (d) $\mathrm{TiO}_{2}$ anatásio e para o (e); (f) $\mathrm{ZrO}_{2}$ tetragonal em relação ao valor experimental ${ }^{120-122}$. 
Analisando-se os resultados da Tabela 4 e das Figuras 6 e 7, observou-se que, para a energia de corte igual a $300 \mathrm{eV}$ e malha de pontos $\mathrm{k} 3 \times 3 \times 3$, foram obtidos parâmetros de rede com valores próximos ao experimental (diferenças menores que 2,5\%), tanto para $0 \mathrm{TiO}_{2}$ rutilo, quanto para o anatásio e $\mathrm{ZrO}_{2}$ tetragonal. Sendo um indício de que essa combinação poderia ser usada nos cálculos de adsorção. Para valores de energia de corte acima de 300 eV, em todas as combinações, não foram observadas melhoras significativas que justificassem 0 aumento do custo computacional.

O uso da energia de corte igual a $250 \mathrm{eV}$, principalmente para os cálculos usando o funcional PBE e para o $\mathrm{ZrO}_{2}$, com ambos os funcionais, apresentou em algumas combinações das variáveis usadas na otimização, valores para os parâmetros de rede mais próximos aos resultados experimentais, em relação à combinação de 300 eV e 3×3×3 para a energia de corte e malha de pontos k, respectivamente. Porém, comparando-se as energias de corte usadas nos cálculos com os valores contidos nos pseudopotenciais do titânio, zircônio, oxigênio, carbono e hidrogênio, para os quais a energia máxima de corte do funcional PW91 é igual a 178,367 eV, 229,898 eV, 250,000 eV, 273,894 eV e 250,000 eV, respectivamente. Para o funcional PBE são iguais a 178,330 eV, 229,839 eV, 282,841 eV, 273,901 eV e 250,000 eV, respectivamente. A energia de corte de $250 \mathrm{eV}$ apresenta-se inferior, igual ou superior à energia máxima de corte para os funcionais usados nos cálculos. De modo que, para o pseudopotencial PAW-PBE do oxigênio e quando for feita a adsorção, incluindo-se o pseudopotencial do carbono, a utilização dessa energia de corte não cumpriria a condição de usar um valor maior do que aquele em que o pseudopotencial foi parametrizado. Por isso, selecionou-se a energia de corte igual a $300 \mathrm{eV}$, que dentro dos critérios adotados de comparação com os dados experimentais, é maior que todas as energias máximas de corte contidas nos pseudopotenciais.

Usando os parâmetros de rede e as coordenadas fracionárias obtidas na otimização do bulk com o valor da energia de corte das ondas planas igual a $300 \mathrm{eV}$ e os pontos $k$ de $3 \times 3 \times 3$, fez-se uma análise da convergência da energia em função dos pontos $\mathrm{k}$ e da energia de corte. Para isso, calculou-se a energia total (eV) da geometria obtida na etapa anterior, conforme apresentado na Figura 8, na qual, em "a" e "b" tem-se a energia total (eV) em função da energia de corte (eV) e dos pontos 
k para o $\mathrm{TiO}_{2}$ rutilo, em "c" e "d" para o $\mathrm{TiO}_{2}$ anatásio e, em "e" e "f" para o $\mathrm{ZrO}_{2}$ tetragonal.

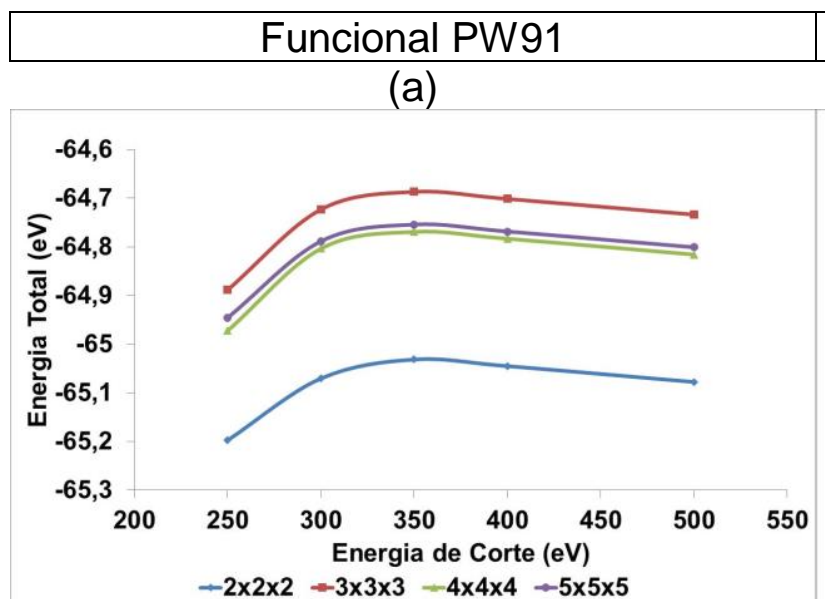

(c)

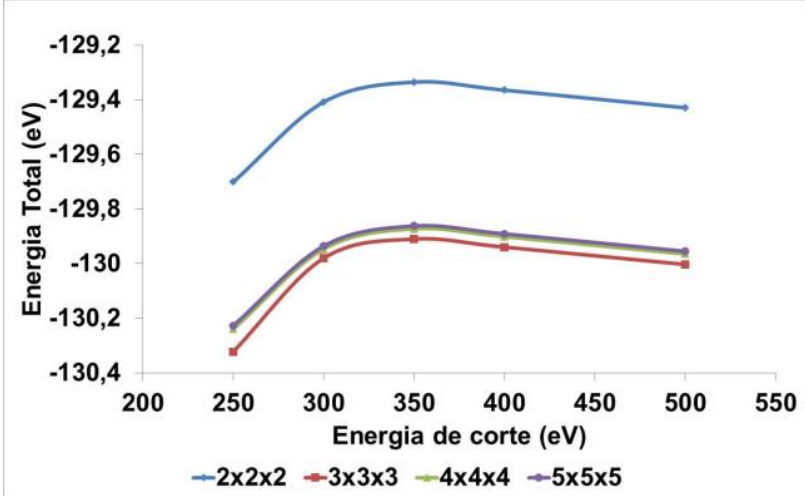

(e)

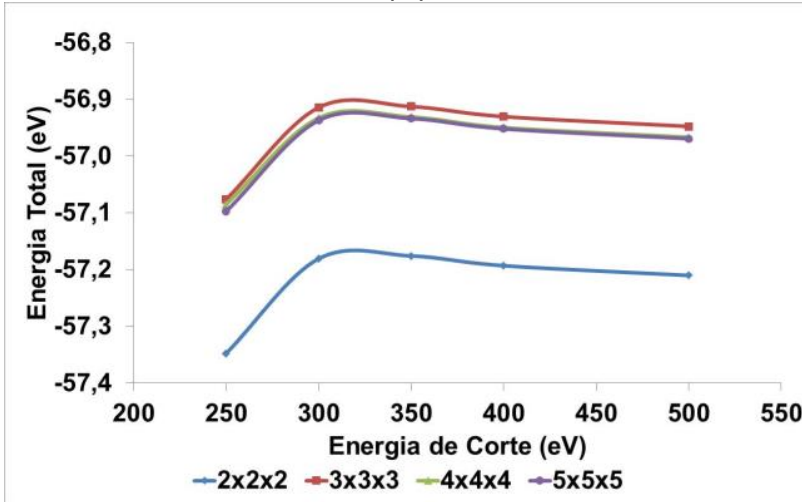

\section{Funcional PBE}

(b)

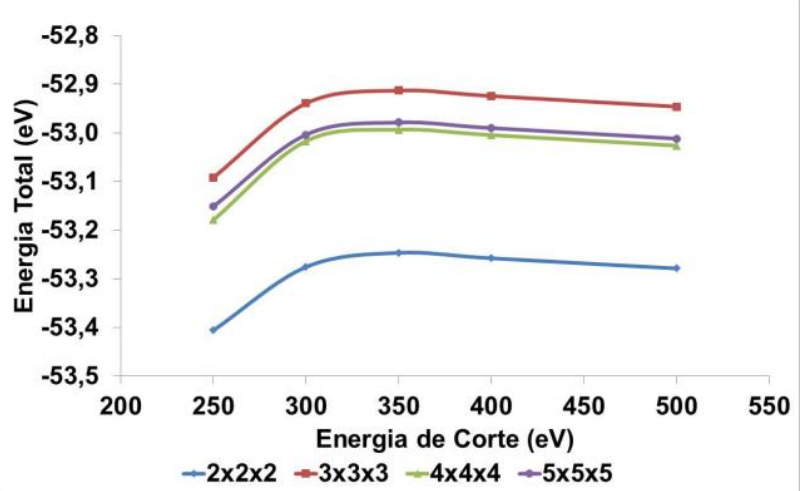

(d)

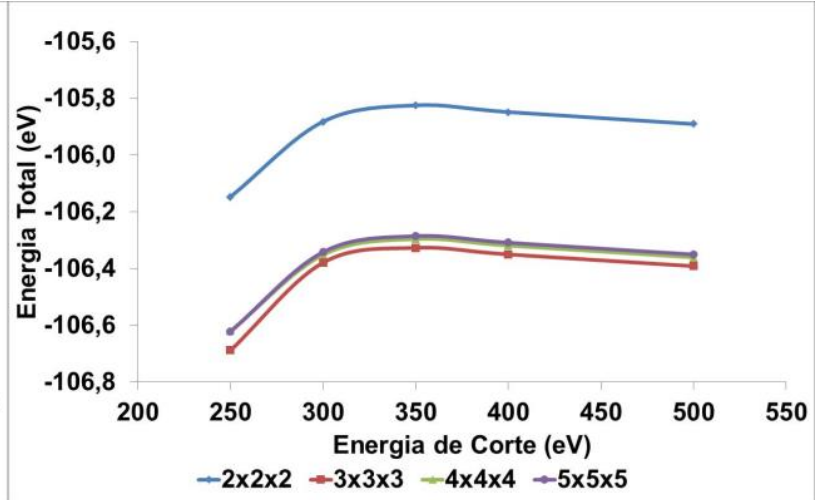

(f)

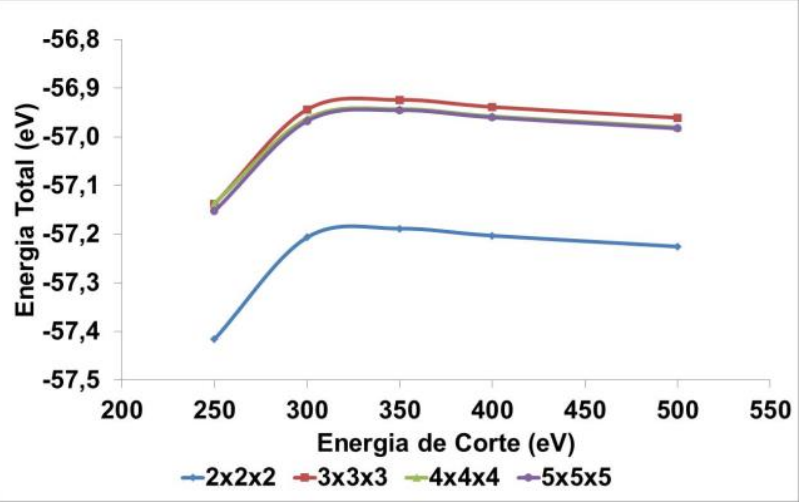

Figura 8. Energia total $(\mathrm{eV})$ em função da energia de corte $(\mathrm{eV})$ para cada uma das malhas de pontos $\mathrm{k}$ calculadas para o (a) e (b) $\mathrm{TiO}_{2}$ rutilo; para o (c) e (d) $\mathrm{TiO}_{2}$ anatásio e para o (e) e (f) $\mathrm{ZrO}_{2}$ tetragonal usando os funcionais PW91 e PBE.

Por meio da análise dos resultados de energia total apresentados na Figura 8, pode-se observar que, com o valor obtido para a energia de corte igual a $300 \mathrm{eV}$ e o número de pontos $\mathrm{k}$ de $3 \times 3 \times 3$, a diferença da energia total em relação à configuração onde utilizou-se a maior energia de corte (500 eV) e a maior malha de 
pontos k (5x5x5) foi de 0,0778 eV (PW91) e 0,0858 eV (PBE) para o $\mathrm{TiO}_{2}$ rutilo; de 0,0253 eV (PW91) e -0,0027 eV (PBE) para o $\mathrm{TiO}_{2}$ anatásio e para o $\mathrm{ZrO}_{2}$ tetragonal foi de $0,0550 \mathrm{eV}$ (PW91) e 0,0390 eV (PBE). A diferença ficou na segunda e terceira casas decimais, sendo, portanto, suficiente para estudos de adsorção, uma vez que as energias de adsorção são em geral superiores a este valor. Dessa forma, o uso de 300 eV e $3 \times 3 \times 3$ para a energia de corte das ondas planas e para o número de pontos $\mathrm{k}$, respectivamente, foram considerados apropriados para descrever os fenômenos que serão estudados.

\subsection{2 - Análise do Número de Camadas das Superfícies (110) do $\mathrm{TiO}_{2}$ Rutilo, (101) do $\mathrm{TiO}_{2}$ Anatásio e (001) do $\mathrm{ZrO}_{2}$ tetragonal}

Com os parâmetros cristalográficos do bulk que foram otimizados usando-se a energia de corte das ondas planas igual a $300 \mathrm{eV}$ e o espaço de pontos $\mathrm{k}$ igual a $3 \times 3 \times 3$, fez-se o corte do plano cristalino na direção (110) do $\mathrm{TiO}_{2}$ rutilo, (101) do $\mathrm{TiO}_{2}$ anatásio e (001) do $\mathrm{ZrO}_{2}$ tetragonal. A partir da superfície $(1 \times 1)$, variou-se o número de camadas do slab conforme mostrado na Tabela 5 , na qual, a primeira coluna indica a quantidade de camadas e a segunda, terceira e quarta colunas apresentam a energia da superfície, em $\mathrm{J} / \mathrm{m}^{2}$, para a superfície (110) do $\mathrm{TiO}_{2}$ rutilo, (101) do $\mathrm{TiO}_{2}$ anatásio e (001) do $\mathrm{ZrO}_{2}$ tetragonal, respectivamente.

Tabela 5. Energia da superfície em $\mathrm{J} / \mathrm{m}^{2}$ em função do número de camadas para a superfície (110) do $\mathrm{TiO}_{2}$ rutilo, (101) do $\mathrm{TiO}_{2}$ anatásio e (001) do $\mathrm{ZrO}_{2}$ tetragonal usando os funcionais de troca e correlação PW91 e PBE.

\begin{tabular}{c|c|c|c}
\hline \multirow{4}{*}{ Funcional PW91 } \\
\hline \multirow{2}{*}{ Número de Camadas } & \multicolumn{3}{|c}{ Energia da superfície $\left(\mathrm{J} / \mathrm{m}^{2}\right)$} \\
\cline { 2 - 4 } & $\mathrm{TiO}_{2}$ rutilo & $\mathrm{TiO}_{2}$ anatásio & $\mathrm{ZrO}_{2}$ tetragonal \\
\hline 4 & 0,8476 & 0,8408 & 1,1539 \\
\hline 6 & 0,8326 & 0,8479 & 1,1443 \\
\hline 8 & 0,8072 & 0,8557 & 1,1303 \\
\hline 10 & 0,7895 & 0,8649 & 1,1240 \\
\hline \multicolumn{4}{|c}{ Funcional PBE } \\
\hline Número de Camadas & 0,7692 & 0,8741 & 1,1089 \\
\cline { 2 - 4 } & $\mathrm{TiO}_{2}$ rutilo & $\mathrm{TiO}_{2}$ anatásio & $\mathrm{ZrO}_{2}$ tetragonal \\
\hline 4 & 0,8424 & 0,8295 & 1,0985 \\
\hline 6 & 0,8224 & 0,8291 & 1,0800 \\
\hline 8 & 0,8030 & 0,8304 & 1,0552 \\
\hline 10 & 0,7742 & 0,8316 & 1,0310 \\
\hline 12 & 0,7587 & 0,8293 & 1,0082 \\
\hline
\end{tabular}


A análise da quantidade de camadas que são necessárias para simular a superfície foi feita através da convergência da energia da superfície calculada a partir da Equação 11 em função do número de camadas. Como os cálculos realizados são periódicos, em cada uma das supercélulas adicionou-se um vácuo de $20 \AA$ para reduzir a interação entre as superfícies paralelas. Os sistemas analisados possuem quatro, seis, oito, dez e doze camadas, de modo que, para simular as camadas internas do slab, otimizou-se somente em uma das extremidades a metade do número de camadas. Por exemplo, para uma superfície com oito camadas, otimizou-se quatro em um dos lados do sistema. A supercélula que foi utilizada para cada uma das superfícies analisadas nestes cálculos possuem parâmetros de rede e área superficial conforme apresentados na Tabela 6. A superfície $(1 \times 1)$ para $\circ \mathrm{TiO}_{2}$ rutilo possui 2 átomos de titânio e 4 átomos de oxigênio por camada, para $0 \mathrm{TiO}_{2}$ anatásio, a supercélula utilizada possui 4 átomos de titânio e 8 átomos de oxigênio por camada e para o $\mathrm{ZrO}_{2}$ tetragonal, possui 1 átomo de zircônio e 2 átomos de oxigênio.

Tabela 6. Parâmetros de rede $(\AA)$ e área superficial $\left(\AA^{2}\right)$ para as superfícies $(1 \times 1)$ dos planos $(110)$ do $\mathrm{TiO}_{2}$ rutilo, (101) do $\mathrm{TiO}_{2}$ anatásio e (001) do $\mathrm{ZrO}_{2}$ tetragonal usando os funcionais PW91 e PBE.

\begin{tabular}{|c|c|c|c|}
\hline \multicolumn{4}{|c|}{ Funcional PW91 } \\
\hline & Parâmetro a $(\AA ̊)$ & Parâmetro b $(\AA ̊)$ & Área superficial $\left(\AA^{2}\right)$ \\
\hline $\mathrm{TiO}_{2}$ rutilo & 2,954 & 6,521 & 19,265 \\
\hline $\mathrm{TiO}_{2}$ anatásio & 3,777 & 10,381 & 39,207 \\
\hline $\mathrm{ZrO}_{2}$ tetragonal & 3,638 & 3,638 & 13,235 \\
\hline \multicolumn{4}{|c|}{ Funcional PBE } \\
\hline & Parâmetro a $(\AA ̊ A)$ & Parâmetro b $(\AA)$ & Área superficial $\left(\AA^{2}\right)$ \\
\hline $\mathrm{TiO}_{2}$ rutilo & 2,973 & 6,557 & 19,494 \\
\hline $\mathrm{TiO}_{2}$ anatásio & 3,799 & 10,430 & 39,624 \\
\hline $\mathrm{ZrO}_{2}$ tetragonal & 3,636 & 3,636 & 13,220 \\
\hline
\end{tabular}

Conforme pode ser observado na Tabela 5 , a partir do sistema com quatro camadas, para a superfície (110) do $\mathrm{TiO}_{2}$ rutilo, (101) do $\mathrm{TiO}_{2}$ anatásio e (001) do $\mathrm{ZrO}_{2}$ tetragonal, o aumento do número de camadas altera a energia da superfície na segunda, terceira ou quarta casas decimais. Apesar da energia da superfície dos sistemas com seis, oito, dez e doze camadas estarem, no geral, se aproximando entre si, a utilização de um sistema com mais camadas tornaria o custo computacional do estudo da adsorção das moléculas de BTEX cada vez mais elevado. Portanto, a superfície com quatro camadas pode ser utilizada para 
representar o sistema. A energia da superfície calculada está em concordância com o material e com valores encontrados na literatura, que variam de $0,73 \mathrm{~J} / \mathrm{m}^{2}$ a 0,84 $\mathrm{J} / \mathrm{m}^{2}$ para a superfície (110) do $\mathrm{TiO}_{2}$ rutilo em cálculos que usam a aproximação

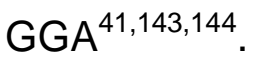

Para a superfície (101) do $\mathrm{TiO}_{2}$ anatásio, os dados de energia da superfície apresentam um aumento com o número de camadas, em concordância com a literatura ${ }^{41}$. No trabalho de Christensen e Carter ${ }^{67}$ foi feito o estudo das superfícies do $\mathrm{ZrO}_{2}$ utilizando a teoria do funcional de densidade com condições de contorno periódicas e a aproximação LDA, sendo obtido nesse trabalho o valor de 1,577 J/m para a energia da superfície (001) do $\mathrm{ZrO}_{2}$ tetragonal. Ao aumentar o número de camadas ocorre, conforme esperado, a estabilização das superfícies como pode ser observado na diminuição da diferença de energia entre cada um dos sistemas calculados e a superfície com 12 camadas.

\subsection{3 - Análise da Área Superficial das Superfícies (110) do $\mathrm{TiO}_{2}$ Rutilo, (101) do $\mathrm{TiO}_{2}$ Anatásio e (001) do $\mathrm{ZrO}_{2}$ tetragonal}

Uma vez determinada a espessura do modelo de superfície. Resta somente encontrar o número de células unitárias que serão usadas na supercélula, de forma a determinar a área superficial para que não ocorra a interação lateral entre as moléculas do adsorbato. Para isso, foi feita a análise das energias totais para as moléculas isoladas de benzeno, tolueno, etilbenzeno, o-xileno, m-xileno e $\mathrm{p}$-xileno em supercélulas que possuem o mesmo tamanho das células das superfícies (110)

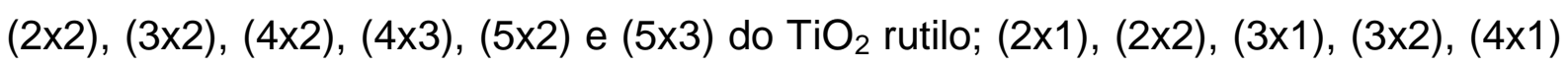

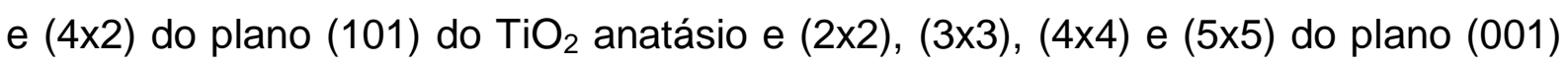
do $\mathrm{ZrO}_{2}$ tetragonal. Os cálculos realizados para cada uma das moléculas de BTEX que foram previamente otimizadas, ocorreram sem a otimização da geometria.

As moléculas foram mantidas na mesma posição quando aumentou-se o tamanho da supercélula, analisando desta forma, a interação lateral entre elas. $\mathrm{Na}$ Tabela 7 estão os parâmetros de rede a $(\AA ̊)$ e b $(\AA ̊)$ das supercélulas estudadas para cada uma das superfícies usando o funcional PW91. A molécula de benzeno apresenta uma área de aproximadamente $22,219 \AA^{2}(5,052 \AA \times 4,398 \AA)$, a de tolueno $26,687 \AA^{2}(6,068 \AA \times 4,398 \AA)$, a de etilbenzeno $30,834 \AA^{2}(7,011 \AA \times 4,398$ 
$\AA$ ), a de p-xileno $31,041 \AA^{2}\left(7,058 \AA\right.$ x 4,398 $\AA$ ) e as de o-xileno e m-xileno $32,397 \AA^{2}$ $(6,068 \AA ̊ x \times 5,339 \AA)$.

Tabela 7. Parâmetros de rede a e b das supercélulas estudadas para a superfície (110) do $\mathrm{TiO}_{2}$ rutilo, (101) do $\mathrm{TiO}_{2}$ anatásio e (001) do $\mathrm{ZrO}_{2}$ tetragonal.

\begin{tabular}{c|c|c|c|c|c|c}
\hline & & & & & \\
$\mathrm{TiO}_{2}$ Rutilo & $(2 \times 2)$ & $(3 \times 2)$ & $(4 \times 2)$ & $(4 \times 3)$ & $(5 \times 2)$ & $(5 \times 3)$ \\
\hline $\mathrm{a}(\AA)$ & 5,908 & 8,862 & 11,816 & 11,816 & 14,770 & 14,770 \\
\hline $\mathrm{b}(\AA)$ & 13,042 & 13,042 & 13,042 & 19,563 & 13,042 & 19,563 \\
\hline & & & & & & \\
$\mathrm{TiO}_{2}$ Anatásio & $(2 \times 1)$ & $(2 \times 2)$ & $(3 \times 1)$ & $(3 \times 2)$ & $(4 \times 1)$ & $(4 \times 2)$ \\
\hline $\mathrm{a}(\AA)$ & 7,554 & 7,554 & 11,331 & 11,331 & 15,108 & 15,108 \\
\hline $\mathrm{b}(\AA)$ & 10,381 & 20,762 & 10,381 & 20,762 & 10,381 & 20,762 \\
\hline $\mathrm{ZrO}_{2} \mathrm{Tetragonal}$ & $(2 \times 2)$ & $(3 \times 3)$ & $(4 \times 4)$ & $(5 \times 5)$ & & \\
\hline $\mathrm{a}(\AA)$ & 7,272 & 10,908 & 14,544 & 18,180 & & \\
\hline $\mathrm{b}(\AA)$ & 7,272 & 10,908 & 14,544 & 18,180 & & \\
\hline
\end{tabular}

Na Figura 9 pode ser visualizada a energia total para as moléculas de benzeno, tolueno, etilbenzeno, o-xileno, m-xileno e p-xileno nas supercélulas descritas anteriormente para o (a) e (b) $\mathrm{TiO}_{2}$ rutilo; (c) e (d) $\mathrm{TiO}_{2}$ anatásio e (e) e (f) $\mathrm{ZrO}_{2}$ tetragonal. 


Funcional PBE

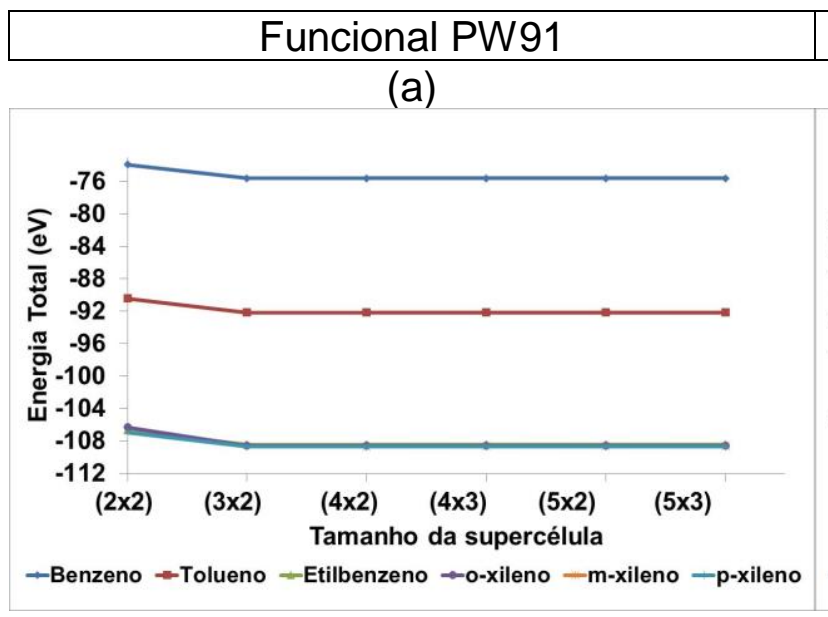

(a)

(c)

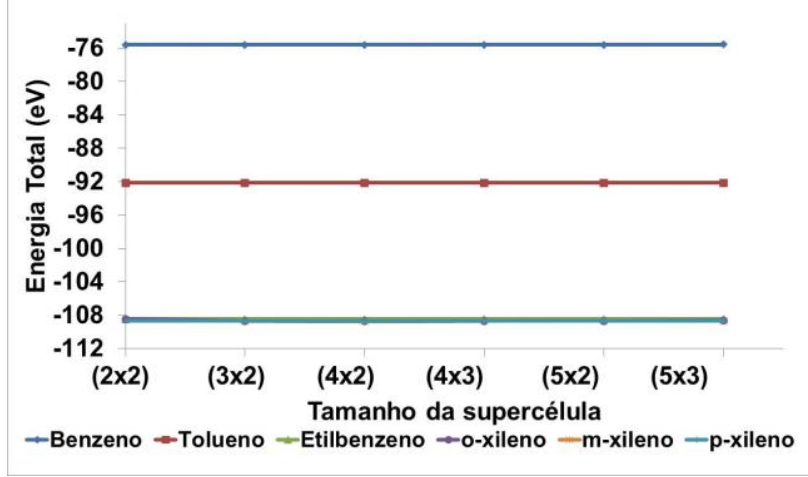

(e)

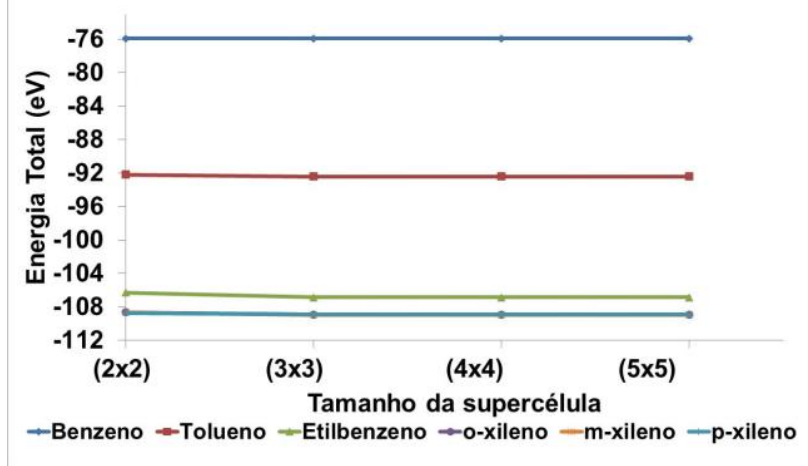

(b)

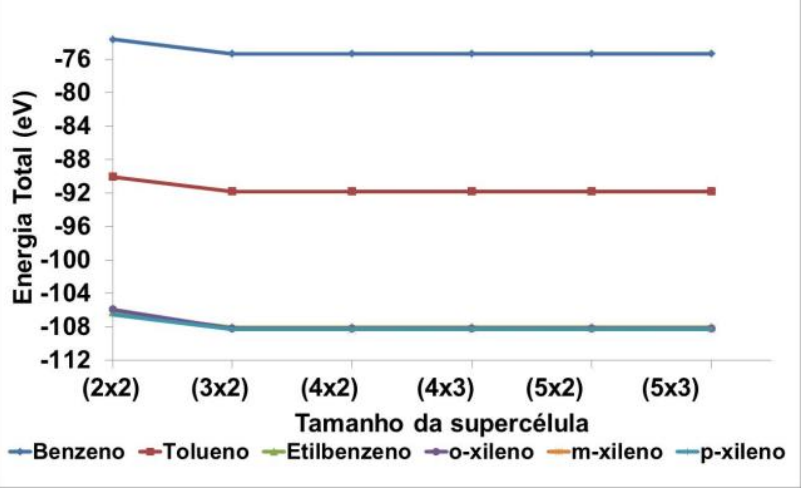

(d)

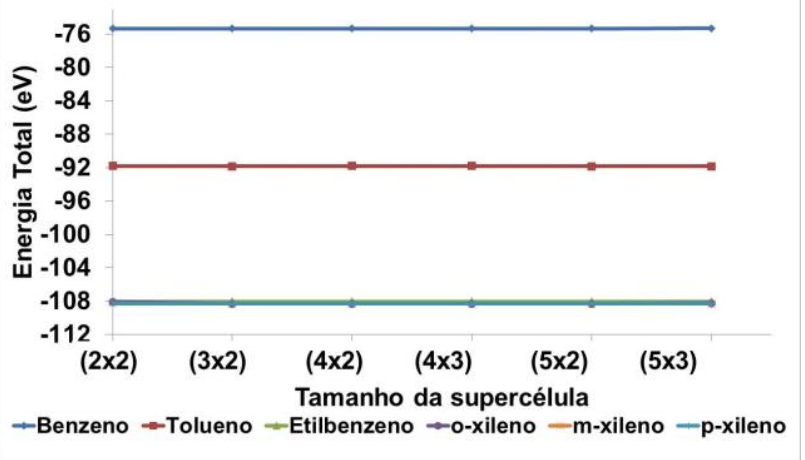

(f)

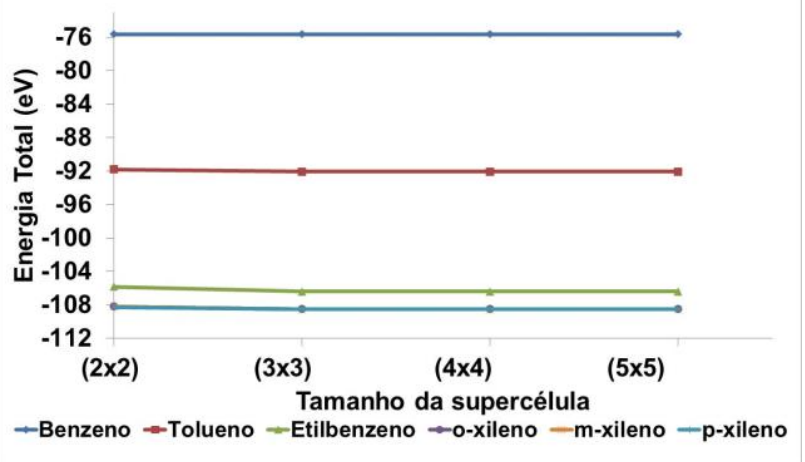

Figura 9. Energia total para as moléculas de benzeno, tolueno, etilbenzeno, o-xileno, m-xileno e $p$ xileno em relação ao tamanho da supercélula para o (a), (b) $\mathrm{TiO}_{2}$ rutilo, (c), (d) $\mathrm{TiO}_{2}$ anatásio e (e), (f) $\mathrm{ZrO}_{2}$ tetragonal usando os funcionais PW91 e PBE.

Analisando-se a relação entre a energia total e o tamanho da supercélula (Figura 9), observou-se para $\circ \mathrm{TiO}_{2}$ rutilo que a partir da estrutura (3x2), a variação na energia total ocorreu na terceira, quarta e quinta casas decimais em relação às supercélulas maiores, muito inferior à precisão do método, além disso, a área da supercélula $(3 \times 2)$ é de $115,578 \AA^{2}(a=8,862 \AA$ e $b=13,042 \AA)$ e $116,964 \AA^{2}(a=$ $8,919 \AA$ e $b=13,114 \AA$ ), usando o funcionais PW91 e PBE, respectivamente. Comparando-se com a área de $32,397 \AA^{2}(6,068 \AA$ x 5,339 $\AA$ ) do o-xileno e m-xileno, 
que são as maiores moléculas a serem adsorvidas, confirma-se que a superfície (3x2) pode ser utilizada para a adsorção do BTEX. A maior diferença de energia entre os cálculos para a supercélula $(2 \times 2)$ em relação às demais, deve-se à proximidade das moléculas quando a supercélula é replicada no cálculo periódico.

Para $0 \mathrm{TiO}_{2}$ anatásio, a partir da supercélula (3x1), a variação na energia total ocorre na terceira, quarta e quinta casas decimais comparado com a supercélula (4x2). A área da superfície $(3 \times 1)$ é de $117,627 \AA^{2}(a=11,331 \AA$ e $b=$ $10,381 \AA$ ) usando o funcional PW91 e 118,871 $\AA^{2}$ ( $a=11,397 \AA$ e $b=10,430 \AA$ ) para o funcional PBE, mostrando que esta superfície também pode ser usada para a adsorção do BTEX. O mesmo ocorreu com a supercélula (3x3) do $\mathrm{ZrO}_{2}$ tetragonal, apresentando uma área superficial de $118,984 \AA^{2}(a=10,908 \AA$ e b = 10,908 $\AA$ ) e $119,837 \AA^{2}(a=10,947 \AA$ e $b=10,947 \AA)$, usando o funcionais PW91 e PBE, respectivamente.

\section{2 - Adsorção de BTEX: Formação dos Complexos $\mathrm{BTEX}^{-\mathrm{TiO}_{2}}$ Rutilo}

\subsection{1 - Adsorção das Moléculas de BTEX}

Dentre as formas de degradação das moléculas de BTEX, está a sua adsorção em óxidos metálicos, tal como o dióxido de titânio, e posterior degradação. O estudo teórico da adsorção desses compostos nas superfícies do $\mathrm{TiO}_{2}$ é importante, levando à compreensão em nível molecular dos sítios de interação, da energia de adsorção e da análise estrutural e eletrônica das espécies adsorvidas e das superfícies.

A adsorção das moléculas de BTEX foram estudadas usando supercélulas (3x2) com quatro camadas para a superfície (110) do $\mathrm{TiO}_{2}$ rutilo. As configurações iniciais das moléculas de BTEX aplicadas nesse trabalho foram baseadas nos resultados obtidos por Zhou e colaboradores ${ }^{22}$, no qual, os autores realizaram estudos da adsorção do benzeno na superfície (110) do $\mathrm{TiO}_{2}$ rutilo usando a aproximação da densidade local (LDA), suportada por técnicas de microscopia de tunelamento com varredura (scanning tunneling microscopy - STM) e dessorção térmica programada (temperature programmed desorption - TPD). Zhou ${ }^{22}$ sugeriu 
quatro sítios de interação, com o centro de massa da molécula de benzeno sobre os pontos marcados com um " $x$ ", conforme mostrado na Figura 10. Dentre os sítios propostos, foi obtido que o benzeno adsorve mais fortemente no topo da linha de titânios pentacoordenados (sítios "C" e "D"), formando estruturas de cadeias individuais ao longo desses átomos de titânio que estão expostos.

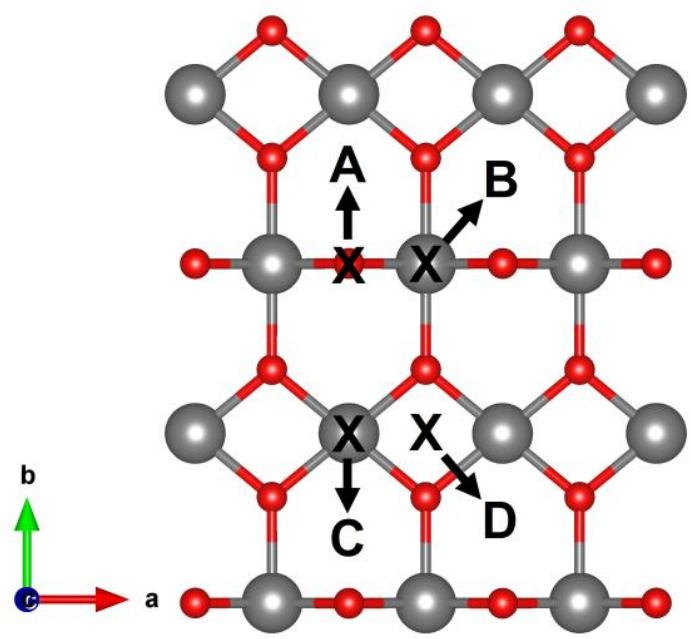

Figura 10. Vista superior da superfície (110) do $\mathrm{TiO}_{2}$ rutilo, indicando por um "x" os sítios para a adsorção da molécula de benzeno. Adaptado da referência 22.

No estudo realizado por Zhou ${ }^{22}$, empregando a LDA para a adsorção de uma molécula de benzeno foi utilizado uma superfície (3x2) com quatro camadas, no qual, as duas superiores foram otimizadas, mantendo-se fixas as da base, igual ao modelo que foi usado nas adsorções das moléculas de BTEX neste trabalho. Para a adsorção do benzeno, Zhou e colaboradores ${ }^{22}$, realizaram uma otimização parcial do complexo benzeno-superfície (duas camadas da superfície e somente a direção $z$ da molécula de benzeno - otimização parcial), por isso, foram estudadas as quatro posições de interação apresentadas na Figura 10, pois, não foi permitido o relaxamento da molécula de benzeno nas direções x e y. Foi encontrado como posição mais estável, aquela em que a molécula ficou paralela à superfície, e com o centro do anel benzênico localizado na posição mediana do vale formado entre as pontes dos átomos de oxigênio bicoordenados $\left(\mathrm{O}_{2} \mathrm{C}\right)$ e entre os átomos de titânio pentacoordenados $\left(\mathrm{Ti}_{5 \mathrm{C}}\right)$, correspondente ao sítio $\mathrm{D}$ na Figura 10.

A otimização da adsorção realizada neste trabalho foi feita através do relaxamento das duas camadas superiores da superfície e das moléculas de BTEX (otimização completa). Inicialmente foram feitos cálculos com os adsorbatos na 
posição paralela e perpendicular aos substratos. A configuração mais estável na posição perpendicular pode ser visualizada na Figura 11 para a molécula de benzeno. As energias de adsorção apresentaram-se menores em mais de $38 \%$ comparadas com a adsorção das moléculas paralelamente à superfície (as energias de adsorção das moléculas de BTEX paralelas à superfície serão apresentadas mais adiante - Tabela 11).
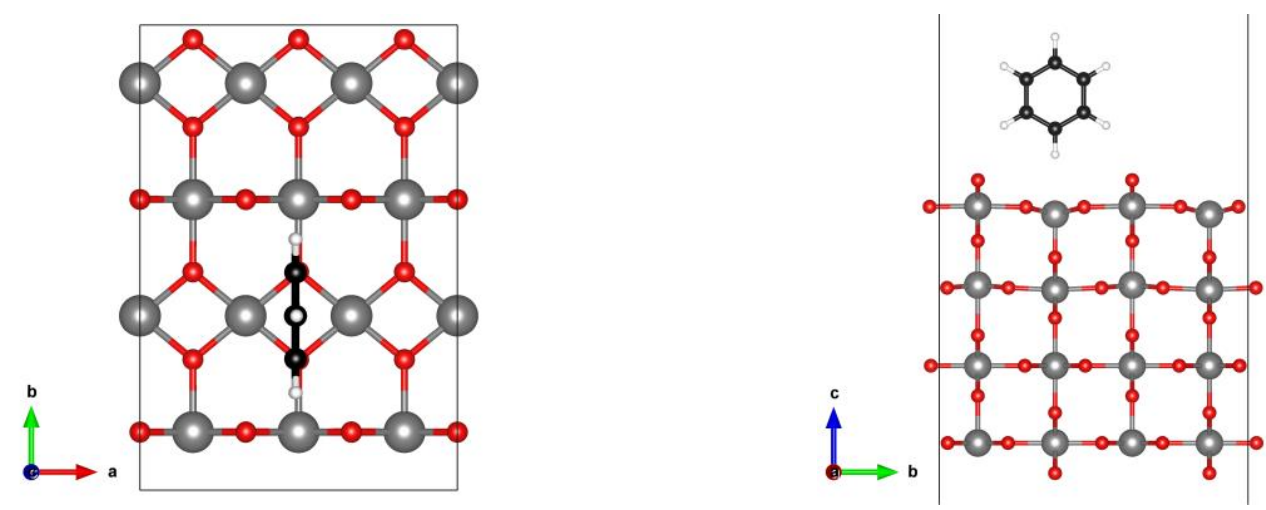

Figura 11. Estrutura otimizada da interação da molécula de benzeno perpendicular à superfície (110) do $\mathrm{TiO}_{2}$ rutilo usando o funcional PW91. Aqui e nas demais figuras o preto e o branco representam os átomos de carbono e hidrogênio, respectivamente.

As energias de adsorção das moléculas de BTEX na posição perpendicular à superfície, na geometria mais estável (Figura 11), usando os funcionais PW91, PBE e PBE-D2 estão apresentadas na Tabela 8.

Tabela 8. Energias de adsorção $(\mathrm{kJ} / \mathrm{mol})$ das moléculas de BTEX perpendiculares à superfície usando o funcionais PW91, PBE e PBE-D2.

\begin{tabular}{cccc}
\hline Eadsorção $_{\text {Benzeno }}$ & PW91 & PBE & PBE-D2 \\
\hline Tolueno & 10,13 & 10,08 & 37,02 \\
Etilbenzeno & 9,92 & 8,15 & 26,32 \\
o-xileno & 10,19 & 7,77 & 38,09 \\
m-xileno & 11,71 & 9,42 & 31,47 \\
p-xileno & 10,37 & 8,45 & 27,45 \\
\hline
\end{tabular}

Duas configurações mais estáveis que a perpendicular foram encontradas, nas quais, o plano do anel das moléculas de BTEX são paralelas à superfície. Devido a sua maior estabilidade, estas estruturas serão estudadas com maiores detalhes neste trabalho. Essas configurações planares tem a ligação CC do anel aromático centrada em uma configuração em ponte. As pontes são formadas sobre os átomos de oxigênio tricoordenados $\left(\mathrm{BTEX}-\mathrm{O}_{3 \mathrm{C}}\right.$-rutilo) e sobre os átomos de titânio 
pentacoordenados (BTEX-Ti ${ }_{5 \mathrm{C}}$-rutilo). Na Figura 12 podem ser visualizadas as estruturas otimizadas para os complexos BTEX-O $\mathrm{O}_{3 \mathrm{C}}$-rutilo. Essas geometrias foram obtidas usando o funcional PW91.

(a)

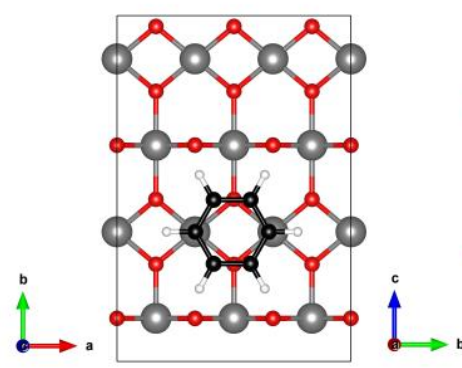

(c)

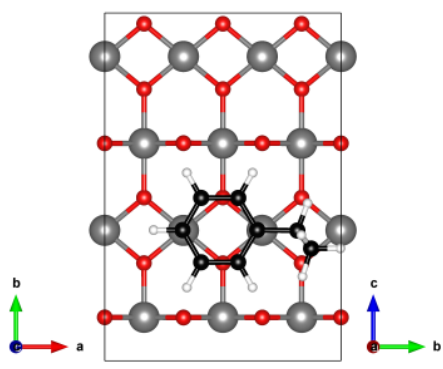

(e)

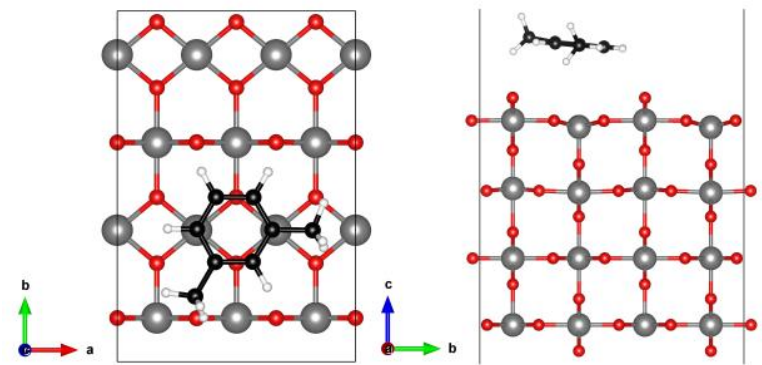

(b)
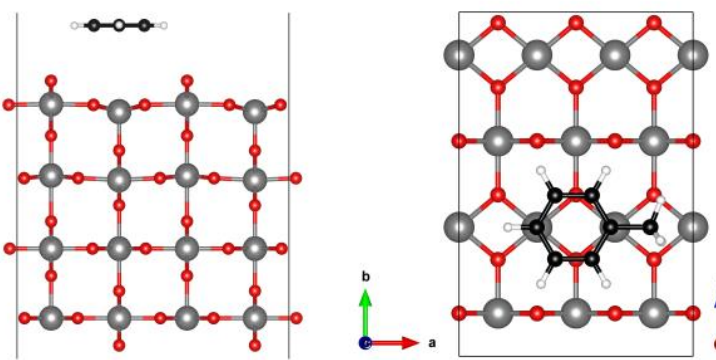

(d)
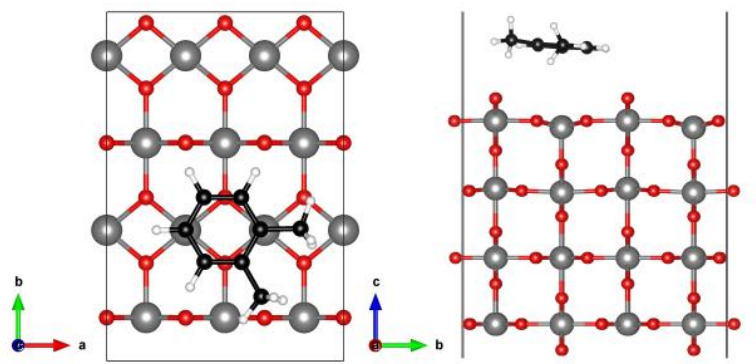

(f)
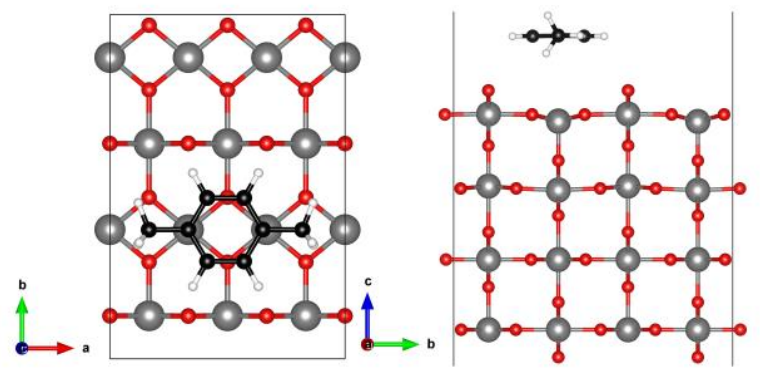

Figura 12. Estruturas otimizadas usando o funcional PW91 da interação das moléculas de BTEX com a superfície (110) do $\mathrm{TiO}_{2}$ rutilo, mostrando as ligações $\mathrm{CC}$ em uma configuração em ponte sobre os $\mathrm{O}_{3 \mathrm{C}}$ : (a) benzeno- $\mathrm{O}_{3 \mathrm{C}}$-rutilo; (b) tolueno- $\mathrm{O}_{3 \mathrm{C}}$-rutilo; (c) etilbenzeno- $\mathrm{O}_{3 \mathrm{C}}$-rutilo; (d) o-xileno- $\mathrm{O}_{3 \mathrm{C}}$-rutilo; (e) m-xileno- $\mathrm{O}_{3 \mathrm{C}}$-rutilo e (f) p-xileno- $\mathrm{O}_{3 \mathrm{c}}$-rutilo.

As estruturas otimizadas para os complexos BTEX-Ti $i_{5 c}$-rutilo podem ser visualizadas na Figura 13. Essas geometrias são resultados dos cálculos usando o funcional PW91, contudo, o uso do funcional PBE, conforme foi obtido para os complexos $\mathrm{BTEX}-\mathrm{O}_{3 \mathrm{C}}$-rutilo, mostrou resultados similares. As posições otimizadas das moléculas de BTEX usando os dois funcionais são semelhantes, com diferenças nas distâncias das moléculas em relação à superfície e nos ângulos de inclinação, 
conforme será discutido adiante. As moléculas de BTEX nas configurações BTEX$\mathrm{O}_{3 \mathrm{C}}$-rutilo e BTEX-Ti ${ }_{5 \mathrm{C}}$-rutilo estão alinhadas em configurações simétricas separadas por um ângulo de $30^{\circ}$.

(a)

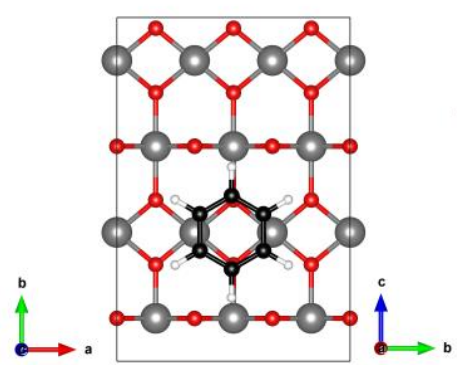

(c)

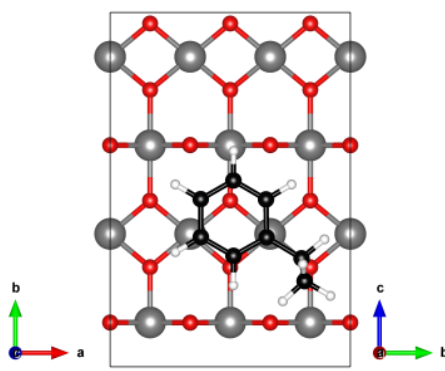

(e)

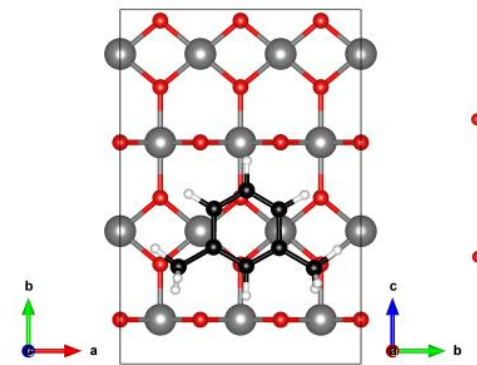

(b)
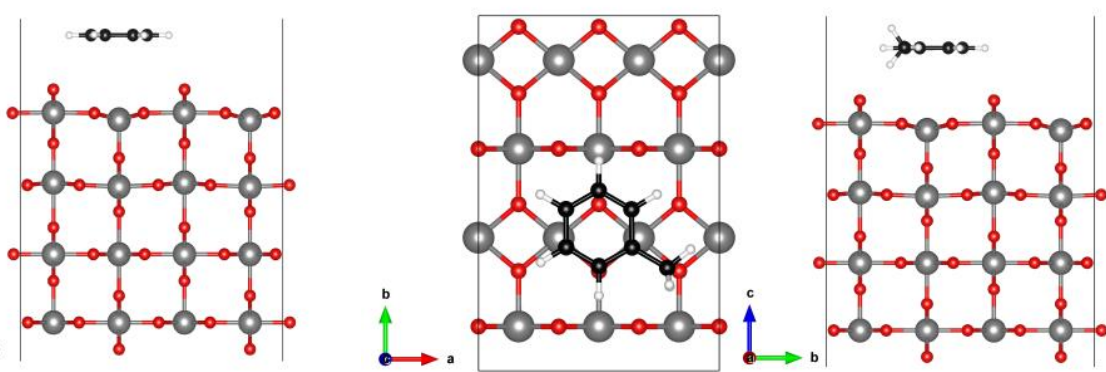

(d)
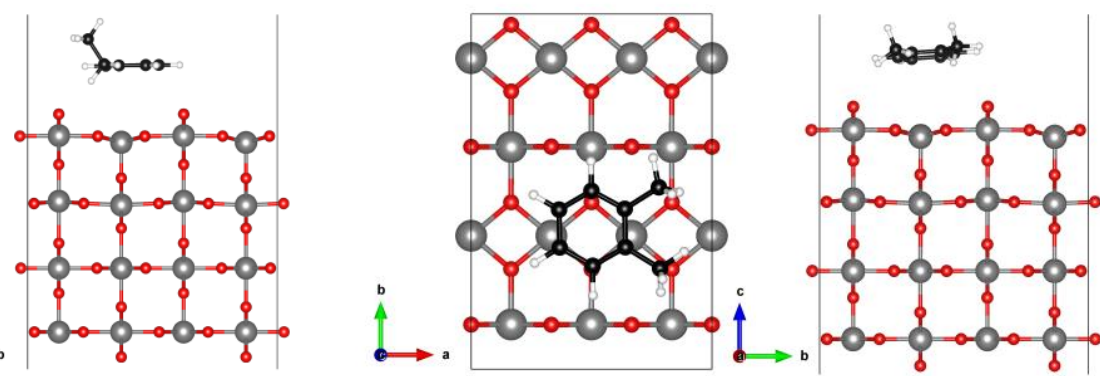

(f)
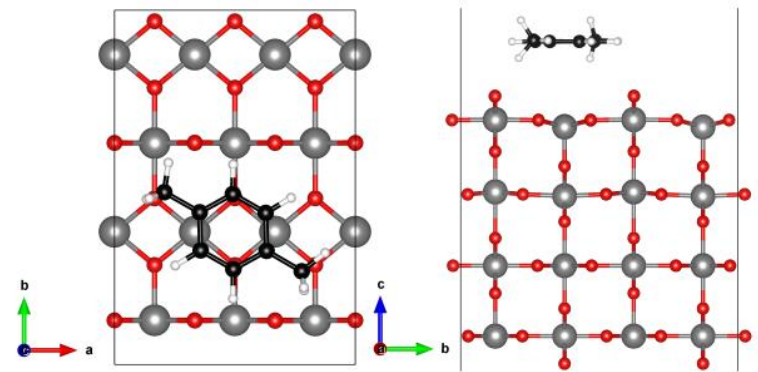

Figura 13. Estruturas otimizadas usando o funcional PW91 da interação das moléculas de BTEX com a superfície (110) do $\mathrm{TiO}_{2}$ rutilo, mostrando as ligações $\mathrm{CC}$ em uma configuração em ponte sobre os $\mathrm{Ti}_{5 \mathrm{5}}$ : (a) benzeno-Ti $\mathrm{T}_{5 c}$-rutilo; (b) tolueno- $\mathrm{Ti}_{5 c}$-rutilo; (c) etilbenzeno-Ti $\mathrm{i}_{5 c}$-rutilo; (d) o-xileno-Ti $\mathrm{Ti}_{5 \mathrm{C}}$-rutilo; (e) $\mathrm{m}$-xileno-Ti $\mathrm{i}_{5 c}$-rutilo e (f) p-xileno-Ti $\mathrm{i}_{5 c}$-rutilo.

A menor distância entre os átomos de carbono das moléculas dos adsorbatos (BTEX) e os átomos de titânio pentacoordenados $\left(\mathrm{Ti}_{5 \mathrm{C}}\right)$ da superfície foi obtida para os sistemas otimizados (Tabela 9). A distância interatômica para o benzeno- $\mathrm{TiO}_{2}$ foi encontrada na literatura usando a aproximação LDA de aproximadamente $3,4 \AA^{22}$, menor que os resultados obtidos neste trabalho. As distâncias $\mathrm{BTEX}-\mathrm{TiO}_{2}$ calculadas mostram uma pequena variação em relação aos 
funcionais utilizados, com variações de $0,00-0,43 \AA$ para o BTEX- ${ }_{3 c}$-rutilo e de 0,00-0,15 A para o BTEX-Ti ${ }_{5 c}$-rutilo. As maiores diferenças foram encontradas em relação ao funcional PW91 e o PBE-D2 para o complexo p-xileno- $\mathrm{O}_{3 \mathrm{C}}$-rutilo, e em relação ao funcional PW91 e o PBE para o complexo o-xileno-Ti ${ }_{5 C}$-rutilo.

Tabela 9. Distância adsorbato-superfície $(\AA)$ entre as moléculas de BTEX e os átomos de titânio pentacoordenados $\left(\mathrm{Ti}_{5 \mathrm{C}}\right)$ : BTEX-O $\mathrm{O}_{3 \mathrm{C}}$-rutilo e BTEX-Ti $\mathrm{ic}_{5 \mathrm{C}}$-rutilo, usando os funcionais PW91, PBE e PBE-D2.

\begin{tabular}{ccccccc}
\hline \multicolumn{7}{c}{ BTEX-O $_{3 \mathrm{C}}$-rutilo } \\
\hline Funcional & Benzeno & Tolueno & Etilbenzeno & o-xileno & m-xileno & p-xileno \\
\hline PW91 & 4,05 & 3,98 & 3,92 & 3,90 & 3,92 & 3,97 \\
PBE & 4,00 & 3,97 & 3,87 & 3,69 & 3,63 & 3,60 \\
PBE-D2 & 4,00 & 3,99 & 3,89 & 3,69 & 3,63 & 3,54 \\
\hline \multicolumn{7}{c}{ BTEX-Ti $_{5 C}$-rutilo } \\
\hline Funcional & Benzeno & Tolueno & Etilbenzeno & o-xileno & m-xileno & p-xileno \\
PW91 & 4,05 & 3,98 & 3,92 & 3,76 & 3,94 & 3,95 \\
PBE & 3,96 & 3,97 & 3,90 & 3,91 & 3,81 & 3,88 \\
PBE-D2 & 4,00 & 3,98 & 3,90 & 3,83 & 3,85 & 3,92 \\
\hline
\end{tabular}

Para os complexos $\mathrm{BTEX}-\mathrm{TiO}_{2}$-rutilo, as maiores diferenças para as distâncias adsorbato- $\mathrm{TiO}_{2}$ são para a interação do orto-, meta- e para-xileno em ambas as configurações, usando os funcionais PW91 e PBE. Para essas moléculas, o grupo metil encontra-se próximo aos átomos de oxigênio bicoordenados $\left(\mathrm{O}_{2 \mathrm{C}}\right)$ (Figura 12 e 13), para os quais observou-se a formação de um ângulo maior entre o adsorbato e a superfície (Tabela 10), comparado com as demais moléculas. O benzeno e o tolueno apresentaram o menor ângulo devido a sua simetria. Entre os xilenos, o p-xileno devido a simetria dos grupos metil, apresentou apenas um pequeno ângulo em relação à superfície. De um modo geral, quando houve diferença significativa entre a distância do adsorbato e a superfície usando os funcionais PW91 e PBE, quanto mais próximo a molécula ficou da superfície, maior foi o ângulo formado. $O$ ângulo entre o etilbenzeno e a superfície ficou próximo a 2,5ำ em ambas as configurações, com apenas pequenas variações da distância em relação à superfície, comparando-se as duas configurações e os funcionais utilizados. 
Tabela 10. Ângulos entre as moléculas adsorvidas e o plano da superfície (110) do $\mathrm{TiO}_{2}$ rutilo

\begin{tabular}{c|cccccc}
\hline \multicolumn{7}{c}{ BTEX-O $_{3 C}$-rutilo } \\
\hline Funcional & Benzeno & Tolueno & Etilbenzeno & o-xileno & m-xileno & p-xileno \\
\hline PW91 & 0,381 & 0,607 & 2,505 & 4,890 & 6,042 & 0,712 \\
PBE & 0,435 & 0,686 & 2,598 & 7,600 & 9,513 & 1,455 \\
PBE-D2 & 0,437 & 0,531 & 2,594 & 7,257 & 9,408 & 1,731 \\
\hline \multicolumn{7}{c}{ BTEX-Ti $_{5 C}$-rutilo } \\
\hline Funcional & Benzeno & Tolueno & Etillbenzeno & o-xileno & m-xileno & p-xileno \\
PW91 & 0,651 & 0,612 & 2,477 & 7,540 & 6,061 & 0,892 \\
PBE & 0,445 & 0,614 & 2,949 & 2,111 & 6,703 & 1,892 \\
PBE-D2 & 0,095 & 0,590 & 2,560 & 2,496 & 6,481 & 1,288 \\
\hline
\end{tabular}

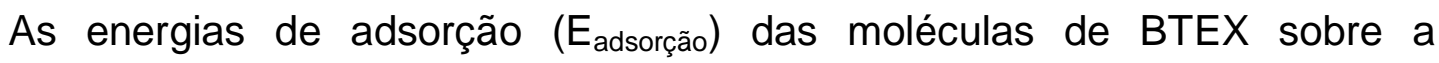
superfície (110) do $\mathrm{TiO}_{2}$ rutilo são mostradas na Tabela 11. Os resultados obtidos com os funcionais PW91 e PBE apresentaram a mesma tendência para as energias de adsorção. Esses funcionais não levam em conta as interações de dispersão, e a energia foi corrigida com a inclusão do termo semiempírico de Grimme para as interações de van der Waals (DFT-D2). ${ }^{135}$ As otimizações foram feitas usando o PBE-D2 e a geometria PBE otimizada com a energia calculada com o PBE-D2 (PBED2//PBE). Foi demonstrado que a contribuição da energia de van der Waals para a estabilização é fundamental para alterar a ligação das moléculas de BTEX, de fraca para uma adsorção relativamente forte sobre a superfície (110) do $\mathrm{TiO}_{2}$ rutilo.

As energias corrigidas (Tabela 11) mostram que o funcionais PW91 e PBE subestimam a energia de adsorção. A adsorção das moléculas de BTEX sobre o rutilo indicam que o termo de dispersão é importante para os resultados energéticos, apesar de seu pequeno efeito sobre a geometria. É evidente a pequena mudança na distância entre o carbono-metal na adsorção das moléculas de BTEX sobre a superfície (110) do rutilo, que também é reportada na literatura para o estudo dos efeitos das interações de van der Waals na adsorção do benzeno sobre a superfície (111) da Platina (Pt). ${ }^{145}$

Para as moléculas mais próximas à superfície, a energia de adsorção usando os funcionais PBE-D2//PBE e PBE-D2 foram maiores. Resultados teóricos reportados na literatura indicam valores para a adsorção do benzeno de 48,24 $\mathrm{kJ} / \mathrm{mol}$ (não foi informado o método ab initio utilizado) e 64,65 kJ/mol (usando a aproximação LDA) para o complexo benzene- ${ }_{3 c}$-rutilo e de $65,61 \mathrm{~kJ} / \mathrm{mol}$ (não foi informado o método ab initio utilizado) e $74,29 \mathrm{~kJ} / \mathrm{mol}$ (usando a aproximação LDA) para o benzeno-Ti ${ }_{5 c}$-rutilo. ${ }^{22,86}$ Experimentalmente, ${ }^{86}$ estudos de TPD mostram uma 
energia de adsorção de $56,93 \mathrm{~kJ} / \mathrm{mol}$, no qual, os resultados obtidos neste trabalho estão em concordância, sugerindo-se que as moléculas do vapor de benzeno devem interagir fraca e reversivelmente com os filmes de $\mathrm{TiO}_{2}{ }^{80}$ Além disso, na literatura ${ }^{22,86}$ foi relatado que a interação do benzeno com a ligação $\mathrm{CC}$ em ponte com o $\mathrm{Ti}_{5 \mathrm{C}}$ (benzeno- $\mathrm{Ti}_{5 \mathrm{c}}$-rutilo) é mais estável que a geometria em ponte com o $\mathrm{O}_{3} \mathrm{C}$ (benzeno- $\mathrm{O}_{3 \mathrm{C}}$-rutilo). Contudo, os resultados obtidos para a energia de adsorção neste trabalho, entre as configurações benzeno- $\mathrm{Ti}_{5 \mathrm{C}}$-rutilo e benzeno- $\mathrm{O}_{3 \mathrm{C}}$-rutilo, foi possível observar uma grande diferença para as geometrias otimizadas com os funcionais PBE-D2 $(0,14 \mathrm{~kJ} / \mathrm{mol})$ e PBE-D2//PBE $(8,87 \mathrm{~kJ} / \mathrm{mol})$. No geral, a diferença entre os funcionais PBE-D2 e PBE-D2//PBE foi menor que $11 \%$, o maior desvio foi para o p-xileno-Ti $i_{5 c}$-rutilo. A energia de adsorção obtida com o PBE-D2 aumenta fortemente em relação ao PBE (e PW91), principalmente para as espécies xileno. A fraca interação do benzeno implica em uma superfície de energia potencial rasa, permitindo que as moléculas de benzeno (consequentemente para o tolueno, etilbenzeno e xilenos) facilmente se difundam sobre a superfície, como foi encontrado por microscopia de tunelamento em metais. ${ }^{146}$

Tabela 11. Energias de adsorção ( $\mathrm{kJ} / \mathrm{mol})$ usando o funcionais PW91, PBE, PBE-D2//PBE e PBE-D2 para os complexos BTEX-O ${ }_{3 c}$-rutilo e BTEX-Ti $i_{5 C}$-rutilo.

\begin{tabular}{|c|c|c|c|c|}
\hline \multirow{2}{*}{$E_{\text {adsorção }}$} & \multicolumn{4}{|c|}{ BTEX-O ${ }_{3 c}$-rutilo } \\
\hline & PW91 & PBE & PBE-D2//PBE & PBE-D2 \\
\hline Benzeno & 26,51 & 25,00 & 53,54 & $60,04^{\mathrm{a}}$ \\
\hline Tolueno & 23,61 & 23,59 & 67,64 & 65,21 \\
\hline Etilbenzeno & 25,79 & 23,83 & 74,54 & 72,38 \\
\hline o-xileno & 18,58 & 18,72 & 78,39 & 75,19 \\
\hline m-xileno & 20,23 & 19,00 & 80,14 & 77,98 \\
\hline p-xileno & 20,66 & 17,19 & 91,30 & 93,49 \\
\hline \multirow{2}{*}{$E_{\text {adsorção }}$} & \multicolumn{4}{|c|}{ BTEX-Ti ${ }_{5 c}$-rutilo } \\
\hline & PW91 & PBE & PBE-D2/PBE & PBE-D2 \\
\hline Benzeno & 27,01 & 25,58 & 62,41 & $60,18^{\mathrm{b}}$ \\
\hline Tolueno & 25,50 & 22,65 & 67,13 & 67,45 \\
\hline Etilbenzeno & 23,78 & 21,86 & 70,31 & 67,28 \\
\hline o-xileno & 24,89 & 16,52 & 74,69 & 67,99 \\
\hline m-xileno & 30,47 & 20,68 & 75,50 & 71,03 \\
\hline p-xileno & 18,63 & 17,58 & 80,10 & 72,62 \\
\hline
\end{tabular}

${ }^{a, b}$ Resultado de TPD: $56,93 \mathrm{~kJ} / \mathrm{mol} ;{ }^{a} 64,65 \mathrm{~kJ} / \mathrm{mol}$ (usando a aproximação LDA) e $48,24 \mathrm{~kJ} / \mathrm{mol}$ (não foi informado o método ab initio); ${ }^{b} 74,29 \mathrm{~kJ} / \mathrm{mol}$ (usando a aproximação LDA) e $65,61 \mathrm{~kJ} / \mathrm{mol}$ (não foi informado o método $a b$ initio).

A representação espacial da diferença de densidade de carga (CDD) dos complexos BTEX-TiO - -rutilo são mostradas na Figura 14. Apenas resultados usando 
a correção de van der Waals (PBE-D2//PBE) são apresentados. Os resultados usando os demais funcionais apresentaram o mesmo comportamento, diferindo apenas na intensidade da distribuição de carga, mas mantendo as mesmas regiões onde as cargas foram distribuídas após a adsorção. A CDD permite analisar a natureza da interação entre as moléculas de BTEX e a superfície do $\mathrm{TiO}_{2}$. A CDD foi calculada usando a seguinte equação:

$$
\Delta \rho=\rho_{\mathrm{BTEX}-\mathrm{TiO}_{2}}-\rho_{\mathrm{TiO}_{2}}-\rho_{\mathrm{BTEX}}
$$

No qual, $\Delta \rho$ é a diferença de densidade de carga, $\rho_{\mathrm{BTEX}-\mathrm{TiO}_{2}}$ é a carga da superfície com as moléculas de BTEX adsorvidas, $\rho_{\mathrm{TiO}_{2}}$ é a carga da superfície livre e $\rho_{\mathrm{BTEX}}$ é a carga da molécula de BTEX na fase gasosa. Os últimos dois termos da Equação 14 foram calculados usando a geometria fixa com as coordenadas da estrutura otimizada BTEX-TiO .

Todos os mapas de CDD apresentaram a mesma tendência para as moléculas de BTEX, o aumento da densidade eletrônica na região $\pi$ do anel aromático perto da superfície (região azul). Além disso, a interação do p-xileno apresentou o maior aumento da densidade eletrônica, o que está correlacionada com a maior energia de adsorção. Isso indica que a interação do p-xileno é influenciada principalmente pela interação aromática $\pi$. Foi observado que quanto maior foi a transferência de carga, maior foi a energia de interação entre as moléculas de BTEX e a superfície para os resultados obtidos com o funcional PBED2//PBE e PBE-D2.

A interação das moléculas de BTEX e a superfície do $\mathrm{TiO}_{2}$ rutilo também apresentou um decréscimo qualitativo de carga nas vizinhanças dos átomos de hidrogênio e próximo aos oxigênios tricoordenados da superfície $\left(\mathrm{O}_{3 \mathrm{C}}\right)$. Além disso, a interação entre os átomos de hidrogênio e os de oxigênio bicoordenados $\left(\mathrm{O}_{2 \mathrm{C}}\right)$ da superfície é suportada pelo aumento da densidade eletrônica sobre os $\mathrm{O}_{2 \mathrm{C}}$. 
(a)

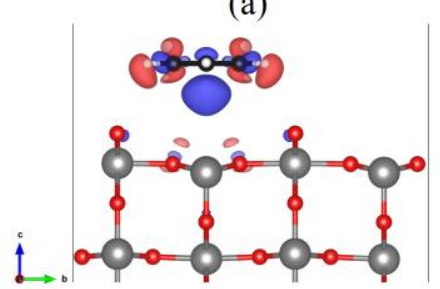

(e)

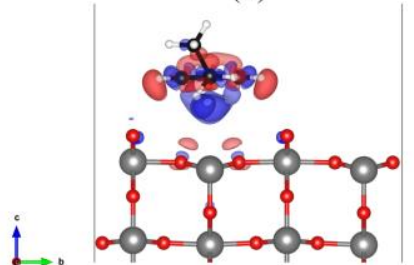

(i)

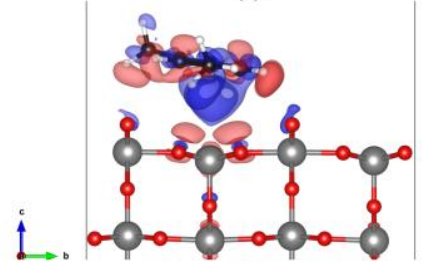

(b)

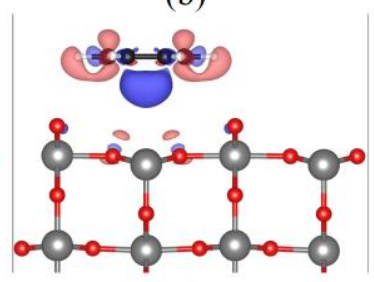

(f)

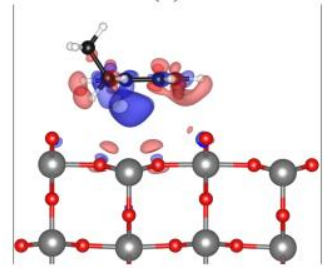

(j)

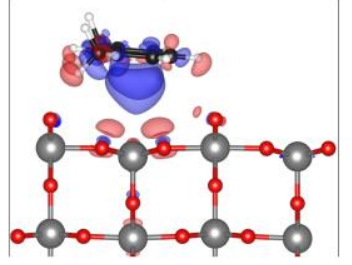

(c)

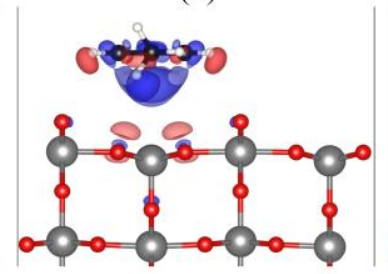

(g)

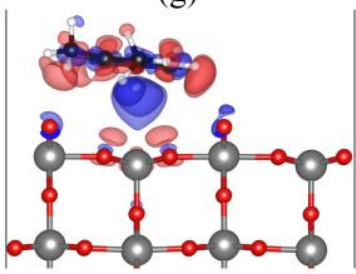

(1)

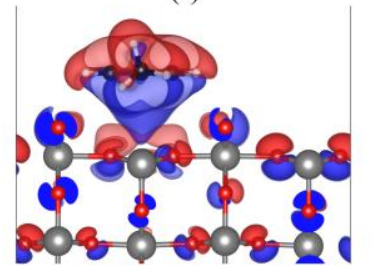

(d)

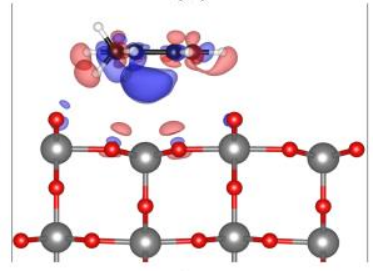

(h)

Figura 14. Diferença de densidade de carga (CDD) do (a) Benzeno- $\mathrm{O}_{3 \mathrm{C}}$-rutilo; (b) Benzeno-Ti ${ }_{5 \mathrm{C}}-\mathrm{rutil}_{\mathrm{l}}$; (c) Tolueno- $\mathrm{O}_{3 \mathrm{c}}$-rutilo; (d) Tolueno-Ti ${ }_{5 \mathrm{c}}$-rutilo; (e) Etilbenzeno-O $\mathrm{O}_{3 \mathrm{c}}$-rutilo; (f) Etilbenzeno-Ti ${ }_{5 \mathrm{c}}-\mathrm{rutil}_{\mathrm{l}}$; (g) o-Xileno- ${ }_{3 c}$-rutilo; (h) o-Xileno-Ti ${ }_{5 c}$-rutilo; (i) m-Xileno- ${ }_{3 c}$-rutilo; (j) m-Xileno-Ti ${ }_{5 c}$-rutilo; (l) p-Xileno$\mathrm{O}_{3 c}$-rutilo; $(\mathrm{m}) \mathrm{p}$-Xileno-Ti $\mathrm{F}_{5}$-rutilo. A cor vermelha é para valores negativos (decréscimo de densidade eletrônica), e azul para valores positivos (aumento da densidade eletrônica). O valor da isosuperfície é 0,0005 e/bohr ${ }^{3}$.

As cargas de Bader são baseadas na metodologia conhecida como "Átomos em Moléculas", possibilitando a aplicação da química quântica em sistemas complexos. A partição do sistema molecular é baseado em propriedades topológicas da densidade eletrônica. ${ }^{147,148}$

As cargas de Bader (e) das moléculas de BTEX foram calculadas para as adsorções nas configurações BTEX- ${ }_{3}$-rutilo e BTEX-Ti ${ }_{5 c}$-rutilo (Tabela 12). Os valores das cargas foram obtidos usando o funcional PW91. Observou-se que houve pouca transferência de carga entre as moléculas de BTEX e a superfície, em concordância com os dados da CDD, que indicaram uma interação na região dos elétrons $\pi$. A maior variação de carga ocorreu para a molécula de benzeno na configuração benzeno- $\mathrm{O}_{3 \mathrm{C}}$-rutilo e para $0 \mathrm{~m}$-xileno na configuração m-xileno- $\mathrm{Ti}_{5 \mathrm{C}^{-}}$ rutilo. 
Tabela 12. Cargas (e) das moléculas de BTEX após a adsorção usando o modelo de Bader.

\begin{tabular}{|c|c|}
\hline \multirow{2}{*}{ Carga de Bader } & BTEX-O ${ }_{3 C}$-rutilo \\
\hline & PW91 \\
\hline Benzeno & 0,14 \\
\hline Tolueno & 0,00 \\
\hline Etilbenzeno & 0,03 \\
\hline o-xileno & $-0,02$ \\
\hline m-xileno & $-0,03$ \\
\hline p-xileno & 0,01 \\
\hline \multirow{2}{*}{ Carga de Bader } & BTEX-Ti ${ }_{5 c}$-rutilo \\
\hline & PW91 \\
\hline Benzeno & 0,03 \\
\hline Tolueno & 0,01 \\
\hline Etilbenzeno & 0,01 \\
\hline o-xileno & $-0,03$ \\
\hline m-xileno & 0,24 \\
\hline p-xileno & 0,00 \\
\hline
\end{tabular}

Nas Figuras 15 e 16, podem ser visualizadas as análises da localização dos elétrons através da função de localização eletrônica (Electron localization function ELF), foi utilizado o programa Visualization for Eletronic and Structural Analysis ${ }^{136,137}$ (VESTA) para geração das imagens. Na Figura 15, tem-se o ELF para as moléculas de BTEX isoladas na geometria otimizada da configuração BTEX-O ${ }_{3 c}$-rutilo. $\mathrm{Na}$ Figura 16, estão os mapas do ELF para os complexos BTEX-TiO 2 -rutilo nas configurações BTEX-O ${ }_{3 c}$-rutilo e BTEX-Ti $i_{5 c}$-rutilo. Em ambas, o valor da isosuperfície é 0,80 .

(a)
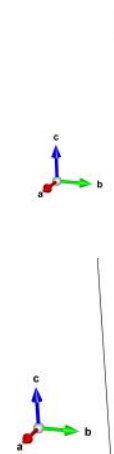

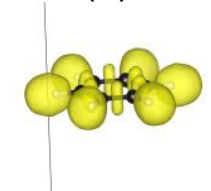

(d)

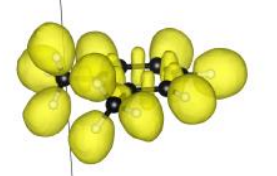

(b)
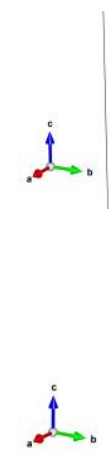

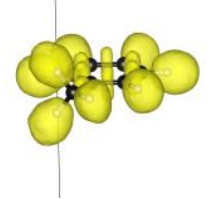

(e)

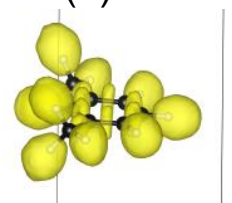

(c)

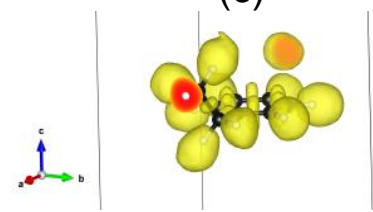

(f)

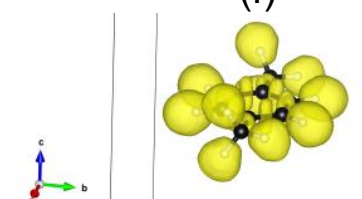

Figura 15. ELF das moléculas de BTEX na geometria otimizada BTEX- $\mathrm{O}_{3 \mathrm{C}}$-rutilo: (a) benzeno; (b) tolueno; (c) etilbenzeno; (d) o-xileno; (e) m-xileno e (f) p-xileno. O valor da isosuperfície é 0,8. 
(a)

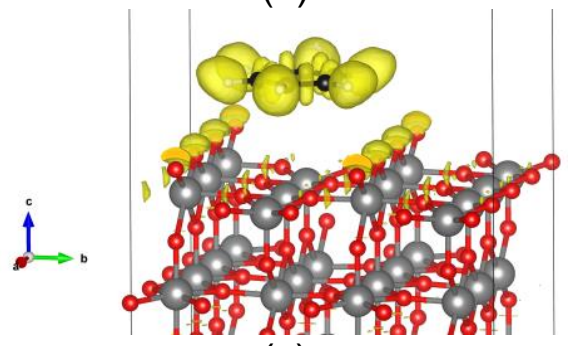

(c)

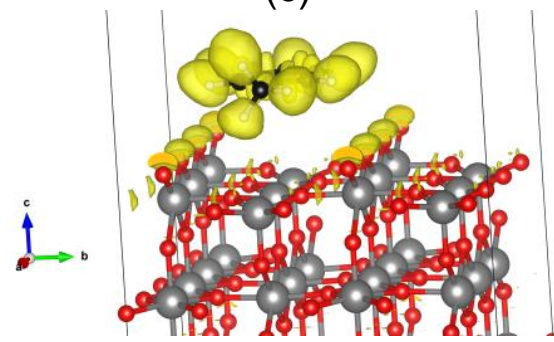

(e)

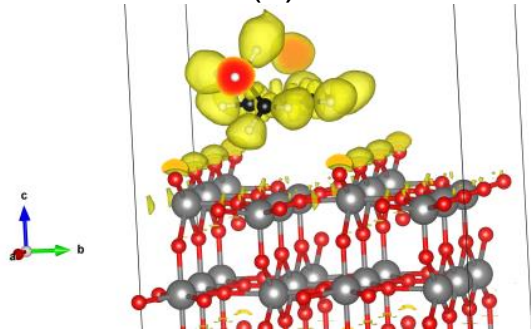

(g)

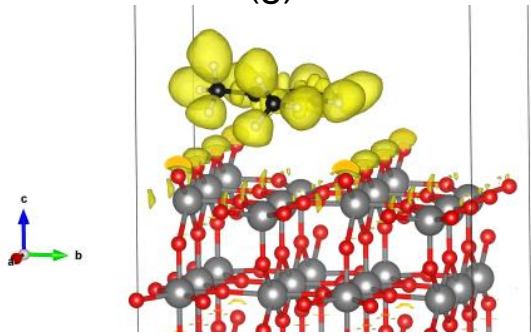

(i)

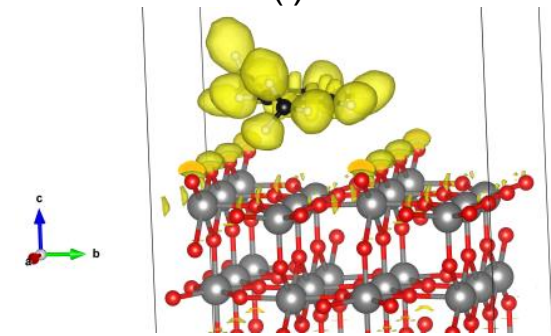

(I)

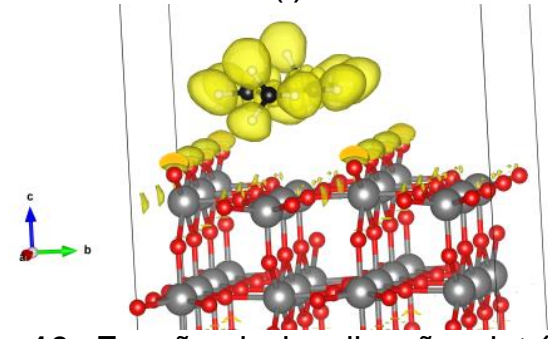

(b)

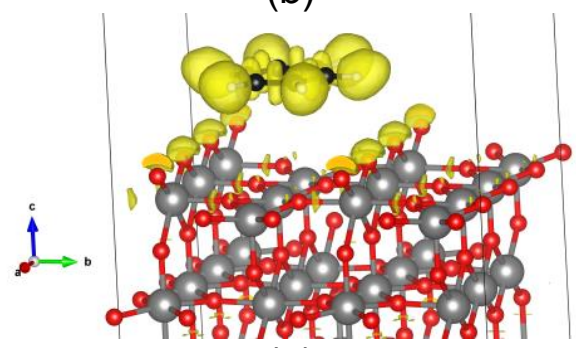

(d)

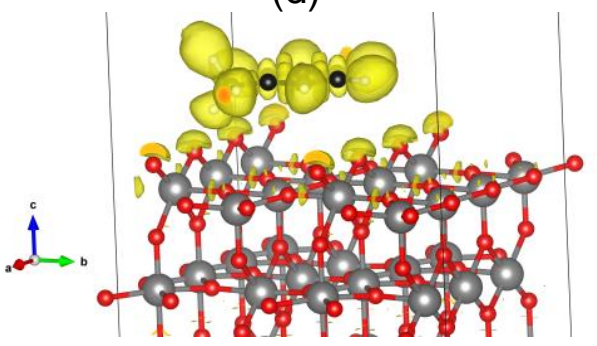

(f)

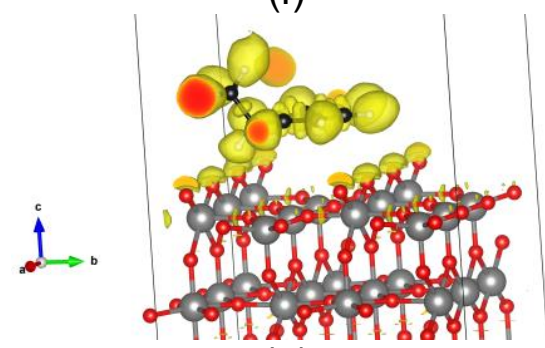

(h)

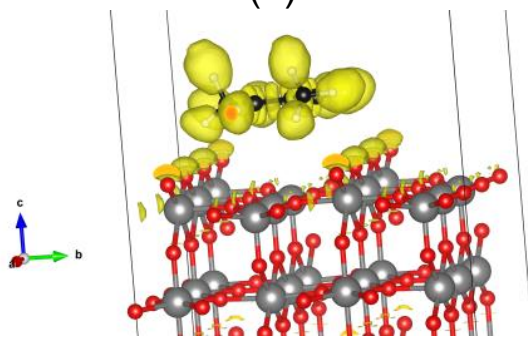

(j)

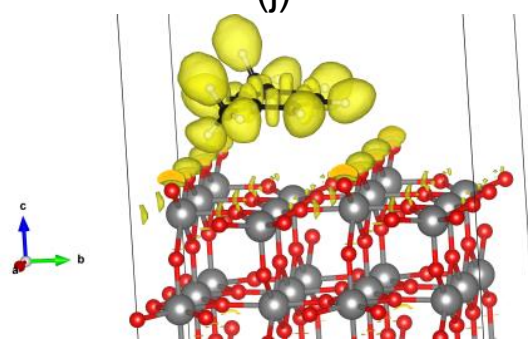

(m)

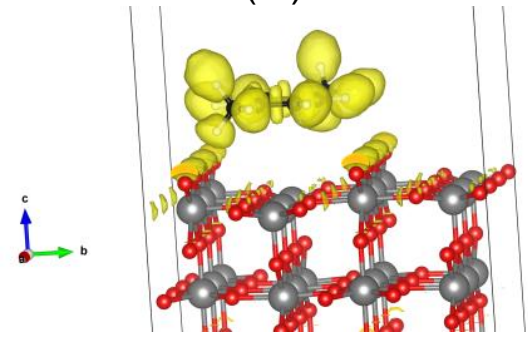

Figura 16. Função de localização eletrônica (ELF) para os complexos (a) Benzeno- $\mathrm{O}_{3 c}$-rutilo; (b) Benzeno-Ti ${ }_{5 \mathrm{c}}$-rutilo; (c) Tolueno- $\mathrm{O}_{3 \mathrm{C}}$-rutilo; (d) Tolueno-Ti ${ }_{5 \mathrm{C}}$-rutilo; (e) Etilbenzeno- $\mathrm{O}_{3 \mathrm{c}}$-rutilo; (f) Etilbenzeno-Ti ${ }_{5 c}$-rutilo; (f) o-Xileno- ${ }_{3 c}$-rutilo; (g) o-Xileno-Ti ${ }_{5 c}$-rutilo; (h) m-Xileno- $\mathrm{O}_{3 c}$-rutilo; (i) mXileno-Ti ${ }_{5 c}$-rutilo; (I) p-Xileno- $\mathrm{O}_{3 c}$-rutilo; (m) p-Xileno-Ti ${ }_{5 c}$-rutilo. O valor da isosuperfície é $0,8$. 
Através da análise do ELF representado nas Figuras 15 e 16, pode-se observar características em concordância com os resultados da diferença de densidade de carga (CDD). Em ambos, há uma alteração na densidade eletrônica próximo aos oxigênios bicoordenados $\left(\mathrm{O}_{2 \mathrm{C}}\right)$, indicando uma interação entre os hidrogênios das moléculas de BTEX com esses átomos, sendo evidenciado no ELF por uma contração da distribuição eletrônica na região dos hidrogênios das moléculas de BTEX adsorvidas, comparadas com a sua fase gasosa (Figura 15).

A Figura 17 mostra: (a) na parte inferior, a densidade de estados (DOS) total da superfície (110) do $\mathrm{TiO}_{2}$ rutilo livre e após a adsorção na configuração Benzeno$\mathrm{O}_{3 \mathrm{C}}$-rutilo; no meio, tem-se o DOS total da superfície (110) do $\mathrm{TiO}_{2}$ rutilo livre e do benzeno isolado e, na parte superior, o DOS total do complexo Benzeno- $\mathrm{O}_{3 \mathrm{c}}$-rutilo e da molécula de benzeno após a adsorção. As densidades de estados apresentadas em (b) correspondem às mesmas estruturas, porém, quando foi feita a adsorção da molécula de benzeno com a ligação CC do anel aromático centrada em uma configuração em ponte com relação aos átomos de titânio pentacoordenados (Benzeno-Ti $i_{5 \mathrm{C}}$-rutilo).

Analisando as densidades de estado da parte inferior, para os complexos Benzeno- $\mathrm{O}_{3 \mathrm{C}}$-rutilo e Benzeno-Ti $\mathrm{i}_{5 \mathrm{c}}$-rutilo, pode-se verificar que o DOS da superfície

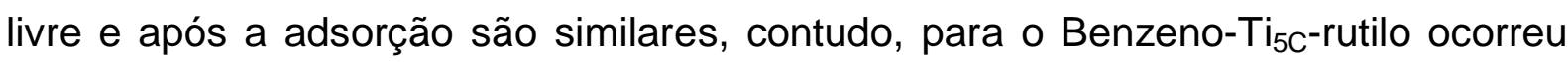
uma translação dos estados para regiões de menor energia após a adsorção, indicando uma estabilização do sistema ao formar os complexos, o que não foi observado para o complexo Benzeno- $\mathrm{O}_{3 \mathrm{c}}$-rutilo. A ausência de semelhante translação mostra que o sitio de adsorção $\mathrm{O}_{3 \mathrm{C}}$ não é estabilizado pelas bandas da superfície. Isso pode ser associado a diferença de energia de adsorção entre os complexos Benzeno- $\mathrm{O}_{3 \mathrm{C}}$-rutilo e Benzeno- $\mathrm{Ti}_{5 \mathrm{C}}$-rutilo. Os outros adsorbatos possuem grupos $-\mathrm{CH}_{3}$ que incluem a interação através dos hidrogênios desse grupo além da interação $\pi$, que justifica as diferenças observadas nas energias de adsorção. Dois pontos principais se alternam e corroboram com a sugestão da CDD para a interação $\pi$ das moléculas de BTEX. Primeiro, a translação expressiva de estados da superfície para os complexos $\mathrm{Ti}_{5 \mathrm{c}}$-rutilo mencionados anteriormente, e o segundo é a diferença nos DOS do benzeno isolado comparado com o adsorvido. Portanto, a interação $\pi$ está presente em todos os adsorbatos, mas para o $p$-xileno, isso domina 
o processo de adsorção e os hidrogênios do grupo metil apresentam a segunda maior influência.

(a)

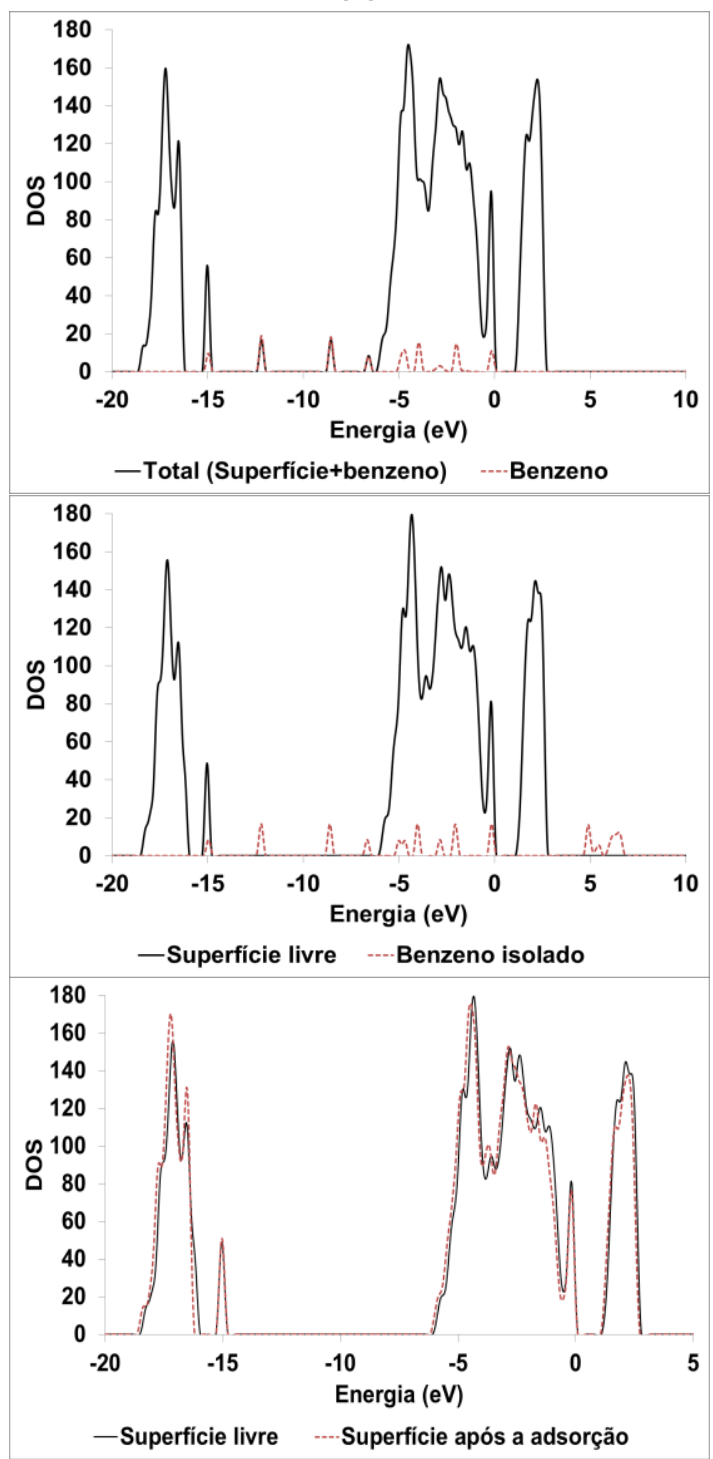

(b)
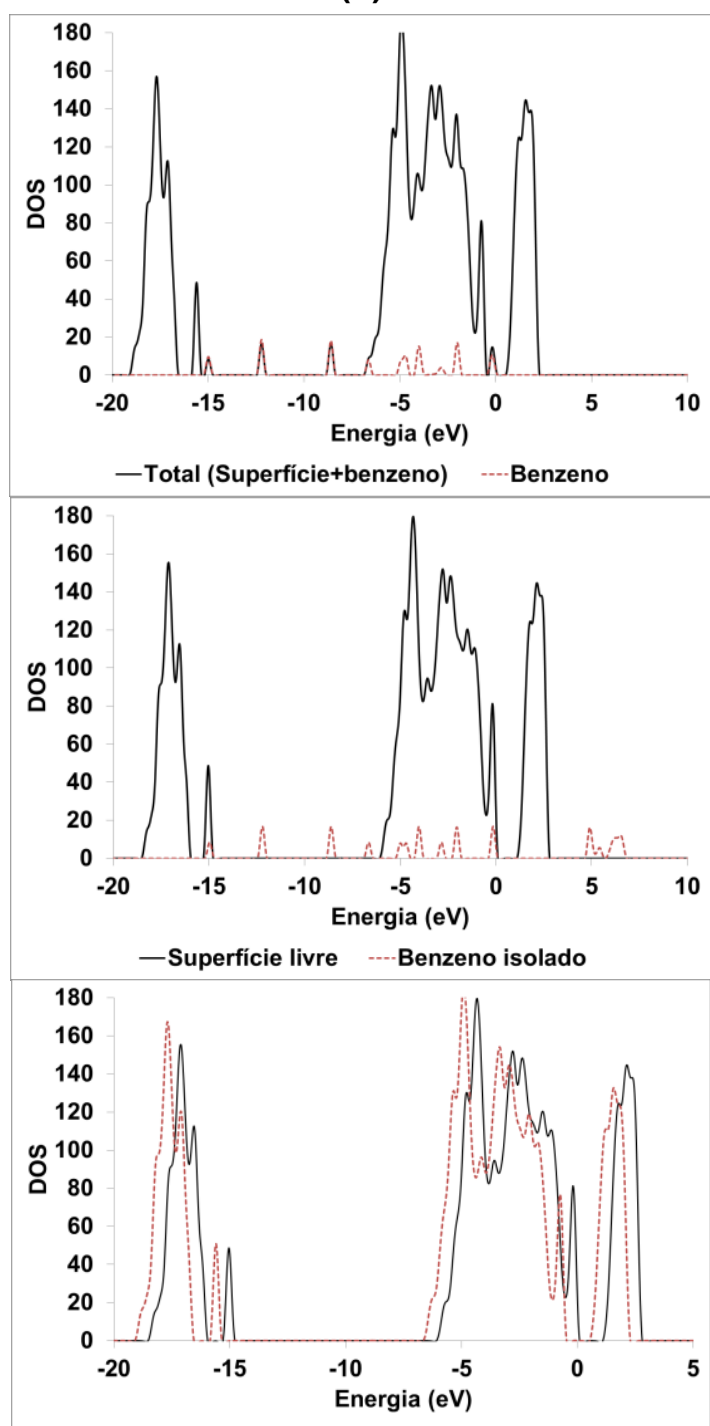

-Superfície livre ----Superfície após a adsorção

Figura 17. Densidade de estados total e projetada para a adsorção da molécula de benzeno na superfície (110) do $\mathrm{TiO}_{2}$ rutilo: (a) Benzeno- ${ }_{3 c}$-rutilo e (b) Benzeno- $\mathrm{Ti}_{5 \mathrm{C}}$-rutilo. Na parte inferior: DOS total da superfície livre e projetado sobre a superfície após a adsorção. No meio: DOS total da superfície livre e do benzeno isolado. Na parte superior: DOS total dos complexos benzeno- $\mathrm{O}_{3 \mathrm{C}}$-rutilo e benzeno- $\mathrm{Ti}_{5 \mathrm{C}}$-rutilo e projetado sobre a molécula de benzeno do complexo. A energia de Fermi está definida para zero.

Pode ser observado nas curvas da Figura 17 (a) e (b), que a interação com a superfície muda a banda de valência do benzeno, de regiões de maior energia, para um pouco abaixo da borda da banda de valência dos complexos BTEX-TiO 2 -rutilo. Essa característica sugere uma estabilização da molécula de benzeno após a adsorção e reflete as propriedades do benzeno, no qual, a sobreposição entre 
estados de buraco da superfície (que podem ser ocasionados pela foto-oxidação) são preenchidos pelos adsorbatos. A adsorção do benzeno (e das outras moléculas de BTEX) mostra uma contribuição líquida de carga para a superfície, criando doadores na banda de valência. Eventualmente, os elétrons injetados na banda de valência combinam com os buracos, reduzindo assim o número de portadores de carga e aumentando a resistência da superfície. A energia de adsorção das moléculas de BTEX na superfície (110) caracteriza uma interação relativamente fraca. Consequentemente, diminuindo-se a concentração de BTEX na atmosfera, inverte-se esse processo, diminuindo o número de estados doadores criados pelas moléculas de benzeno (e BTEX) adsorvidos na superfície.

Todas as densidades de estados apresentadas na Figura 17 foram obtidas usando-se o funcional PW91. As densidades de estados para as adsorções do benzeno, tolueno, etilbenzeno e xilenos, nas duas configurações, usando os funcionais PW91 e PBE, apresentaram resultados que também sugerem uma estabilização do sistema após a adsorção.

A adsorção da molécula de benzeno possui um pequeno efeito sobre a densidade de estados projetada (PDOS) d do titânio da superfície e p da molécula de benzeno. Na Figura 18 (a) e (b) pode ser visualizada a densidade de estados projetada d dos átomos de titânio para a primeira camada da superfície (110) do $\mathrm{TiO}_{2}$ rutilo livre e com o benzeno adsorvido ((a) Benzeno-O ${ }_{3 \mathrm{c}}$-rutilo e (b) BenzenoTi $_{5 c}$-rutilo), no qual, os PDOS são semelhantes. Observou-se apenas uma translação dessas bandas para regiões de menor energia em relação à molécula e superfície livre, assim como ocorreu para o DOS total. O DOS projetado da Figura 18 foi obtido com os resultados usando o funcional PW91.

A densidade de estados projetada $p$ do benzeno sugere um decréscimo de estados de alta energia para o benzeno adsorvido, esses estados são redistribuídos na região de estados d do titânio da superfície, sugerindo uma fraca hibridização entre estados $d$ do $\mathrm{Ti}_{5 \mathrm{c}}$ e estados $\mathrm{p}$ do benzeno, em concordância com os resultados da CDD, que mostraram um aumento de carga na região entre a molécula de benzeno e o $\mathrm{Ti}_{5 \mathrm{c}}$. Isso ocorreu devido a interação dos orbitais $\mathrm{p}_{\mathrm{z}}$ do carbono com os orbitais $d_{z}^{2}$ do titânio pentacoordenado. A mesma tendência foi encontrada para as outras moléculas de BTEX e para os demais funcionais usados. 
(a)

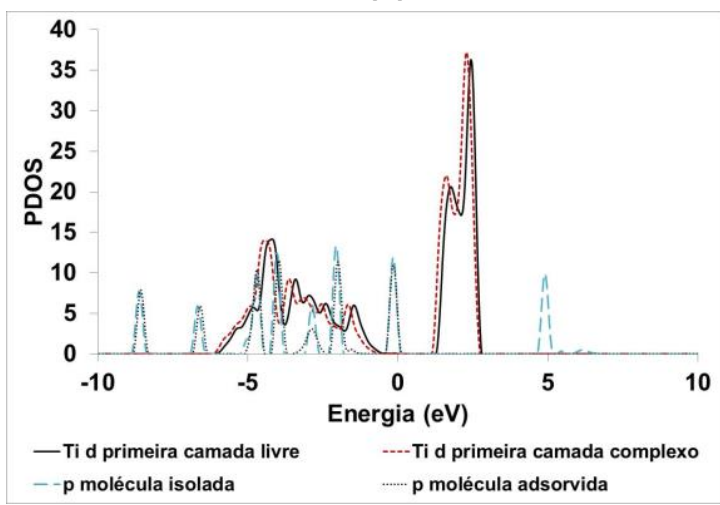

(b)

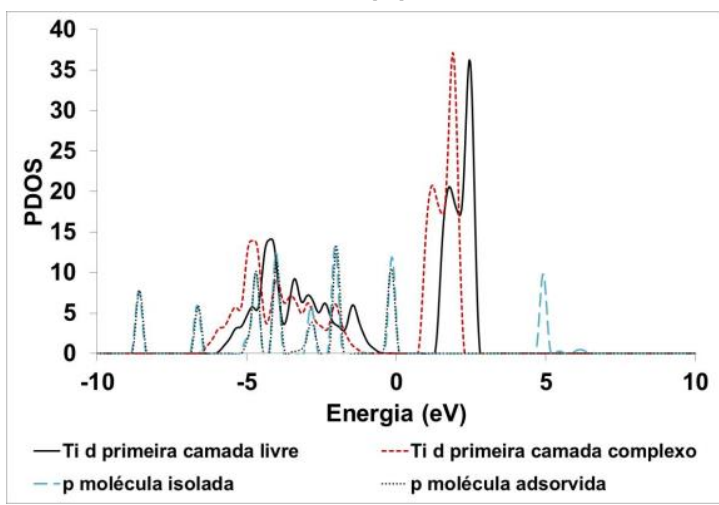

Figura 18. PDOS calculado para os estados d dos titânios da primeira camada da superfície (110) do $\mathrm{TiO}_{2}$ rutilo livre e após a adsorção do benzeno. PDOS para os estados $\mathrm{p}$ do benzeno isolado e adsorvido sobre a superfície (110) do $\mathrm{TiO}_{2}$ rutilo. (a) Benzeno-O $\mathrm{O}_{3 \mathrm{C}}$-rutilo; (b) Benzeno-Ti ${ }_{5 c}$-rutilo. A energia de Fermi está definida para zero.

Reiss e colaboradores ${ }^{86}$ estudaram a adsorção do benzeno na superfície (110) do $\mathrm{TiO}_{2}$ rutilo através de espectroscopia de fotoelétrons excitados por raios- $\mathrm{X}$ (X-ray Photoelectron Spectroscopy - XPS). Através dessa análise, foram obtidas as energias de ligação dos níveis do caroço C1s e Ti2p. Na Tabela 13 podem ser visualizadas as energias de ligação dos níveis C1s e Ti2p obtidas na literatura ${ }^{86}$ e através dos cálculos realizados neste trabalho usando os funcionais PW91, PBE e PBE-D2. A razão $\mathrm{C} 1 \mathrm{~s} / \mathrm{Ti2p}$ obtida nos cálculos teóricos para cada um dos funcionais foi igual a 0,60 , em concordância com o valor experimental de $0,62^{86}$.

Tabela 13. Energias de ligação dos níveis do caroço C1s Ti2p.

\begin{tabular}{|c|c|c|c|c|}
\hline \multirow{2}{*}{ Energias de ligação (eV) } & \multicolumn{4}{|c|}{ BTEX-O ${ }_{3 \mathrm{C}}$-rutilo } \\
\hline & PW91 & PBE & PBE-D2 & Experimenta \\
\hline C1s & 266,7 & 266,1 & 266,1 & 284,5 \\
\hline Ti2p & 444,4 & 444,2 & 444,2 & 458,8 \\
\hline Razão C1s/Ti2p & 0,60 & 0,60 & 0,60 & 0,62 \\
\hline \multirow{2}{*}{ Energias de ligação (eV) } & \multicolumn{4}{|c|}{ BTEX-Ti ${ }_{5 c}$-rutilo } \\
\hline & PW91 & PBE & PBE-D2 & Experimenta \\
\hline C1s & 266,4 & 266,2 & 266,1 & 284,5 \\
\hline Ti2p & 444,4 & 444,2 & 444,1 & 458,8 \\
\hline Razão C1s/Ti2p & 0,60 & 0,60 & 0,60 & 0,62 \\
\hline
\end{tabular}

\subsection{2 - Efeito da Concentração}

Na superfície (3x2) do $\mathrm{TiO}_{2}$ rutilo existem dois sítios para a adsorção das moléculas de BTEX. Para coberturas próximas a uma monocamada, as moléculas 
de BTEX devem preencher completamente os vales formados entre os átomos de oxigênio bicoordenados $\left(\mathrm{O}_{2} \mathrm{C}\right)$, formando uma cadeia de moléculas de BTEX paralelas ao substrato. Na Figura 19, podem ser visualizadas as estruturas otimizadas usando o funcional PW91, no qual, as duas moléculas de BTEX foram construídas paralelas à superfície, e com as duas ligações $C C$ do anel benzênico centradas em uma configuração em ponte sobre os átomos de oxigênio tricoordenados (BTEX- $\mathrm{O}_{3 \mathrm{C}}-\mathrm{O}_{3 \mathrm{C}}$-rutilo).

$\mathrm{Na}$ cobertura próxima a uma monocamada, os pressupostos geométricos podem ser utilizados como indício das possíveis configurações das moléculas de BTEX na superfície (110) do $\mathrm{TiO}_{2}$ rutilo. Além das conformações em que as moléculas de BTEX estão paralelas à superfície, com as duas ligações CC do anel benzênico centradas em uma configuração em ponte sobre os átomos de oxigênio tricoordenados (BTEX-O ${ }_{3 \mathrm{C}}-\mathrm{O}_{3 \mathrm{C}}$-rutilo), foram otimizados os complexos BTEXsuperfícies que alternam entre a configuração em ponte sobre os átomos de oxigênio tricoordenados $\left(\mathrm{O}_{3 \mathrm{C}}\right)$ e, sobre os átomos de titânio pentacoordenados, $\mathrm{Ti}_{5 \mathrm{C}}$ (BTEX- ${ }_{3 c}-$ Ti $_{5 c}$-rutilo). Essas duas configurações tem o objetivo de minimizar a interação repulsiva entre os adsorbatos vizinhos. A configuração com as duas moléculas de BTEX paralelas à superfície e as duas ligações $C C$ em ponte sobre os átomos de titânio pentacoordenados não foi utilizada, esta geometria apresenta uma maior proximidade entre as moléculas de BTEX e, consequentemente, uma maior repulsão entre os adsorbatos vizinhos. 
(a)

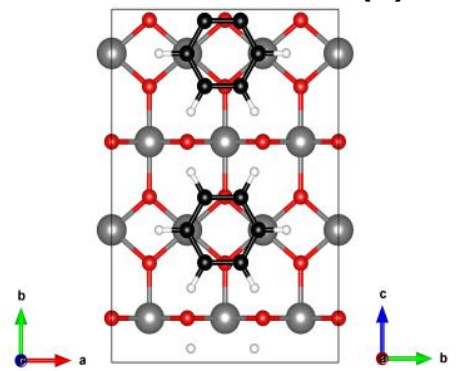

(c)
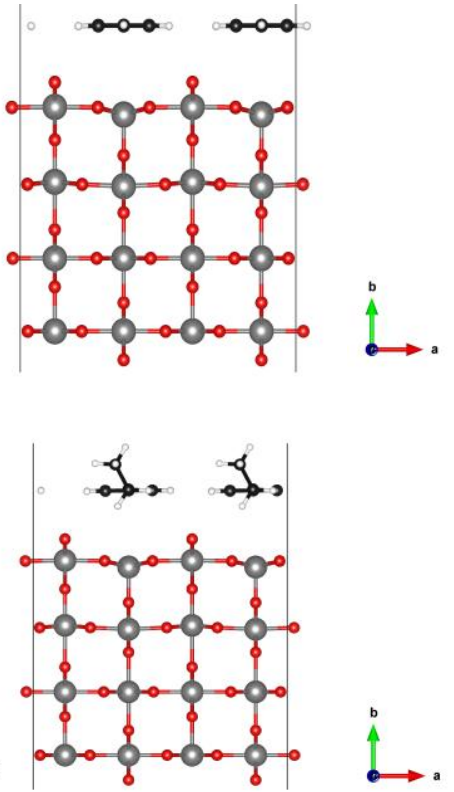

(e)

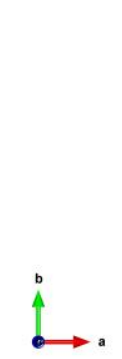

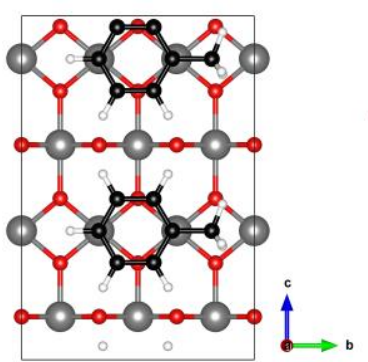

(d)
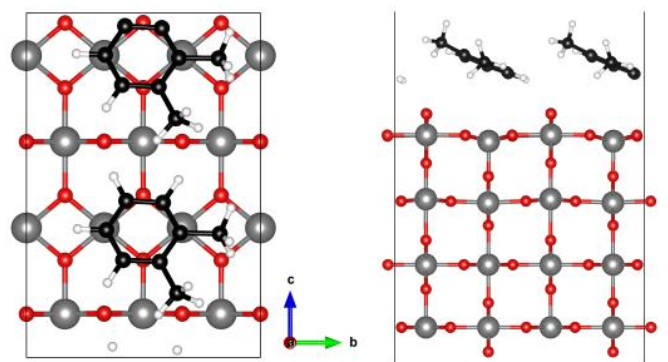

(f)
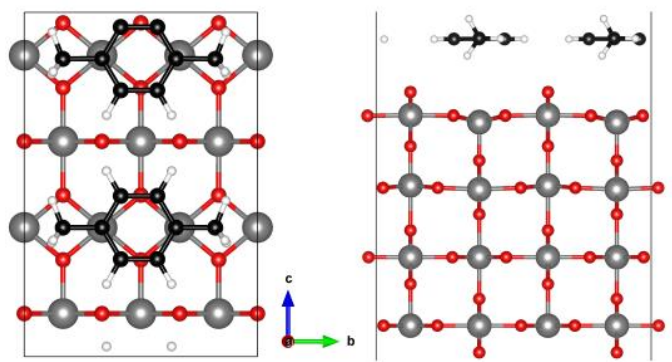

Figura 19. Estruturas otimizadas usando o funcional PW91 da interação das moléculas de BTEX nos dois sítios da superfície (110) do $\mathrm{TiO}_{2}$ rutilo: (a) benzeno- $\mathrm{O}_{3 \mathrm{c}}-\mathrm{O}_{3 \mathrm{c}}$-rutilo; (b) tolueno- $\mathrm{O}_{3 \mathrm{C}}-\mathrm{O}_{3 \mathrm{c}}$-rutilo; (c) etilbenzeno- $\mathrm{O}_{3 \mathrm{c}}-\mathrm{O}_{3 \mathrm{c}}$-rutilo; (d) o-xileno- $\mathrm{O}_{3 \mathrm{c}}-\mathrm{O}_{3 \mathrm{c}}$-rutilo; (e) m-xileno- $\mathrm{O}_{3 \mathrm{c}}-\mathrm{O}_{3 \mathrm{c}}$-rutilo e (f) p-xileno- $\mathrm{O}_{3 \mathrm{C}^{-}}$ $\mathrm{O}_{3 \mathrm{C}}$-rutilo.

$\mathrm{Na}$ Figura 20 podem ser visualizadas as estruturas otimizadas dos complexos BTEX-O $\mathrm{O}_{3 \mathrm{C}}-\mathrm{Ti}_{5 \mathrm{c}}$-rutilo usando o funcional PW91. As geometrias otimizadas para os complexos BTEX-O ${ }_{3 c}-\mathrm{O}_{3 c}$-rutilo e BTEX-O ${ }_{3 \mathrm{C}}-\mathrm{Ti}_{5 \mathrm{C}}$-rutilo usando o funcional PBE apresentaram as posições das moléculas de BTEX similares, com diferenças nas distâncias das moléculas em relação à superfície e nos ângulos de inclinação. 
(a)

(b)

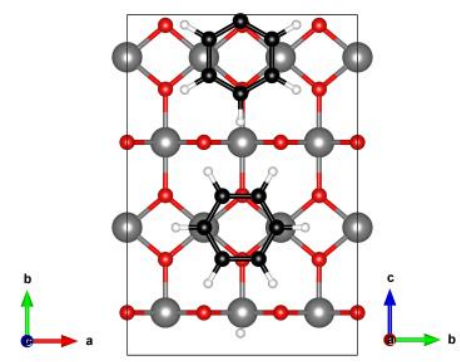

(c)

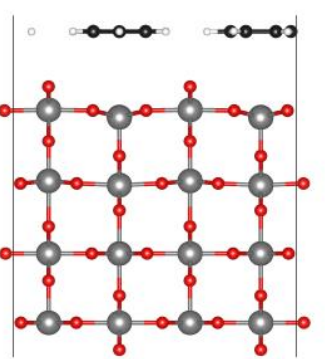

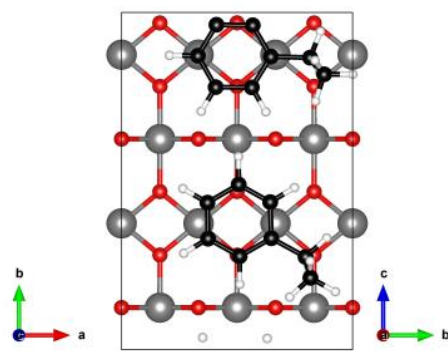

(e)
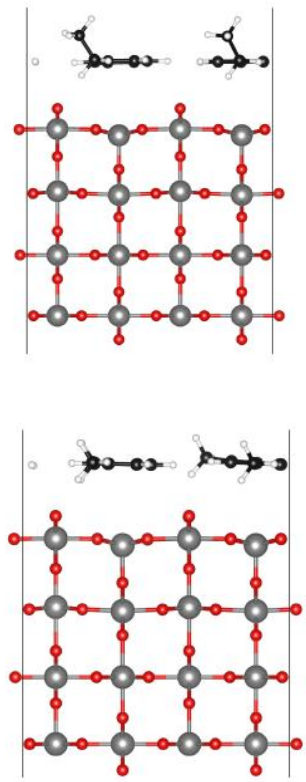
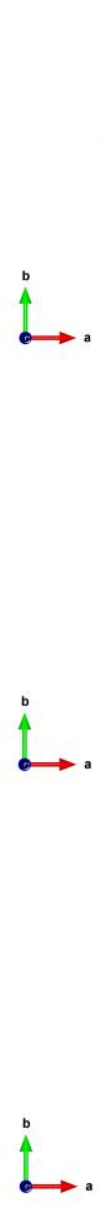
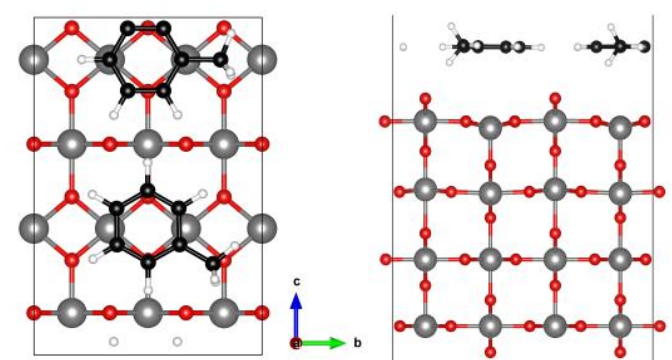

(d)
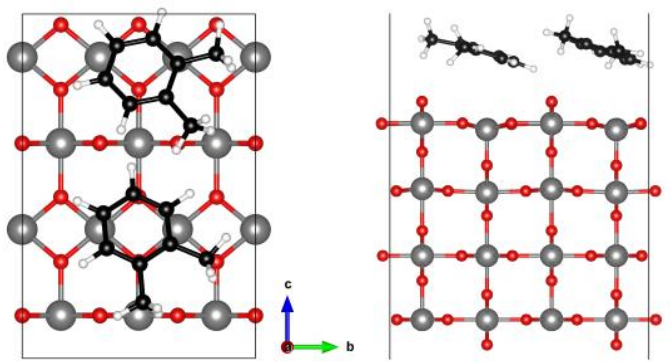

(f)

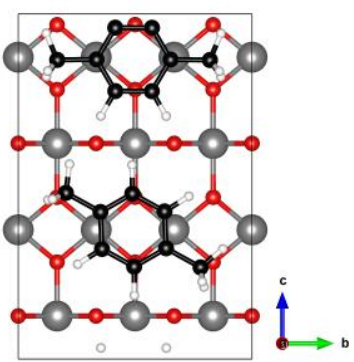

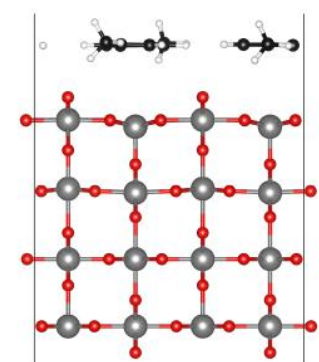

Figura 20. Estruturas otimizadas usando o funcional PW91 da interação das moléculas de BTEX nos dois sítios da superfície (110) do $\mathrm{TiO}_{2}$ rutilo: (a) benzeno- $\mathrm{O}_{3 \mathrm{C}}-\mathrm{Ti}_{5 \mathrm{C}}$-rutilo; (b) tolueno- $\mathrm{O}_{3 \mathrm{C}}-\mathrm{Ti}_{5 \mathrm{C}}$-rutilo; (c) etilbenzeno- $\mathrm{O}_{3 c^{-}}-\mathrm{Ti}_{5 \mathrm{c}}$-rutilo; (d) o-xileno- $\mathrm{O}_{3 \mathrm{c}}-\mathrm{Ti}_{5 \mathrm{c}}$-rutilo; (e) m-xileno- $\mathrm{O}_{3 \mathrm{c}}-\mathrm{Ti}_{5 \mathrm{c}}$-rutilo e (f) p-xileno- $\mathrm{O}_{3 \mathrm{C}^{-}}$ $\mathrm{Ti}_{5 \mathrm{C}}$-rutilo.

A menor distância entre os átomos de carbono das moléculas dos adsorbatos (BTEX) e os átomos de titânio pentacoordenados $\left(\mathrm{Ti}_{5 \mathrm{C}}\right)$ são apresentadas na Tabela 14. Para o complexo BTEX-O ${ }_{3 \mathrm{C}}-\mathrm{O}_{3 \mathrm{C}}$-rutilo, a variação das distâncias entre as duas moléculas de BTEX adsorvidas ficaram entre 0,00 e 0,03 $\AA$. Essa pequena variação ocorreu porque os adsorbatos apresentam a mesma configuração. As duas moléculas de BTEX adsorvidas no complexo BTEX- $\mathrm{O}_{3 C^{-}}-\mathrm{Ti}_{5 C^{-}}$ rutilo apresentam configurações diferentes, na Tabela 14, as duas distâncias são representadas pela posição $\mathrm{O}_{3 \mathrm{C}}$ para as moléculas de BTEX que estão em ponte sobre os átomos de oxigênio tricoordenados e por $\mathrm{Ti}_{5 \mathrm{C}}$, quando os adsorbatos estão em ponte sobre os átomos de titânio pentacoordenados. As distâncias entre os dois adsorbatos e a superfície para o complexo BTEX-O ${ }_{3 C}-\mathrm{Ti}_{5 \mathrm{C}}$-rutilo variou de 0,00 a $0,23 \AA$ A. As distâncias $\mathrm{BTEX}-\mathrm{TiO}_{2}$ calculadas mostram uma variação em relação aos funcionais utilizados, com valores de 0,00-0,51 Å para o BTEX-O ${ }_{3 \mathrm{C}}-\mathrm{O}_{3 \mathrm{C}}$-rutilo e de 
0,02-0,65 Å para o BTEX-O $\mathrm{O}_{3 \mathrm{C}}-\mathrm{Ti}_{5 \mathrm{C}}$-rutilo. As maiores diferenças foram encontradas em relação ao funcional PW91 e o PBE-D2 para os complexos o-xileno- $\mathrm{O}_{3 \mathrm{C}^{-}} \mathrm{O}_{3 \mathrm{C}^{-}}$ rutilo e o-xileno- $\mathrm{O}_{3 \mathrm{C}}-\mathrm{Ti}_{5 \mathrm{C}}$-rutilo.

Tabela 14. Distância adsorbato-superfície $(\AA ̊)$ entre as moléculas de BTEX e os átomos de titânio pentacoordenados $\left(\mathrm{Ti}_{5 \mathrm{C}}\right)$ : $\mathrm{BTEX}-\mathrm{O}_{3 \mathrm{C}}-\mathrm{O}_{3 \mathrm{C}}$-rutilo e BTEX- $\mathrm{O}_{3 \mathrm{C}}-\mathrm{Ti}_{5 \mathrm{C}}$-rutilo, usando os funcionais PW91, PBE e PBE-D2.

\begin{tabular}{|c|c|c|c|c|c|c|c|}
\hline 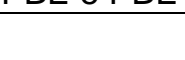 & & & & $\mathrm{x}-\mathrm{O}_{3 \mathrm{C}}-\mathrm{O}_{3 \mathrm{C}}-\mathrm{ru}$ & & & \\
\hline Funci & nal & Benzeno & Tolueno & Etilbenzeno & o-xileno & m-xileno & p-xileno \\
\hline PW & & 3,98 & 3,97 & 3,93 & 3,53 & 3,68 & 3,97 \\
\hline & & 3,98 & 3,98 & 3,94 & 3,51 & 3,65 & 3,97 \\
\hline $\mathrm{PB}$ & & 3,95 & 3,75 & 3,78 & 3,37 & 3,45 & 3,93 \\
\hline & & 3,95 & 3,75 & 3,78 & 3,37 & 3,45 & 3,92 \\
\hline PBE. & & 3,96 & 3,61 & 3,74 & 3,02 & 3,24 & 3,93 \\
\hline & & 3,96 & 3,61 & 3,75 & 3,03 & 3,25 & 3,94 \\
\hline & & & & $\mathrm{X}-\mathrm{O}_{3 \mathrm{C}}-\mathrm{Ti} \mathrm{i}_{5 \mathrm{c}}-\mathrm{ru}$ & & & \\
\hline Funcional & Posição & Benzeno & Tolueno & Etilbenzeno & o-xileno & m-xileno & p-xileno \\
\hline PW91 & $\mathrm{O}_{3 \mathrm{C}}$ & 4,05 & 3,96 & 3,94 & 3,60 & 3,95 & 3,96 \\
\hline & $\mathrm{Ti}_{5 \mathrm{C}}$ & 4,06 & 3,96 & 3,91 & 3,46 & 3,94 & 3,95 \\
\hline PRF & $\mathrm{O}_{3 \mathrm{C}}$ & 3,99 & 3,89 & 3,58 & 3,20 & 3,57 & 3,65 \\
\hline & $\mathrm{Ti}_{5 \mathrm{C}}$ & 3,98 & 3,87 & 3,45 & 3,40 & 3,34 & 3,62 \\
\hline & $\mathrm{O}_{3 \mathrm{C}}$ & 4,02 & 3,93 & 3,55 & 2,95 & 3,55 & 3,63 \\
\hline PBE-U2 & $\mathrm{Ti}_{5 \mathrm{C}}$ & 4,02 & 3,91 & 3,42 & 3,17 & 3,34 & 3,60 \\
\hline
\end{tabular}

As distâncias entre os átomos de carbono e a superfície para complexos com uma maior cobertura (BTEX- $\mathrm{O}_{3 \mathrm{C}}-\mathrm{O}_{3 \mathrm{C}}$-rutilo e BTEX-O $\mathrm{O}_{3 \mathrm{C}}-\mathrm{Ti}_{5 \mathrm{C}}$-rutilo) apresentaram variações em relação àqueles com uma menor concentração: 1) Usando o funcional PW91, as distâncias foram diminuídas para os complexos oxileno- $\mathrm{O}_{3 \mathrm{c}}-\mathrm{O}_{3 \mathrm{c}}$-rutilo, m-xileno- $\mathrm{O}_{3 \mathrm{c}}-\mathrm{O}_{3 \mathrm{c}}$-rutilo e o-xileno- $\mathrm{O}_{3 \mathrm{c}}-\mathrm{Ti}_{5 \mathrm{c}}$-rutilo. Para os demais complexos usando esse funcional, a distância manteve-se praticamente inalterada; 2) Usando os funcionais PBE e PBE-D2, as moléculas de tolueno, etilbenzeno, o-xileno e m-xileno nas duas configurações $\left(\mathrm{O}_{3 \mathrm{c}}-\mathrm{O}_{3 \mathrm{c}}\right.$-rutilo e $\mathrm{O}_{3 \mathrm{C}^{-}} \mathrm{Ti}_{5 \mathrm{C}^{-}}$ rutilo), apresentaram distâncias de interação menores. $\mathrm{O}$ complexo $\mathrm{p}$-xileno- $\mathrm{O}_{3 \mathrm{C}^{-}}$ $\mathrm{O}_{3 c}$-rutilo foi o único que apresentou distâncias maiores, de forma que, para o $\mathrm{p}$ xileno- $\mathrm{O}_{3 \mathrm{C}}-\mathrm{Ti}_{5 \mathrm{c}}$-rutilo as distâncias foram menores. A distância de interação da molécula de benzeno nas duas configurações manteve-se praticamente inalterada.

As maiores variações nas distâncias de interação entre os adsorbatos e a superfície foram acompanhadas de alterações na inclinação das moléculas de BTEX (Tabela 15) em relação aos complexos com menor cobertura. Essas diferenças ocorreram principalmente para as moléculas de orto- e m-xileno, nas quais, foram 
observadas as maiores variações nas distâncias. O aumento no ângulo para os complexos envolvendo o orto- e m-xileno ocorreu devido à proximidade das moléculas e entre o grupo metil e os átomos de oxigênio bicoordenados $\left(\mathrm{O}_{2 \mathrm{C}}\right)$ da superfície (Figuras 19 e 20). Os ângulos dos demais adsorbatos apresentaram variações menores em relação ao complexo de menor cobertura.

Tabela 15. Ângulos entre as moléculas adsorvidas e o plano da superfície (110) do $\mathrm{TiO}_{2}$ rutilo

\begin{tabular}{|c|c|c|c|c|c|c|c|}
\hline & & & & $\mathrm{X}-\mathrm{O}_{3 \mathrm{C}}-\mathrm{O}_{3 \mathrm{C}}-\mathrm{ru}$ & & & \\
\hline Func & & Benzeno & Tolueno & Etilbenzeno & o-xileno & m-xileno & p-xileno \\
\hline PW & & 0,718 & 0,777 & 2,445 & 21,168 & 16,488 & 0,715 \\
\hline & & 0,727 & 0,788 & 2,486 & 21,101 & 16,065 & 0,733 \\
\hline $\mathrm{PE}$ & & 0,646 & 1,671 & 1,786 & 22,177 & 21,949 & 1,111 \\
\hline & & 0,648 & 1,680 & 2,388 & 22,222 & 22,668 & 0,957 \\
\hline PBE & & 0,815 & 2,051 & 1,801 & 22,060 & 19,022 & 0,946 \\
\hline & & 0,821 & 2,066 & 2,312 & 22,489 & 19,281 & 0,874 \\
\hline & & & & $\mathrm{x}-\mathrm{O}_{3 \mathrm{c}}-\mathrm{Ti} \mathrm{i}_{5 \mathrm{c}}-\mathrm{ru}$ & & & \\
\hline Funcional & Posição & Benzeno & Tolueno & Etilbenzeno & o-xileno & m-xileno & p-xileno \\
\hline PW91 & $\mathrm{O}_{3 \mathrm{C}}$ & 0,270 & 0,842 & 1,365 & 18,489 & 4,766 & 0,749 \\
\hline & $\mathrm{Ti}_{5 \mathrm{C}}$ & 0,318 & 1,442 & 2,806 & 16,363 & 1,720 & 2,195 \\
\hline PBE & $\mathrm{O}_{3 \mathrm{C}}$ & 0,341 & 1,078 & 2,603 & 27,520 & 12,464 & 2,258 \\
\hline & $\mathrm{Ti}_{5 \mathrm{C}}$ & 0,384 & 1,902 & 5,662 & 18,075 & 11,346 & 4,483 \\
\hline & $\mathrm{O}_{3 \mathrm{C}}$ & 0,716 & 0,919 & 2,599 & 26,612 & 12,469 & 2,505 \\
\hline Lc & $\mathrm{Ti}_{5 \mathrm{C}}$ & 0,274 & 1,543 & 5,503 & 16,959 & 10,038 & 4,872 \\
\hline
\end{tabular}

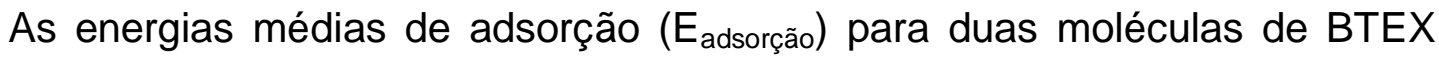
sobre a supercélula (3×2) da superfície (110) do $\mathrm{TiO}_{2}$ rutilo são mostradas na Tabela

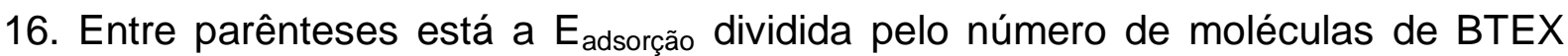
adsorvidas $\left(E_{\text {adsorçãol }}\right.$ ). Os resultados usando o funcional PW91 foram maiores que os obtidos para o PBE, com exceção das adsorções do orto- e meta-xileno. Para estas moléculas, a energia de adsorção $\left(E_{\text {adsorçãol}} / 2\right)$ usando o funcional PBE foi maior que àquela obtida para a adsorção de somente uma molécula. Como discutido anteriormente, essas moléculas apresentaram um ângulo maior em relação à superfície, o que pode ter ocasionado uma interação mais efetiva com os titânios pentacoordenados (energia de adsorção maior usando o funcional PBE-D2), que poderá ser observado nas análises das diferenças de densidade de carga. A correção da energia com a inclusão do termo semiempírico de Grimme para as interações de van der Waals (DFT-D2) ${ }^{135}$ foi realizado nos cálculos PBE-D2//PBE e PBE-D2. Foi demonstrado mais uma vez, que a energia de van der Waals é muito importante para a estabilização dos complexos $\mathrm{BTEX}-\mathrm{TiO}_{2}$ rutilo, contribuindo para 
os resultados da energia de adsorção, porém, com pequeno efeito sobre a geometria.

Tabela 16. Energias de adsorção $(\mathrm{kJ} / \mathrm{mol})$ usando o funcionais PW91, PBE, PBE-D2//PBE e PBE-D2 para os complexos BTEX- $\mathrm{O}_{3 \mathrm{C}}-\mathrm{O}_{3 \mathrm{C}}$-rutilo e $\mathrm{BTEX}-\mathrm{O}_{3 \mathrm{C}}-\mathrm{Ti}_{5 \mathrm{C}}$-rutilo. Entre parênteses está a $\mathrm{E}_{\text {adsorção }}$ dividida pelo número de moléculas de BTEX adsorvidas ( $\left.E_{\text {adsorçãol }} / 2\right)$.

\begin{tabular}{|c|c|c|c|c|}
\hline \multirow{2}{*}{$E_{\text {adsorção }}$} & \multicolumn{4}{|c|}{ BTEX-O ${ }_{3 c}-O_{3 c}$-rutilo } \\
\hline & PW91 & PBE & PBE-D2//PBE & PBE-D2 \\
\hline Benzeno & $29,87(14,94)$ & $27,04(13,52)$ & $101,10(50,55)$ & $107,11(53,56)$ \\
\hline Tolueno & $34,05(17,03)$ & $27,45(13,73)$ & $135,49(67,75)$ & $144,44(72,22)$ \\
\hline Etilbenzeno & $33,69(16,85)$ & $25,84(12,92)$ & $136,35(68,18)$ & $139,06(69,53)$ \\
\hline o-xileno & $34,90(17,45)$ & $44,45(22,23)$ & $148,98(74,49)$ & $184,37(92,19)$ \\
\hline m-xileno & $35,88(17,94)$ & $44,28(22,14)$ & $147,07(73,54)$ & $163,47(81,74)$ \\
\hline p-xileno & $29,82(14,91)$ & $29,15(14,58)$ & $137,03(68,52)$ & $135,00(67,50)$ \\
\hline \multirow{2}{*}{$E_{\text {adsorção }}$} & \multicolumn{4}{|c|}{ BTEX-O ${ }_{3 c}-\mathrm{Ti}_{5 \mathrm{C}}$-rutilo } \\
\hline & PW91 & PBE & PBE-D2/PBE & PBE-D2 \\
\hline Benzeno & $36,80(18,40)$ & $28,44(14,22)$ & $100,13(50,07)$ & $104,60(52,30)$ \\
\hline Tolueno & $34,14(17,07)$ & $31,83(15,92)$ & $121,37(60,69)$ & $124,59(62,30)$ \\
\hline Etilbenzeno & $34,77(17,39)$ & $20,94(10,47)$ & $150,35(75,18)$ & $151,31(75,66)$ \\
\hline o-xileno & $37,81(18,91)$ & $42,47(21,24)$ & $158,58(79,29)$ & $184,36(92,18)$ \\
\hline m-xileno & $24,95(12,48)$ & $24,96(12,48)$ & $152,64(76,32)$ & $153,97(76,99)$ \\
\hline p-xileno & $30,39(15,20)$ & $26,28(13,14)$ & $159,38(79,69)$ & $161,80(80,90)$ \\
\hline
\end{tabular}

As diferenças de densidade de carga para os complexos BTEX-O $\mathrm{O}_{3 C^{-}}-\mathrm{O}_{3 C^{-}}$ rutilo e BTEX-O $\mathrm{O}_{3 \mathrm{C}}-\mathrm{Ti}_{5 \mathrm{C}}$-rutilo estão representadas na Figura 21. Apenas os resultados dos cálculos $\mathrm{PBE}-\mathrm{D} 2 / / \mathrm{PBE}$ são mostrados. Os resultados usando os demais funcionais apresentaram o mesmo comportamento, diferindo apenas na intensidade da distribuição de carga, mas mantendo as mesmas regiões onde as cargas foram distribuídas após a adsorção. O cálculo da CDD foi feito usando a equação 14. A densidade eletrônica apresentou um aumento na região entre as moléculas de BTEX e a superfície (região azul), sugerindo uma interação aromática $\pi$. Esse aumento de densidade é mais evidente nos complexos etilbenzeno- $\mathrm{O}_{3 \mathrm{C}^{-}}$ $\mathrm{Ti}_{5 \mathrm{c}}$-rutilo, o-xileno- $\mathrm{O}_{3 \mathrm{c}}-\mathrm{Ti}_{5 \mathrm{c}}$-rutilo, m-xileno- $\mathrm{O}_{3 \mathrm{c}}-\mathrm{Ti}_{5 \mathrm{c}}$-rutilo e p-xileno- $\mathrm{O}_{3 \mathrm{C}}-\mathrm{Ti}_{5 \mathrm{c}}$-rutilo.

A interação das moléculas de BTEX e a superfície do $\mathrm{TiO}_{2}$ rutilo mostrou um decréscimo de carga nas vizinhanças dos átomos de hidrogênio, e um aumento da densidade eletrônica sobre os $\mathrm{O}_{2 \mathrm{C}}$, indicando uma interação entre esses átomos. Essa interação tornou-se mais evidente com o aumento da concentração. 
(a)

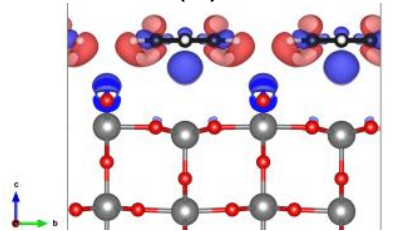

(c)

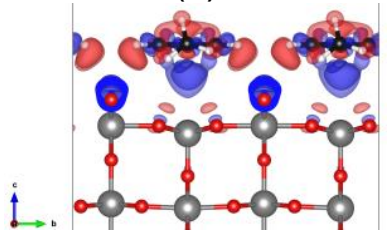

(e)

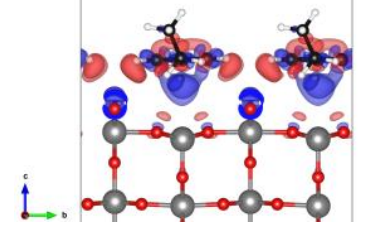

(g)

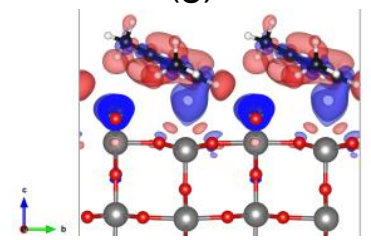

(i)

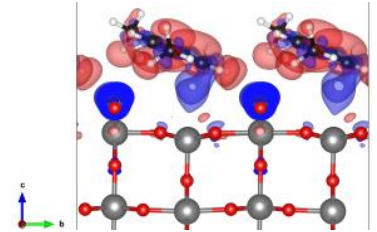

(I)

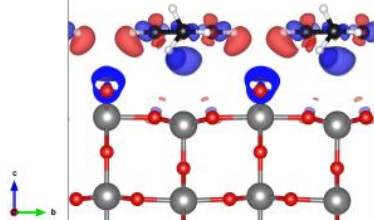

(b)

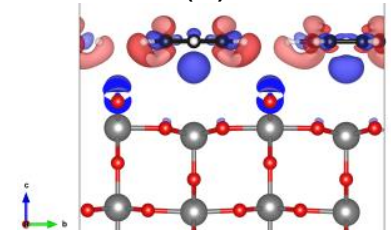

(d)

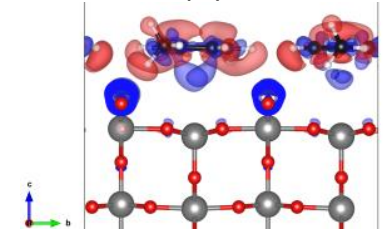

(f)

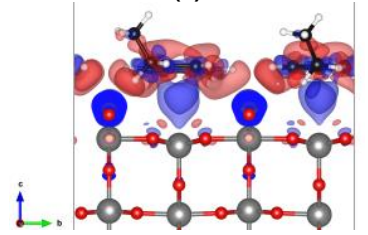

(h)

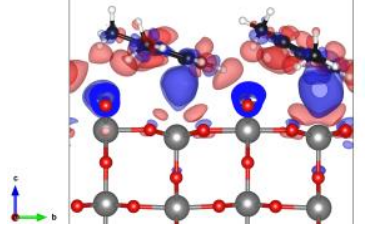

(j)

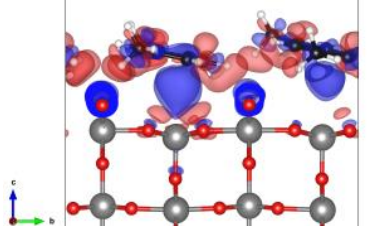

(m)

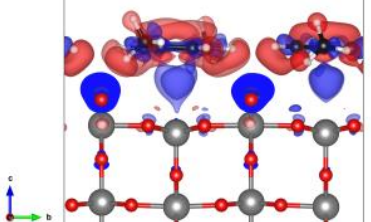

Figura 21. Diferença de densidade de carga (CDD) do (a) Benzeno- $\mathrm{O}_{3 \mathrm{C}^{-}} \mathrm{O}_{3 \mathrm{C}}$-rutilo; (b) Benzeno- $\mathrm{O}_{3 C^{-}}$ $\mathrm{Ti}_{5 \mathrm{C}}$-rutilo; (c) Tolueno- $\mathrm{O}_{3 \mathrm{C}}-\mathrm{O}_{3 \mathrm{C}}$-rutilo; (d) Tolueno- $\mathrm{O}_{3 \mathrm{C}}-\mathrm{Ti}_{5 \mathrm{C}}$-rutilo; (e) Etilbenzeno- $\mathrm{O}_{3 \mathrm{C}}-\mathrm{O}_{3 \mathrm{C}}$-rutilo; (f) Etilbenzeno- $\mathrm{O}_{3 \mathrm{C}}-\mathrm{Ti}_{5 \mathrm{c}}$-rutilo; (f) o-Xileno- $\mathrm{O}_{3 \mathrm{c}}-\mathrm{O}_{3 \mathrm{c}}$-rutilo; (g) o-Xileno- ${ }_{3 \mathrm{C}}-\mathrm{Ti}_{5 \mathrm{c}}$-rutilo; (h) m-Xileno- $\mathrm{O}_{3 \mathrm{c}^{-}}$ $\mathrm{O}_{3 c}$-rutilo; (i) m-Xileno- $\mathrm{O}_{3 \mathrm{c}}-\mathrm{Ti}_{5 \mathrm{c}}$-rutilo; (I) $\mathrm{p}$-Xileno- $\mathrm{O}_{3 \mathrm{c}}-\mathrm{O}_{3 \mathrm{c}}$-rutilo; (m) $\mathrm{p}$-Xileno- $\mathrm{O}_{3 \mathrm{c}}-\mathrm{Ti}_{5 \mathrm{c}}$-rutilo. A cor vermelha é para valores negativos (decréscimo de densidade eletrônica), e azul para valores positivos (aumento da densidade eletrônica). O valor da isosuperfície é 0,0005 e/bohr ${ }^{3}$.

As cargas de Bader (e) das moléculas de BTEX foram calculadas para as adsorções nas configurações BTEX-O $\mathrm{O}_{3 \mathrm{C}}-\mathrm{O}_{3 \mathrm{C}}$-rutilo e BTEX-O $\mathrm{O}_{3 \mathrm{C}}-\mathrm{Ti}_{5 \mathrm{C}}$-rutilo (Tabela 17). Os valores das cargas foram obtidos usando o funcional PW91. Foi observado que houve uma pequena transferência de carga entre as moléculas de BTEX e a superfície, em concordância com os dados da CDD, que indicaram uma interação na 
região dos elétrons $\pi$. A maior variação de carga ocorreu nas moléculas de benzeno.

Tabela 17. Cargas (e) das moléculas de BTEX após a adsorção usando o modelo de Bader.

\begin{tabular}{c|c|cccccc}
\hline \multicolumn{2}{c}{ Carga de Bader } & \multicolumn{7}{c}{ BTEX-O $_{3 \mathrm{C}}-\mathbf{O}_{3 \mathrm{C}}$-rutilo } \\
\cline { 3 - 8 } \multicolumn{2}{c|}{} & Benzeno & Tolueno & Etilbenzeno & o-xileno & m-xileno & p-xileno \\
\hline \multicolumn{2}{c}{ PW91 } & 0,07 & 0,02 & 0,03 & 0,00 & $-0,03$ & $-0,08$ \\
\hline Carga de & \multirow{2}{*}{ Posição } & 0,08 & 0,02 & 0,02 & $-0,04$ & $-0,02$ & $-0,08$ \\
\cline { 3 - 8 } Bader & & Benzeno & Tolueno & Etilbenzeno & 0-xileno & m-xileno & p-xileno \\
\hline PW91 & $\mathrm{O}_{3 \mathrm{C}}$ & 0,02 & 0,00 & 0,01 & $-0,02$ & $-0,00$ & $-0,07$ \\
& $\mathrm{Ti}_{5 \mathrm{C}}$ & 0,03 & 0,04 & 0,04 & 0,03 & $-0,02$ & $-0,02$ \\
\hline
\end{tabular}

Nas Figuras 22 e 23, podem ser visualizadas as análises da localização dos elétrons através da função de localização eletrônica (Electron localization function ELF) usando o programa VESTA ${ }^{136,137}$. Na Figura 22, tem-se o ELF para as moléculas de BTEX isoladas na geometrias $\mathrm{BTEX}-\mathrm{O}_{3 \mathrm{C}}-\mathrm{O}_{3 \mathrm{C}}$-rutilo e $\mathrm{BTEX}-\mathrm{O}_{3 \mathrm{C}}-\mathrm{Ti}_{5 \mathrm{C}}-$

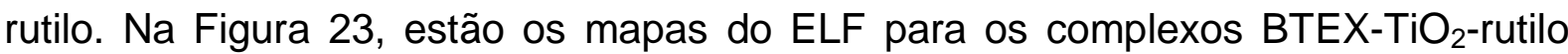
nas configurações BTEX- $\mathrm{O}_{3 \mathrm{C}}-\mathrm{O}_{3 \mathrm{C}}$-rutilo e $\mathrm{BTEX}-\mathrm{O}_{3 \mathrm{C}}-\mathrm{Ti}_{5 \mathrm{C}}$-rutilo. Em ambas, o valor da isosuperfície é 0,80 . Através do ELF pode-se observar que a interação não ocorre somente com a superfície, mas também entre as moléculas adsorvidas, podendo ser notado através da contração da distribuição eletrônica próximo aos átomos de hidrogênio entre os dois adsorbatos isolados (Figura 22).

Através da análise do ELF representada nas Figuras 22 e 23, também podese observar características em concordância com os resultados da diferença de densidade de carga. Em ambos, há uma alteração na densidade eletrônica próximo aos oxigênios bicoordenados $\left(\mathrm{O}_{2} \mathrm{C}\right)$, indicando uma interação entre os hidrogênios das moléculas de BTEX com esses átomos. 
(a)

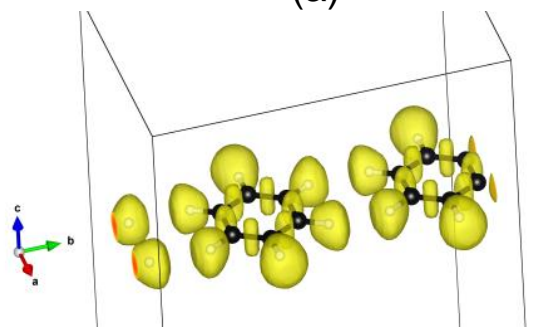

(c)

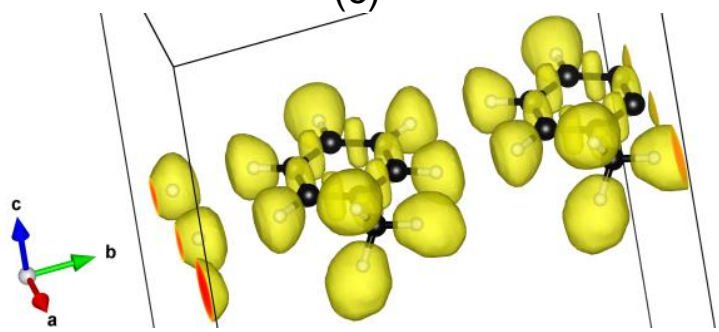

(e)

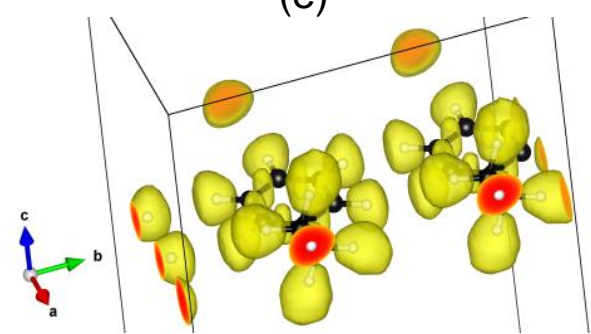

(g)

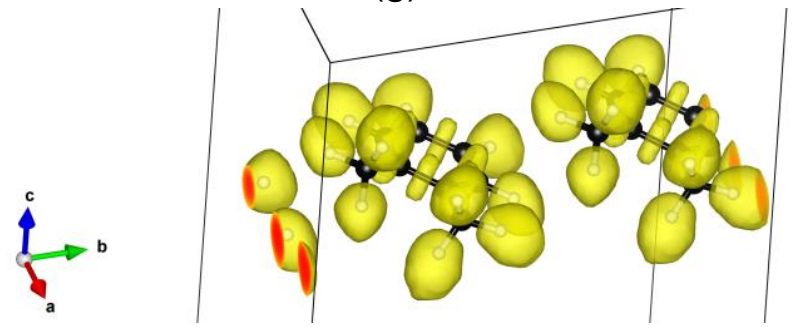

(i)

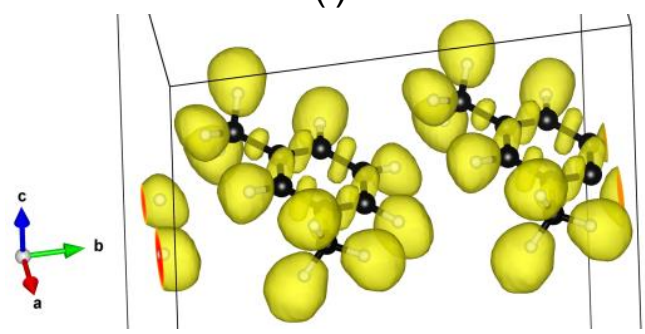

(I)

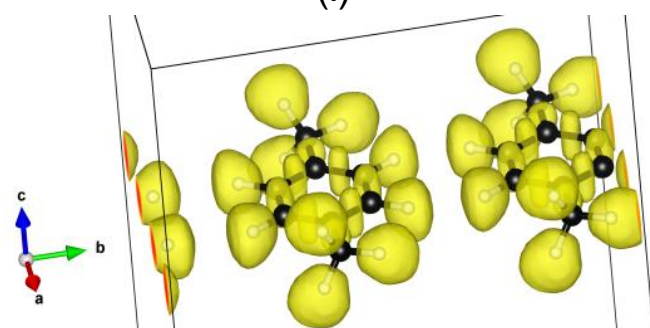

(b)

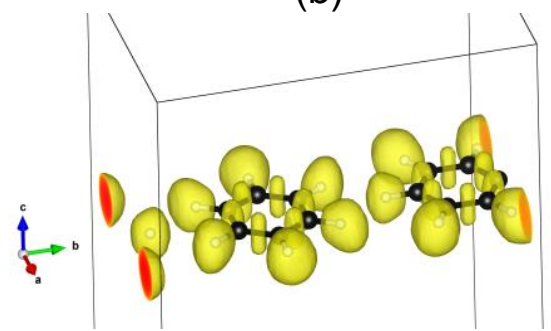

(d)

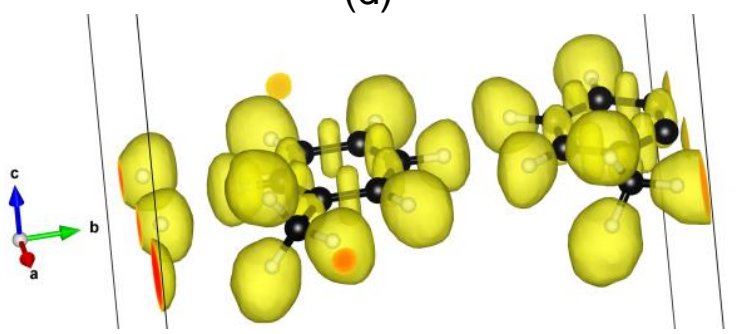

(f)

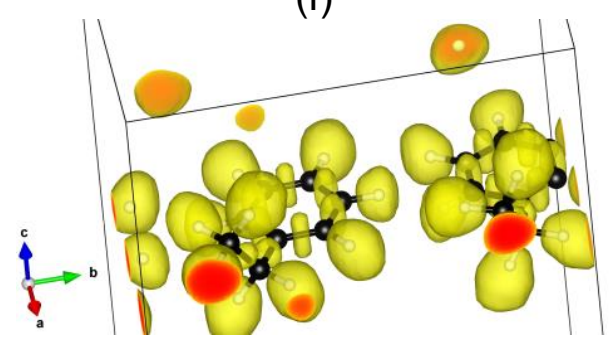

(h)

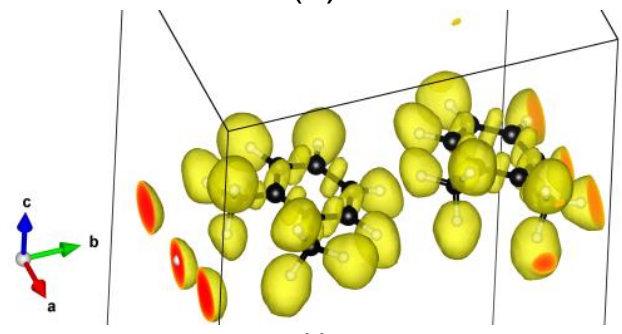

(j)

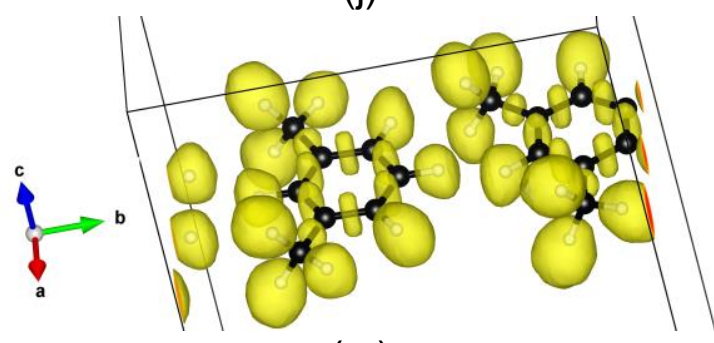

(m)

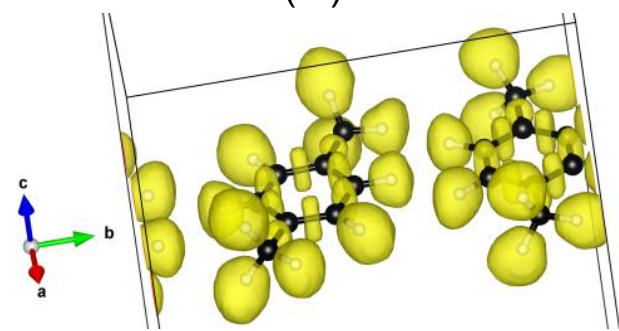

Figura 22. ELF das moléculas de BTEX na geometria otimizada $B T E X-\mathrm{O}_{3 C}-\mathrm{O}_{3 c}$-rutilo e $B T E X-\mathrm{O}_{3 C^{-}}$ Ti ${ }_{5 c}$-rutilo: (a) e (b) benzeno; (c) e (d) tolueno; (d) e (f) etilbenzeno; (g) e (h) o-xileno; (i) e (j) m-xileno; (l) e (m) p-xileno. 
(a)

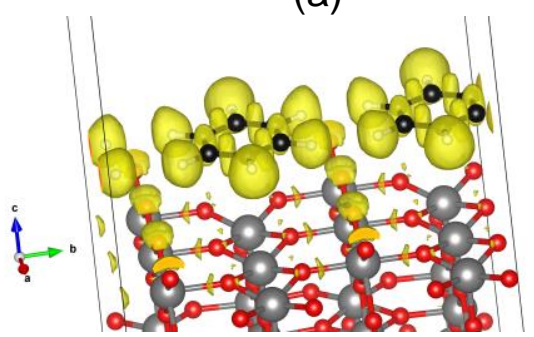

(c)

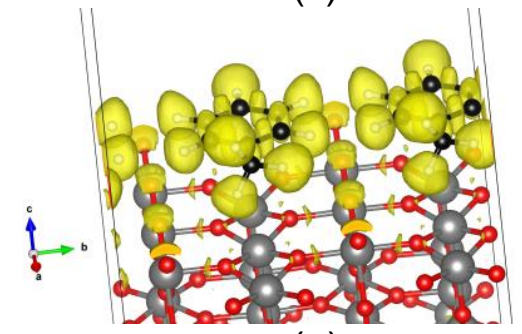

(e)

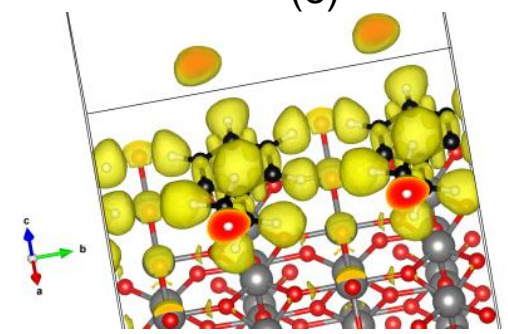

(g)

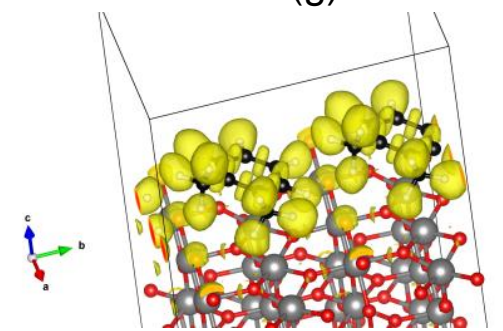

(i)

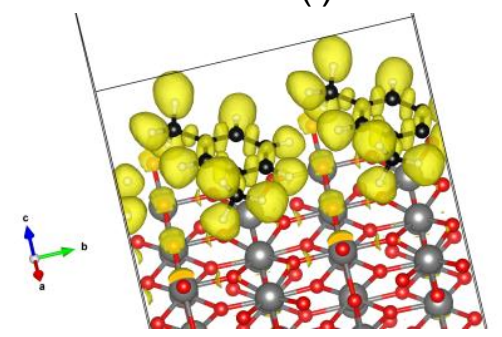

(I)

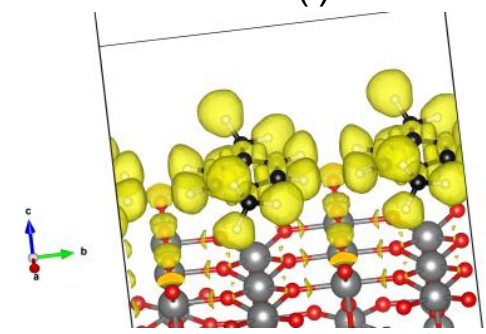

(b)

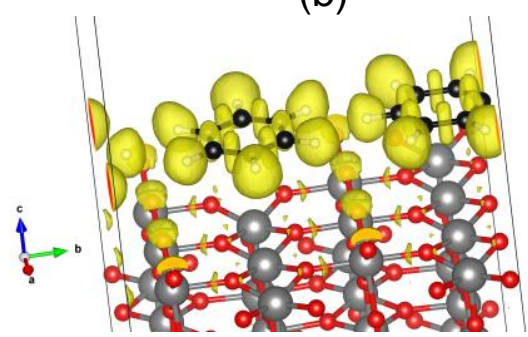

(d)

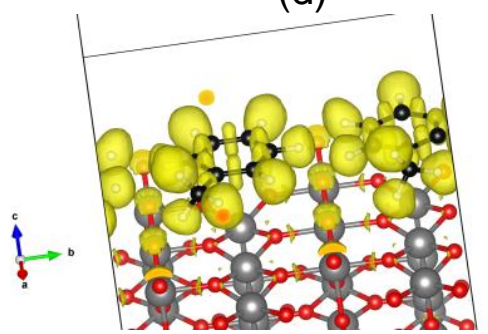

(f)

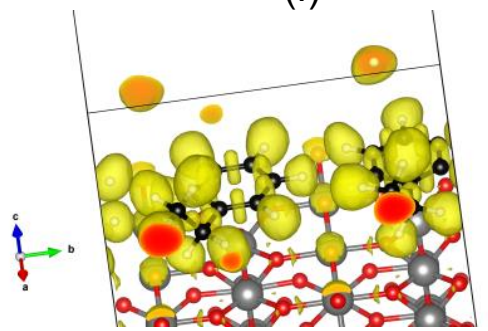

(h)

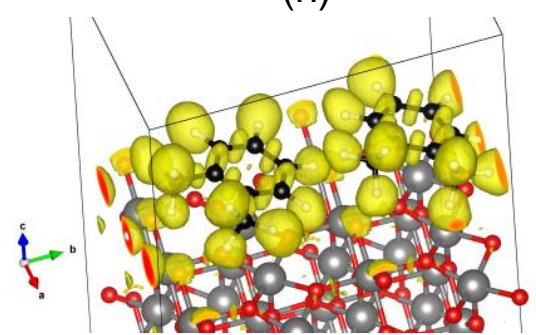

(j)

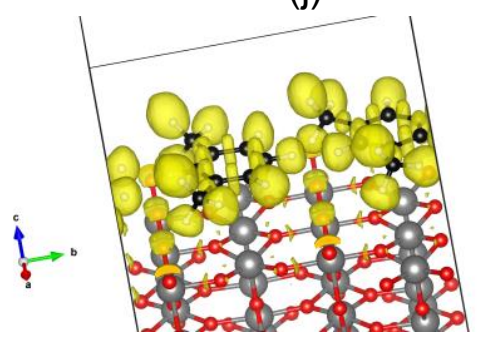

(m)

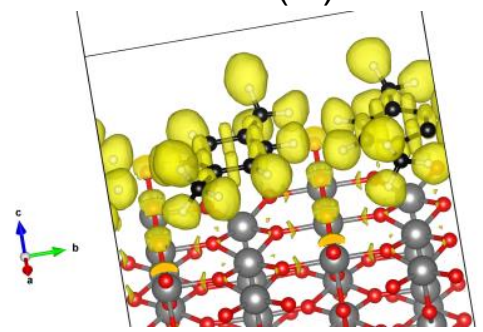

Figura 23. Função de localização eletrônica (ELF) para os complexos (a) Benzeno- $\mathrm{O}_{3 \mathrm{C}}-\mathrm{O}_{3 c}$-rutilo; (b)

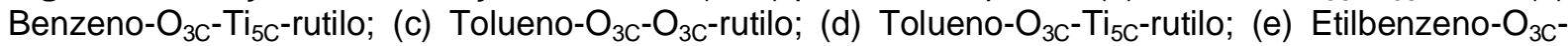
$\mathrm{O}_{3 \mathrm{C}}$-rutilo; (f) Etilbenzeno- $\mathrm{O}_{3 \mathrm{C}}-\mathrm{Ti}_{5 \mathrm{c}}$-rutilo; (f) o-Xileno- $\mathrm{O}_{3 \mathrm{C}}-\mathrm{O}_{3 \mathrm{C}}$-rutilo; (g) o-Xileno- $\mathrm{O}_{3 \mathrm{C}}-\mathrm{Ti}_{5 \mathrm{C}}$-rutilo; (h) mXileno- $\mathrm{O}_{3 \mathrm{c}}-\mathrm{O}_{3 \mathrm{c}}$-rutilo; (i) $\mathrm{m}$-Xileno- $\mathrm{O}_{3 \mathrm{c}}-\mathrm{Ti}_{5 \mathrm{c}}$-rutilo; (I) $\mathrm{p}$-Xileno- $\mathrm{O}_{3 \mathrm{c}}-\mathrm{O}_{3 \mathrm{c}}$-rutilo; (m) p-Xileno- $\mathrm{O}_{3 \mathrm{c}} \mathrm{Ti}_{5 \mathrm{c}}$ rutilo. O valor da isosuperfície é 0,8 . 
A Figura 24 mostra: (a) na parte inferior, a densidade de estados (DOS) total da superfície (110) do $\mathrm{TiO}_{2}$ rutilo livre e após a adsorção na configuração Benzeno$\mathrm{O}_{3 \mathrm{C}}-\mathrm{O}_{3 \mathrm{C}}$-rutilo; no meio, tem-se o DOS total da superfície (110) do $\mathrm{TiO}_{2}$ rutilo livre e do benzeno isolado e, na parte superior, o DOS total do complexo Benzeno- $\mathrm{O}_{3 \mathrm{C}^{-}} \mathrm{O}_{3 \mathrm{C}^{-}}$ rutilo e da molécula de benzeno após a adsorção. As densidades de estados apresentadas em (b) correspondem às mesmas estruturas, porém, quando foi feita a adsorção das moléculas de benzeno alternando a configuração em ponte com os oxigênios bicoordenados e titânios pentacoordenados (Benzeno- $\mathrm{O}_{3 \mathrm{C}}-\mathrm{Ti}_{5 \mathrm{C}}$-rutilo).

Analisando as densidades de estados da parte inferior, para os complexos Benzeno- $\mathrm{O}_{3 \mathrm{C}}-\mathrm{O}_{3 \mathrm{C}}$-rutilo e Benzeno- $\mathrm{O}_{3 \mathrm{C}}-\mathrm{Ti}_{5 \mathrm{C}}$-rutilo, pode-se verificar que o DOS da superfície livre e após a adsorção são similares.

Pode ser observado nas curvas da Figura 24 (a) e (b), que a interação com a superfície muda a banda de valência do benzeno, de regiões de maior energia, para

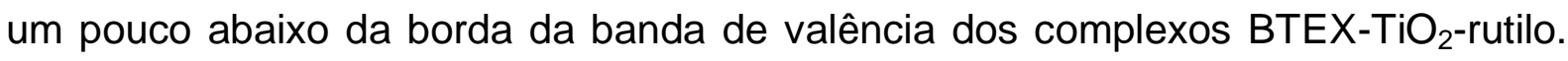
Comparando-se esses resultados com os obtidos para os complexos Benzeno- $\mathrm{O}_{3 \mathrm{C}^{-}}$ rutilo e Benzeno- $\mathrm{Ti}_{5 \mathrm{C}}$-rutilo, os comportamentos foram idênticos, alterando somente a intensidade dos picos referentes ao benzeno adsorvido e na fase gasosa, o que era esperado, pois a concentração foi aumentada. Essa característica sugere a estabilização das moléculas de benzeno após a adsorção.

Todas as densidades de estado apresentadas na Figura 24 foram obtidas usando-se o funcional PW91. As densidades de estado para as adsorções de BTEX nas duas configurações, usando o funcional PBE, apresentaram resultados que mostram o mesmo comportamento. 
(a)
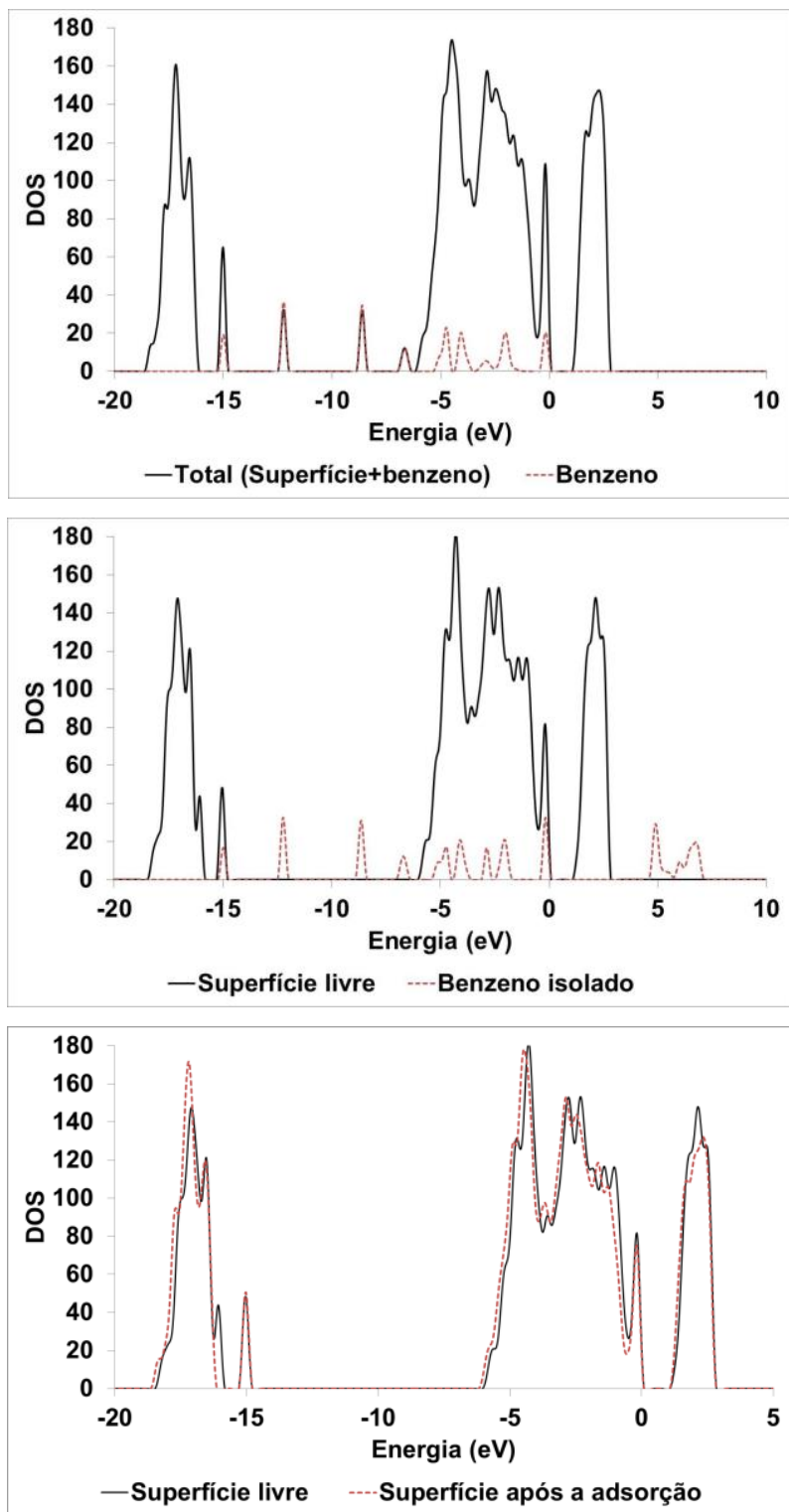

(b)

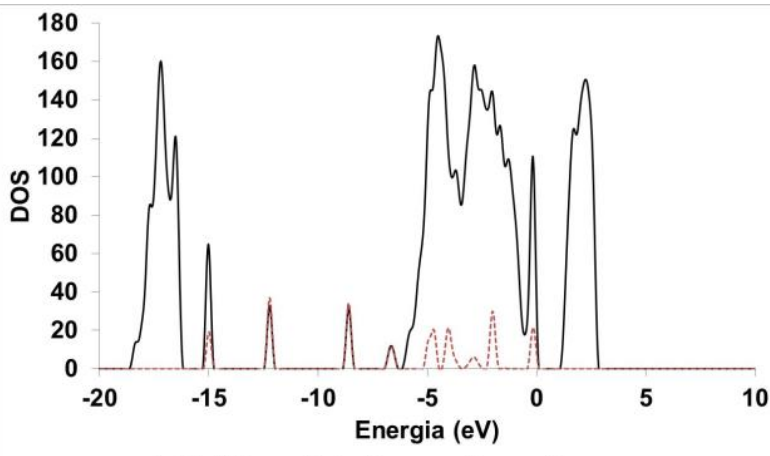

-Total (Superfície+benzeno) -.--Benzeno
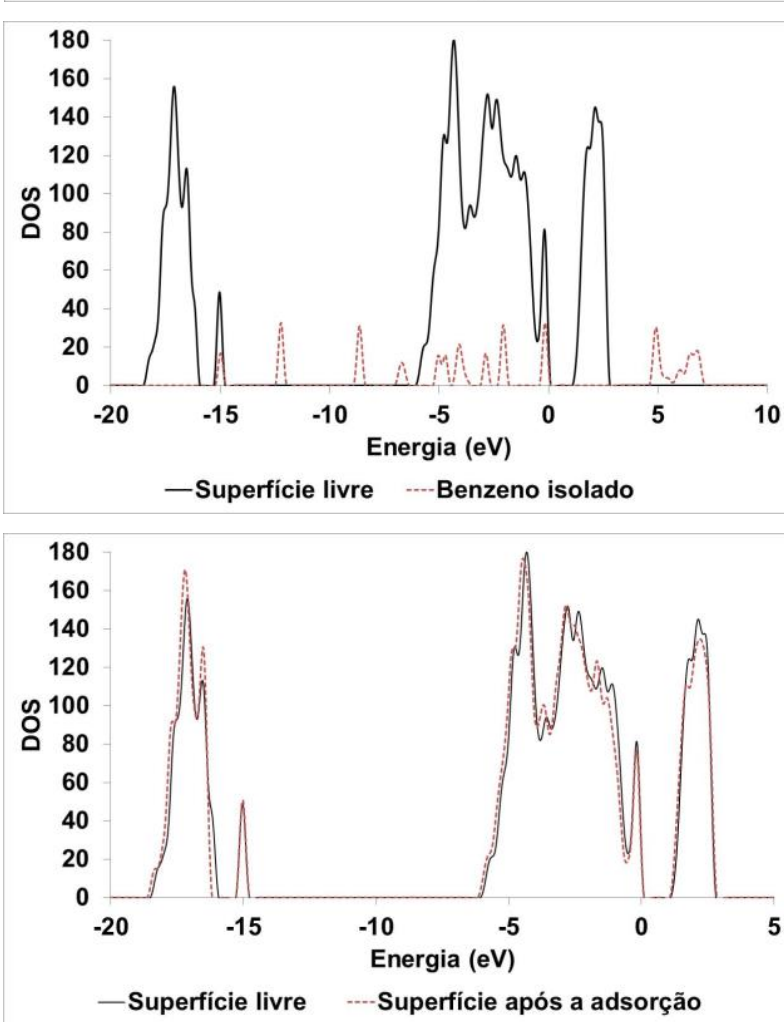

Figura 24. Densidade de estados total e projetada para a adsorção da molécula de benzeno na superfície (110) do $\mathrm{TiO}_{2}$ rutilo: (a) Benzeno- $\mathrm{O}_{3 \mathrm{C}}-\mathrm{O}_{3 \mathrm{C}}$-rutilo e (b) Benzeno- $\mathrm{O}_{3 \mathrm{C}}-\mathrm{Ti}_{5 \mathrm{C}}$-rutilo. Na parte inferior: DOS total da superfície livre e projetado sobre a superfície após a adsorção. No meio: DOS total da superfície livre e do benzeno isolado. Na parte superior: DOS total dos complexos benzeno$\mathrm{O}_{3 \mathrm{C}}-\mathrm{O}_{3 \mathrm{C}}$-rutilo e benzeno- $\mathrm{O}_{3 \mathrm{C}}-\mathrm{Ti}_{5 \mathrm{C}}$-rutilo e projetado sobre a molécula de benzeno do complexo. A energia de Fermi está definida para zero.

A adsorção da molécula de benzeno possui um pequeno efeito sobre a densidade de estados projetada (PDOS) d do titânio da superfície e p da molécula de benzeno. Na Figura 25 (a) e (b) pode ser visualizada a densidade de estados projetada d dos átomos de titânio para a primeira camada da superfície (110) do $\mathrm{TiO}_{2}$ rutilo livre e com os benzenos adsorvidos ((a) Benzeno- $\mathrm{O}_{3 \mathrm{C}}-\mathrm{O}_{3 \mathrm{c}}$-rutilo e (b) Benzeno- $\mathrm{O}_{3 \mathrm{C}}-\mathrm{Ti}_{5 \mathrm{C}}$-rutilo), no qual, os PDOS são semelhantes. Após a adsorção, observou-se apenas a translação de bandas $p$ do benzeno para regiões de menor 
energia em relação à molécula isolada, assim como ocorreu para o DOS total. O DOS total e projetado da Figura 25 foi obtido com os resultados usando o funcional PW91.

A densidade de estados projetada $p$ dos benzenos sugere um decréscimo de estados de alta energia para os benzenos adsorvidos, esses estados são redistribuídos na região de estados d do titânio da superfície, indicando uma fraca hibridização entre estados $d$ do $T i_{5 c}$ e estados $p$ do benzeno, em concordância com os resultados da CDD, que mostraram um aumento de carga na região entre a molécula de benzeno e o Ti $i_{5 c}$. Isso ocorreu devido a interação dos orbitais $p_{z}$ do carbono com os orbitais $d_{z}^{2}$ do titânio pentacoordenado. A mesma tendência foi encontrada para as outras moléculas de BTEX e para os demais funcionais usados.

(a)

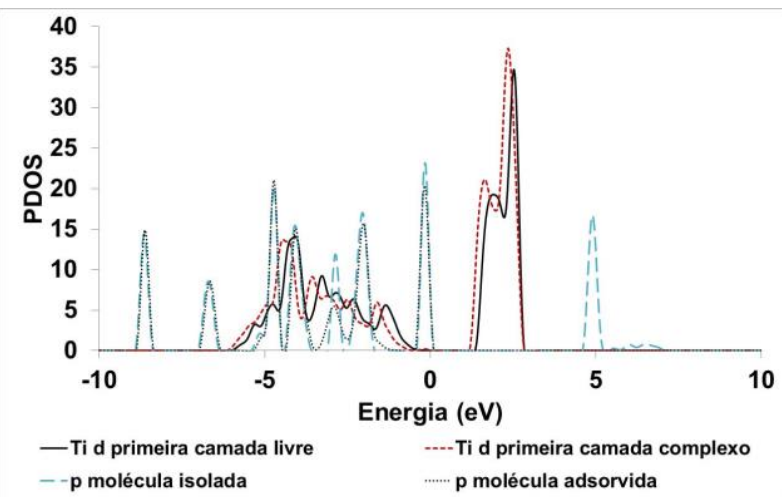

(b)

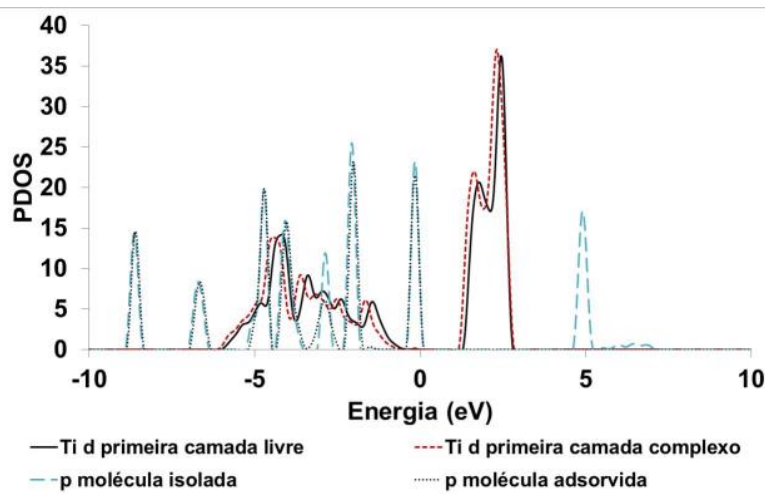

Figura 25. PDOS calculado para os estados d dos titânios da primeira camada da superfície (110) do $\mathrm{TiO}_{2}$ rutilo livre e após a adsorção dos benzenos. PDOS para os estados $\mathrm{p}$ dos benzenos isolados e adsorvidos sobre a superfície (110) do $\mathrm{TiO}_{2}$ rutilo. (a) Benzeno- $\mathrm{O}_{3 \mathrm{C}}-\mathrm{O}_{3 \mathrm{C}}$-rutilo; (b) Benzeno- $\mathrm{O}_{3 \mathrm{C}^{-}}-\mathrm{Ti}_{5 \mathrm{C}^{-}}$ rutilo. A energia de Fermi está definida para zero.

\section{3 - Adsorção de BTEX: Formação dos Complexos $\mathrm{BTEX}^{-\mathrm{TiO}_{2}}$} Anatásio

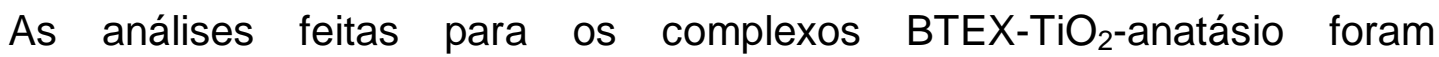
semelhantes àquelas realizadas para $0 \mathrm{TiO}_{2}$ rutilo. Porém, não foram encontrados trabalhos teóricos ou experimentais da adsorção do BTEX em planos específicos, como foi descrita na adsorção de benzeno no plano (110) do $\mathrm{TiO}_{2}$ rutilo. ${ }^{22}$ Contudo, a decomposição do BTEX na superfície do $\mathrm{TiO}_{2}$ ocorre em catalisadores com a sua composição formada por $\mathrm{TiO}_{2}$ rutilo e anatásio, conforme mostrado na literatura. ${ }^{24,82}$ Apesar da fase anatásio do $\mathrm{TiO}_{2}$ apresentar importantes aplicações na catálise e 
fotocatálise, experimentalmente existem dificuldades em obter amostras de boa qualidade, dificultando o entendimento das propriedades da superfície e da reatividade do material. ${ }^{147}$

A adsorção inicial das moléculas de BTEX na superfície (101) do $\mathrm{TiO}_{2}$ anatásio foi feita com o centro de massa das moléculas próximo a um átomo de titânio pentacoordenado, conforme foi realizado para a superfície (110) do $\mathrm{TiO}_{2}$ rutilo. É importante notar que essa posição inicial de interação das moléculas de BTEX representa apenas um melhor ponto de início dos cálculos, pois na última etapa de relaxação, as duas camadas da superfície e todas as coordenadas dos adsorbatos foram relaxadas. Nas Figuras 26 e 27 tem-se uma visão superior e lateral das estruturas otimizadas mais estáveis dos complexos $\mathrm{BTEX}-\mathrm{TiO}_{2}$-anatásio, usando o funcional PW91. As duas configurações mais estáveis foram encontradas com o plano do anel benzênico das moléculas de BTEX paralelo à superfície. Na primeira configuração, mostrada na Figura 26, o anel aromático está quase centrado sobre o $\mathrm{Ti}_{5 \mathrm{C}}$, sendo denominado aqui como BTEX-Ti $\mathrm{ic}_{5 \mathrm{C}}$-anatásio.

(a)

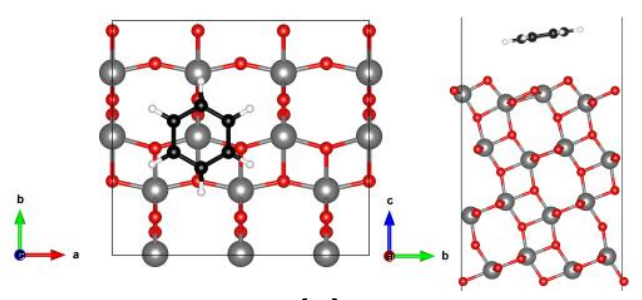

(c)

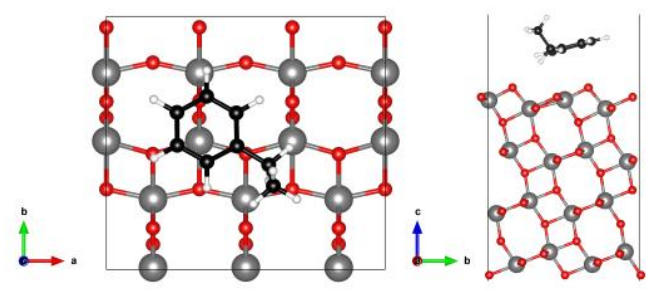

(e)

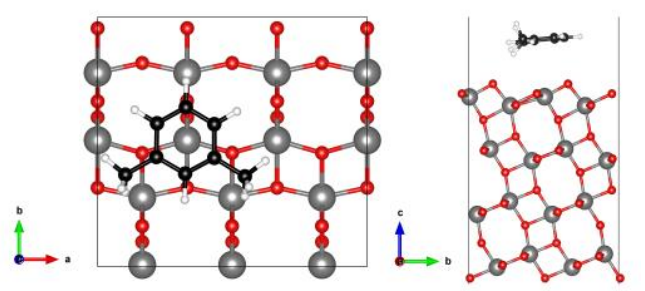

(b)

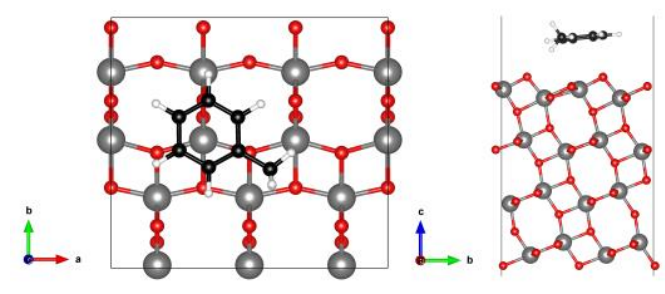

(d)

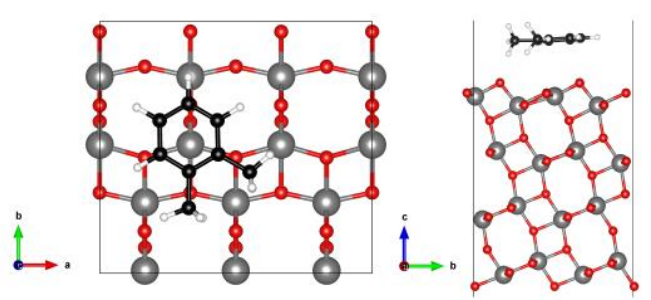

(f)

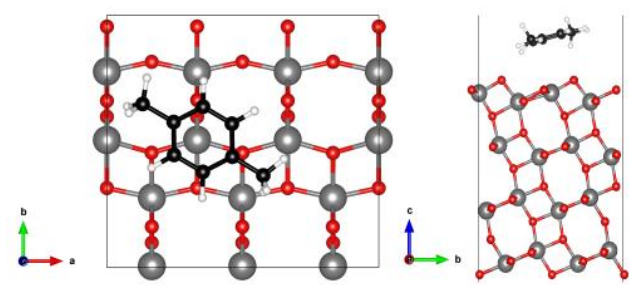

Figura 26. Estruturas otimizadas usando o funcional PW91 da interação das moléculas de BTEX com a superfície (101) do $\mathrm{TiO}_{2}$ anatásio: (a) benzeno- $\mathrm{Ti}_{5 \mathrm{C}}$-anatásio; (b) tolueno- $\mathrm{Ti}_{5 \mathrm{C}}$-anatásio; (c) etilbenzeno-Ti ${ }_{5 c}$-anatásio; (d) o-xileno-Ti ${ }_{5 c}$-anatásio; (e) m-xileno-Ti ${ }_{5 c}$-anatásio e (f) p-xileno- $\mathrm{Ti}_{5 \mathrm{C}^{-}}$ anatásio. 
A otimização dos complexos $\mathrm{BTEX}-\mathrm{TiO}_{2}$-anatásio com a rotação em $90^{\circ}$ das moléculas de BTEX em relação ao eixo z também foi feito. Ao realizar a rotação, o anel aromático ficou quase centrado sobre $0 \mathrm{O}_{3 \mathrm{C}}$, sendo denominado aqui como BTEX-O $\mathrm{O}_{3 \mathrm{C}}$-anatásio. Na Figura 27, tem-se a visão superior e lateral das estruturas otimizadas dos complexos BTEX-O ${ }_{3 c}$-anatásio otimizados usando o funcional PW91.

As estruturas otimizadas dos complexos BTEX-Ti ${ }_{5 \mathrm{C}}$-anatásio e BTEX-O ${ }_{3 C^{-}}$ anatásio usando o funcional PBE apresentaram diferenças na distância de interação e na inclinação de algumas moléculas de BTEX em relação à superfície, porém, a posição mantém-se praticamente inalterada entre os resultados obtidos com os diferentes funcionais utilizados.

(a)

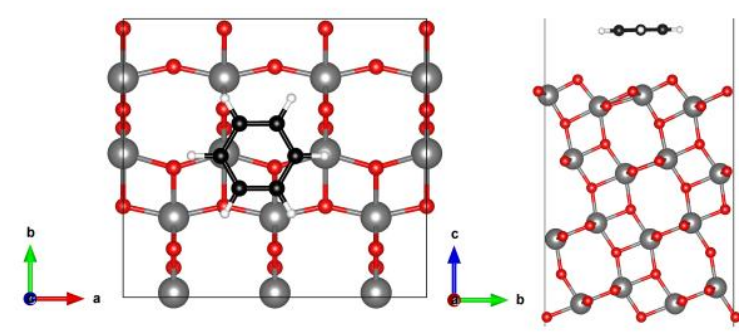

(c)

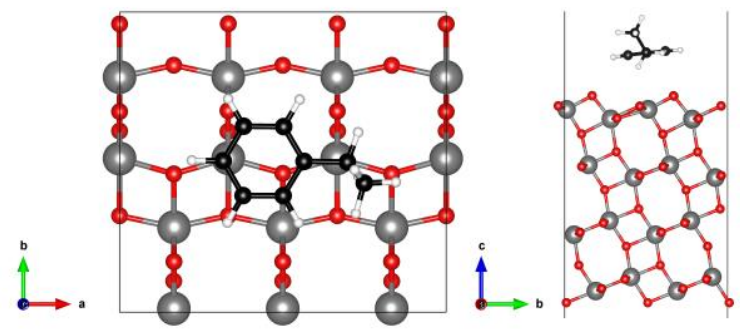

(e)

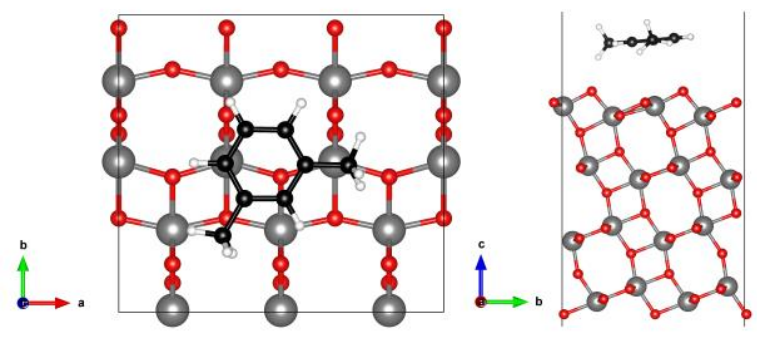

(b)

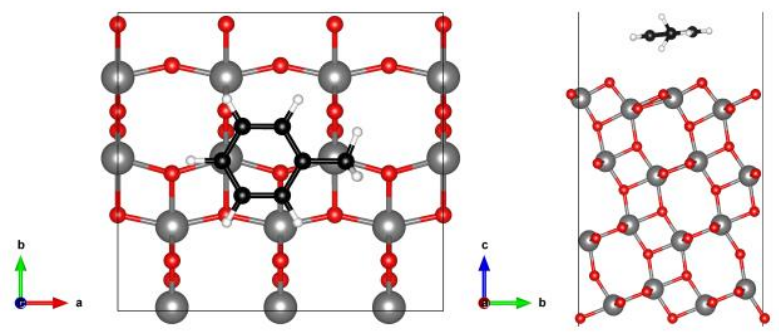

(d)
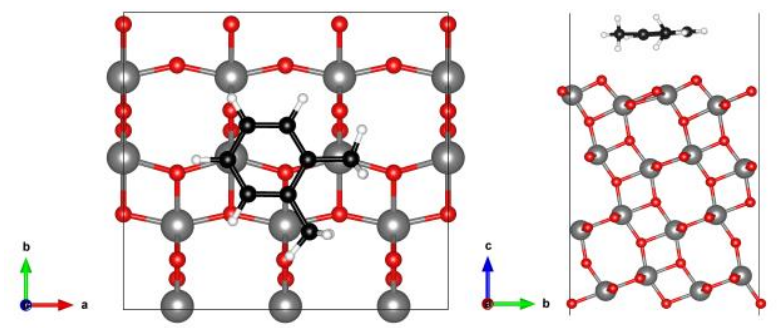

(f)

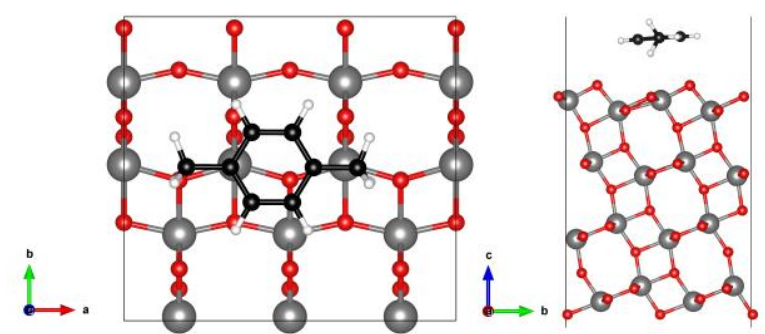

Figura 27. Estruturas otimizadas usando o funcional PW91 da interação das moléculas de BTEX com

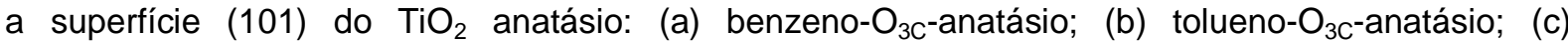
etilbenzeno- $\mathrm{O}_{3 \mathrm{C}}$-anatásio; (d) o-xileno- $\mathrm{O}_{3 \mathrm{C}}$-anatásio; (e) m-xileno- $\mathrm{O}_{3 \mathrm{c}}$-anatásio e (f) p-xileno- $\mathrm{O}_{3 \mathrm{C}^{-}}$ anatásio. 
A menor distância entre os átomos de carbono das moléculas dos adsorbatos (BTEX) e os átomos de titânio pentacoordenados $\left(\mathrm{Ti}_{5 \mathrm{C}}\right)$ da superfície foi obtida para os sistemas otimizados (Tabela 18). As distâncias $\mathrm{BTEX}-\mathrm{TiO}_{2}$ calculadas mostram uma pequena variação em relação aos funcionais utilizados, com valores

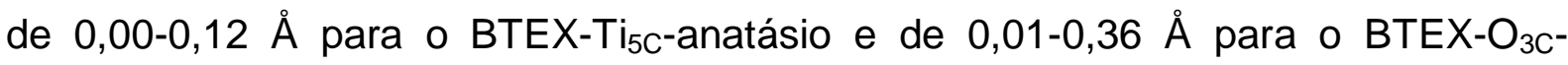
anatásio. As maiores diferenças foram encontradas em relação ao funcional PW91 e o PBE-D2 para o complexo tolueno- $\mathrm{T}_{5 \mathrm{C}}$-anatásio e para o complexo $\mathrm{m}$-xileno- $\mathrm{O}_{3 \mathrm{C}}$ anatásio.

Tabela 18. Distância adsorbato-superfície $(\AA ̊)$ entre as moléculas de BTEX e os átomos de titânio pentacoordenados $\left(\mathrm{Ti}_{5 \mathrm{C}}\right)$ : BTEX-Ti ${ }_{5 \mathrm{C}}$-anatásio e BTEX-O $\mathrm{O}_{3 \mathrm{C}}$-anatásio, usando os funcionais PW91, PBE e PBE-D2.

\begin{tabular}{ccccccc}
\hline \multicolumn{7}{c}{ BTEX-Ti $_{5 c}$-anatásio } \\
\hline Funcional & Benzeno & Tolueno & Etilbenzeno & o-xileno & m-xileno & p-xileno \\
\hline PW91 & 3,53 & 3,43 & 3,33 & 3,51 & 3,67 & 3,40 \\
PBE & 3,45 & 3,32 & 3,23 & 3,47 & 3,65 & 3,31 \\
PBE-D2 & 3,48 & 3,31 & 3,22 & 3,46 & 3,65 & 3,30 \\
\hline \multicolumn{7}{c}{ BTEX-O 3 -anatásio } \\
\hline Funcional & Benzeno & Tolueno & Etilbenzeno & o-xileno & m-xileno & p-xileno \\
\hline PW91 & 3,53 & 3,42 & 3,39 & 3,46 & 3,68 & 3,43 \\
PBE & 3,41 & 3,40 & 3,33 & 3,49 & 3,64 & 3,42 \\
PBE-D2 & 3,40 & 3,38 & 3,32 & 3,37 & 3,32 & 3,39 \\
\hline
\end{tabular}

As distâncias de interação mais estáveis para os complexos BTEX-Ti $i_{5-}$ anatásio e BTEX-O ${ }_{3 c}$-anatásio apresentaram resultados diferenciados entre as moléculas adsorvidas, e entre a mesma molécula usando funcionais diferentes. Os resultados podem ser relacionados com os ângulos de interação, no qual, os adsorbatos possuem maior liberdade de rotação em relação à superfície do $\mathrm{TiO}_{2}$ rutilo. Os ângulos de interação são mostrados na Figura 28 para a formação do complexo (a) BTEX-Ti $i_{5 c}$-anatásio e (b) BTEX-O ${ }_{3 c}$-anatásio. Pode ser observado que para um mesmo adsorbato, quanto menor a diferença entre os ângulos de interação usando os funcionais PW91, PBE e PBE-D2, menor e a variação da distância interatômica entre o adsorbato e a superfície. Esta relação pode ser exemplificada para os complexos o-xileno- $\mathrm{Ti}_{5 \mathrm{C}}$-anatásio, m-xileno- $\mathrm{Ti}_{5 \mathrm{C}}$-anatásio e p-xileno- $\mathrm{O}_{3 \mathrm{C}^{-}}$ anatásio. 
(a)

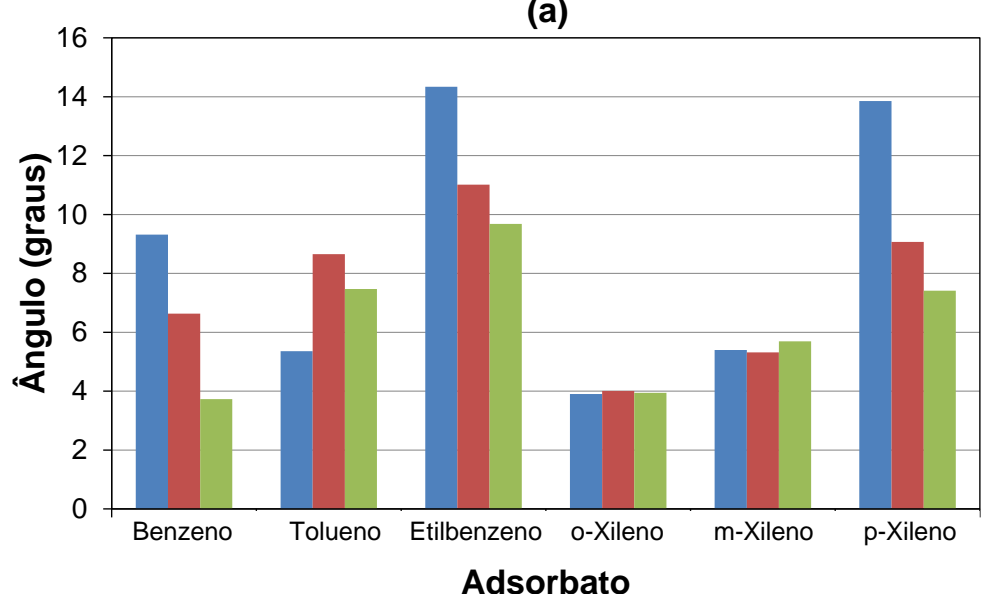

-PW91 —PBE $\approx \mathrm{PBE}-\mathrm{D} 2$

(b)

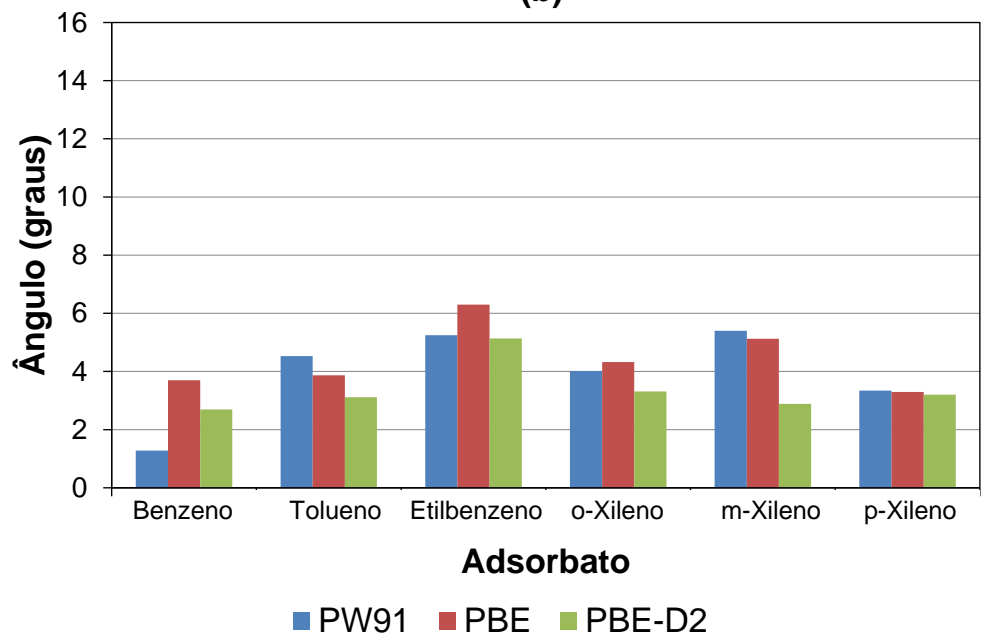

Figura 28. Ângulos formados entre as moléculas de BTEX e o plano da superfície (101) do $\mathrm{TiO}_{2}$ anatásio para a interação: (a) BTEX-Ti ${ }_{5 \mathrm{C}}$-anatásio e (b) BTEX-O ${ }_{3 \mathrm{C}}$-anatásio.

As energias de adsorção das moléculas de BTEX na superfície do $\mathrm{TiO}_{2}$ anatásio, para cada um dos funcionais estudados, são apresentadas na Tabela 19. Os resultados calculados usando o funcional PBE mostraram-se inferiores aos obtidos com o PW91 para todos os adsorbatos estudados. Esses funcionais não quantificam o efeito das interações de dispersão, o que foi obtido através dos cálculos incluindo a energia de dispersão à geometria otimizada usando o funcional PBE (PBE//PBE-D2) e através de uma nova otimização, com a inclusão da correção semiempírica de van der Waals, proposta por Grimme (PBE-D2). ${ }^{135}$ As energias de interação corrigidas apresentadas na Tabela 19, mostram que os cálculos usando os funcionais PW91 e PBE falham na descrição dessa interação, subestimando a energia de adsorção, o que pode ser observado para a adsorção do $\mathrm{BTEX}$ no $\mathrm{TiO}_{2}$ é que a contribuição do termo de dispersão é o mais importante no caso dessas 
interações. Assim como para os complexos $\mathrm{BTEX}-\mathrm{TiO}_{2}$-rutilo, a adsorção das moléculas de BTEX sobre a superfície (101) do $\mathrm{TiO}_{2}$ anatásio, indicam que o termo de dispersão é importante para os resultados energéticos, apesar de seu pequeno efeito sobre a geometria. Esta baixa influência sobre a geometria pode ser observada pelas pequenas variações nas distâncias e nos ângulos de interação usando os funcionais com e sem a correção de van der Waals, principalmente entre os funcionais PBE e PBE-D2. As energias de adsorção obtidas para os complexos $\mathrm{BTEX}-\mathrm{TiO}_{2}$-anatásio foram menores que àquelas para os complexos $\mathrm{BTEX}-\mathrm{TiO}_{2}$ rutilo, independentemente do funcional utilizado.

Tabela 19. Energias de adsorção ( $\mathrm{kJ} / \mathrm{mol}$ ) usando o funcionais PW91, PBE, PBE-D2//PBE e PBE-D2 para os complexos BTEX-Ti ${ }_{5 \mathrm{C}}$-anátasio e $\mathrm{BTEX}-\mathrm{O}_{3 \mathrm{C}}$-anatásio.

\begin{tabular}{|c|c|c|c|c|}
\hline \multirow{2}{*}{$E_{\text {adsorção }}$} & \multicolumn{4}{|c|}{ BTEX-Ti ${ }_{5 C}$-anatásio } \\
\hline & PW91 & PBE & PBE-D2//PBE & PBE-D2 \\
\hline Benzeno & 14,25 & 9,30 & 43,76 & 42,55 \\
\hline Tolueno & 13,30 & 12,50 & 58,71 & 58,20 \\
\hline Etilbenzeno & 18,73 & 13,66 & 64,09 & 63,86 \\
\hline o-xileno & 10,16 & 7,07 & 58,69 & 59,33 \\
\hline m-xileno & 16,73 & 14,09 & 55,81 & 55,84 \\
\hline p-xileno & 19,99 & 9,75 & 62,59 & 61,47 \\
\hline \multirow{2}{*}{$E_{\text {adsorção }}$} & \multicolumn{4}{|c|}{ BTEX- $\mathrm{O}_{3 \mathrm{C}}$-anatásio } \\
\hline & PW91 & PBE & PBE-D2//PBE & PBE-D2 \\
\hline Benzeno & 12,47 & 10,40 & 48,64 & 48,98 \\
\hline Tolueno & 10,78 & 6,61 & 54,60 & 54,99 \\
\hline Etilbenzeno & 11,38 & 8,21 & 59,30 & 59,44 \\
\hline o-xileno & 7,37 & 6,99 & 57,26 & 58,36 \\
\hline m-xileno & 14,27 & 11,39 & 54,24 & 61,40 \\
\hline p-xileno & 5,97 & 2,73 & 59,81 & 60,42 \\
\hline
\end{tabular}

A representação espacial da diferença de densidade de carga dos complexos $\mathrm{BTEX}-\mathrm{TiO}_{2}$-anatásio são mostradas na Figura 29. Apenas resultados usando a correção de van der Waals (PBE-D2//PBE) são mostrados. Os resultados usando os demais funcionais apresentaram o mesmo comportamento, diferindo apenas na intensidade da distribuição de carga, mas mantendo as mesmas regiões onde as cargas foram distribuídas após a adsorção. A CDD foi calculada usando Equação 14.

As diferenças de densidade de carga (CDD) apresentadas na Figura 29 mostram um aumento na densidade eletrônica na região $\pi$ do anel aromático perto 
da superfície (região azul). Pode ser observado que quanto maior a transferência de carga, maior foi a energia de ligação entre as moléculas de BTEX e a superfície.

A interação das moléculas de BTEX com a superfície do $\mathrm{TiO}_{2}$ anatásio apresentou um pequeno aumento da densidade eletrônica nos $\mathrm{O}_{2 \mathrm{C}}$ e $\mathrm{O}_{3 \mathrm{C}}$, sendo de maior magnitude sobre os $\mathrm{O}_{2 \mathrm{C}}$ que estão mais próximos às moléculas de BTEX. Em uma das extremidades das moléculas de BTEX, próxima à superfície ocorreu um decréscimo da densidade eletrônica sobre os átomos de carbono, indicando uma interação da superfície com essa região das moléculas.

(a)

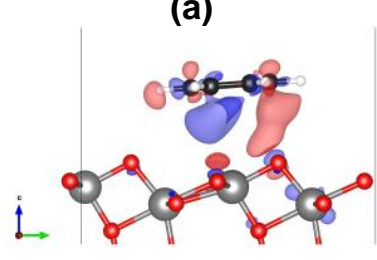

(e)

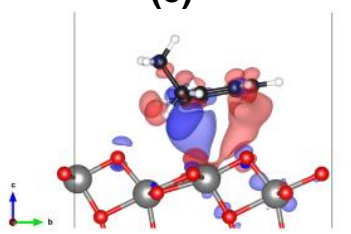

(i)

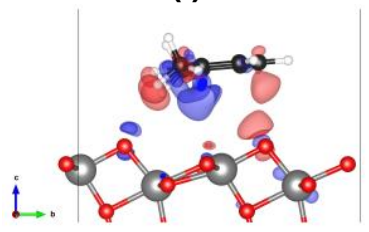

(b)

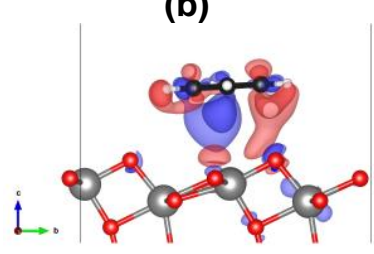

(f)

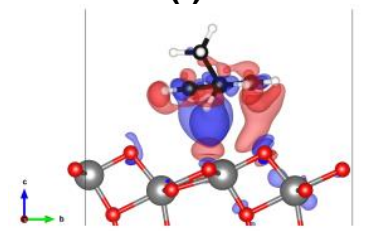

(j)

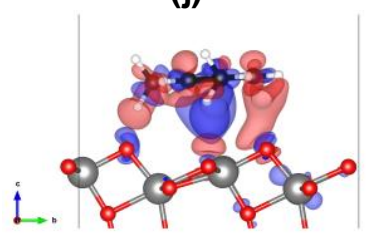

(c)

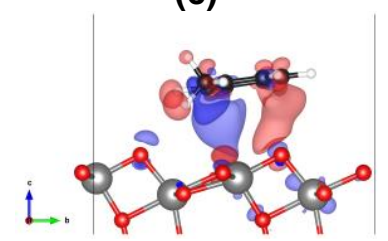

(g)

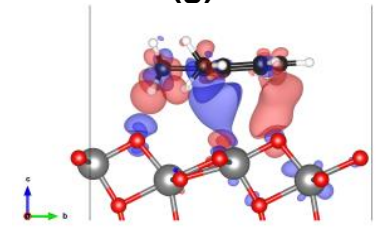

(I)

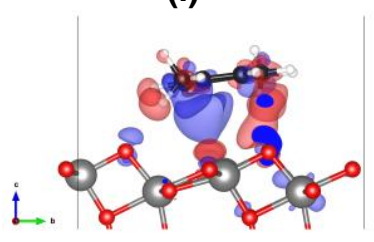

(d)

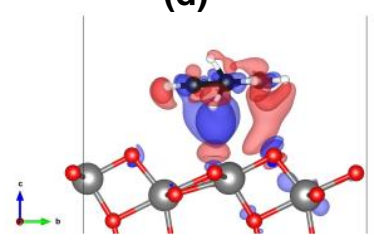

(h)

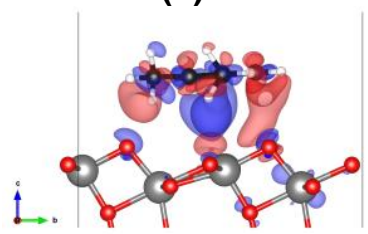

(m)

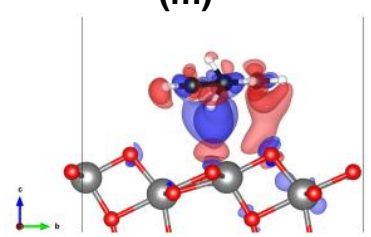

Figura 29. Diferença de densidade de carga (CDD) do (a) Benzeno- $\mathrm{Ti}_{5 \mathrm{C}}$-anatásio; (b) Benzeno- $\mathrm{O}_{3 \mathrm{C}^{-}}$ anatásio; (c) Tolueno- $\mathrm{Ti}_{5 \mathrm{C}}$-anatásio; (d) Tolueno- $\mathrm{O}_{3 \mathrm{C}}$-anatásio; (e) Etilbenzeno-Ti ${ }_{5 \mathrm{C}}$-anatásio; (f)

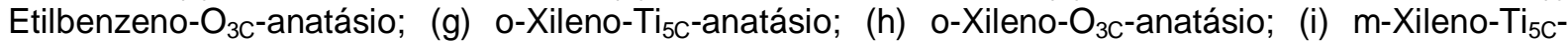
anatásio; (j) m-Xileno- $\mathrm{O}_{3 \mathrm{c}}$-anatásio; (I) p-Xileno-Ti ${ }_{5 \mathrm{c}}$-anatásio; (m) p-Xileno- $\mathrm{O}_{3 \mathrm{c}}$-anatásio. A cor vermelha é para valores negativos (decréscimo de densidade eletrônica), e azul para valores positivos (aumento da densidade eletrônica). O valor da isosuperfície é 0,0005 e/bohr ${ }^{3}$.

As cargas de Bader (e) das moléculas de BTEX foram calculadas para as adsorções nas configurações BTEX-Ti ${ }_{5 c}$-anatásio e BTEX-O ${ }_{3 c}$-anatásio (Tabela 20). Os valores das cargas foram obtidos usando o funcional PW91. Observou que houve pouca transferência de carga entre as moléculas de BTEX e a superfície, em concordância com os dados da CDD, que indicaram uma interação na região dos elétrons $\pi$. A maior variação de carga ocorreu na molécula de benzeno na configuração benzeno-Ti ${ }_{5 c}$-anatásio. 
Tabela 20. Cargas (e) das moléculas de BTEX após a adsorção usando o modelo de Bader.

\begin{tabular}{|c|c|}
\hline \multirow{2}{*}{ Carga de Bader } & BTEX-Ti ${ }_{5 c}$-anatásio \\
\hline & PW91 \\
\hline Benzeno & 0,32 \\
\hline Tolueno & 0,04 \\
\hline Etilbenzeno & 0,04 \\
\hline o-xileno & 0,04 \\
\hline m-xileno & 0,02 \\
\hline p-xileno & $-0,02$ \\
\hline \multirow{2}{*}{ Carga de Bader } & $\mathrm{BTEX}-\mathrm{O}_{3 \mathrm{C}}$-anatásio \\
\hline & PW91 \\
\hline Benzeno & 0,03 \\
\hline Tolueno & 0,03 \\
\hline Etilbenzeno & 0,03 \\
\hline o-xileno & 0,03 \\
\hline m-xileno & 0,02 \\
\hline p-xileno & 0,03 \\
\hline
\end{tabular}

Nas Figuras 30 e 31, podem ser visualizadas as análises da localização dos elétrons através da função de localização eletrônica, usando o programa VESTA $^{136,137}$. Na Figura 30, tem-se o ELF para as moléculas de BTEX na geometria da configuração BTEX-Ti ${ }_{5 c}$-anatásio e, na Figura 31, o ELF para os complexos BTEX-TiO ${ }_{2}$-anatásio nas configurações BTEX-Ti $i_{5 c}$-anatásio e $\mathrm{BTEX}-\mathrm{O}_{3 \mathrm{C}}$-anatásio. Em ambas, o valor da isosuperfície é 0,80 .

(a)

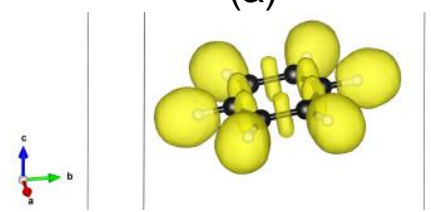

(d)

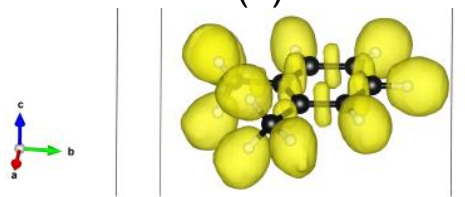

(b)
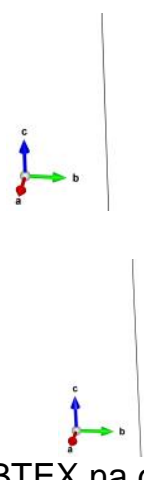

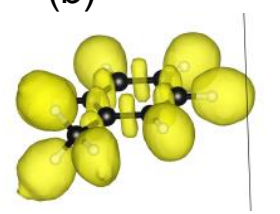

(e)

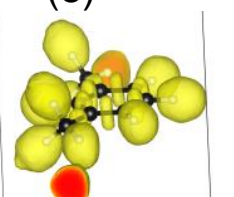

(c)

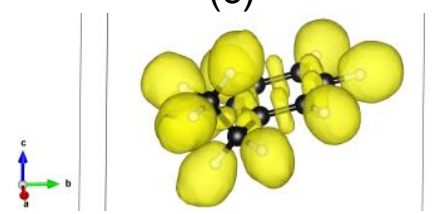

(f)

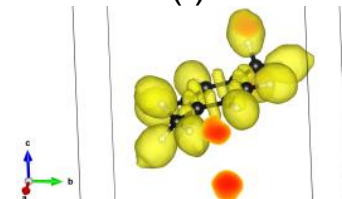

Figura 30. ELF das moléculas de BTEX na geometria otimizada BTEX-Ti ${ }_{5 c}$-anatásio: (a) benzeno; (b) tolueno; (c) etilbenzeno;(d) o-xileno; (e) m-xileno e (f) p-xileno. O valor da isosuperfície é 0,8. 
(a)

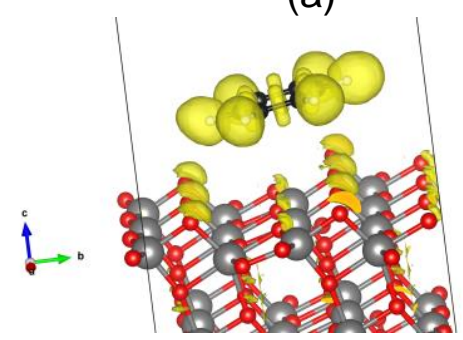

(c)

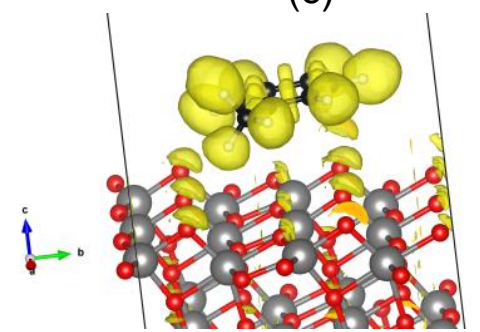

(e)

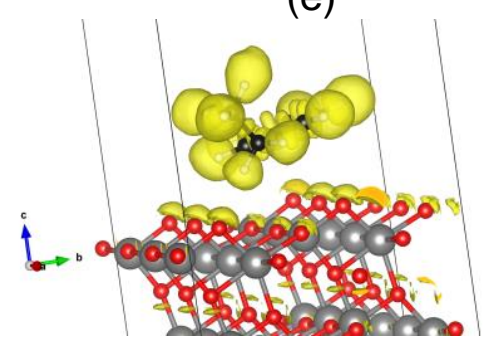

(g)

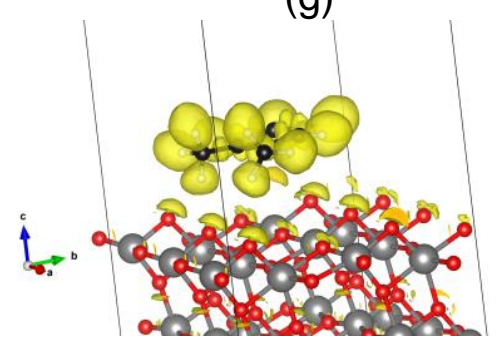

(i)

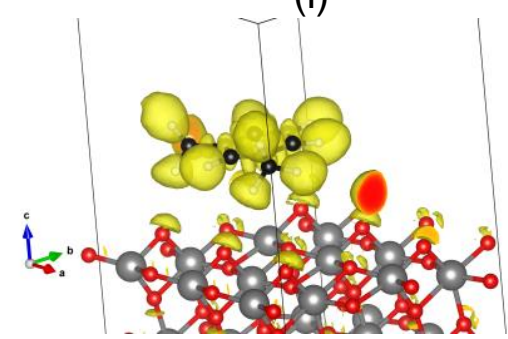

(I)

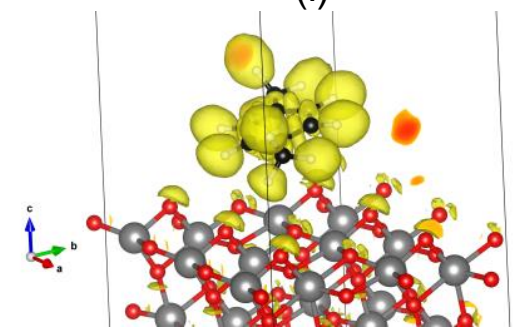

(b)

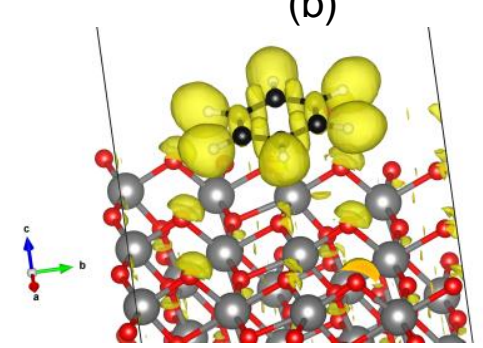

(d)

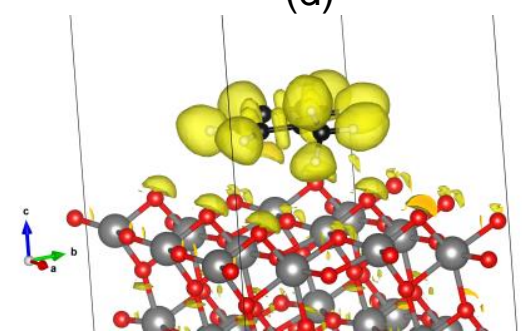

(f)

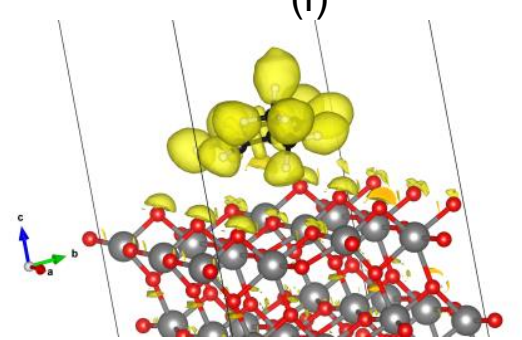

(h)

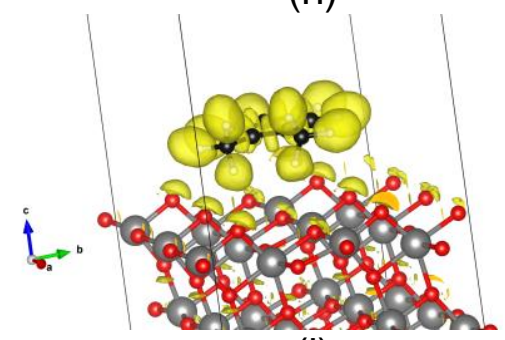

(j)

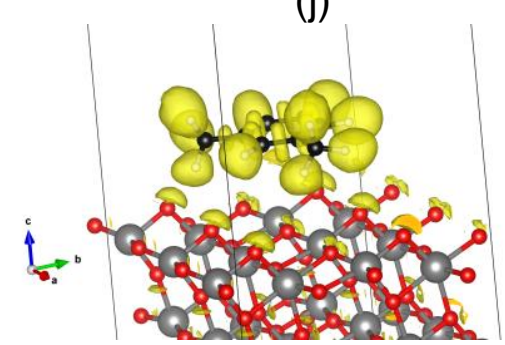

(m)

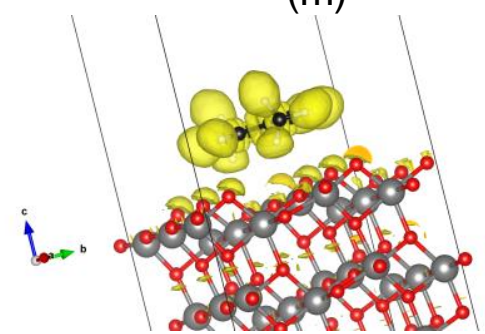

Figura 31. Função de localização eletrônica (ELF) para os complexos (a) Benzeno-Ti ${ }_{5 c}$-anatásio; (b) Benzeno- $\mathrm{O}_{3 c}$-anatásio; (c) Tolueno- $\mathrm{Ti}_{5 \mathrm{c}}$-anatásio; (d) Tolueno- $\mathrm{O}_{3 \mathrm{c}}$-anatásio; (e) Etilbenzeno- $\mathrm{Ti}_{5 \mathrm{C}^{-}}$ anatásio; (f) Etilbenzeno- $\mathrm{O}_{3 \mathrm{c}}$-anatásio; (g) o-Xileno-Ti ${ }_{5 \mathrm{c}}$-anatásio; (h) o-Xileno- $\mathrm{O}_{3 \mathrm{c}}$-anatásio; (i) mXileno-Ti ${ }_{5 c}$-anatásio; (j) m-Xileno- ${ }_{3 c}$-anatásio; (I) p-Xileno-Ti ${ }_{5 c}$-anatásio; (m) p-Xileno- ${ }_{3 c}$-anatásio. O valor da isosuperfície é 0,8 . 
Através da análise do ELF representado nas Figuras 30 e 31, pode-se observar características em concordância com os resultados da diferença de densidade de carga (CDD). Em ambos, há uma alteração na densidade eletrônica próximo aos oxigênios bicoordenados $\left(\mathrm{O}_{2} \mathrm{C}\right)$ e tricoordenados $\left(\mathrm{O}_{3} \mathrm{C}\right)$, indicando uma interação entre os hidrogênios das moléculas de BTEX com esses átomos, sendo evidenciado no ELF por uma contração da distribuição eletrônica na região dos hidrogênios das moléculas de BTEX adsorvidas, comparadas com a sua fase gasosa (Figura 30).

A Figura 32 mostra: (a) na parte inferior, a densidade de estados (DOS) total da superfície (101) do $\mathrm{TiO}_{2}$ anatásio livre e após a adsorção; no meio, tem-se o DOS total da superfície (101) do $\mathrm{TiO}_{2}$ anatásio livre e do benzeno isolado e, na parte superior, o DOS total do complexo Benzeno- $\mathrm{Ti}_{5 \mathrm{C}}$-anatásio e da molécula de benzeno após a adsorção. As densidades de estados apresentadas em (b) correspondem às mesmas estruturas, porém, quando foi feita a adsorção da molécula de benzeno na configuração Benzeno- $\mathrm{O}_{3 \mathrm{C}}$-anatásio.

A translação dos estados para regiões de menor energia nos complexos Benzeno- $\mathrm{Ti}_{5 \mathrm{C}}$-anatásio e Benzeno- $\mathrm{O}_{3 \mathrm{C}}$-anatásio sugerem uma estabilização dos sistemas após a adsorção. Pode ser observado nas curvas da Figura 32 (a) e (b), que a interação com a superfície muda a banda de valência do benzeno, de regiões de maior energia, para um pouco abaixo da borda da banda de valência. Essa característica demonstra uma estabilização da molécula de benzeno após a adsorção, e, reflete as propriedades do benzeno, no qual, a sobreposição entre estados de "buraco" da superfície, e esses estados preenchidos pelo benzeno, favorecem a transferência de elétrons para preencher os "buracos". Todas as densidades de estados apresentadas na Figura 32 foram obtidas usando-se o funcional PW91. A mesma tendência foi observada na densidade de estados para as outras moléculas adsorvidas e usando-se o funcional PBE. 
(a)
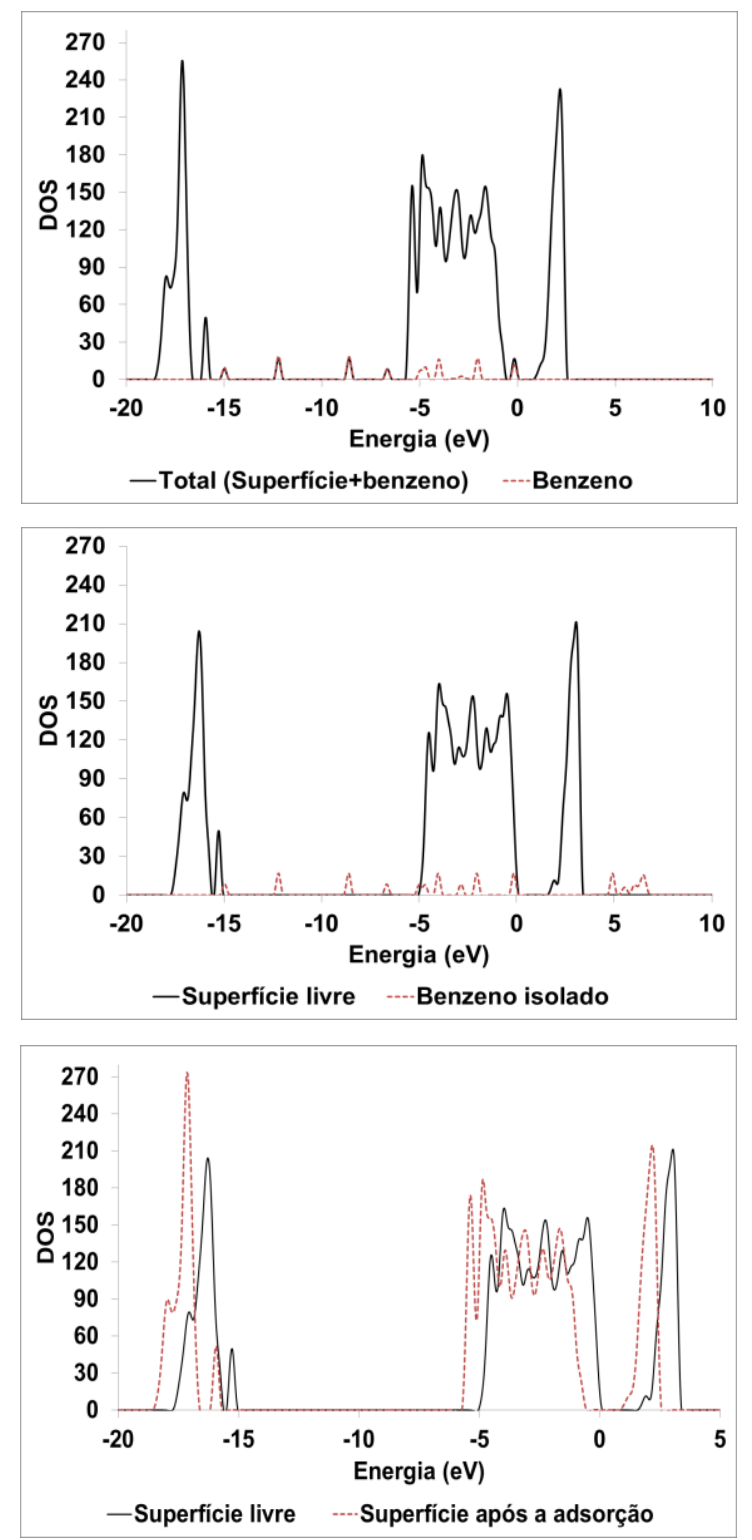

(b)
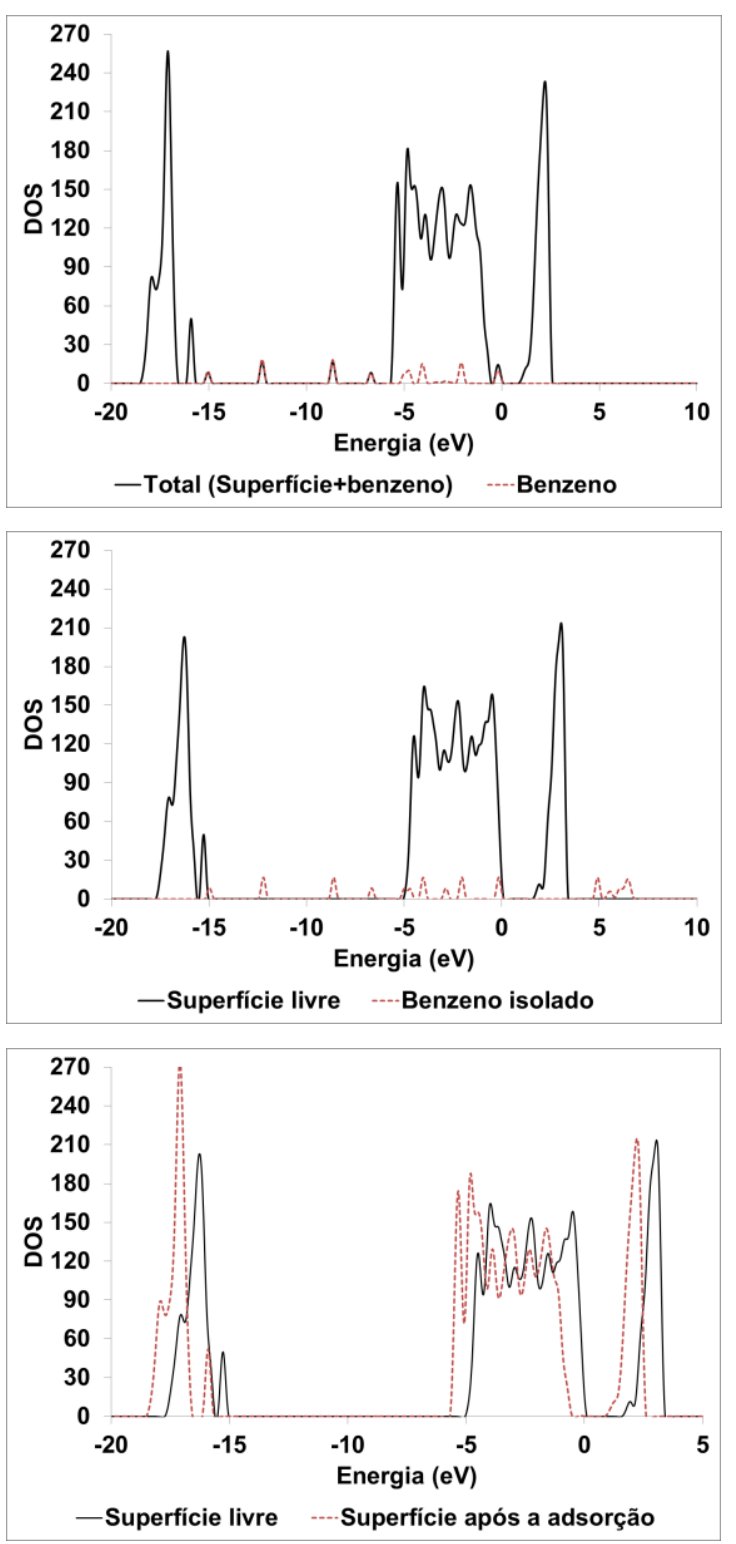

Figura 32. Densidade de estados total e projetada para a adsorção da molécula de benzeno na superfície (101) do $\mathrm{TiO}_{2}$ anatásio: (a) Benzeno-Ti ${ }_{5 c}$-anatásio e (b) Benzeno- $\mathrm{O}_{3 \mathrm{c}}$-anatásio. Na parte inferior: DOS total da superfície livre e projetado sobre superfície após a adsorção. No meio: DOS total da superfície livre e do benzeno isolado. Na parte superior: DOS total dos complexos Benzeno$\mathrm{Ti}_{5 \mathrm{C}}$-anatásio e Benzeno- $\mathrm{O}_{3 \mathrm{c}}$-anatásio e projetado sobre a molécula de benzeno do complexo. A energia de Fermi está definida para zero.

A adsorção da molécula de benzeno altera a densidade de estados projetada (PDOS) d do titânio da superfície e p da molécula de benzeno. Na Figura 33 (a) e (b), pode ser visualizada a densidade de estados projetada d dos átomos de titânio para a primeira camada da superfície (101) do $\mathrm{TiO}_{2}$ anatásio livre e, com o benzeno adsorvido ((a) Benzeno-Ti ${ }_{5 c}$-anatásio e (b) Benzeno-O ${ }_{3 c}$-anatásio), no qual, os PDOS são similares, observando-se apenas a translação para regiões de menor 
energia, assim como ocorreu para o DOS total. O DOS projetado da Figura 33 foi obtido usando o funcional PW91.

Para a densidade de estados p projetada do benzeno isolado e adsorvido na superfície, ocorreu um decréscimo de estados de maior energia para o benzeno adsorvido, esses estados foram redistribuídos na região dos estados d dos titânios da superfície, indicando uma fraca hibridização entre os estados d do $\mathrm{Ti}_{5 \mathrm{c}}$ e estados $\mathrm{p}$ dos carbonos do benzeno. Assim como foi observado na diferença de densidade de carga (CDD) através do acúmulo de carga na região entre a molécula de benzeno e o $\mathrm{Ti}_{5 \mathrm{c}}$. Isso ocorreu devido a interação dos orbitais $\mathrm{p}_{z}$ do carbono com os orbitais $d_{z}^{2}$ do titânio pentacoordenado. O mesmo comportamento foi observado para as demais moléculas de BTEX e para os demais funcionais usados.

(a)

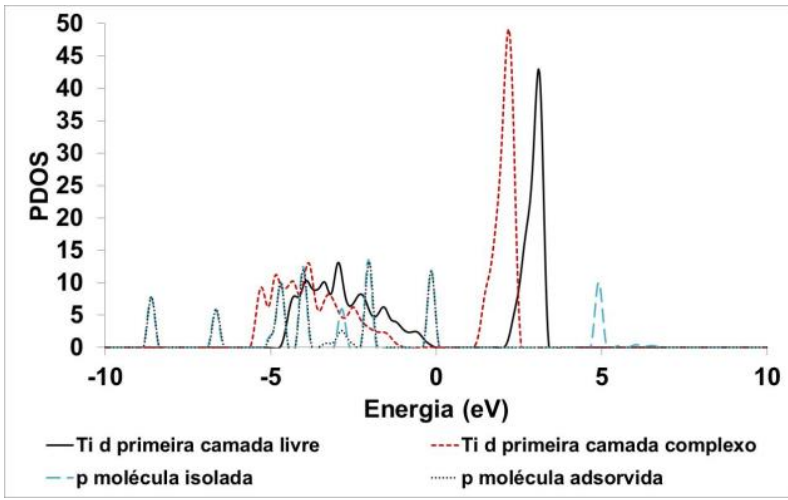

(b)

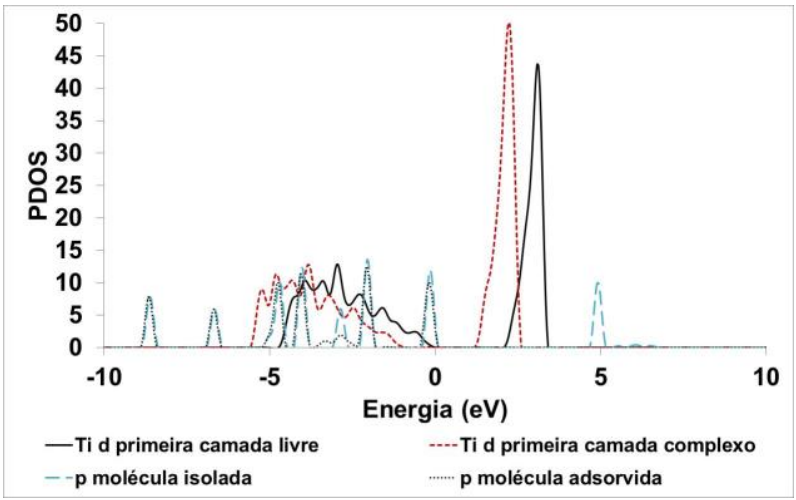

Figura 33. PDOS calculado para os orbitais d dos titânios da primeira camada da superfície (101) do $\mathrm{TiO}_{2}$ anatásio livre e após a adsorção do benzeno. PDOS para os orbitais $\mathrm{p}$ do benzeno isolado e adsorvido sobre a superfície (101) do $\mathrm{TiO}_{2}$ anatásio. (a) Benzeno- $\mathrm{Ti}_{5 \mathrm{C}^{-}}$-anatásio; (b) Benzeno- $\mathrm{O}_{3 \mathrm{C}^{-}}$ anatásio. A energia de Fermi está definida para zero.

\section{4 - Adsorção de BTEX: Formação dos Complexos BTEX-ZrO $\mathrm{rO}_{2}$ Tetragonal}

O dióxido de zircônio $\left(\mathrm{ZrO}_{2}\right)$, também conhecido com zircônia, é um material que apresenta importância tecnológica, sendo usado, por exemplo, como catalisador e sensor de gases. Portanto, o estudo das propriedades desse sólido, de suas superfícies e das suas propriedades na adsorção de compostos, tais como o BTEX, apresenta relevância, sendo descrita nos próximos tópicos.

Para iniciar os cálculos da adsorção das moléculas de BTEX sobre a superfície (001) do $\mathrm{ZrO}_{2}$ tetragonal, foram construídas as estruturas com o centro de 
massa das moléculas sobre o átomo de zircônio hexacoordenado $\left(\mathrm{Zr}_{6 \mathrm{CC}}\right)$. Nessa posição, foram analisados duas configurações: a) com a ligação CC do anel aromático em ponte sobre os átomos de oxigênio bicoordenados mais próximos à superfície (BTEX-O ${ }_{2} \mathrm{Cs}_{-}-\mathrm{ZrO}_{2}$-tetragonal); b) com a ligação $\mathrm{CC}$ do anel aromático em ponte sobre os átomos de oxigênio bicoordenados mais internos à superfície (BTEX$\mathrm{O}_{2 \mathrm{Cl}}-\mathrm{ZrO}_{2}$-tetragonal). $\mathrm{Na}$ Figura 34 , tem-se uma visão superior e lateral das estruturas otimizadas para os complexos $\mathrm{BTEX}-\mathrm{O}_{2 \mathrm{Cs}}-\mathrm{ZrO}_{2}$-tetragonal usando o funcional PW91. A linha formada pelos átomos de oxigênio bicoordenados mais próximos à superfície $\left(\mathrm{O}_{2 \mathrm{cs}}\right)$ está na direção de "a", segundo a orientação mostrada na Figura 34.

(a)

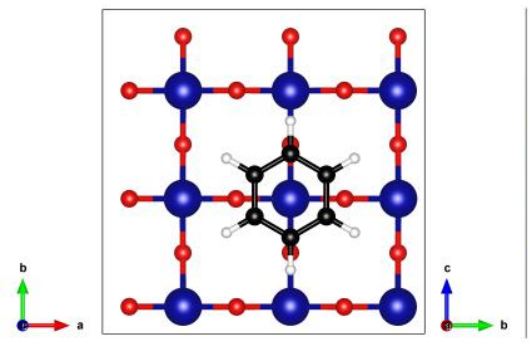

(c)

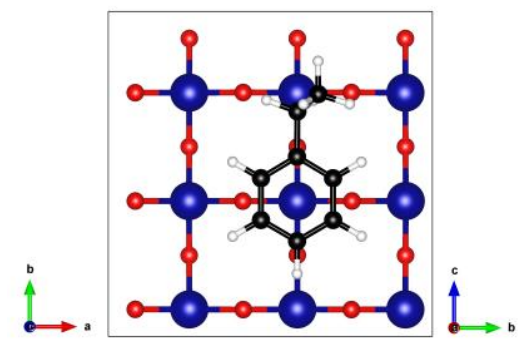

(e)

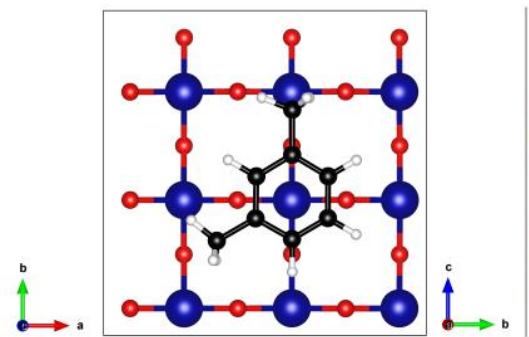

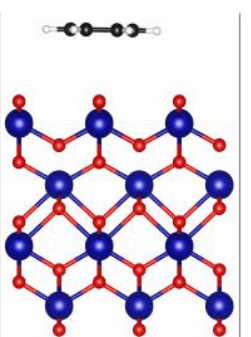

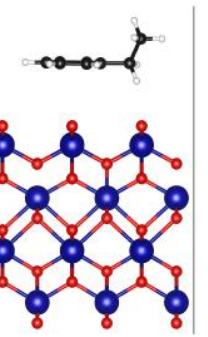

to-os-

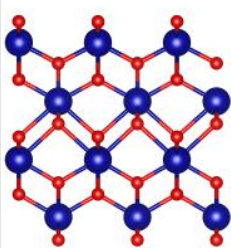

(b)
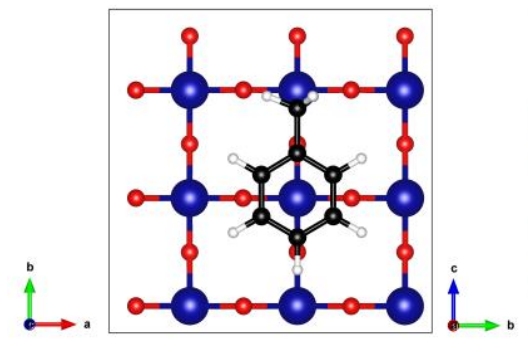

(d)
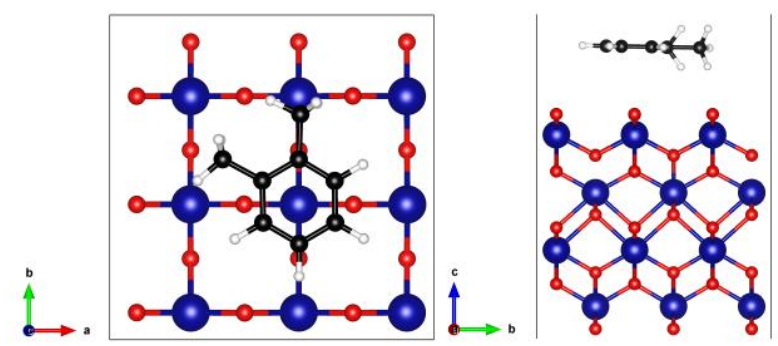

(f)
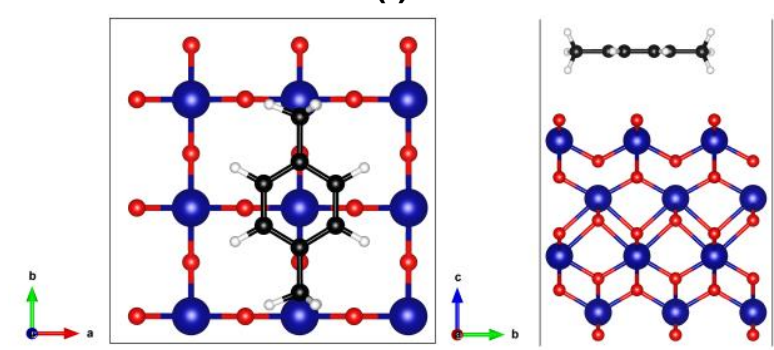

Figura 34. Estruturas otimizadas usando o funcional PW91, da interação das moléculas de BTEX com a superfície (001) do $\mathrm{ZrO}_{2}$ tetragonal, mostrando as ligações $\mathrm{CC}$ em uma configuração em ponte sobre os $\mathrm{O}_{2 \mathrm{cs}}$ : (a) benzeno- $\mathrm{O}_{2 \mathrm{Cs}}-\mathrm{ZrO}_{2}$-tetragonal; (b) tolueno- $\mathrm{O}_{2 \mathrm{Cs}}-\mathrm{ZrO}_{2}$-tetragonal; (c) etilbenzeno-

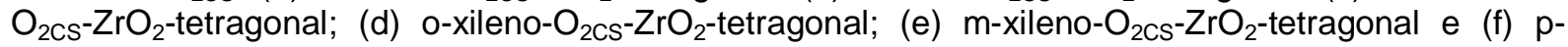
xileno- $\mathrm{O}_{2 \mathrm{CS}}-\mathrm{ZrO}_{2}$-tetragonal.

$\mathrm{Na}$ Figura 35, tem-se a visão superior e lateral das estruturas otimizadas dos complexos BTEX- $\mathrm{O}_{2 \mathrm{Cl}}-\mathrm{ZrO}_{2}$-tetragonal usando o funcional PW91. A linha formada 
pelos átomos de oxigênio bicoordenados mais internos à superfície está na direção de "b", segundo a orientação mostrada na Figura 35. A otimização da adsorção nos complexos $\mathrm{BTEX}-\mathrm{O}_{2 \mathrm{CS}}-\mathrm{ZrO}_{2}$-tetragonal e $\mathrm{BTEX}-\mathrm{O}_{2 \mathrm{Cl}}-\mathrm{ZrO}_{2}$-tetragonal foi realizada através do relaxamento das duas camadas superiores da superfície e das moléculas de BTEX (otimização completa).

(a)

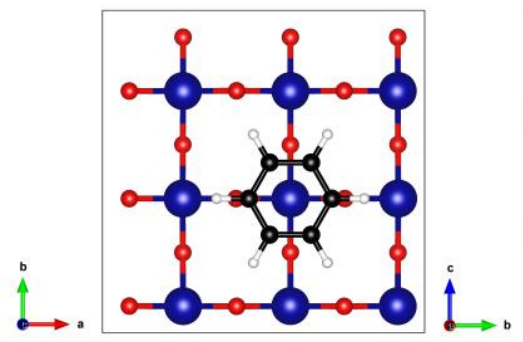

(c)

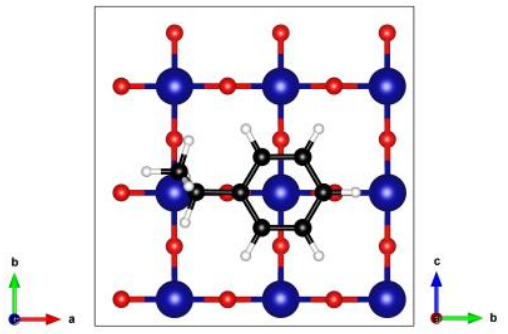

(e)

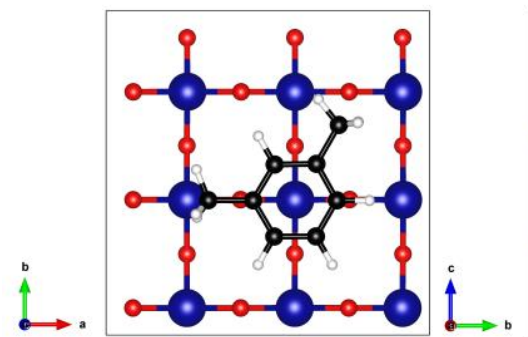

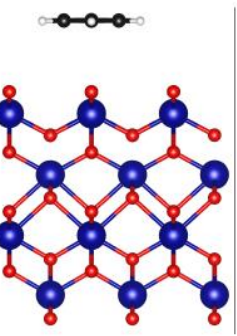

a.
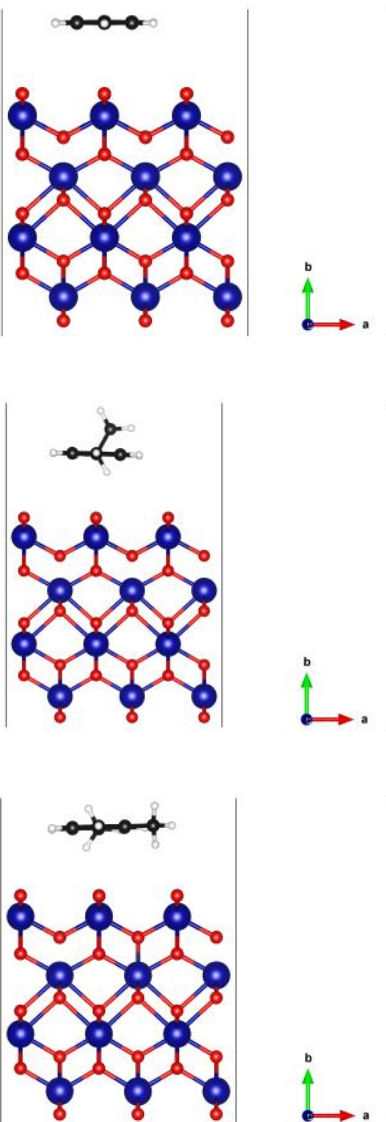

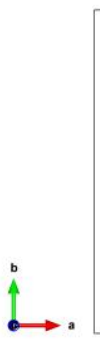

(b)

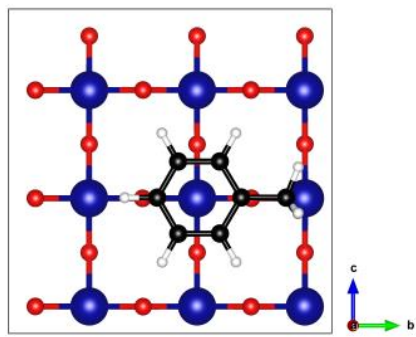

(d)
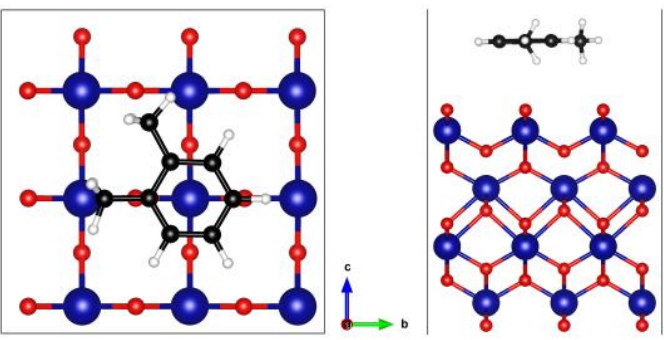

(f)
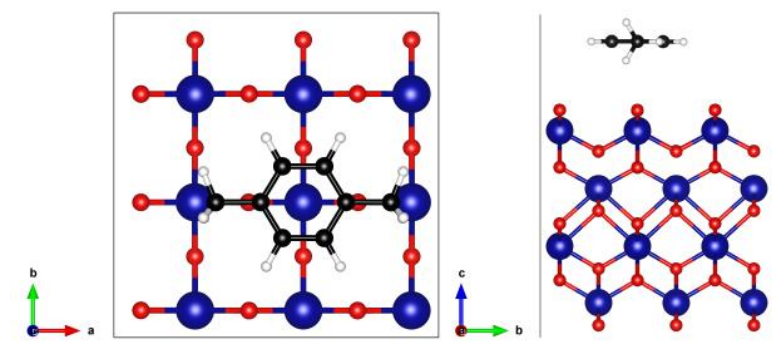

Figura 35. Estruturas otimizadas usando o funcional PW91, da interação das moléculas de BTEX com a superfície (001) do $\mathrm{ZrO}_{2}$ tetragonal, mostrando as ligações $\mathrm{CC}$ em uma configuração em ponte sobre os $\mathrm{O}_{2 \mathrm{Cl}}$ : (a) benzeno- $\mathrm{O}_{2 \mathrm{Cl}}-\mathrm{ZrO}_{2}$-tetragonal; (b) tolueno- $\mathrm{O}_{2 \mathrm{Cl}^{-}} \mathrm{ZrO}_{2}$-tetragonal; (c) etilbenzeno- $\mathrm{O}_{2 \mathrm{Cl}^{-}}$ $\mathrm{ZrO}_{2}$-tetragonal; (d) o-xileno- $\mathrm{O}_{2 \mathrm{Cl}^{-}} \mathrm{ZrO}_{2}$-tetragonal; (e) m-xileno- $\mathrm{O}_{2 \mathrm{Cl}^{-}} \mathrm{ZrO}_{2}$-tetragonal e (f) p-xileno- $\mathrm{O}_{2 \mathrm{Cl}^{-}}$ $\mathrm{ZrO}_{2}$-tetragonal.

A menor distância entre os átomos de carbono das moléculas dos adsorbatos (BTEX) e os átomos de zircônio hexacoordenados $\left(Z r_{6 C}\right)$ da superfície foi obtida para os sistemas otimizados (Tabela 21). As distâncias BTEX-ZrO $\mathrm{rr}_{2}$ calculadas não mostraram variação em relação aos funcionais utilizados e às diferentes configurações estudadas. A molécula de m-xileno foi a que ficou mais próxima à

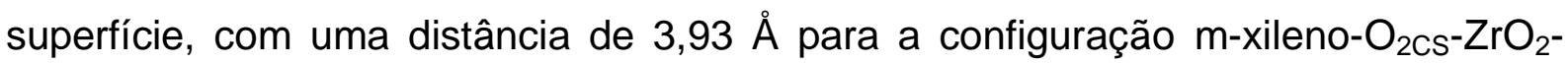


tetragonal. O etilbenzeno apresentou a maior distância da superfície $(4,21 \AA$ em ambas as configurações.

Tabela 21. Distância adsorbato-superfície $(\AA ̊)$ entre as moléculas de BTEX e os átomos de zircônio hexacoordenados $\left(\mathrm{Zr}_{6 \mathrm{C}}\right)$ : $\mathrm{BTEX}-\mathrm{O}_{2 \mathrm{Cs}}-\mathrm{ZrO}_{2}$-tetragonal e $\mathrm{BTEX}-\mathrm{O}_{2 \mathrm{Cl}}-\mathrm{ZrO}_{2}$-tetragonal, usando os funcionais PW91 e PBE.

\begin{tabular}{|c|c|c|c|c|c|c|}
\hline \multicolumn{7}{|c|}{ BTEX-O ${ }_{2 \mathrm{Cs}-\mathrm{ZrO}_{2} \text {-tetragonal }}$} \\
\hline Funcional & Benzeno & Tolueno & Etilbenzeno & o-xileno & m-xileno & p-xileno \\
\hline $\begin{array}{c}\text { PW91 } \\
\text { PBE }\end{array}$ & $\begin{array}{l}4,06 \\
4,06\end{array}$ & $\begin{array}{l}4,21 \\
4,21\end{array}$ & $\begin{array}{l}4,10 \\
4,10\end{array}$ & $\begin{array}{l}4,04 \\
4,04\end{array}$ & $\begin{array}{l}3,93 \\
3,93\end{array}$ & $\begin{array}{l}4,13 \\
4,13\end{array}$ \\
\hline \multicolumn{7}{|c|}{ BTEX-O ${ }_{2 \mathrm{Cl}}-\mathrm{ZrO}_{2}$-tetragonal } \\
\hline Funcional & Benzeno & Tolueno & Etilbenzeno & o-xileno & m-xileno & p-xileno \\
\hline $\begin{array}{l}\text { PW91 } \\
\text { PBE }\end{array}$ & $\begin{array}{l}4,07 \\
4,07\end{array}$ & $\begin{array}{l}4,21 \\
4,20\end{array}$ & $\begin{array}{l}4,09 \\
4,09\end{array}$ & $\begin{array}{l}4,10 \\
4,10\end{array}$ & $\begin{array}{l}4,01 \\
4,01\end{array}$ & $\begin{array}{l}4,13 \\
4,13\end{array}$ \\
\hline
\end{tabular}

Os ângulos de interação são mostrados na Tabela 22 para a formação dos complexos BTEX-O $\mathrm{O}_{2 \mathrm{C}}-\mathrm{ZrO}_{2}$-tetragonal e BTEX-O $\mathrm{O}_{2 \mathrm{Cl}}-\mathrm{ZrO}_{2}$-tetragonal. Os adsorbatos apresentaram uma pequena inclinação em relação à superfície, variando de $0,456^{\circ}$ a $2,023^{\circ}$ para os complexos p-xileno- $\mathrm{O}_{2 \mathrm{Cs}}-\mathrm{ZrO}_{2}$-tetragonal e etilbenzeno- $\mathrm{O}_{2 \mathrm{Cl}}-\mathrm{ZrO}_{2}-$ tetragonal, respectivamente. As maiores diferenças entre os ângulos calculados usando os funcionais PW91 e PBE foram obtidas para os complexos tolueno- $\mathrm{O}_{2 \mathrm{Cl}^{-}}$ $\mathrm{ZrO}_{2}$-tetragonal e o-xileno- $\mathrm{O}_{2 \mathrm{Cs}}-\mathrm{ZrO}_{2}$-tetragonal.

Tabela 22. Ângulos entre as moléculas adsorvidas e o plano da superfície (001) do $\mathrm{ZrO}_{2}$ tetragonal.

\begin{tabular}{|c|c|c|c|c|c|c|}
\hline \multicolumn{7}{|c|}{ BTEX-O ${ }_{2 \mathrm{Cs}}-\mathrm{ZrO}_{2}$-tetragonal } \\
\hline Funcional & Benzeno & Tolueno & Etilbenzeno & o-xileno & m-xileno & p-xileno \\
\hline PW91 & 0,902 & 0,910 & 1,873 & 1,055 & 1,810 & 0,456 \\
\hline PBE & 0,902 & 0,904 & 1,873 & 1,171 & 1,808 & 0,458 \\
\hline \multicolumn{7}{|c|}{ BTEX-O ${ }_{2 \mathrm{Cl}}-\mathrm{ZrO}_{2}$-tetragonal } \\
\hline Funcional & Benzeno & Tolueno & Etilbenzeno & o-xileno & m-xileno & p-xileno \\
\hline PW91 & 0,847 & 0,911 & 2,022 & 1,053 & 1,998 & 0,458 \\
\hline PBE & 0,846 & 0,575 & 2,023 & 1,057 & 2,001 & 0,488 \\
\hline
\end{tabular}

As energias de adsorção das moléculas de BTEX na superfície (001) do $\mathrm{ZrO}_{2}$ tetragonal para os funcionais PW91, PBE e PBE-D2//PBE são apresentadas na Tabela 23. Os resultados calculados usando o funcional PBE mostraram-se inferiores aos obtidos com o PW91 para todos os adsorbatos estudados, assim como foi observado para as adsorções no $\mathrm{TiO}_{2}$. Esse funcionais não quantificam o efeito das interações de dispersão, o que foi obtido através dos cálculos incluindo a energia de dispersão à geometria otimizada usando o funcional PBE (PBED2//PBE). As energias de interação corrigidas apresentadas na Tabela 23 mostram 
que os cálculos usando os funcionais PW91 e PBE falham na descrição dessa interação, subestimando a energia de adsorção, o que pode ser observado para a adsorção do BTEX no $\mathrm{ZrO}_{2}$, é que a contribuição do termo de dispersão é o mais importante no caso dessas interações. As energias de adsorção obtidas para os complexos BTEX-ZrO $\mathrm{rO}_{2}$-tetragonal foram menores que àquelas para os complexos BTEX-TiO 2 -rutilo e BTEX-TiO ${ }_{2}$-anatásio, independentemente do funcional utilizado.

Tabela 23. Energias de adsorção $(\mathrm{kJ} / \mathrm{mol})$ usando o funcionais PW91, PBE e PBE-D2//PBE para os

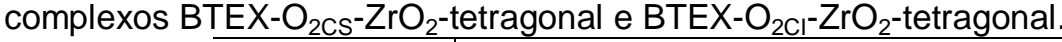

\begin{tabular}{|c|c|c|c|}
\hline \multirow{2}{*}{$E_{\text {adsorção }}$} & \multicolumn{3}{|c|}{ BTEX-O ${ }_{2 \mathrm{cs}}-\mathrm{ZrO}_{2}$-tetragonal } \\
\hline & PW91 & PBE & PBE-D2//PBE \\
\hline Benzeno & 6,75 & 4,29 & 33,35 \\
\hline Tolueno & 7,69 & 5,34 & 36,97 \\
\hline Etilbenzeno & 6,11 & 3,97 & 40,21 \\
\hline o-xileno & 6,93 & 4,59 & 47,70 \\
\hline m-xileno & 5,58 & 3,10 & 49,82 \\
\hline p-xileno & 5,83 & 3,57 & 44,98 \\
\hline \multirow{2}{*}{$E_{\text {adsorção }}$} & \multicolumn{3}{|c|}{ BTEX-O ${ }_{2 \mathrm{Cl}}-\mathrm{ZrO}_{2}$-tetragonal } \\
\hline & PW91 & PBE & PBE-D2//PBE \\
\hline Benzeno & 7,36 & 5,27 & 34,34 \\
\hline Tolueno & 9,48 & 6,90 & 38,74 \\
\hline Etilbenzeno & 8,73 & 6,02 & 42,40 \\
\hline o-xileno & 6,70 & 4,16 & 45,66 \\
\hline m-xileno & 5,24 & 2,71 & 46,81 \\
\hline p-xileno & 8,76 & 6,06 & 47,70 \\
\hline
\end{tabular}

A diferença de densidade de carga dos complexos BTEX-ZrO $\mathrm{rO}_{2}$-tetragonal são mostradas na Figura 36. Apenas resultados usando o funcional PW91 são mostrados. Os resultados usando os demais funcionais apresentaram o mesmo comportamento, diferindo apenas na intensidade da distribuição de carga, mas mantendo as mesmas regiões onde as cargas foram distribuídas após a adsorção. $A$ CDD foi calculada usando Equação 14.

As diferenças de densidade de carga (CDD) apresentadas na Figura 36, mostram um aumento na densidade eletrônica (região em azul) próximo a alguns átomos de carbono das moléculas de BTEX e aos oxigênios bicoordenados da superfície, indicando uma interação das moléculas de BTEX com essa região da superfície. Sobre os átomos de hidrogênio mais próximos à superfície (tolueno, etilbenzeno e xilenos) e, sobre alguns átomos de carbono das moléculas de BTEX, ocorreu um decréscimo da densidade eletrônica (região em vermelho). 
(a)

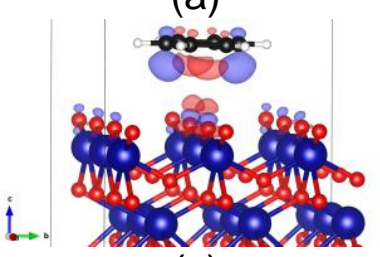

(c)

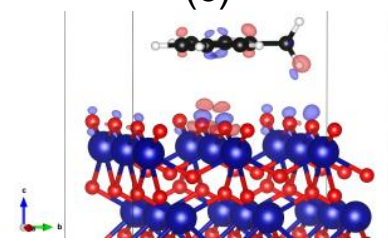

(e)

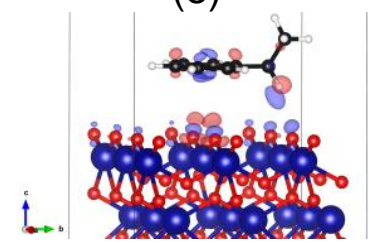

(g)

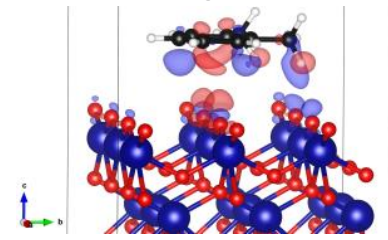

(i)

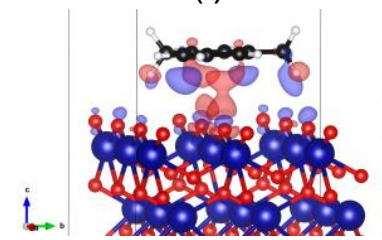

(I)

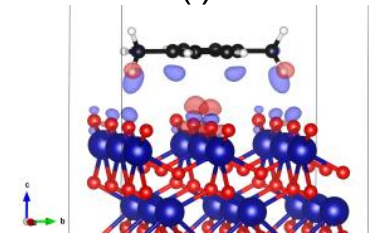

(b)

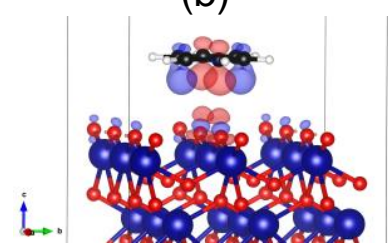

(d)

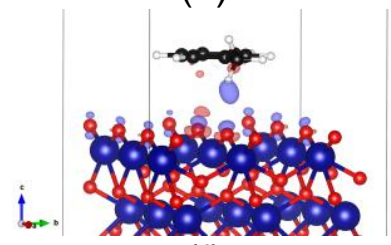

(f)

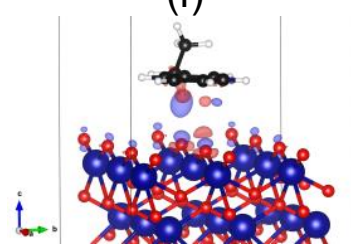

(h)

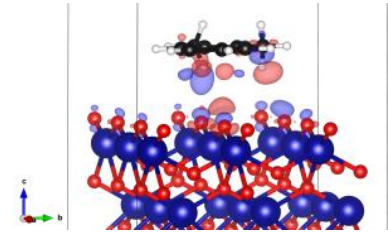

(j)

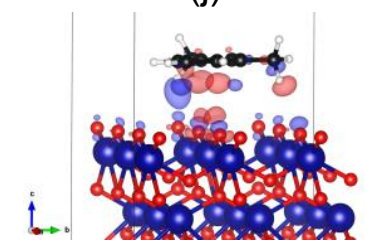

(m)

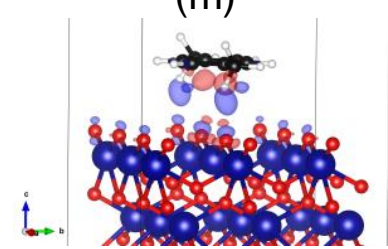

Figura 36. Diferença de densidade de carga (CDD) do (a) Benzeno- $\mathrm{O}_{2 \mathrm{Cs}}-\mathrm{ZrO}_{2}$-tetragonal; (b) Benzeno- $\mathrm{O}_{2 \mathrm{Cl}}-\mathrm{ZrO}_{2}$-tetragonal; (c) Tolueno- $\mathrm{O}_{2 \mathrm{Cs}}-\mathrm{ZrO}_{2}$-tetragonal; (d) Tolueno- $\mathrm{O}_{2 \mathrm{Cl}}-\mathrm{ZrO}_{2}$-tetragonal; (e) Etilbenzeno- $\mathrm{O}_{2 \mathrm{Cs}}-\mathrm{ZrO}_{2}$-tetragonal; (f) Etilbenzeno- $\mathrm{O}_{2 \mathrm{Cl}}-\mathrm{ZrO}_{2}$-tetragonal; (g) o-Xileno-O $\mathrm{O}_{2 \mathrm{Cs}}-\mathrm{ZrO}_{2}$ -

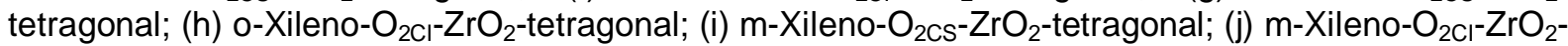
tetragonal; (I) p-Xileno- $\mathrm{O}_{2 \mathrm{cs}}-\mathrm{ZrO}_{2}$-tetragonal; $(\mathrm{m}) \mathrm{p}$-Xileno- $\mathrm{O}_{2 \mathrm{Cl}}-\mathrm{ZrO}_{2}$-tetragonal. A cor vermelha é para valores negativos (decréscimo de densidade eletrônica), e azul para valores positivos (aumento da

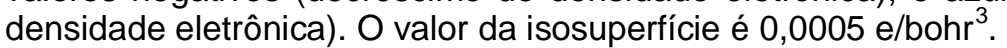

As cargas de Bader (e) das moléculas de BTEX foram calculadas paras as adsorções nas configurações $\mathrm{BTEX}-\mathrm{O}_{2 \mathrm{Cs}}-\mathrm{ZrO}_{2}$-tetragonal e $\mathrm{BTEX}-\mathrm{O}_{2 \mathrm{Cl}}-\mathrm{ZrO}_{2}$ tetragonal. As moléculas de BTEX após a adsorção mantiveram uma carga de 0,00 e, em concordância com os dados de CDD, no qual podem ser observados apenas uma pequena transferência de carga (Figura 36). 
Nas Figuras 37 e 38, podem ser visualizadas as análises da localização dos elétrons através da função de localização eletrônica usando o programa VESTA ${ }^{136,137}$. Na Figura 37, tem-se o ELF para as moléculas de BTEX na geometria da configuração BTEX- $\mathrm{O}_{2 \mathrm{Cs}}-\mathrm{ZrO}_{2}$-tetragonal e, na Figura 38, o ELF para os

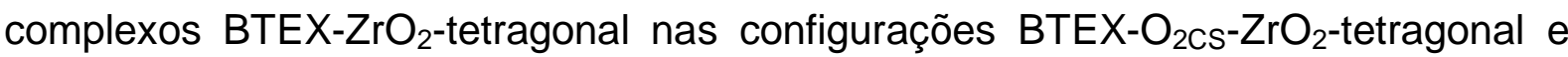
BTEX-O $\mathrm{O}_{2 \mathrm{Cl}}-\mathrm{ZrO}_{2}$-tetragonal. Em ambas, o valor da isosuperfície é 0,80 .

(a)

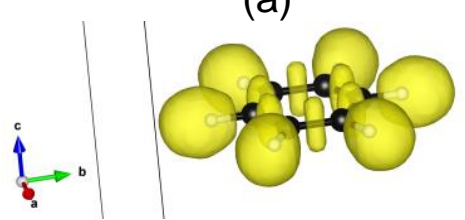

(d)

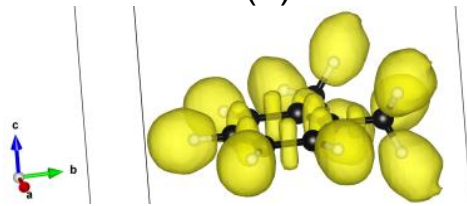

(b)
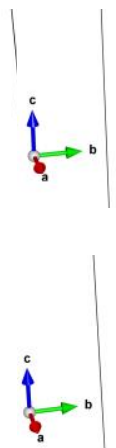

(e)
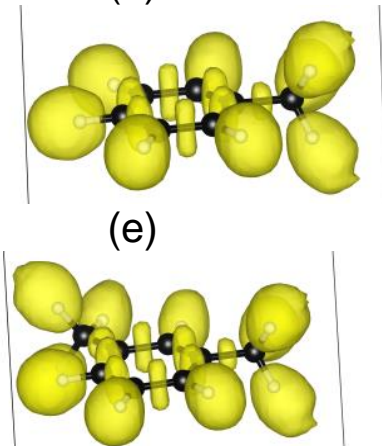

(c)

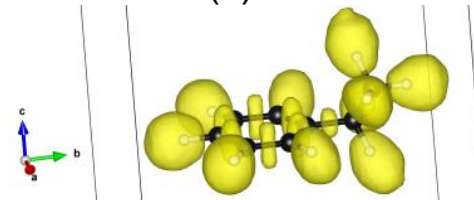

(f)

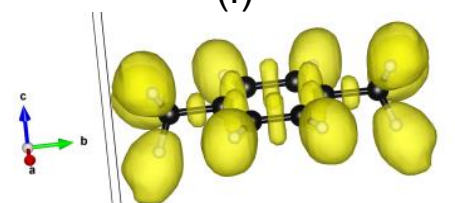

Figura 37. ELF das moléculas de BTEX na geometria otimizada BTEX-O $\mathrm{O}_{2}-\mathrm{ZrO}_{2}$-tetragonal: (a) benzeno; (b) tolueno; (c) etilbenzeno;(d) o-xileno; (e) m-xileno e (f) p-xileno. O valor da isosuperfície é 0,8 .

Através da análise do ELF representado nas Figuras 37 e 38, pode-se observar características em concordância com os resultados da diferença de densidade de carga (CDD). Em ambos, há uma alteração na densidade eletrônica próximo aos oxigênios bicoordenados $\left(\mathrm{O}_{2 \mathrm{C}}\right)$, indicando uma interação entre os hidrogênios das moléculas de BTEX com esses átomos, sendo evidenciado no ELF por uma contração da distribuição eletrônica na região dos hidrogênios das moléculas de BTEX adsorvidas, comparadas com a sua fase gasosa (Figura 37). 
(a)

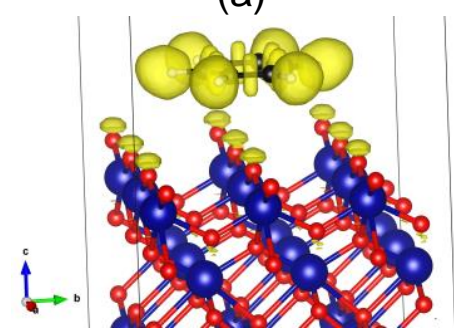

(c)

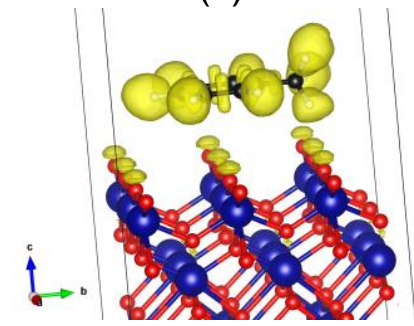

(e)

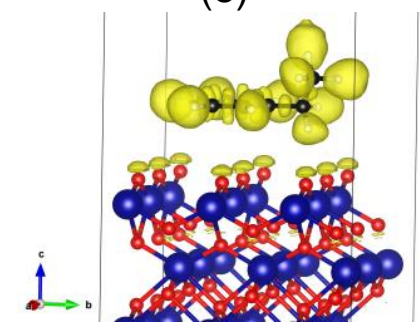

(g)

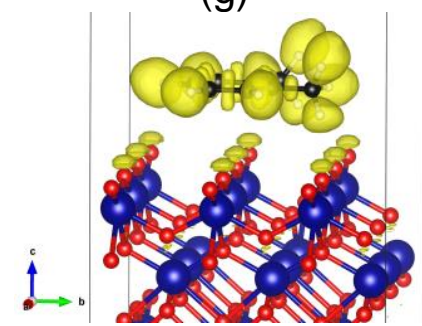

(i)

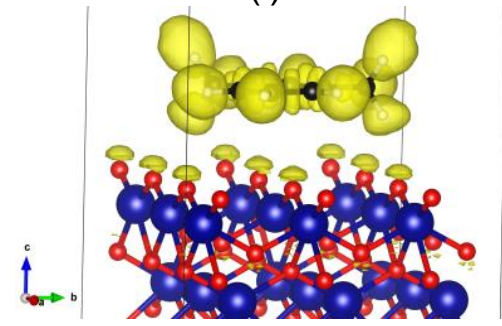

(I)

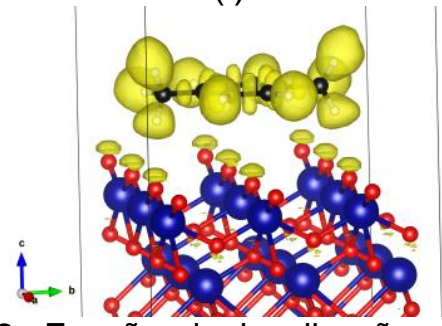

(b)

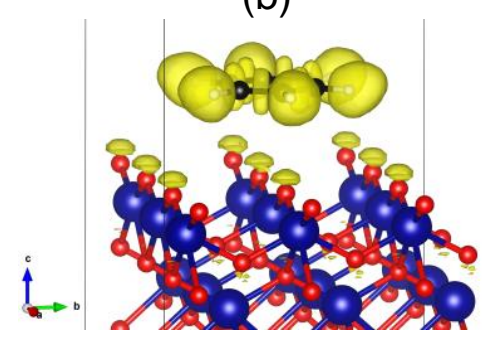

(d)

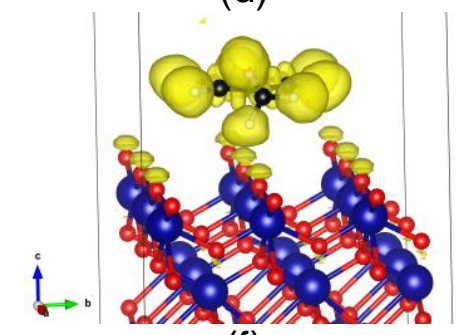

(f)

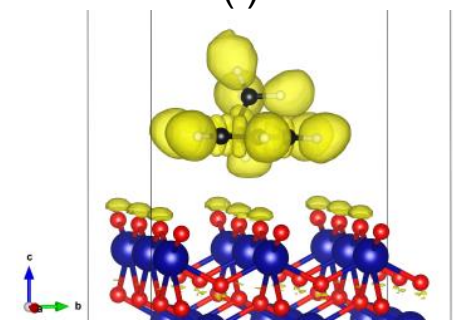

(h)

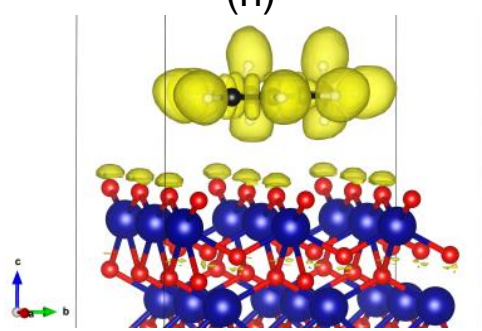

(j)

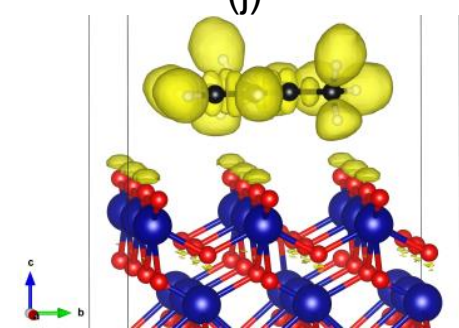

(m)

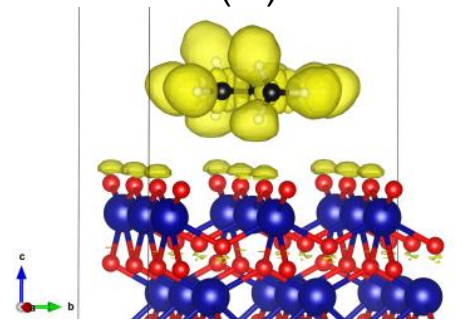

Figura 38. Função de localização eletrônica (ELF) para os complexos (a) Benzeno- $\mathrm{O}_{2 \mathrm{Cs}}-\mathrm{ZrO}_{2}-$ tetragonal; (b) Benzeno- $\mathrm{O}_{2 \mathrm{Cl}}-\mathrm{ZrO}_{2}$-tetragonal; (c) Tolueno- $\mathrm{O}_{2 \mathrm{Cs}}-\mathrm{ZrO}_{2}$-tetragonal; (d) Tolueno- $\mathrm{O}_{2 \mathrm{Cl}^{-}}$

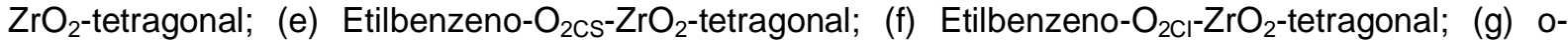

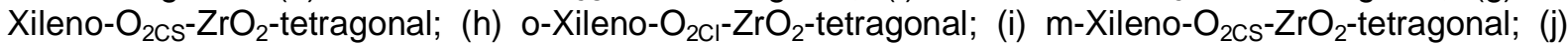
$\mathrm{m}$-Xileno- $\mathrm{O}_{2 \mathrm{Cl}}-\mathrm{ZrO}_{2}$-tetragonal; (I) $\mathrm{p}$-Xileno- $\mathrm{O}_{2 \mathrm{CS}}-\mathrm{ZrO}_{2}$-tetragonal; (m) $\mathrm{p}$-Xileno- $\mathrm{O}_{2 \mathrm{Cl}}-\mathrm{ZrO}_{2}$-tetragonal. O valor da isosuperfície é 0,8 . 
A Figura 39 mostra: (a) na parte inferior, a densidade de estados (DOS) total da superfície (001) do $\mathrm{ZrO}_{2}$ tetragonal livre e após a adsorção; no meio, tem-se o DOS total da superfície (001) do $\mathrm{ZrO}_{2}$ tetragonal livre e do benzeno isolado e, na parte superior, o DOS total do complexo Benzeno- $\mathrm{O}_{2 \mathrm{Cs}}-\mathrm{ZrO}_{2}$-tetragonal e da molécula de benzeno após a adsorção. As densidades de estados apresentadas em (b) correspondem às mesmas estruturas, porém, quando foi feita a adsorção da molécula de benzeno na configuração Benzeno- $\mathrm{O}_{2 \mathrm{Cl}}-\mathrm{ZrO}_{2}$-tetragonal.

(a)

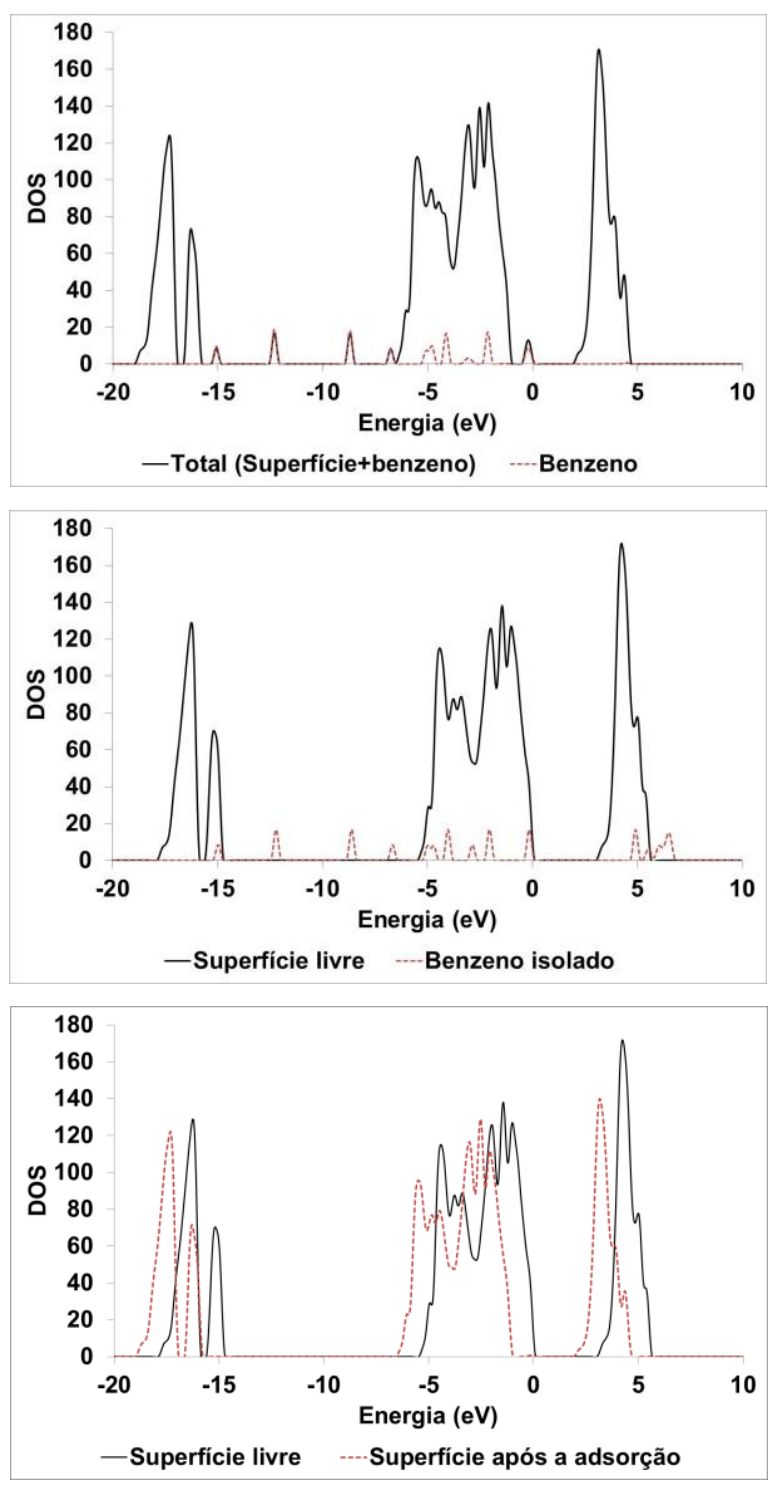

(b)
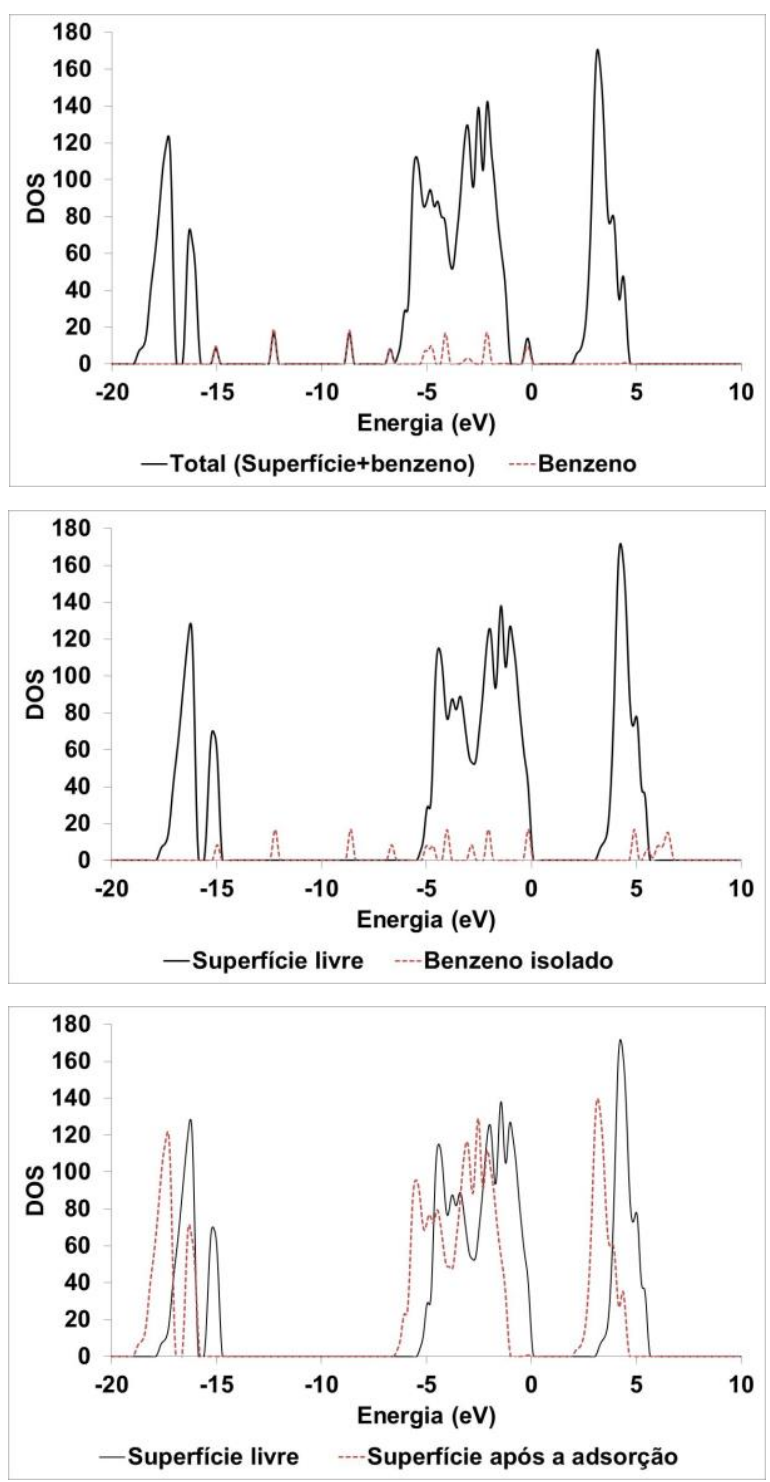

Figura 39. Densidade de estados total e projetada para a adsorção da molécula de benzeno na

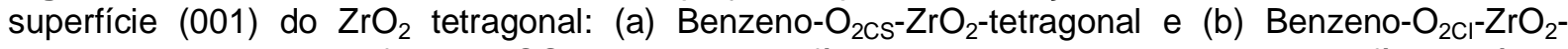
tetragonal. $\mathrm{Na}$ parte inferior: DOS total da superfície livre e projetado sobre superfície após a adsorção. No meio: DOS total da superfície livre e do benzeno isolado. Na parte superior: DOS total

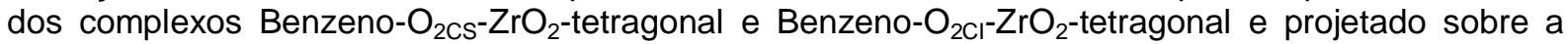
molécula de benzeno do complexo. A energia de Fermi está definida para zero. 


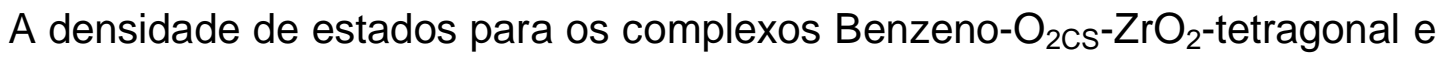
Benzeno- $\mathrm{O}_{2 \mathrm{Cl}}-\mathrm{ZrO}_{2}$-tetragonal sugere uma estabilização dos sistemas após a adsorção. Pode ser observado nas curvas da Figura 39 (a) e (b), que a interação com a superfície muda a banda de valência do benzeno, de regiões de maior energia, para um pouco abaixo da borda da banda de valência. Todas as densidades de estado apresentadas na Figura 39 foram obtidas usando-se o funcional PW91.

\section{5 - Considerações Finais}

As análises das energias de interação entre as moléculas de BTEX e as superfícies estudadas, indicaram que a adsorção ocorre com as moléculas dispostas paralelamente à superfície. Para todos os sistemas, analisou-se em que região da superfície a interação ocorreu com maior intensidade. Para o rutilo, os adsorbatos ficaram dispostos no vale formado entre as pontes de oxigênios bicoordenados, com o centro de massa do anel benzênico entre os titânios pentacoordenados, assumindo duas configurações, separados por um ângulo de $90^{\circ}$. Para o anatásio, também existem duas configurações mais estáveis, a primeira, com os adsorbatos sobre o titânio pentacoordenado, e a segunda, com o centro de massa do anel benzênico sobre um átomo de oxigênio tricoordenado. No $\mathrm{ZrO}_{2}$ tetragonal, as moléculas de BTEX ficaram dispostas sobre o zircônio hexacoordenado, em duas configurações.

As distâncias de interação entre as moléculas de BTEX e as superfícies foram menores para $\circ \mathrm{TiO}_{2}$ anatásio, seguidas pelo rutilo e, então pelo $\mathrm{ZrO}_{2}$ tetragonal. Essas distâncias estão relacionadas com os ângulos de inclinação, de modo que, quanto maior o ângulo, mais próximo a molécula ficou da superfície. As interações com o $\mathrm{ZrO}_{2}$ mostraram as menores variações dos ângulos, isso ocorreu, pois a superfície (001) do $\mathrm{ZrO}_{2}$ tetragonal é bastante regular. Para o rutilo, as maiores inclinações ocorreram para os adsorbatos mais volumosos e menos simétricos (etilbenzeno e xilenos), que devido à proximidade dos oxigênios bicoordenados da superfície, apresentaram uma maior inclinação. Os maiores ângulos foram obtidos das interações com o anatásio, devido à maior irregularidade da superfície. 
As energias de adsorção obtidas para todos os complexos apresentaram a mesma tendência entre os funcionais PW91 e PBE. Para as interações das moléculas de BTEX com as superfícies do rutilo e anatásio, foi feita a análise da influência da correção semiempírica de van der Waals proposta por Grimme na geometria otimizada. Observou-se para os dois casos, que a correção altera de forma significativa a energia de adsorção, indicando uma importante contribuição dessas interações de dispersão na formação desses sistemas. Contudo, as geometrias dos complexos otimizadas com a correção de van der Waals (PBE-D2), apresentaram-se praticamente inalteradas, comparando-se com as obtidas com o funcional PBE, como pode ser observado pelas distâncias e ângulos formados pelos adsorbatos.

Para as interações das moléculas de BTEX com a superfície (001) do $\mathrm{ZrO}_{2}$ tetragonal, foi feita somente a contribuição da correção de van de Waals na energia de adsorção. A contribuição das interações de dispersão para esse sistema, também mostrou-se bastante importante, levando à elevação da energia de adsorção. A partir dos resultados das energias de adsorção para todos os sistemas estudados, a interação das moléculas de BTEX foi maior com a superfície (110) do $\mathrm{TiO}_{2}$ rutilo, seguida pela (101) do $\mathrm{TiO}_{2}$ anatásio, e por último a (001) do $\mathrm{ZrO}_{2}$ tetragonal. Essa ordem na interação das moléculas de BTEX deve ocorrer devido a fatores estruturais. A superfície (110) do rutilo é plana, com os sítios de interação (metal e oxigênios) ficando mais expostos, já no anatásio, a superfície é irregular, mas o metal ainda está exposto para a interação (por isso, os maiores ângulos em uma das configurações). No $\mathrm{ZrO}_{2}$, a superfície também é irregular, porém, os oxigênios estão na parte externa e o metal mais internamente na superfície.

As análises de CDD para as interações com o rutilo e o anatásio apresentaram um aumento da densidade eletrônica entre as moléculas de BTEX e a superfície. Além disso, foi observado um decréscimo de carga nas vizinhanças dos átomos de hidrogênio e próximo aos oxigênios tricoordenados. Essas observações sugerem uma interação entre os átomos de hidrogênio e os de oxigênio bicoordenados $\left(\mathrm{O}_{2} \mathrm{C}\right)$, evidenciada pela diminuição da densidade eletrônica sobre os átomos de hidrogênio e pelo aumento sobre os $\mathrm{O}_{2 \mathrm{C}}$. Essa última característica também foi observada na análise do ELF. As cargas de Bader para os adsorbatos nesses dois complexos mostraram uma pequena alteração. A maior transferência 
para o $\mathrm{TiO}_{2}$ rutilo foi observado para o m-xileno e benzeno, para o anatásio foi com o benzeno.

A CDD para os complexos BTEX-ZrO2-tetragonal apresentou uma menor alteração nas cargas. Houve um decréscimo de carga sobre os hidrogênios mais próximos à superfície, e um aumento, sobre os oxigênios bicoordenados, em concordância com a análise da função de localização eletrônica. A análise das cargas de Bader não mostrou mudança na carga total dos adsorbatos, ocorreu apenas uma alteração das cargas dos carbonos e hidrogênios comparado com as moléculas de BTEX isoladas.

A densidade de estados para todos os sistemas estudados apresentou uma translação dos estados para regiões de menor energia após a adsorção, sugerindo uma estabilização do sistema ao formar os complexos. Ocorrendo a mudança da banda de valência das moléculas de BTEX, de regiões de maior energia, para um pouco abaixo da borda da banda de valência dos complexos.

O estudo do efeito da concentração realizado para a superfície (110) do $\mathrm{TiO}_{2}$ rutilo apresentou a mesma tendência de resultados para as duas configurações estudadas. Essas geometrias foram escolhidas com o objetivo de minimizar a interação lateral entre as moléculas de BTEX. Nos complexos em que houve uma maior inclinação do adsorbato em relação à superfície (principalmente para o oxileno e m-xileno), a distância de interação sofreu uma redução. As energias de adsorção dos complexos que possuem uma maior inclinação, em relação aos sistemas de menor cobertura, apresentaram uma elevação. Esse comportamento foi observado principalmente para a configuração alternada (BTEX-O ${ }_{3 C}-\mathrm{Ti}_{5 c}$-rutilo) e quando utilizou-se a correção de van der Waals (PBE-D2//PBE e PBE-D2). 


\section{Capítulo 5}

\section{5 - Conclusões}

Os cálculos periódicos usando a DFT com os funcionais PW91 e PBE, com funções de base de ondas planas e pseudopotenciais, permitiram determinar 0 melhor conjunto de energia de corte das ondas planas e da malha de pontos k para representar $\circ \mathrm{TiO}_{2}$ rutilo e anatásio e $\circ \mathrm{ZrO}_{2}$ tetragonal. Os parâmetros obtidos foram $300 \mathrm{eV}$ para a energia de corte e $3 \times 3 \times 3$ para os pontos $\mathrm{k}$.

A análise do número de camadas e da área de adsorção possibilitou encontrar um número de camadas igual a quatro para descrever acuradamente a espessura de todas as superfícies estudadas. Em outros trabalhos teóricos que estudaram esses mesmos materiais, os resultados foram semelhantes, indicando também que, com essa espessura, é possível descrever as camadas internas da superfície. As energias das superfícies (110) do $\mathrm{TiO}_{2}$ rutilo, (101) do $\mathrm{TiO}_{2}$ anatásio e (001) do $\mathrm{ZrO}_{2}$ tetragonal mostraram semelhanças com os resultados teóricos existentes na literatura. As supercélulas que foram utilizadas para estudar teoricamente a adsorção das moléculas de BTEX, são as que possuem o mesmo tamanho das células das superfícies (110) (3x2) do $\mathrm{TiO}_{2}$ rutilo, (101) (3×1) do $\mathrm{TiO}_{2}$ anatásio e (001) (3×3) do $\mathrm{ZrO}_{2}$ tetragonal.

Nos estudos das energias de interação dos complexos $\mathrm{BTEX}-\mathrm{TiO}_{2}$ e BTEX$\mathrm{ZrO}_{2}$, os resultados obtidos indicaram a adsorção das moléculas de BTEX na posição paralela à superfície. Os valores das energias de adsorção sugerem que as moléculas gasosas de BTEX devem interagir fraca e reversivelmente com os filmes de $\mathrm{TiO}_{2}$ e $\mathrm{ZrO}_{2}$. A influência das interações de dispersão são descritas de forma insuficiente pelos potenciais de troca e correlação PW91 e PBE, por isso, as correções de van der Waals foram levadas em consideração através da correção semiempírica DFT-D2. A contribuição da dispersão para a estabilização dos complexos $\mathrm{BTEX}-\mathrm{TiO}_{2}$ e BTEX-ZrO $\mathrm{Zr}_{2}$ foi significativa, alterando a interação das moléculas de BTEX, de uma adsorção fraca para relativamente forte. Os estudos da adsorção das moléculas de BTEX sobre o rutilo e anatásio indicam que o termo de dispersão é importante para os resultados energéticos, apesar de seu pequeno 
efeito sobre a geometria. Essa conclusão é evidenciada pelas pequenas alterações nas distâncias e ângulos de interação das moléculas de BTEX.

As curvas de diferença de densidade carga mostram uma redistribuição das cargas após adsorção. Para os complexos $\mathrm{BTEX}-\mathrm{TiO}_{2}$, ocorreu um aumento da densidade eletrônica entre as moléculas de BTEX e a superfície, sugerindo uma interação $\pi$ das moléculas de BTEX. Observou-se também um decréscimo de cargas nas vizinhanças dos átomos de hidrogênio e próximo aos oxigênios tricoordenados da superfície. Além disso, verificou-se o aumento da densidade eletrônica sobre os $\mathrm{O}_{2 \mathrm{C}}$. Todas essas características sugerem uma interação dos adsorbatos com a superfície e dos hidrogênios com os oxigênios bicoordenados, sendo a última evidenciada pela análise do ELF. A análise da carga dos adsorbatos mostrou uma pequena alteração, indicando uma transferência entre a superfície e o adsorbato. Para a adsorção no $\mathrm{ZrO}_{2}$, a CDD apresentou uma menor redistribuição das cargas após a adsorção, sendo mais evidente na região dos hidrogênios (decréscimo de densidade eletrônica) e dos oxigênios bicoordenados (aumento da densidade eletrônica). Sugerindo uma interação nessa região, que foi observada também no ELF através da densidade eletrônica sobre os oxigênios bicoordenados e da contração da densidade sobre os hidrogênios mais próximos a essas regiões. $A$ CDD está diretamente relacionada com a energia de interação. Pode ser observado que quanto maior a transferência de carga, maior foi a energia de interação entre as moléculas de BTEX e a superfície.

A densidade de estados para todos os sistemas estudados, sugere uma estabilização do sistema ao formar os complexos.

Os valores das energias de adsorção, em concordância com as tendências experimentais, indicam uma interação entre as moléculas de BTEX e as superfícies estudadas para o rutilo, anatásio e $\mathrm{ZrO}_{2}$ tetragonal. Portanto, estes materiais são candidatos promissores que poderiam ser utilizados como sensores químicos e catalisadores para a adsorção de moléculas de BTEX. 


\section{Capítulo 6}

\section{6 - Perspectivas}

- Estudar a influência de defeitos e dopantes nas superfícies do $\mathrm{TiO}_{2}$ e $\mathrm{ZrO}_{2}$ sobre a adsorção dos COVs.

- $\mathrm{O} \mathrm{TiO}_{2}$ é utilizado como catalisador na fotodegradação de compostos orgânicos, portanto, o estudo teórico dos mecanismos de fotodissociação dos hidrocarbonetos monoaromáticos nas superfícies do $\mathrm{TiO}_{2}$ apresenta-se como uma importante área de estudo.

- A identificação da contaminação ambiental causada por hidrocarbonetos aromáticos com substituintes mais polares, também é uma área importante. Dessa forma, o desenvolvimento de estudos da adsorção desses compostos nas superfícies do $\mathrm{TiO}_{2}$ e $\mathrm{ZrO}_{2}$, surge como perspectiva de trabalho. 


\section{Capítulo 7}

\section{7 - Referências Bibliográficas}

1. Drexler, K. E.; Peterson, C.; Pergamit, G.; Unbounding the future: the nanotechnology revolution, William Morrow and Company: New York, USA, 1991.

2. Becher, R.; Hongslo, J. K.; Jantunen, M. J.; Dybing, E. Toxicology Letters 1996, 86, 155.

3. Field, R. A.; Goldstone, M. E.; Lester, J. N.; Perry, R. Atmospheric Environment. Part A. General Topics 1992, 26, 2983.

4. Hansen, A. B.; Palmgren, F. Science of The Total Environment 1996, 189-190, 451.

5. Masood, F.; Grohmann, E.; Akhtar, R.; Malik, A. In Environmental Deterioration and Human Health; Malik, A., Grohmann, E., Akhtar, R., eds.; Springer Netherlands, 2014; ch. 1.

6. Bertoni, G.; Ciuchini, C.; Pasini, A.; Tappa, R. Journal of Environmental Monitoring 2002, 4, 903.

7. Černá, M.; Pochmanová, D.; Pastorková, A.; Beneš, I.; Leníček, J.; Topinka, J.; Binková, B. Mutat. Res., Genet. Toxicol. Environ. Mutagen. 2000, 469, 71.

8. Cocheo, V.; Sacco, P.; Boaretto, C.; De Saeger, E.; Ballesta, P. P.; Skov, H.; Goelen, E.; Gonzalez, N.; Caracena, A. B. Nature 2000, 404, 141.

9. Franco, M.; Chairez, I.; Poznyak, T.; Poznyak, A. Journal of Environmental Management 2012, 95, Supplement, S55.

10. Godoi, A. F. L.; Godoi, R. H. M.; Azevedo, R. d.; Maranho, L. T. Quim. Nova 2010, 33, 827.

11. Laurentino, L. d. S.; Marques, M. R. d. C.; Corrêa, S. M. Quim. Nova 2012, 35, 1865.

12. Liu, Z.; Ye, W.; Little, J. C. Building and Environment 2013, 64, 7.

13. Sarigiannis, D. A.; Karakitsios, S. P.; Gotti, A.; Liakos, I. L.; Katsoyiannis, A. Environment International 2011, 37, 743.

14. Seinfeld, J. H.; Spyros, N. P.; Atmospheric Chemistry and Physics: From Air Pollution to Climate Change; $2^{\text {nd }}$ ed.; John Wiley and Sons: New Jersey, 2006.

15. IARC.; Chemical Agents and Related Occupations (vol. 100F). IARC Monographs on the Evaluation of Carcinogenic Risks to Human: Lyon, France, 2012.

16. Chen, M. S.; Santra, A. K.; Goodman, D. W. The Journal of Physical Chemistry B 2004, 108, 17940.

17. Gomez-Romero, P. Adv. Mater. 2001, 13, 163.

18. Jenkins, S. J. Proceedings of the Royal Society of London A: Mathematical, Physical and Engineering Sciences 2009, 465, 2949.

19 Kang, H.; Lim, S.; Park, N.; Chun, K.-Y.; Baik, S. Sensors and Actuators B: Chemical 2010, 147, 316.

20. Kronik, L.; Koch, N. MRS Bulletin 2010, 35, 417.

21. Tautz, F. S. Prog. Surf. Sci. 2007, 82, 479. 
22. Zhou, J.; Dag, S.; Senanayake, S. D.; Hathorn, B. C.; Kalinin, S. V.; Meunier, V.; Mullins, D. R.; Overbury, S. H.; Baddorf, A. P. Phys. Rev. B: Condens. Matter Mater. Phys. 2006, 74.

23. Henderson, M. A. J. Phys. Chem. C 2013, 117, 14113.

24. Jwo, C. S.; Tien, D. C.; Chen, L. C.; Teng, T. P.; Chang, H.; Lin, C. H.; Tsung, T. T. Photodecomposition of gaseous toluene using $\mathrm{TiO}_{2}$ prepared by SANSS. In 7th International Symposium on Measurement Technology and Intelligent Instruments; Jiang, X. J., Whitehouse, D. J., eds.; Journal of Physics Conference Series, 2005; vol. 13; 438.

25. Jwo, C. S.; Chang, H.; Kao, M. J.; Lin, C. H. J. Nanosci. and Nanotechnol. 2007, 7, 1947.

26. Labaki, M.; Siffert, S.; Lamonier, J. F.; Zhilinskaya, E. A.; Aboukais, A. Applied Catalysis B - Environmental 2003, 43, 261.

27. Miller, T. M.; Grassian, V. H. J. Am. Chem. Soc. 1995, 117, 10969.

28. Tanizaki, T.; Murakami, Y.; Hanada, Y.; Ishikawa, S.; Suzuki, M.; Shinohara, R. Journal of Health Science 2007, 53, 514.

29. Yu, K.; Huang, L.; Lou, L. L.; Chang, Y.; Dong, Y.; Wang, H.; Liu, S. Environ. Technol. 2015, 36, 1008.

30. Barsoum, M.; Barsoum, W.; Fundamentals of Ceramics, Taylor \& Francis: New York, USA, 2003.

31. Carter, C. B.; Norton, G.; Ceramic Materials: Science and Engineering, Springer: New York, USA, 2007.

32. Chen, X.; Mao, S. S. Chem. Rev. (Washington, DC, U. S.) 2007, 107, 2891.

33. Yamazoe, S.; Masutani, Y.; Shishido, T.; Tanaka, T. Research on Chemical Intermediates 2008, 34, 487.

34. Jaffe, J. E.; Bachorz, R. A.; Gutowski, M. Phys. Rev. B: Condens. Matter Mater. Phys. 2005, 72.

35. Kumari, L.; Li, W. Z.; Xu, J. M.; Leblanc, R. M.; Wang, D. Z.; Li, Y.; Guo, H.; Zhang, J. Cryst. Growth Des. 2009, 9, 3874.

36. Diebold, U. Appl. Phys. A: Mater. Sci. Process. 2003, 76, 681.

37. Herman, G. S.; Sievers, M. R.; Gao, Y. Phys. Rev. Lett. 2000, 84, 3354.

38. Lazzeri, M.; Vittadini, A.; Selloni, A. Phys. Rev. B: Condens. Matter Mater. Phys. 2001, 63.

39. Lazzeri, M.; Vittadini, A.; Selloni, A. Phys. Rev. B: Condens. Matter Mater. Phys. 2002, 65.

40. Arrouvel, C.; Digne, M.; Breysse, M.; Toulhoat, H.; Raybaud, P. Journal of Catalysis 2004, 222, 152.

41. Labat, F.; Baranek, P.; Adamo, C. J. Chem. Theory Comput. 2008, 4, 341.

42. Perron, H.; Domain, C.; Roques, J.; Drot, R.; Simoni, E.; Catalette, H. Theor. Chem. Acc. 2007, 117, 565.

43. Bennett, R. A.; Stone, P.; Price, N. J.; Bowker, M. Phys. Rev. Lett. 1999, 82, 3831.

44. Diebold, U.; Anderson, J. F.; Ng, K. O.; Vanderbilt, D. Phys. Rev. Lett. 1996, 77, 1322.

45 Hebenstreit, W.; Ruzycki, N.; Herman, G. S.; Gao, Y.; Diebold, U. Phys. Rev. B: Condens. Matter Mater. Phys. 2000, 62, R16334.

46. Hengerer, R.; Bolliger, B.; Erbudak, M.; Grätzel, M. Surf. Sci. 2000, 460, 162.

47. Hird, B.; Armstrong, R. A. Surf. Sci. 1997, 385, L1023.

48. Lindsay, R.; Wander, A.; Ernst, A.; Montanari, B.; Thornton, G.; Harrison, N. M. Phys. Rev. Lett. 2005, 94. 
49. Diebold, U. Surf. Sci. Rep. 2003, 48, 53.

50. Fang, W.; Liu, W.; Guo, X.; Lu, X.; Lu, L. J. Phys. Chem. C 2011, 115, 8622.

51. Mazheika, A. S.; Bredow, T.; Matulis, V. E.; Ivashkevich, O. A. J. Phys. Chem. C 2011, 115, 17368.

52. McGill, P. R.; Muir, J. M. R.; Idriss, H.; Soehnel, T. RSC Adv. 2013, 3, 16829.

53. Mutombo, P.; Balazs, N.; Majzik, Z.; Berko, A.; Chab, V. Applied Surface Science 2012, 258, 4478.

54. Nieto-Lopez, I.; Hernandez-Garcia, L.; Bonilla-Cruz, J.; Sanchez, M. Journal of Molecular Modeling 2014, 20.

55. Suzuki, S.; Tsuneda, T.; Hirao, K. J. Chem. Phys. 2012, 136.

56. Wanbayor, R.; Deak, P.; Frauenheim, T.; Ruangpornvisuti, V. J. Chem. Phys. 2011, 134.

57. Wei, Z.; Zhang, S.; Pan, Z.; Liu, Y. Applied Surface Science 2011, 258, 1192.

58. Zhao, Z.; Li, Z.; Zou, Z. J. Phys. Chem. C 2012, 116, 7430.

59. Chuang, Y. H.; Hong, G. B.; Chang, C. T. Journal of the Air \& Waste Management Association 2014, 64, 738.

60. Jeong, J.; Sekiguchi, K.; Lee, W.; Sakamoto, K. Journal of Photochemistry and Photobiology A: Chemistry 2005, 169, 279.

61. Palau, J.; Colomer, M.; Penya-Roja, J. M.; Martinez-Soria, V. Ind. Eng. Chem. Res. 2012, 51, 5986.

62. Zhang, F.; Zhu, X.; Ding, J.; Qi, Z.; Wang, M.; Sun, S.; Bao, J.; Gao, C. Catalysis Letters 2014, 144, 995.

63. Bai, J.; Zhou, B. Chem. Rev. (Washington, DC, U. S.) 2014, 114, 10131.

64. Nisar, J.; Topalian, Z.; De Sarkar, A.; Osterlund, L.; Ahuja, R. ACS Appl. Mater. Interfaces 2013, 5, 8516.

65. Ricca, C.; Ringuede, A.; Cassir, M.; Adamo, C.; Labat, F. Journal of Computational Chemistry 2015, 36, 9.

66. Hofmann, A.; Clark, S. J.; Oppel, M.; Hahndorf, I. Physical Chemistry Chemical Physics 2002, 4, 3500.

67. Christensen, A.; Carter, E. A. Phys. Rev. B: Condens. Matter Mater. Phys. 1998, 58, 8050.

68. Orlando, R.; Pisani, C.; Ruiz, E.; Sautet, P. Surf. Sci. 1992, 275, 482.

69. Miller, T. M.; Grassian, V. H. J. Am. Chem. Soc. 1995, 117, 10969.

70. Kogler, M.; Koeck, E.-M.; Perfler, L.; Bielz, T.; Stoeger-Pollach, M.; Hetaba, W.; Willinger, M.; Huang, X.; Schuster, M.; Kloetzer, B.; Penner, S. Chem. Mater. 2014, 26, 1690.

71. Miura, N.; Sato, T.; Anggraini, S. A.; Ikeda, H.; Zhuiykov, S. Ionics 2014, 20, 901.

72. Pokrovski, K.; Jung, K. T.; Bell, A. T. I Langmuir 2001, 17, 4297.

73. Leclercq, J.; Giraud, F.; Bianchi, D.; Gaillard, F. Catalysis Communications 2015, 67, 35.

74. BRASIL. Ministério do Trabalho e Emprego. Portaria $n^{0} 3.214$, de 8 de julho de 1978. NR 15 - Atividades e Operações Insalubres. Diponível em $<$ http://portal.mte.gov.br/>, acessado em fevereiro de 2015.

75. IARC. Re-evaluation of Some Organic Chemicals, Hydrazine and Hydrogen Peroxide (vol. 71). IARC Monographs on the Evaluation of Carcinogenic Risks to Human: Lyon, France, 1999.

76. IARC. Some Industrial Chemicals (vol. 77). IARC Monographs on the Evaluation of Carcinogenic Risks to Human: Lyon, France, 2000. 
77. Allouch, A.; Le Calve, S.; Serra, C. A. Sensors and Actuators B - Chemical 2013, 182, 446.

78. Imanaka, N.; Masui, T.; Yasuda, K. Chem. Lett. 2011, 40, 780.

79. Laokiat, L.; Khemthong, P.; Grisdanurak, N.; Sreearunothai, P.; Pattanasiriwisawa, W.; Klysubun, W. Korean J. Chem. Eng. 2012, 29, 377.

80. Mabrook, M.; Hawkins, P. Sensors 2002, 2, 374.

81. Prates Ramalho, J. P.; Illas, F. Chemical Physics Letters 2011, 501, 379.

82. Korologos, C. A.; Nikolaki, M. D.; Zerva, C. N.; Philippopoulos, C. J.; Poulopoulos, S. G. Journal of Photochemistry and Photobiology A - Chemistry 2012, 244, 24.

83. Liu, H.; Wang, X.; Pan, C.; Liew, K. M. J. Phys. Chem. C 2012, 116, 8044.

84. Muir, J. M. R.; Idriss, H. Surf. Sci. 2013, 617, 60.

85. Pillay, D.; Wang, Y.; Hwang, G. S. Korean J. Chem. Eng. 2004, 21, 537.

86. Reiss, S.; Krumm, H.; Niklewski, A.; Staemmler, V.; Woll, C. J. Chem. Phys. 2002, 116, 7704.

87. Suzuki, S.; Yamaguchi, Y.; Onishi, H.; Sasaki, T.; Fukui, K.; Iwasawa, Y. Journal of the Chemical Society - Faraday Transactions 1998, 94, 161.

88. Tatsumi, H.; Sasahara, A.; Tomitori, M. J. Phys. Chem. C 2013, 117, 10410.

89. Haase, F.; Sauer, J. J. Am. Chem. Soc. 1998, 120, 13503.

90. Shen, P. J.; Ding, W. Z.; Zhou, Y. D.; Huang, S. Q. Chem. Res. Chin. Univ. 2010, 26, 460.

91. Amberg, M.; Gunter, J. R. Solid State lonics 1996, 84, 313.

92. Tanabe, K. Materials Chemistry and Physics 1985, 13, 347.

93. Levine, I. N.; Quantum Chemistry, $5^{\text {th }}$ ed.; Prentice Hall: New Jersey, USA, 2000.

94. Lowe, J. P.; Peterson, K. A.; Quantum Chemistry, $3^{\text {rd }}$ ed. Elsevier Academic Press: Burlington, USA, 2006.

95 McQuarrie, D. A.; Simon, J. D.; Physical Chemistry: A Molecular Approach, University Science Books, USA, 1997.

96. Vianna, J. D. M.; FAZZIO, A.; CANUTO, S.; Teoria quântica de moléculas e sólidos: simulação computacional, Livraria da Física: São Paulo, Brasil, 2004.

97. Szabo, A.; Ostlund, N. S.; Modern Quantum Chemistry: Introduction to Advanced Electronic Structure Theory, McGraw-Hill: New York, USA, 1989.

98. Morgon, N. H.; Coutinho, K.; Métodos de Química Teórica E Modelagem Molecular, Editora Livraria da Física: São Paulo, Brasil, 2007.

99 Fermi, E. Accademia Nazionale dei Lincei 1927, 6, 602.

100. Hohenberg, P.; Kohn, W. Phys. Rev. B: Condens. Matter Mater. Phys. 1964, 136, B864.

101. Thomas, L. H. Mathematical Proceedings of the Cambridge Philosophical Society 1927, 23, 542.

102. Geerlings, P.; De Proft, F.; Langenaeker, W. Chem. Rev. (Washington, DC, U. S.) 2003, 103, 1793.

103. Koch, W.; Holthausen, M. C.; A chemist's guide to density functional theory, $2^{\text {nd }}$ ed. Wiley-VCH: Weinheim, Federal Republic of Germany, 2000.

104. Morgon, N. H.; Custódio, R. Quim. Nova 1994, 18, 44.

105. Kohn, W.; Sham, L. J. Phys. Rev. 1965, 140, 1133.

106. Ashcroft, N. W.; Mermin, N. D.; Física do Estado Sólido, Cengage Learning: São Paulo, Brasil, 2011.

107. Kittel, C.; Introdução a fisica do estado solido, $8^{\mathrm{a}}$ ed.; LTC: Rio de Janeiro, Brasil, 2006. 
108. Oliveira, I. S.; Jesus, V. L. B.; Introdução a Física do Estado Sólido, $1^{\text {à ed.; }}$ Livraria da Física: São Paulo, Brasil, 2005.

109. Zunger, A.; Cohen, M. L. Phys. Rev. B: Condens. Matter Mater. Phys. 1978, 18, 5449.

110. Hamann, D. R.; Schluter, M.; Chiang, C. Phys. Rev. Lett. 1979, 43, 1494.

111. Troullier, N.; Martins, J. L. Phys. Rev. B: Condens. Matter Mater. Phys. 1991, 43, 8861.

112. Troullier, N.; Martins, J. L. Phys. Rev. B: Condens. Matter Mater. Phys. 1991, 43, 1993.

113. Lin, J. S.; Qteish, A.; Payne, M. C.; Heine, V. Phys. Rev. B: Condens. Matter Mater. Phys. 1993, 47, 4174.

114. Laasonen, K.; Pasquarello, A.; Car, R.; Lee, C.; Vanderblit, D. Phys. Rev. B: Condens. Matter Mater. Phys. 1993, 47, 10142.

115. Vanderbilt, D. Phys. Rev. B: Condens. Matter Mater. Phys. 1990, 41, 7892.

116. Loucks, T. L. Phys. Rev. 1965, 139, 1181.

117. Loucks, T. L.; Augmented Plane Wave Method: A Guide to Performing Electronic Structure Calculations, W. A. Benjamin, 1967.

118. Andersen, O. K. Phys. Rev. B: Condens. Matter Mater. Phys. 1975, 12, 3060.

119. Blochl, P. E. Phys. Rev. B: Condens. Matter Mater. Phys. 1994, 50, 17953.

120 Burdett, J. K.; Hughbanks, T.; Miller, G. J.; Richardson, J. W.; Smith, J. V. J. Am. Chem. Soc. 1987, 109, 3639.

121. Horn, M.; Schwerdt.Cf; Meagher, E. P. Zeitschrift Fur Kristallographie 1972, 136, 273.

122. Bouvier, P.; Djurado, E.; Ritter, C.; Dianoux, A. J.; Lucazeau, G. International Journal of Inorganic Materials 2001, 3, 647.

123. Farias, S. A. S.; Longo, E.; Gargano, R.; Martins, J. B. L. Journal of Molecular Modeling 2013, 19, 2069.

124. Sorescu, D. C.; Al-Saidi, W. A.; Jordan, K. D. J. Chem. Phys. 2011, 135.

125. Lima, I. P.; Politi, J. R. d. S.; Gargano, R.; Martins, J. B. L. Theor. Chem. Acc. 2015, 134.

126. Kresse, G.; Furthmuller, J. Computational Materials Science 1996, 6, 15.

127. Kresse, G.; Furthmuller, J. Phys. Rev. B: Condens. Matter Mater. Phys. 1996, 54, 11169.

128. Kresse, G.; Hafner, J. Phys. Rev. B: Condens. Matter Mater. Phys. 1993, 47, 558.

129. Kresse, G.; Hafner, J. Phys. Rev. B: Condens. Matter Mater. Phys. 1994, 49, 14251.

130. Perdew, J. P.; Chevary, J. A.; Vosko, S. H.; Jackson, K. A.; Pederson, M. R.; Singh, D. J.; Fiolhais, C. Phys. Rev. B: Condens. Matter Mater. Phys. 1992, 46, 6671.

131. Perdew, J. P.; Chevary, J. A.; Vosko, S. H.; Jackson, K. A.; Pederson, M. R.; Singh, D. J.; Fiolhais, C. Phys. Rev. B: Condens. Matter Mater. Phys. 1993, 48, 4978.

132. Perdew, J. P.; Burke, K.; Ernzerhof, M. Phys. Rev. Lett. 1996, 77, 3865.

133. Perdew, J. P.; Burke, K.; Ernzerhof, M. Phys. Rev. Lett. 1997, 78, 1396.

134. Kresse, G.; Joubert, D. Phys. Rev. B: Condens. Matter Mater. Phys. 1999, 59, 1758.

135. Grimme, S. Journal of Computational Chemistry 2006, 27, 1787.

136. Momma, K.; Izumi, F. J. Appl. Crystallogr. 2008, 41, 653.

137. Momma, K.; Izumi, F. J. Appl. Crystallogr. 2011, 44, 1272. 
138. Schaftenaar, G.; Noordik, J. H. J. Comput.-Aided Mol. Des. 2000, 14, 123.

139. http://cms.mpi.univie.ac.at/odubay/p4vasp_site/news.php, acessado em fevereiro de 2015.

140. Kokalj, A. J. Mol. Graphics Modell. 1999, 17, 176.

141. Kokalj, A. Computational Materials Science 2003, 28, 155.

142. http://vaspview.sourceforge.net/, acessado em fevereiro de 2015.

143. Bates, S. P.; Kresse, G.; Gillan, M. J. Surf. Sci. 1997, 385, 386.

144. Lindan, P. J. D.; Harrison, N. M.; Gillan, M. J.; White, J. A. Phys. Rev. B: Condens. Matter Mater. Phys. 1997, 55, 15919.

145. Liu, W.; Carrasco, J.; Santra, B.; Michaelides, A.; Scheffler, M.; Tkatchenko, A. Phys. Rev. B: Condens. Matter Mater. Phys. 2012, 86, 245405.

146. Carrasco, J.; Liu, W.; Michaelides, A.; Tkatchenko, A. J. Chem. Phys. 2014, 140.

147. Bader, R. F. W. Acc. Chem. Res. 1985, 18, 9.

148. Bader, R. F. W.; Laidig, K. E. J. Mol. Struct. 1991, 234, 75. 


\section{Anexo I}

\section{Artigo Aceito para Publicação}

Revista Virtual de Quimica - 2016 


\section{Otimização de parâmetros de corte em cálculos periódicos DFT de ondas planas para superfícies (110) rutilo e (101) anatase do $\mathrm{TiO}_{2}$}

Vargas, M. R.; de Castro, E. A. S.; Politi, J. R. S.; Martins, J. B. L.'

\section{Optimization of cutoff parameters using DFT periodic calculations for (110) rutile and (101) anatase $\mathrm{TiO}_{2}$ surfaces}

Abstract: $\mathrm{TiO}_{2}$ used as a catalyst in the conversion of Volatile Organic Compounds into less toxic substances is an important application for improving the quality of human life. In this work, $\mathrm{TiO}_{2}$ (110) rutile and (101) anatase surfaces were studied. These surfaces were used for benzene, toluene, ethylbenzene, o-xylene,m-xylene and $p$-xylene (BTEX) molecules adsorption studies. The Density Functional Theory (DFT) with periodic boundary conditions and plane wave basis set with the PW91 exchange-correlation functional were used. The results showed that $300 \mathrm{eV}$ for the cutoff energy of the plane waves and $3 \times 3 \times 3 \mathrm{k}$ points mesh were appropriate for the BTEX adsorption calculation. A supercell with four layers $(3 \times 2)$ for the (110) rutile $\mathrm{TiO}_{2}$, and $(3 \times 1)$ for the (101) anatase $\mathrm{TiO}_{2}$ were considered for the surface modeling. Keywords: Surface; Adsorption; BTEX; Periodic DFT, Plane Wave.

Resumo: $\mathrm{O}$ uso do $\mathrm{TiO}_{2}$ como catalisador na conversão de Compostos Orgânicos Voláteis em substâncias menos tóxicas é uma importante aplicação para a melhoria da qualidade de vida do ser humano. Nesse trabalho, foram estudadas as superfícies (110) rutilo e (101) anatase do $\mathrm{TiO}_{2}$. Estas superfícies foram utilizadas para estudos de adsorção de moléculas de benzeno, tolueno, etilbenzeno, o-xileno, m-xileno e p-xileno (BTEX). A Teoria do Funcional de Densidade (DFT) com condições de contorno periódicas e conjunto de funções de base de ondas planas e o funcional de troca e correlação PW91 foram usados. Os resultados mostraram que o uso de $300 \mathrm{eV}$ e $3 \times 3 \times 3$ para a energia de corte das ondas planas e a malha de pontos $\mathrm{k}$, respectivamente, foram considerados apropriados para os cálculos da adsorção do BTEX. As supercélulas com quatro camadas $(3 \times 2)$ para a superfície (110) do $\mathrm{TiO}_{2}$ rutilo e (3x1) para a superfície (101) do $\mathrm{TiO}_{2}$ anatase foram usadas para a modelagem da superfície.

Palavras-chave: Superfícies; Adsorção; BTEX; DFT periódico, Ondas Planas. 
Universidade de Brasília, Instituto de Química, Laboratório de Química Computacional, CP 4478, Brasília, DF, 70904-970, Brazil.

lopes@unb.br

Otimização de parâmetros de corte em cálculos periódicos DFT de ondas planas para superfícies (110) rutilo e (101) anatase do $\mathrm{TiO}_{2}$

Marcos dos Reis Vargas, ${ }^{a, b}$ Elton Anderson Santos de Castro, ${ }^{c}$ José Roberto dos Santos Politi, ${ }^{a}$ João B. L. Martins ${ }^{a}$

a Universidade de Brasília, Instituto de Química, Laboratório de Química Computacional, CP 4478, Brasília-DF 70904-970, Brazil.

b Instituto Federal de Educação, Ciência e Tecnologia de Goiás, Coordenação de Química Tecnológica, Câmpus Goiânia, 74055-110, Goiânia-GO, Brazil

' Universidade Estadual de Goiás (UEG), Química, Formosa-GO, 73807-250, Brazil. *lopes@unb.br

1. Introdução

2. Detalhes Computacionais

3. Resultados e Discussão

3.1. Análise da Energia de Corte das Ondas Planas e dos Pontos $k$

3.2. Análise do Número de Camadas das Superfícies (110) do $\mathrm{TiO}_{2}$ Rutilo e (101) do $\mathrm{TiO}_{2}$ Anatase

3.3. Análise da Área Superficial das Superfícies (110) do $\mathrm{TiO}_{2}$ Rutilo e (101) Anatase

4. Conclusões

\section{Introdução}

A preocupação da população com as condições ambientais a que estão expostas tem aumentado, gerando várias discussões e estudos. Dentre todos os tipos de poluição, a atmosférica é uma das que tem afetado de forma direta a qualidade de vida nas cidades. A poluição atmosférica pode ocasionar danos aos ecossistemas e causar ou agravar problemas de saúde humana, nos quais muitos dos poluentes são considerados carcinogênicos. ${ }^{1-2}$

As principais causas da poluição atmosférica são as emissões pelas indústrias, a queima de combustíveis pelos automóveis, as perdas por evaporação no 
armazenamento e distribuição de combustíveis e solventes, as emissões biogênicas e a queima da biomassa. A qualidade do ar em ambientes fechados é alterada principalmente pela presença de inúmeros componentes usados em tintas, adesivos, vernizes, ceras, revestimentos, solventes, produtos de limpeza, dentre outros. ${ }^{3-4}$

Entre os compostos químicos utilizados pela indústria que estão diretamente ligados à poluição atmosférica, principalmente em ambientes fechados, estão os denominados Compostos Orgânicos Voláteis (COVs). Esses COVs incluem todo o conjunto de compostos orgânicos presentes na atmosfera na fase de vapor, possuindo pontos de ebulição entre $50{ }^{\circ} \mathrm{C}$ e $260{ }^{\circ} \mathrm{C}$. Dentro desta classe, destacamse, pela sua elevada toxicidade, os hidrocarbonetos monoaromáticos benzeno, tolueno, etilbenzeno e xilenos que são conhecidos pela sigla BTEX. ${ }^{3,5}$

Para a melhora da qualidade do ar, a utilização da nanotecnologia surge como uma proposta eficiente e promissora. Devido às suas características catalíticas, o dióxido de titânio $\left(\mathrm{TiO}_{2}\right)$ é considerado uma alternativa mais econômica nos processos de remoção de COVs, tais como o BTEX. ${ }^{6-10}$

$\mathrm{O} \mathrm{TiO}_{2}$, também chamado de titânia, é um óxido metálico semicondutor $\left(\mathrm{E}_{\text {gap }}\right.$ = 3,0 eV) que apresenta propriedades catalíticas, como na degradação de poluentes orgânicos, bem como sensor de gases, além do uso em dispositivos elétricos. ${ }^{11-13} \mathrm{O}$ estudo das superfícies deste material é relevante para a adsorção e reatividade das espécies adsorvidas. A adsorção das moléculas nas superfícies é a etapa inicial de vários processos químicos, tais como a catálise e a detecção e identificação de gases. $\mathrm{O} \mathrm{TiO}_{2}$ possui três formas alotrópicas, rutilo, anatase e brookita, sendo o rutilo a forma alotrópica mais estável. ${ }^{11-12}$

As estruturas das células unitárias do $\mathrm{TiO}_{2}$ rutilo e anatase possuem octaedros de $\mathrm{TiO}_{6}$, onde cada íon $\mathrm{Ti}^{4+}$ possui em suas vizinhanças um octaedro de seis íons $\mathrm{O}^{2-}$. As distâncias $\mathrm{Ti}-\mathrm{Ti}$ são maiores na fase anatase, enquanto as distâncias Ti-O são maiores na fase rutilo. ${ }^{13-16}$

Nesse trabalho, o objetivo foi estudar os parâmetros de corte das superfícies (110) rutilo e (101) anatase do $\mathrm{TiO}_{2}$, as quais serão utilizadas para estudos de adsorção das moléculas de BTEX. Para tanto, foi empregado o formalismo da Teoria do Funcional de Densidade (DFT) com condições de contorno periódicas e função de base de ondas planas. Os resultados foram comparados com dados já existentes na literatura, auxiliando na compreensão das propriedades das superfícies. 


\section{Detalhes Computacionais}

As estruturas do $\mathrm{TiO}_{2}$ nas fases rutilo e anatase (Figura 1) foram construídas a partir dos arquivos de informação cristalográfica (CIF). Os parâmetros de rede experimentais para o rutilo são $a=4,594 \AA$ e $c=2,959 \AA$, com grupo espacial $\mathrm{P} 4_{2} / \mathrm{mnm}^{17} \mathrm{O}$ anatase possui parâmetros $\mathrm{a}=3,785 \AA$ e $\mathrm{c}=9,520 \AA$, com grupo espacial $14_{1} /$ amd. $^{18}$

(a)

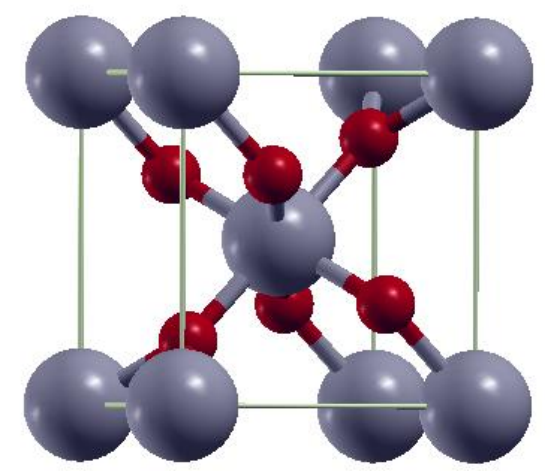

(b)

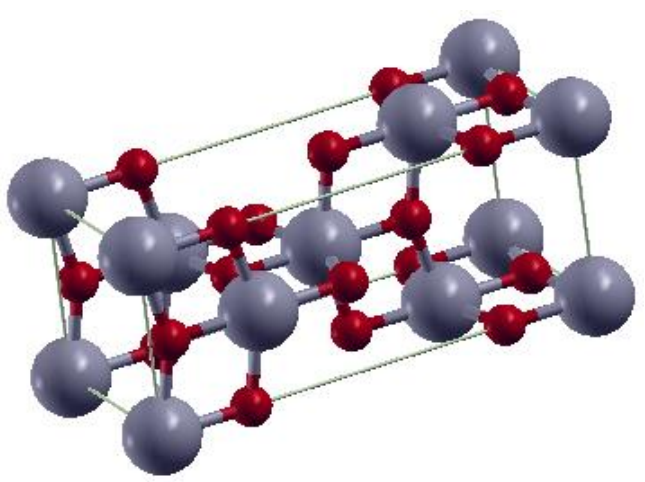

Figura 1. Estruturas da célula unitária: (a) $\mathrm{TiO}_{2}$ rutilo; (b) $\mathrm{TiO}_{2}$ anatase.

Para os cálculos dos sólidos ("bulks") e das superfícies que serão utilizados na adsorção das moléculas de benzeno, tolueno, etilbenzeno, o-xileno, m-xileno e pxileno (BTEX) foi usada a DFT com condições de contorno periódicas. Os cálculos DFT foram realizados com o código computacional de simulação ab initio VASP4. $6^{19-}$ 22 usando a aproximação do gradiente generalizado (GGA) e o funcional de troca e correlação PW9123-24. O VASP4.6 utiliza a densidade eletrônica de valência expandida em um conjunto de bases de ondas planas. A interação dos elétrons de caroço com os elétrons dos níveis de valência foi representada através do método Projected Augmented Wave (PAW) ${ }^{25-26}$ de Blöchl. Os elétrons de valência considerados para cada átomo foram: oxigênio $\left[2 s^{2} 2 p^{4}\right.$ ], titânio [ $\left.3 d^{3} 4 s^{1}\right]$, carbono $\left[2 s^{2} 2 p^{2}\right]$ e hidrogênio $\left[1 s^{1}\right]$. O pseudopotencial usado para tratar os elétrons do caroço foi PAW-PW91.

Para que os cálculos sejam realizados de forma prática é necessário fazer o truncamento da base, usando um conjunto de bases de ondas planas finito. A forma de realizar esse procedimento é através da escolha de uma energia máxima 
(energia de corte), de modo que sejam incluídas na base apenas as ondas planas que apresentam energias menores que o valor escolhido. O número de pontos $\mathrm{k}$ na zona de Brillouin também pode ser variado para obter a densidade eletrônica, sendo que a escolha da energia de corte e a malha de pontos $k$ são feitas para alcançar critérios de convergência. Neste estudo foram analisados os parâmetros de corte: número de pontos $\mathrm{k}$ e energia de corte para a convergência da energia com o menor custo computacional. Os modelos para os sólidos foram otimizados variando-se 0 número de pontos $\mathrm{k}(2 \times 2 \times 2,3 \times 3 \times 3,4 \times 4 \times 4$ e $5 \times 5 \times 5)$ e a energia de corte das ondas planas ( $250 \mathrm{eV}, 300 \mathrm{eV}, 350 \mathrm{eV}, 400 \mathrm{eV}$ e $500 \mathrm{eV}$ ).

A otimização do bulk foi inicialmente realizada permitindo a relaxação dos pontos da rede (denominada de iônica). Em seguida, fez-se a otimização total, ou seja, a relaxação iônica da estrutura cristalina e do volume do bulk (parâmetros de rede), simultaneamente. Os valores obtidos com as otimizações para os parâmetros de rede foram comparados com os resultados experimentais. ${ }^{17-18}$

As estruturas que apresentaram os parâmetros de rede mais próximos ao valor experimental foram utilizadas para analisar a convergência da energia em função dos pontos $k$ e da energia de corte das ondas planas. Para isto, calculou-se a energia total de cada uma das estruturas em função desses parâmetros, sem otimizar a geometria do sistema. Para os cálculos da superfície, foram utilizados o número de pontos $\mathrm{k}$ e a energia de corte, para os quais a energia total apresentava convergência, com valores para os parâmetros de rede não divergindo mais que 2 \% do valor experimental.

Com as estruturas otimizadas, foi realizado o corte dos planos cristalinos na direção (110) para o $\mathrm{TiO}_{2}$ rutilo e (101) para o $\mathrm{TiO}_{2}$ anatase, que são os planos mais estáveis para essas duas estruturas. ${ }^{8} \mathrm{Na}$ Figura 2, podem ser visualizados esses planos, nos quais as superfícies apresentam quatro camadas. Usando a notação de Wood na Figura 2 (a) e (b) tem-se a superfície (4x2) do $\mathrm{TiO}_{2}$ rutilo e na Figura 2 (c) e (d), a superfície $(4 \times 1)$ do $\mathrm{TiO}_{2}$ anatase. As superfícies foram modeladas periodicamente em uma supercélula, onde fez-se somente a relaxação iônica mantendo-se a forma e o volume do sistema. 
(a)

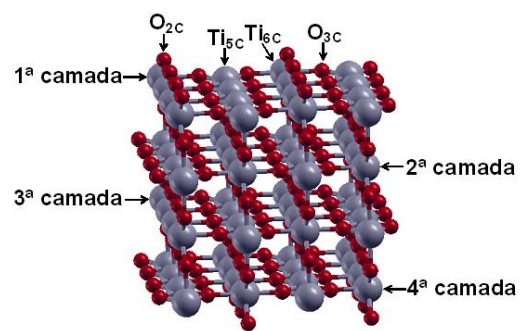

(c)

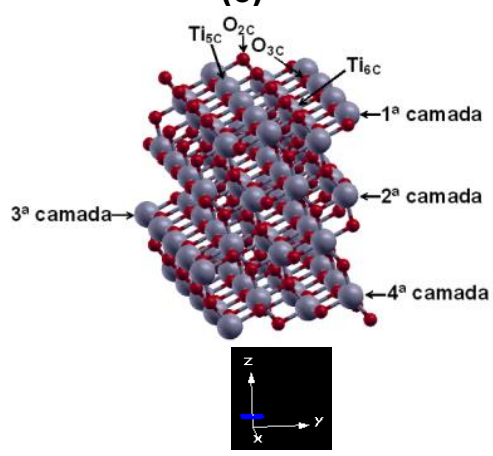

(b)

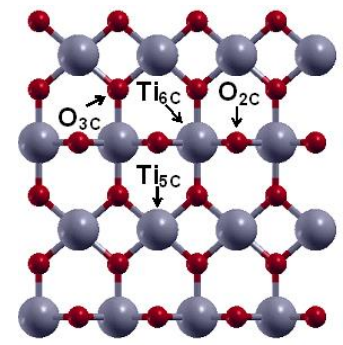

(d)

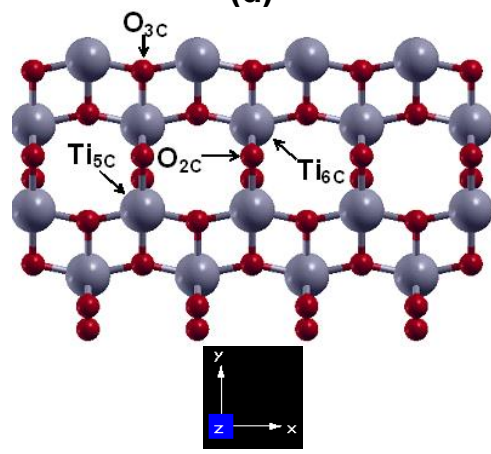

Figura 2. Estruturas do $\mathrm{TiO}_{2}$ rutilo (110) e $\mathrm{TiO}_{2}$ anatase (101): (a) e (b) vista lateral e superior da superfície (110) do $\mathrm{TiO}_{2}$ rutilo, respectivamente; (c) e (d) vista lateral e superior da superfície (101) do $\mathrm{TiO}_{2}$ anatase, respectivamente.

Para simulação das superfícies, analisou-se quantas camadas seriam necessárias para descrevê-la. Essa etapa foi feita avaliando-se a convergência da energia da superfície em função do número de camadas. As energias da superfície para quatro, seis, oito, dez e doze camadas para os slabs (1x1) foram calculadas no estudo da influência da espessura usando-se a Equação 1. Os cálculos foram realizados através da relaxação da metade do número de camadas em um dos lados da superfície, utilizando-se um vácuo de separação de $20 \AA$ entre as superfícies. Este foi previamente testado para garantir que não houvesse interação entre as superfícies. A energia da superfície é dada por:

$$
E_{\text {Superf }}=\frac{\left(E_{\text {slab }}-n E_{\text {bulk }}\right)}{2 A}
$$

no qual $E_{\text {Superf }}$ é a energia da superfície, $E_{s l a b}$ é a energia do slab relaxado. $E_{b u l k}$ é a energia do bulk, n é a razão entre o número de átomos do slab e do bulk e $\mathrm{A}$ é a área da superfície. Na Figura 3 (a) e (b) podem ser visualizadas as superfícies com duas, quatro, seis, oito, dez e doze camadas para $0 \mathrm{TiO}_{2}$ rutilo e anatase, respectivamente. 

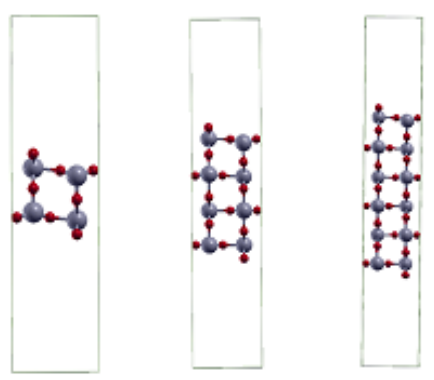

(a)

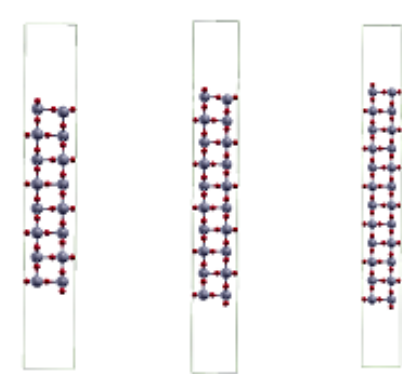

(b)
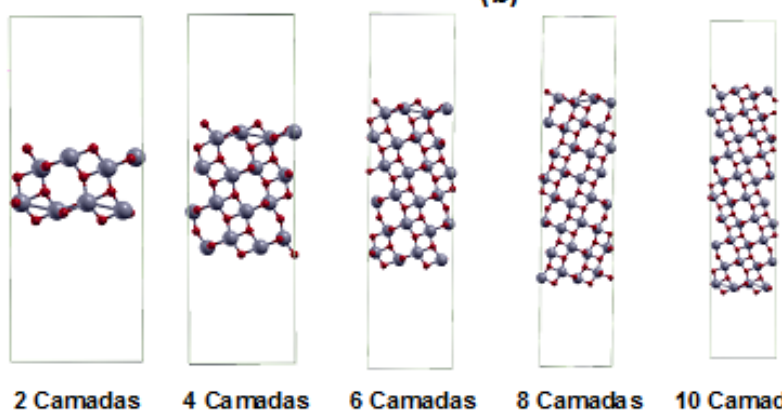

8 Camadas 10 Camadas 12 Camadas

Figura 3. Superfícies com duas, quatro, seis, oito, dez e doze camadas para o (a) $\mathrm{TiO}_{2}$ rutilo (110) e para o (b) $\mathrm{TiO}_{2}$ anatase (101).

Depois de encontrado o número de camadas para simular a superfície, fez-se estudos para determinar qual seria a área da superfície necessária para que não ocorresse interação lateral entre as moléculas que seriam adsorvidas, para isso fezse o cálculo para as moléculas de benzeno, tolueno, etilbenzeno, o-xileno, m-xileno e p-xileno isolados em supercélulas que possuíam o mesmo tamanho das células

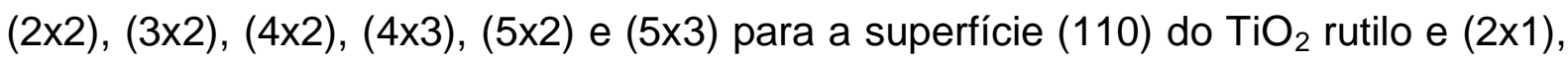
(2x2), (3x1), (3x2), (4x1) e (4x2) para a superfície (101) do $\mathrm{TiO}_{2}$ anatase. $\mathrm{Na}$ Tabela 1 estão os parâmetros de rede a e b $(\AA)$ das supercélulas estudadas para a superfície (110) do $\mathrm{TiO}_{2}$ rutilo e (101) do $\mathrm{TiO}_{2}$ anatase. Foi utilizada a menor superfície em que a energia total manteve-se constante em comparação com outras que possuíam áreas maiores. A molécula de benzeno apresenta uma área de aproximadamente $22,219 \AA^{2}(5,052 \AA \times 4,398 \AA)$, a de tolueno $26,687 \AA^{2}(6,068 \AA x$ $4,398 \AA$ ) , a de etilbenzeno $30,834 \AA^{2}(7,011 \AA \times 4,398 \AA)$, a de p-xileno $31,041 \AA^{2}$ $\left(7,058 \AA\right.$ x 4,398 $\AA$ ) e as de o-xileno e m-xileno $32,397 \AA^{2}(6,068 \AA$ x 5,339 $\AA$ ). 
Tabela 1. Parâmetros de rede a e b das supercélulas estudadas para a superfície (110) do $\mathrm{TiO}_{2}$ rutilo e (101) do $\mathrm{TiO}_{2}$ anatase

\begin{tabular}{c|c|c|c|c|c|c}
\hline Rutilo & $(2 \times 2)$ & $(3 \times 2)$ & $(4 \times 2)$ & $(4 \times 3)$ & $(5 \times 2)$ & $(5 \times 3)$ \\
\hline $\mathrm{a}(\AA)$ & 5,908 & 8,862 & 11,816 & 11,816 & 14,771 & 14,771 \\
\hline $\mathrm{b}(\AA)$ & 13,043 & 13,043 & 13,043 & 19,564 & 13,043 & 19,564 \\
\hline Anatase & $(2 \times 1)$ & $(2 \times 2)$ & $(3 \times 1)$ & $(3 \times 2)$ & $(4 \times 1)$ & $(4 \times 2)$ \\
\hline $\mathrm{a}(\AA)$ & 7,557 & 7,557 & 11,335 & 11,335 & 15,114 & 15,114 \\
\hline $\mathrm{b}(\AA)$ & 10,420 & 20,840 & 10,420 & 20,840 & 10,420 & 20,840 \\
\hline
\end{tabular}

\section{Resultados e Discussão}

\subsection{Análise da Energia de Corte das Ondas Planas e dos Pontos k}

As estruturas do bulk de $\mathrm{TiO}_{2}$ na fase rutilo e anatase foram otimizadas variando-se o número de pontos $\mathrm{k}$ e a energia de corte das ondas planas conforme apresentado na Tabela 2. Em cada uma das combinações de energia de corte e pontos k estão os parâmetros de rede obtidos com a otimização.

Tabela 2. Parâmetros de rede $(\AA ̊)$ do $\mathrm{TiO}_{2}$ rutilo obtidos com os cálculos variando-se o número de pontos $\mathrm{k}$ e a energia de corte das ondas planas.

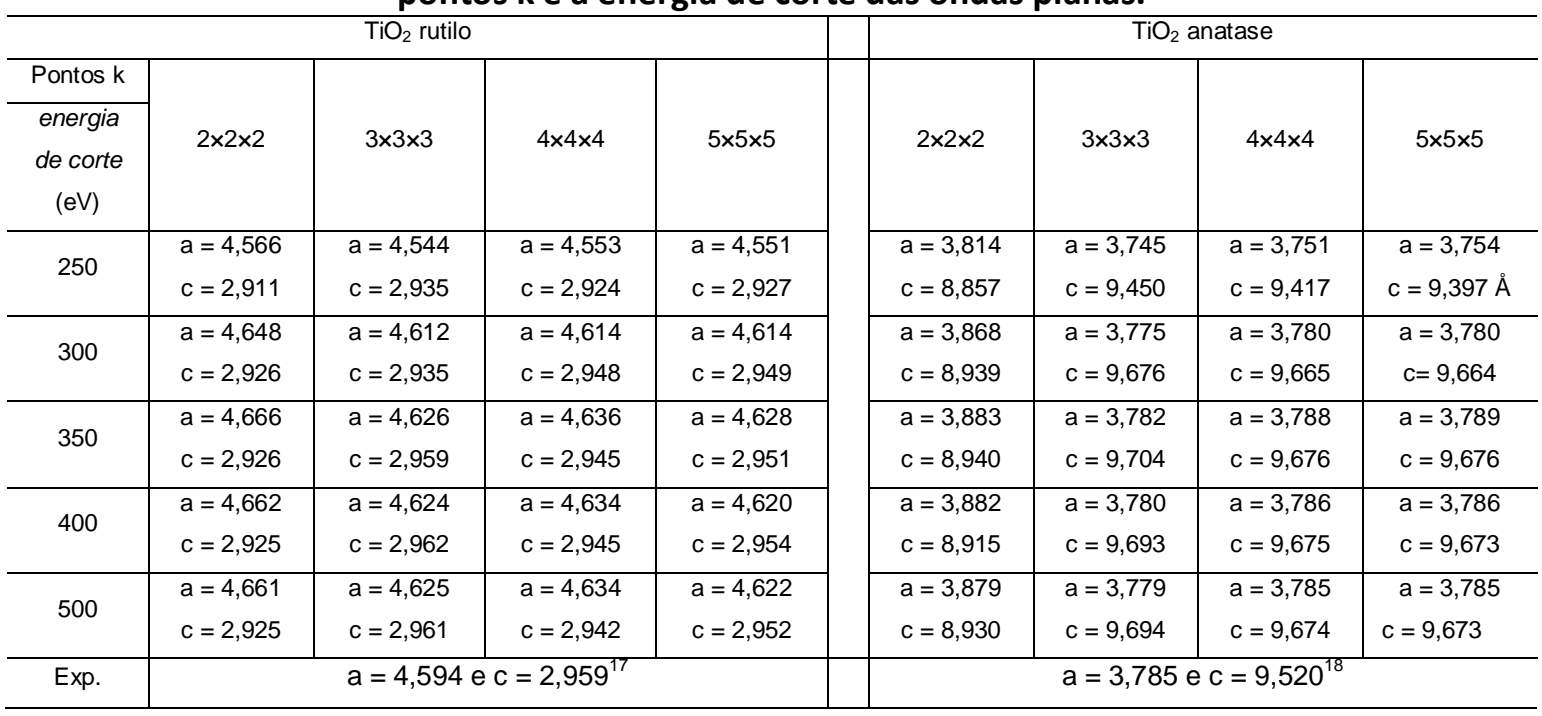

Os valores da Variação Relativa Percentual (VRP) de cada parâmetro de rede obtido com a otimização em relação ao valor experimental ${ }^{17-18}$ estão apresentados na Figura 4 (i) para o parâmetro de rede a do $\mathrm{TiO}_{2}$ rutilo; (ii) para o 
parâmetro de rede $c$ do $\mathrm{TiO}_{2}$ rutilo; (iii) para o parâmetro de rede a do $\mathrm{TiO}_{2}$ anatase e (iv) para o parâmetro de rede $c$ do $\mathrm{TiO}_{2}$ anatase. Como em cada um desses cálculos fez-se a otimização dos parâmetros de rede do bulk, avaliou-se com isso qual combinação de pontos k e energia de corte das ondas planas geram resultados que mais se aproximam do valor experimental do $\mathrm{TiO}_{2}$ rutilo e do anatase ${ }^{17-18}$. Foi possível também buscar uma combinação mínima que possibilitasse a realização dos cálculos da superfície e adsorções de BTEX, já que esses adsorbatos são moléculas relativamente volumosas, que também irão exigir uma supercélula contendo muitos átomos.

(i)

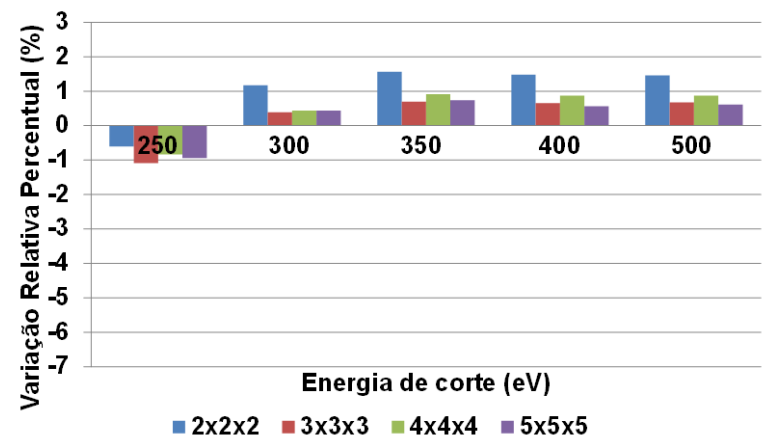

(iii)

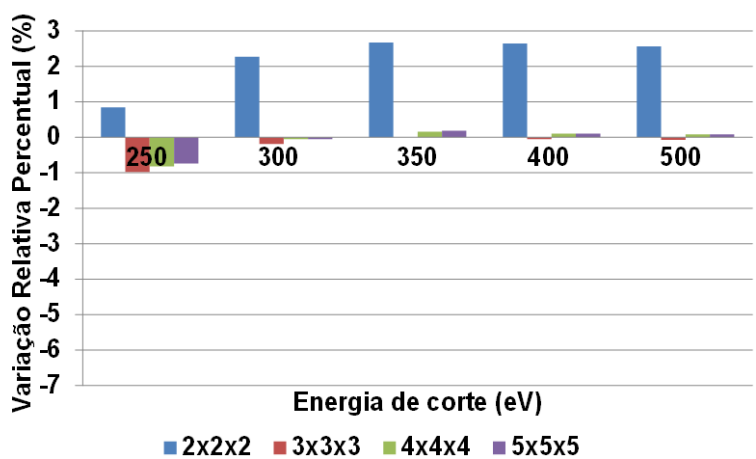

(ii)

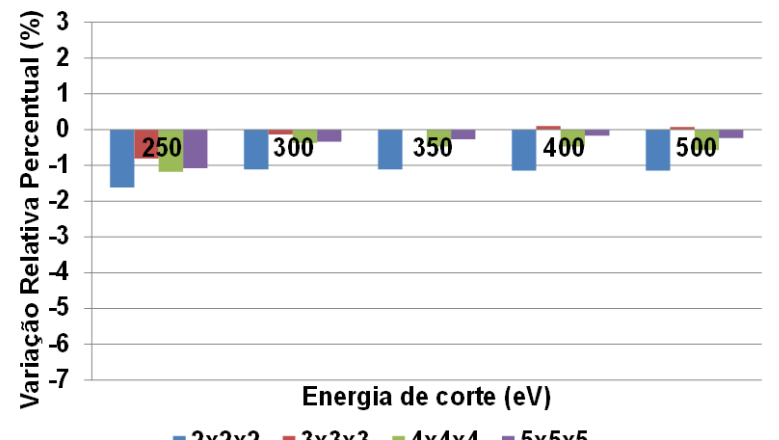

(iv)

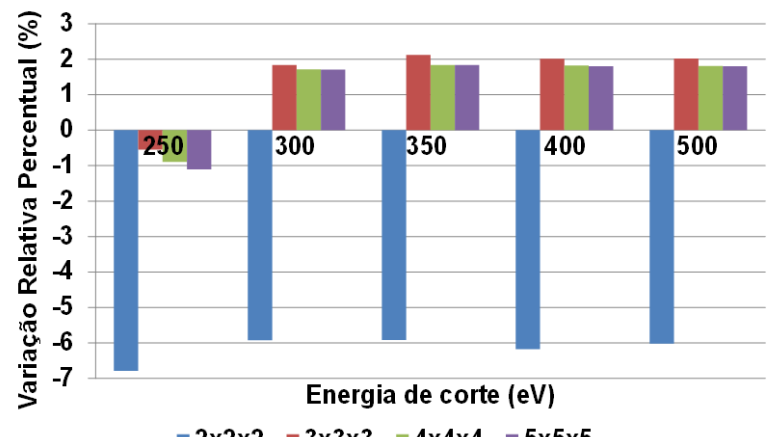

$\because 2 \times 2 \times 2 \quad=3 \times 3 \times 3 \quad=4 \times 4 \times 4 \quad=5 \times 5 \times 5$

Figura 4. Variação Relativa Percentual (VRP) dos parâmetros de rede a e c do (i); (ii) $\mathrm{TiO}_{2}$ rutilo e (iii); (iv) anatase em relação ao valor experimental. ${ }^{17-18}$

Analisando-se os resultados da Tabela 2 e da Figura 4 para o $\mathrm{TiO}_{2}$ rutilo e anatase, observou-se para a energia de corte igual a $250 \mathrm{eV}$, em todos os pontos $\mathrm{k}$ estudados, a maior variação em relação ao experimental. Com a energia de 300 eV e malha de pontos $\mathrm{k} 3 \times 3 \times 3$, foram obtidos valores próximos ao experimental, tanto para $0 \mathrm{TiO}_{2}$ rutilo, quanto para o anatase, sendo um indício de que essa combinação poderia ser usada nos cálculos de adsorção. Para valores de energia de corte acima de 300 eV, em todas as combinações, não foram observadas melhoras significativas 
que justificassem o aumento do custo computacional. Comparando-se as energias de corte usadas nos cálculos com os valores contidos nos pseudopotenciais do titânio, oxigênio, carbono e hidrogênio, para os quais a energia máxima de corte é igual a $178,520 \mathrm{eV}, 282,604 \mathrm{eV}, 250,000 \mathrm{eV}$ e 250,000 eV, respectivamente, observou-se que a energia de corte selecionada $(300 \mathrm{eV})$, dentro dos critérios adotados de comparação com os dados experimentais, é maior que todas as energias máximas de corte contidas nos pseudopotenciais, que foram as utilizadas para parametrizar cada um desses pseudopotenciais.

Usando os parâmetros de rede e as coordenadas fracionárias obtidas na otimização do bulk com o valor da energia de corte das ondas planas igual a $300 \mathrm{eV}$ e os pontos $k$ de $3 \times 3 \times 3$, fez-se uma análise da convergência da energia em função dos pontos $\mathrm{k}$ e da energia de corte. Para isso, calculou-se a energia total $(\mathrm{eV}) \mathrm{da}$ geometria obtida na etapa anterior (apenas energia) conforme apresentado na Figura 5.
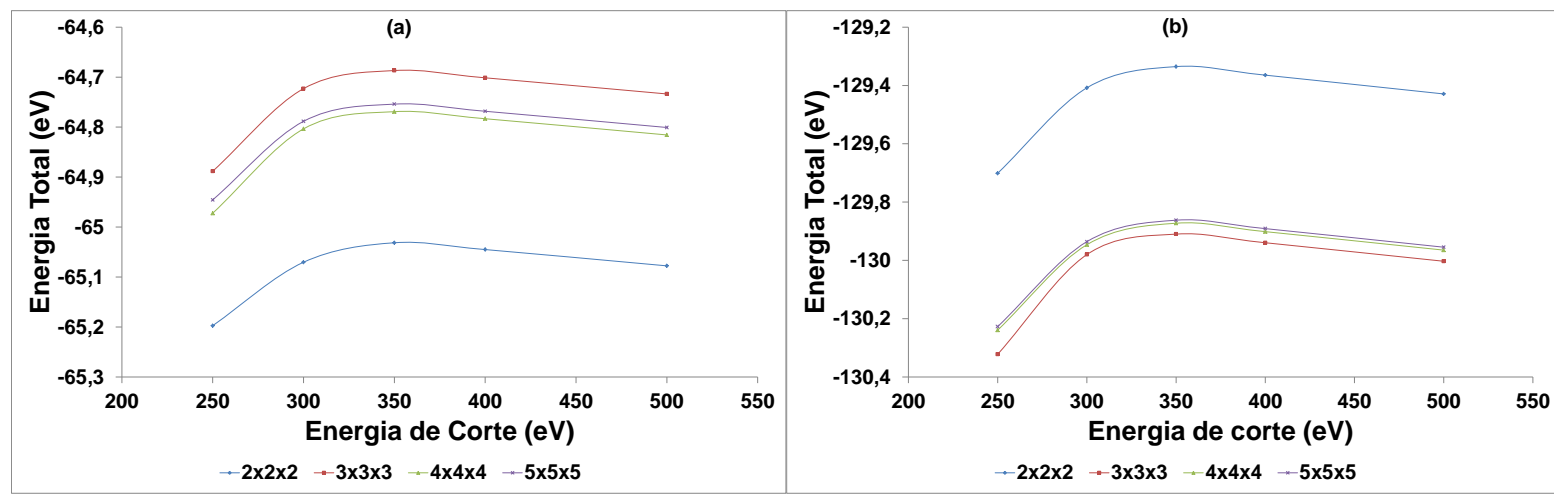

Figura 5. Energia total (eV) em função da energia de corte (eV) para cada uma das malhas de pontos $\mathrm{k}$ calculadas para o (a) $\mathrm{TiO}_{2}$ rutilo e (b) $\mathrm{TiO}_{2}$ anatase.

Por meio da análise dos resultados de energia total apresentados na Figura 5 , pode-se observar que, com o valor obtido para a energia de corte igual a $300 \mathrm{eV} \mathrm{e}$ o número de pontos $\mathrm{k}$ de $3 \times 3 \times 3$, a diferença em relação à configuração onde utilizou-se a maior energia de corte $(500 \mathrm{eV})$ e a maior malha de pontos $\mathrm{k}(5 \times 5 \times 5)$ foi de $0,0778 \mathrm{eV}$ para o $\mathrm{TiO}_{2}$ rutilo e $-0,0253 \mathrm{eV}$ para o anatase, ou seja, a diferença ficou na segunda casa decimal, sendo portanto, suficiente para estudos de adsorção, uma vez que as energias de adsorção são em geral superiores a este valor. Dessa forma, o uso de $300 \mathrm{eV}$ e $3 \times 3 \times 3$ para a energia de corte das ondas 
planas e para o número de pontos $\mathrm{k}$, respectivamente, foram considerados apropriados para descrever os fenômenos que serão estudados.

\subsection{Análise do Número de Camadas das Superfícies (110) do $\mathrm{TiO}_{2}$ Rutilo e (101) do $\mathrm{TiO}_{2}$ Anatase}

Com os parâmetros cristalográficos do bulk que foram otimizados usando-se a energia de corte das ondas planas igual a $300 \mathrm{eV}$ e o espaço de pontos $\mathrm{k}$ igual a $3 \times 3 \times 3$, fez-se o corte do plano cristalino na direção (110) do $\mathrm{TiO}_{2}$ rutilo e (101) do $\mathrm{TiO}_{2}$ anatase. A superfície (110) do $\mathrm{TiO}_{2}$ rutilo é terminada por átomos de oxigênio bicoordenados $\left(\mathrm{O}_{2 \mathrm{C}}\right)$ e tricoordenados $\left(\mathrm{O}_{3 \mathrm{C}}\right)$, além de átomos de titânio pentacoordenados $\left(\mathrm{Ti}_{5 \mathrm{C}}\right)$. Contudo, no bulk, os átomos de oxigênio e titânio são tricoordenados $\left(\mathrm{O}_{3 \mathrm{C}}\right)$ e hexacoordenados $\left(\mathrm{Ti}_{6 \mathrm{C}}\right)$, respectivamente. Na superfície (101) do $\mathrm{TiO}_{2}$ anatase, além dos átomos de oxigênio bicoordenados $\left(\mathrm{O}_{2 \mathrm{C}}\right)$ e tricoordenados $\left(\mathrm{O}_{3 \mathrm{C}}\right)$ e átomos de titânio pentacoordenados $\left(\mathrm{Ti}_{5 \mathrm{C}}\right)$, existem também átomos de titânio hexacoordenados ( $\left.\mathrm{Ti}_{6 \mathrm{C}}\right)$. Assim como na fase rutilo, o bulk do $\mathrm{TiO}_{2}$ anatase apresenta átomos de oxigênio tricoordenados $\left(\mathrm{O}_{3 \mathrm{C}}\right)$ e de titânio hexacoordenados $\left(\mathrm{Ti}_{6 \mathrm{C}}\right)$.

Com a superfície $(1 \times 1)$, variou-se o número de camadas do slab conforme mostrado na Tabela 3 , onde na primeira coluna está indicada a quantidade de camadas e na segunda e terceira, a energia da superfície em $\mathrm{J} \mathrm{m}^{-2}$ para a superfície (110) do $\mathrm{TiO}_{2}$ rutilo e a (101) para o anatase, respectivamente. Como os cálculos realizados são periódicos, em cada uma das supercélulas adicionou-se um vácuo de $20 \AA$ para reduzir a interação entre as superfícies paralelas. Os sistemas analisados possuíam quatro, seis, oito, dez e doze camadas de modo que, para simular as camadas internas do slab, otimizou-se somente em uma das extremidades a metade do número de camadas. Por exemplo, para uma superfície com oito camadas, otimizou-se quatro em um dos lados do sistema. A supercélula que foi utilizada nestes cálculos para o $\mathrm{TiO}_{2}$ rutilo possui 2 átomos de titânio e 4 átomos de oxigênio por camada, o parâmetro de rede $a=2,954 \AA$ e $b=6,521 \AA$ e a área superficial $A=$ $19,265 \AA^{2}$. Para $\mathrm{TiO}_{2}$ anatase, a supercélula utilizada possui 4 átomos de titânio e 8 átomos de oxigênio por camada, o parâmetro de rede $a=3,777 \AA$ e $b=10,381 \AA$, com a área superficial $A=39,207 \AA^{2}$. A análise da quantidade de camadas que 
seriam necessárias para simular a superfície foi feita através da convergência da energia da superfície calculada a partir da Equação 1 em função do número de camadas.

Tabela 3. Energia da superfície em $\mathrm{J} \mathrm{m}^{-2}$ em função do número de camadas para a superfície (110) do $\mathrm{TiO}_{2}$ rutilo e (101) do $\mathrm{TiO}_{2}$ anatase.

\begin{tabular}{c|c|c}
\hline \multirow{2}{*}{ Número de Camadas } & $\mathrm{TiO}_{2}$ rutilo & $\mathrm{TiO}_{2}$ anatase \\
\cline { 2 - 3 } & Energia da superfície $\left(\mathrm{J} \mathrm{m}^{-2}\right)$ & Energia da superfície $\left(\mathrm{J} \mathrm{m}^{-2}\right)$ \\
\hline 4 & 0,8476 & 0,8408 \\
\hline 6 & 0,8326 & 0,8479 \\
\hline 8 & 0,8072 & 0,8557 \\
\hline 10 & 0,7895 & 0,8649 \\
\hline 12 & 0,7692 & 0,8741 \\
\hline
\end{tabular}

Conforme pode ser observado na Tabela 3, a partir do sistema com quatro camadas, para a superfície (110) do $\mathrm{TiO}_{2}$ rutilo e (101) do $\mathrm{TiO}_{2}$ anatase o aumento do número de camadas altera a energia da superfície na segunda e terceira casa decimal, respectivamente. Apesar da energia da superfície dos sistemas com seis, oito, dez e doze camadas estarem se aproximando entre si, a utilização de um sistema com mais camadas tornaria o custo computacional do estudo da adsorção das moléculas de BTEX cada vez mais elevado. Portanto, a superfície com quatro camadas pode ser utilizada para representar o sistema. A energia da superfície calculada está em concordância com o material e com valores encontrados na literatura que variam de $0,73 \mathrm{~J} \mathrm{~m}^{-2}$ a $0,84 \mathrm{~J} \mathrm{~m}^{-2}$ em cálculos que usam a aproximação GGA. ${ }^{27-29}$

Para a superfície (101) do $\mathrm{TiO}_{2}$ anatase, os dados de energia da superfície apresentam um aumento com o número de camadas, em concordância com a literatura. $^{27}$ Ao aumentar o número de camadas ocorre, conforme esperado, a estabilização da superfície como pode ser observado na diminuição da diferença de energia entre cada um dos sistemas calculados e a superfície com 12 camadas.

\subsection{Análise da Área Superficial das Superfícies (110) do $\mathrm{TiO}_{2}$ Rutilo e (101) Anatase}


A espessura da superfície usada para fazer as adsorções será aquela com quatro camadas. Resta somente encontrar o número de células unitárias que serão usadas na supercélula, de forma a determinar a área superficial, para que não ocorra a interação lateral entre as moléculas do adsorbato. Para isso, foi feita a análise das energias totais para as moléculas isoladas de benzeno, etilbenzeno, tolueno, o-xileno, m-xileno e p-xileno em supercélulas que possuem o mesmo

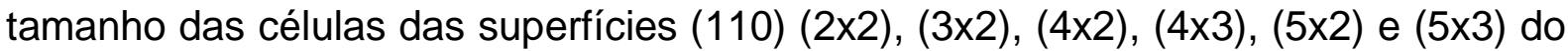

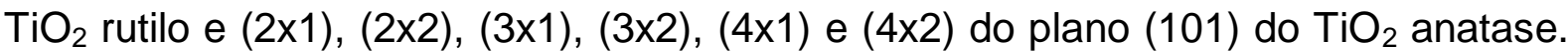
Os cálculos realizados para cada uma das moléculas de BTEX que foram previamente otimizadas, ocorreram sem a otimização da geometria. As moléculas foram mantidas na mesma posição quando aumentou-se o tamanho da supercélula, analisando desta forma, a interação lateral entre elas. Na Figura 6 pode ser visualizada a energia total para as moléculas de benzeno, tolueno, etilbenzeno, oxileno, m-xileno e p-xileno nas supercélulas descritas anteriormente para o (a) $\mathrm{TiO}_{2}$ rutilo e (b) anatase.
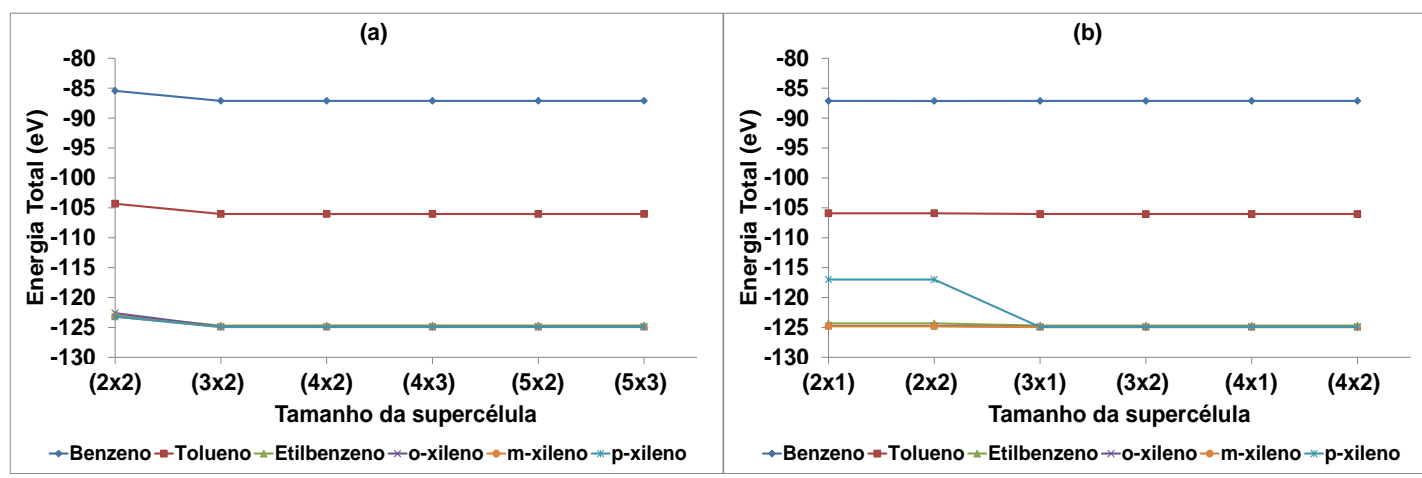

Figura 6. Energia total para as moléculas de benzeno, tolueno, etilbenzeno, o-xileno, $\mathrm{m}$-xileno e $\mathrm{p}$ xileno em relação ao tamanho da supercélula para o (a) $\mathrm{TiO}_{2}$ rutilo e (b) anatase.

Analisando-se a relação entre a energia total e o tamanho da supercélula (Figura 6), observou-se para o $\mathrm{TiO}_{2}$ rutilo que a partir da estrutura (3×2), a variação na energia total ocorreu na terceira, quarta e quinta casas decimais em relação às supercélulas maiores, muito inferior à precisão do método, além disso, a área da supercélula (3x2) é de $115,587 \AA^{2}(a=8,862 \AA$ e $b=13,043 \AA$ ), comparado com a área de $32,397 \AA^{2}(6,068 \AA \times 5,339 \AA)$ do o-xileno e m-xileno que são as maiores moléculas a serem adsorvidas, o que confirma que a superfície $(3 \times 2)$ pode ser utilizada para a adsorção do BTEX. A maior diferença de energia entre os cálculos 
para a supercélula (2x2) em relação às demais deve-se à proximidade das moléculas quando a supercélula é replicada no cálculo periódico.

Para o $\mathrm{TiO}_{2}$ anatase, a partir da supercélula (3×1) a variação na energia total ocorre na terceira, quarta e quinta casas decimais comparado com a supercélula (4x2). A área da superfície $(3 \times 1)$ é de $231,461 \AA^{2}(a=11,335 \AA$ e $b=20,420 \AA)$, mostrando que esta superfície também pode ser usada para a adsorção do BTEX.

\section{Conclusões}

Os estudos realizados permitiram determinar o melhor conjunto de energia de corte das ondas planas e da malha de pontos $\mathrm{k}$ para representar $\mathrm{o} \mathrm{TiO}_{2}$ rutilo e o $\mathrm{TiO}_{2}$ anatase. Os parâmetros obtidos foram $300 \mathrm{eV}$ para a energia de corte e $3 \times 3 \times 3$ para os pontos $\mathrm{k}$.

A análise do número de camadas e da área de adsorção possibilitou encontrar um número de camadas igual a quatro para descrever acuradamente a espessura de todas as superfícies estudadas. Em outros trabalhos teóricos que estudaram esses mesmos materiais os resultados foram semelhantes, indicando também que, com essa espessura é possível descrever as camadas internas da superfície. As energias das superfícies (110) do $\mathrm{TiO}_{2}$ rutilo e (101) do $\mathrm{TiO}_{2}$ anatase mostraram semelhanças com os resultados teóricos existentes na literatura. As supercélulas que poderão ser utilizadas para estudar teoricamente a adsorção das moléculas de BTEX, são as que possuem o mesmo tamanho das células das superfícies (110) (3x2) do $\mathrm{TiO}_{2}$ rutilo e $(3 \times 1)$ do $\mathrm{TiO}_{2}$ anatase.

\section{Agradecimentos}

Ao programa de bolsas para qualificação de servidores PIQS/IFG, CAPES, CNPq, FAPEG e FAPDF.

Referências Bibliográficas

1 Godoi, A. F. L.; Godoi, R. H. M.; Azevedo, R.; Maranho, L. T. Poluição e a densidade de vegetação: BTEX em algumas áreas públicas de Curitiba - PR, Brasil. Quim. Nova. 2010, 33, 827. [CrossRef] 
2 Laurentino, L. S.; Marques, M. R. C.; Corrêa, S. M. Impacto ambiental de kartódromos situados na cidade do Rio de Janeiro: monitoramento de BTEX no ar e do nível de ruído. Quim. Nova. 2012, 35, 1865. [CrossRef]

3 Sarigiannis, D. A.; Karakitsios, S. P.; Gotti, A.; Liakos, I. L.; Katsoyiannis, A. Exposure to major volatile organic compounds and carbonyls in European indoor environments and associated health risk. Environ. Int. 2011, 37, 743. [CrossRef] [PubMed]

${ }^{4}$ Liu, Z.; Ye, W.; Little, J. C. Predicting emissions of volatile and semivolatile organic compounds from building materials: A review. Build. Environ. 2013, 64, 7. [CrossRef]

${ }^{5}$ Seinfeld, J. H.; Pandis, S. N.; Atmospheric Chemistry and Physics: from air pollution to climate change. 2nd ed., John Wiley and Sons: United States of America, 2006.

${ }^{6}$ Suzuki, S.; Yamaguchi, Y.; Onishi, H.; Sasaki, T.; Fukui, K.; Iwasawa, Y. Study of pyridine and its derivatives adsorbed on a $\mathrm{TiO}_{2}(110)-(1 \times 1)$ surface by means of STM, TDS, XPS and MD calculation in relation to surface acid-base interaction. J. Chem. Soc., Faraday Trans. 1998, 94, 161. [CrossRef]

7 Reiß, S.; Krumm, H.; Niklewski, A.; Staemmler, V.; Wöll, C. The adsorption of acenes on rutile $\mathrm{TiO}_{2}$ (110): A multi-technique investigation. J. Chem. Phys. 2002, 116, 7704. [CrossRef]

8 Liu, H.; Wang, X.; Pan, C.; Liew, K. M. First-principles study of formaldehyde adsorption on $\mathrm{TiO}_{2}$ rutile (110) and anatase (001) surfaces. J. Phys. Chem. C. 2012, 116, 8044. [CrossRef]

${ }^{9}$ Korologos, C. A.; Nikolaki, M. D.; Zerva, C. N.; Philippopoulos, C. J.; Poulopoulos, S. G. Photocatalytic oxidation of benzene, toluene, ethylbenzene and $\mathrm{m}$-xylene in the gas-phase over $\mathrm{TiO}_{2}$-based catalysts. J. Photochem. Photobiol. A. 2012, 244, 24. [CrossRef]

${ }^{10}$ Palau, J.; Colomer, M.; Penya-Roja, J. M.; Martínez-Soria, V. Photodegradation of Toluene, $m$-Xylene, and $n$-Butyl Acetate and Their Mixtures over $\mathrm{TiO}_{2}$ Catalyst on Glass Fibers. Ind. Eng. Chem. Res. 2012, 51, 5986. [CrossRef]

${ }^{11}$ Ramalho, J. P. P.; Illas, F. Theoretical study of the adsorption and dissociation of azobenzene on the rutile $\mathrm{TiO}_{2}$ (110) surface. Chem. Phys. Lett. 2011, 501, 379. [CrossRef]

12 Diebold, U. The surface science of titanium dioxide. Surf. Sci. Rep. 2003, 48, 53. [CrossRef] 
Chen, X.; Mao, S. S. Titanium dioxide nanomaterials: Synthesis, properties, modifications, and applications. Chem. Rev. 2007, 107, 2891. [CrossRef] [PubMed] ${ }^{14}$ Pillay, D.; Wang, Y.; Hwang, G. A comparative theoretical study of Au, Ag and $\mathrm{Cu}$ adsorption on $\mathrm{TiO}_{2}$ (110) rutile surfaces. Korean J. Chem. Eng. 2004, 21, 537. [CrossRef]

15 Tatsumi, H.; Sasahara, A.; Tomitori, M. Adsorption of Propylene Carbonate Molecules on a $\mathrm{TiO}_{2}$ (110) Surface. J. Phys. Chem. C. 2013,117, 10410. [CrossRef] ${ }^{16}$ Muir, J. M. R.; Idriss, H. Study of the interaction of formic acid, formaldehyde and formamide with the bulk terminated $(1 \times 1)$ and reconstructed $(2 \times 1)$ surfaces of rutile $\mathrm{TiO}_{2}$ (011). Surf. Sci. 2013, 607, 187. [CrossRef]

17 Baur, V. W. H. Über die Verfeinerung der Kristallstrukturbestimmung einiger Vertreter des Rutiltyps: $\mathrm{TiO}_{2}, \mathrm{SnO}_{2}, \mathrm{GeO}_{2}$ und $\mathrm{MgF}_{2}$. Acta Cryst. 1956, 9, 515. [CrossRef]

18 Rezaee, M.; Khoie, S. M. M.; Liu, K. H. The role of brookite in mechanical activation of anatase-to-rutile transformation of nanocrystalline $\mathrm{TiO}_{2}$ : An XRD and Raman spectroscopy investigation. Cryst. Eng. Comm. 2011, 13, 5055. [CrossRef] ${ }^{19}$ Kresse. G.; Hafner, J. Ab initio molecular dynamics for liquid metals. Phys. Rev. B: Condens. Matter Mater. Phys. 1993, 47, 558. [CrossRef]

${ }^{20}$ Kresse. G.; Hafner, J. Ab initio molecular-dynamics simulation of the liquid-metalamorphous-semiconductor transition in germanium. Phys. Rev. B: Condens. Matter Mater. Phys. 1994, 49, 14251. [CrossRef]

21 Kresse. G.; Furthmüller, J. Efficiency of ab-initio total energy calculations for metals and semiconductors using a plane-wave basis set. Comput. Mater. Sci. 1996, 6, 15. [CrossRef]

${ }^{23}$ Perdew, J. P.; Chevary, J. A.; Vosko, S. H.; Jackson, K. A.; Pederson, M. R.; Fiolhais, C. Atoms, molecules, solids, and surfaces: Applications of the generalized gradient approximation for exchange and correlation. Phys. Rev. B: Condens. Matter Mater. Phys. 1992, 46, 6671. [CrossRef]

${ }^{24}$ Perdew, J. P.; Chevary, J. A.; Vosko, S. H.; Jackson, K. A.; Pederson, M. R.; Singh D. J.; Fiolhais, C. Erratum: Atoms, molecules, solids, and surfaces: Applications of the generalized gradient approximation for exchange and correlation. Phys. Rev. B: Condens. Matter Mater. Phys. 1993, 48, 4978. [CrossRef] 
25 Blöchl, P. E. Projector augmented-wave method. Phys. Rev. B: Condens. Matter Mater. Phys. 1994, 50, 17953. [CrossRef]

26 Kresse, G.; Joubert, D. From ultrasoft pseudopotentials to the projector augmented-wave method. Phys. Rev. B: Condens. Matter Mater. Phys. 1999, 59, 1758. [CrossRef]

27 Labat, F.; Baranek, P.; Adamo, C. Structural and electronic properties of selected rutile and anatase $\mathrm{TiO}_{2}$ surfaces: $\mathrm{An}$ ab Initio investigation. J. Chem. Theory Comput. 2008, 4, 341. [CrossRef]

${ }^{28}$ Bates, S. P.; Kresse, G.; Gillan, M. J. A systematic study of the surface energetics and structure of $\mathrm{TiO}_{2}(110)$ by first-principles calculations. Surf. Sci. 1997, 385, 386. [CrossRef]

${ }^{29}$ Lindan, P. J. D.; Harrison, N. M.; Gillan, M. J.; White, J. A. First-principles spinpolarized calculations on the reduced and reconstructed $\mathrm{TiO}_{2}$ (110) surface. Phys. Rev. B. 1997, 55, 15919. [CrossRef] 